Chapman University

Chapman University Digital Commons

Spring 3-25-2019

\title{
The Intersection of Speech-Language Pathologists' Beliefs, Perceptions, and Practices and the Language Acquisition and Development of Emerging Aided Communicators
}

Margaret Vento-Wilson

Chapman University, vento102@mail.chapman.edu

Follow this and additional works at: https://digitalcommons.chapman.edu/education_dissertations

Part of the Communication Commons, Disability Studies Commons, Morphology Commons, Psycholinguistics and Neurolinguistics Commons, Semantics and Pragmatics Commons, and the Syntax Commons

\section{Recommended Citation}

Vento-Wilson, M. (2019). The intersection of speech-language pathologists' beliefs, perceptions, and practices and the language acquisition and development of emerging aided communicators [Doctoral dissertation, Chapman University]. Chapman University Digital Commons. https://doi.org/10.36837/ chapman. 000040

This Dissertation is brought to you for free and open access by the Dissertations and Theses at Chapman University Digital Commons. It has been accepted for inclusion in Education (PhD) Dissertations by an authorized administrator of Chapman University Digital Commons. For more information, please contact laughtin@chapman.edu. 
The Intersection of Speech-Language Pathologists' Beliefs, Perceptions, and Practices and the Language Acquisition and Development of Emerging Aided Communicators

A Dissertation by Margaret Vento-Wilson

Chapman University Orange, California Donna Ford Attallah College of Educational Studies Submitted in partial fulfillment of the requirements for the degree of Doctor of Philosophy in Education March 2019

Committee in charge:

Dawn Hunter, Ph.D., Chair

Judith Montgomery, Ph.D.

Kelly Kennedy, Ph.D.

Jennifer Ostergren, Ph.D. 
This dissertation of Margaret Vento-Wilson is approved.

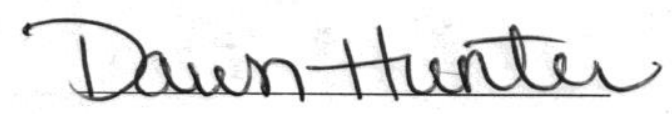

Dawn Hunter, Ph.D., Chair

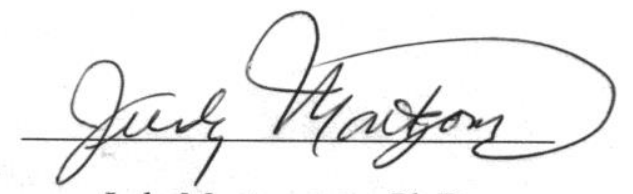

Judy Montgomery, Ph.D.

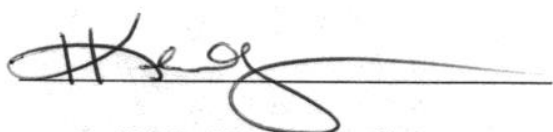

Kelly Kennedy, Ph.D.

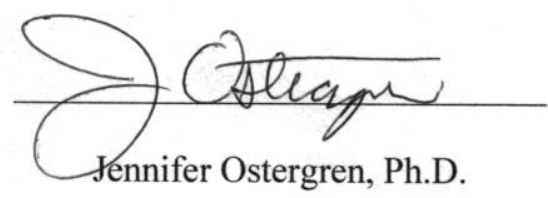

March 2019 
The Intersection of Speech-Language Pathologists' Beliefs, Perceptions, and Practices and the Language Acquisition and Development of Emerging Aided Communicators

Copyright @ 2019

by Margaret Vento-Wilson 


\section{ACKNOWLEDGEMENTS}

Words of gratitude fall short for the many people who have accompanied me along the journey to my dissertation, but I shall try. From my husband Bill, and children Phoebe and Riley, who supported me unquestioningly as I sought to discover my passion and slake my thirst for knowledge; to my family of origin who instilled curiosity and passion in me by modeling precisely those qualities in all they did and continue to do; to my long-suffering friends, neighbors, and colleagues who listened ever so graciously to my ideas, my trials, and my tribulations without judgment—especially my dear colleague and partner in crime for the past six years, Rachel Pyon, M.A., CCC-SLP; and to my very, very patient dissertation committee: Drs. Dawn Hunter, Judy Montgomery, Kelly

Kennedy, and Jennifer Ostergren, who earned their stripes in the IRB process alone — not to mention everything else! And finally, no acknowledgement would be complete without reference to those in my life who have provided mentorship, inspiration, and guidance, and to whom I owe much: Drs. Carolyn Madding, Betty McMicken, Jennifer Ostergren (yes again), and Gerry Wallach. I make a promise to you all that I will pay these kindnesses forward.

And now cried Max, "Let the wild rumpus start!"

Maurice Sendak

(1963, p. 4) 


\begin{abstract}
The Intersection of Speech-Language Pathologists Beliefs, Perceptions, and Practices and the Language Acquisition and Development of Emerging Aided Communicators by Margaret Vento-Wilson
\end{abstract}

This dissertation discusses the convergence of aided augmentative and alternative communication (AAC) systems, the language acquisition and development of young children who are minimally verbal or nonverbal who acquire their native language while simultaneously learning to use an aided AAC system, and explicit and implicit elements that influence language outcomes. Factors investigated include those related to language acquisition universals, the AAC system, the young aided AAC user, and practices, philosophies, and beliefs of speech-language pathologists (SLPs). Further examined were: (a) language acquisition parallels in atypical populations who do not possess the full range of senses who have been shown to develop language, and (b) analogies between the linguistic structures of pidgins, interlanguages, and the syntax of young aided AAC users. This dissertation employed a survey methodology to capture the practices and beliefs of SLPs as a means of identifying potential contributing factors to the reduced linguistic outcomes of these children. Quantitative findings revealed statistically significant differences in SLPs' perceptions of confidence and qualification with the two populations of children with language impairments who use an oral modality and young aided AAC users. Descriptive trends across all constructs measured suggested differences in SLPs' practices, belifes, and perspectives in their work with these two populations. The analysis of the syntactic structures of the language of young aided AAC users revealed definitive parallels with the construct of interlanguages. 
TABLE OF CONTENTS

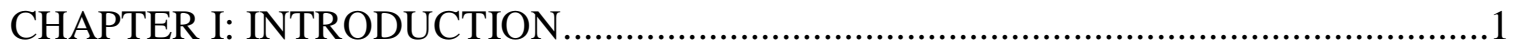

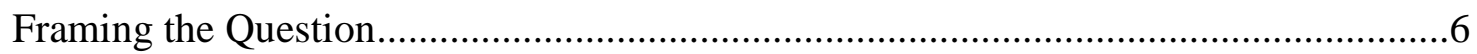

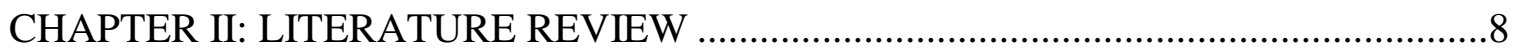

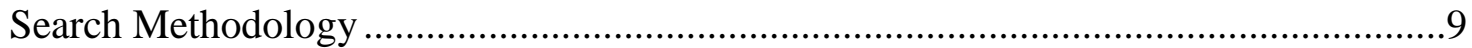

Inclusion and Exclusion Methodology …………………................................... 9

Search Parameters .................................................................................... 10

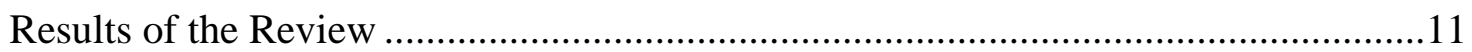

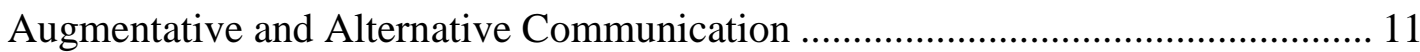

Language Acquisition and Development..............................................................12

Models of Typical Language Development......................................................... 12

Grammatical Morphology and Syntax of EACs ………...............................................17

Structural Analysis of the Language of EACs ....................................................... 18

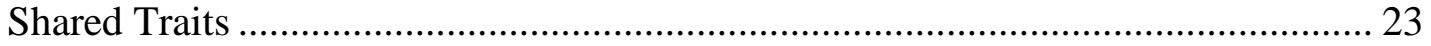

a. This is a theory being put forth in this dissertation.............................................. 24

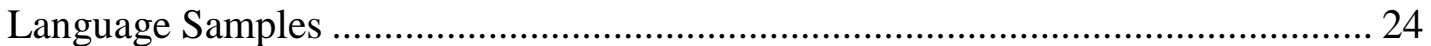

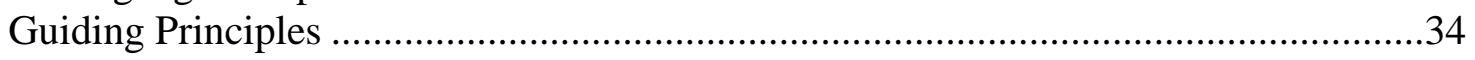

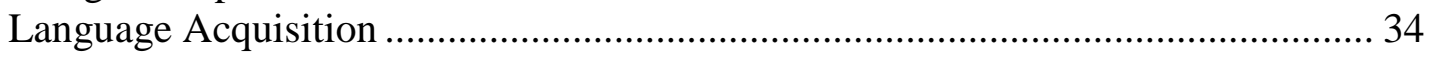

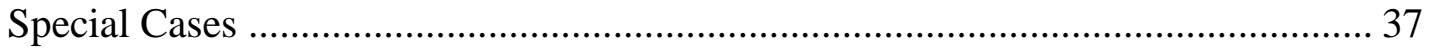

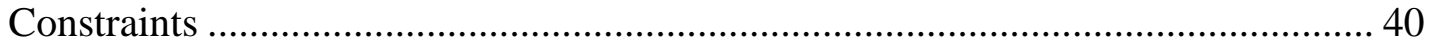

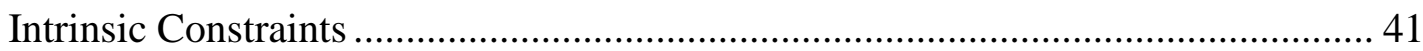

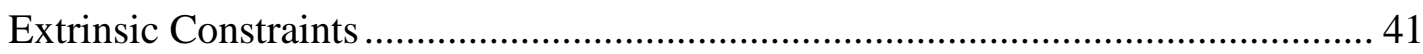

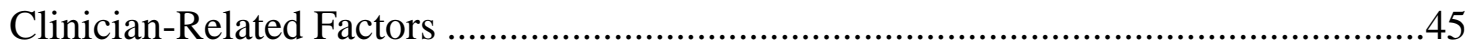

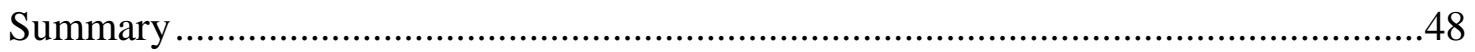

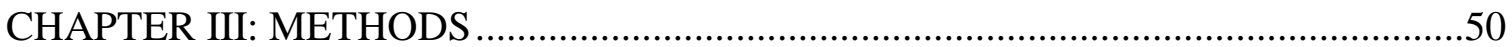

Previous Research on AAC and Language Development ........................................50

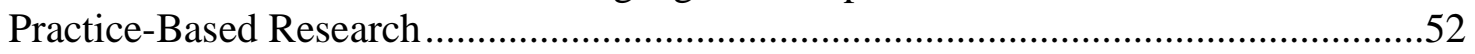

Strengths and Limitations of Survey Methodology ......................................................55

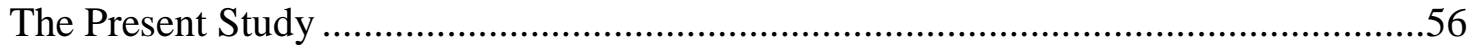

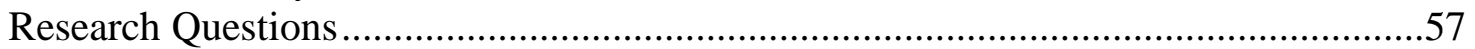

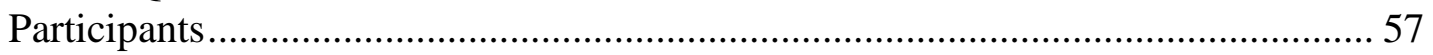

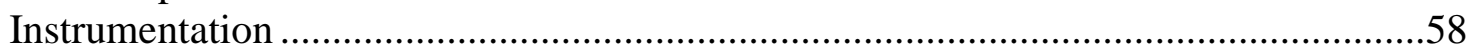

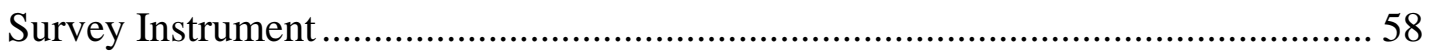

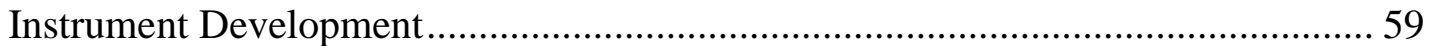

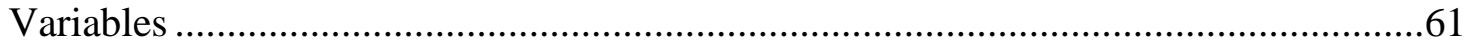

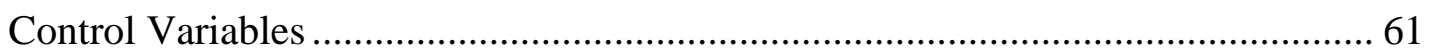

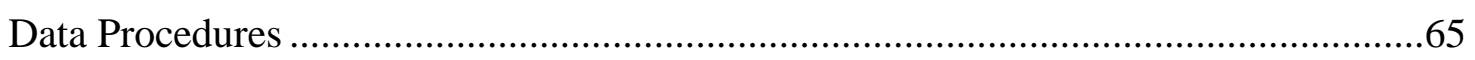

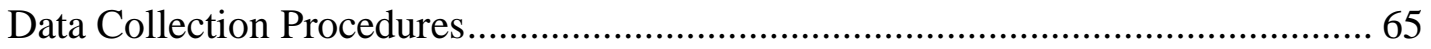

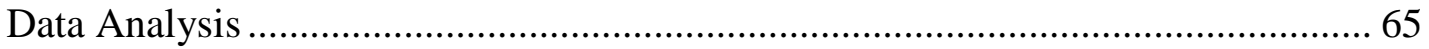

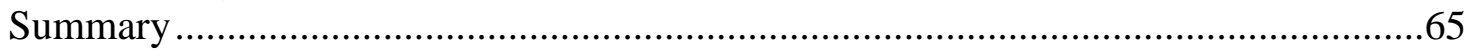

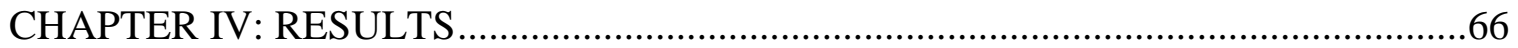




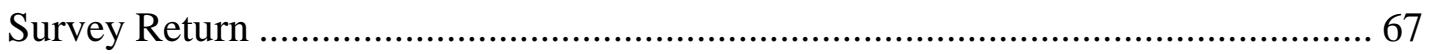

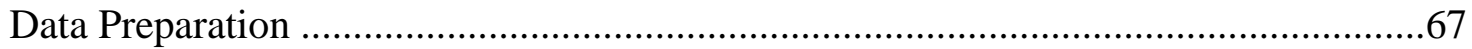

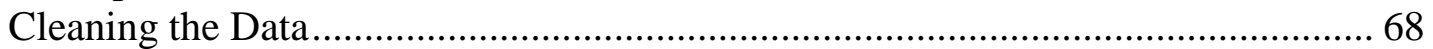

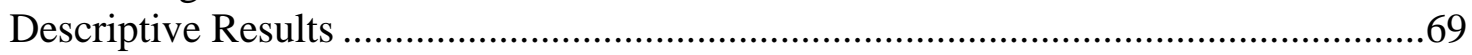

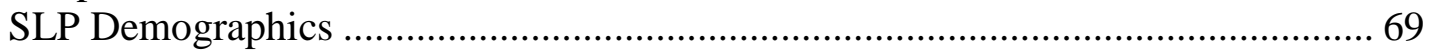

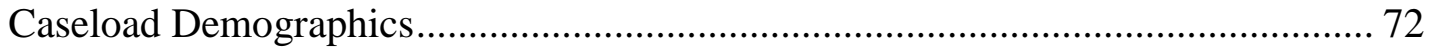

Specific EAC Demographics .......................................................................... 83

Specific Intervention Practices ............................................................................. 91

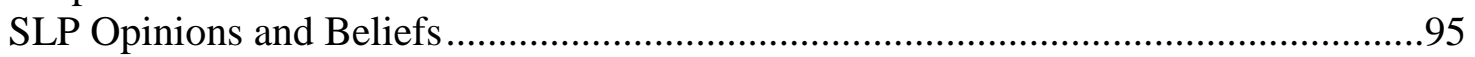

Factors Impacting Language Acquisition and Development ................................... 95

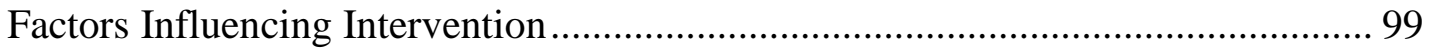

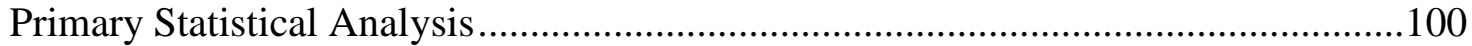

Perceptions of Differences in Beliefs............................................................... 100

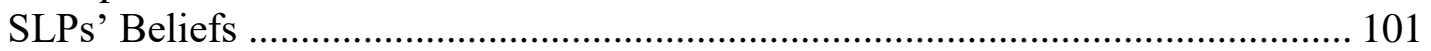

Perceptions of Differences in Practices .............................................................111

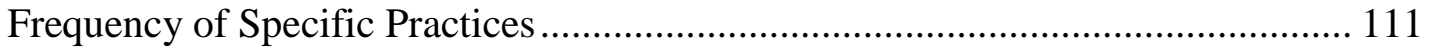

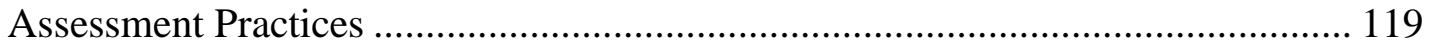

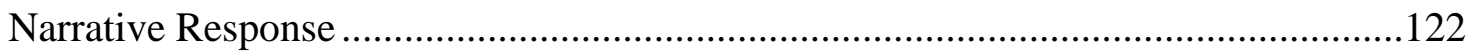

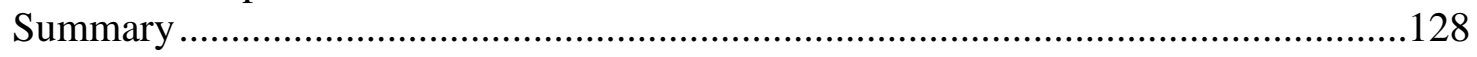

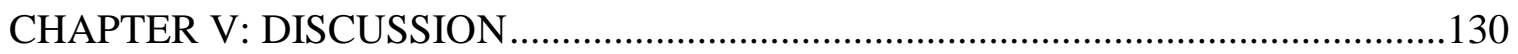

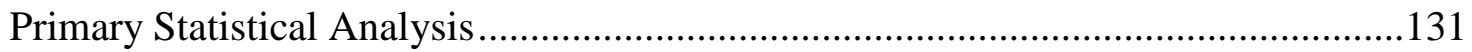

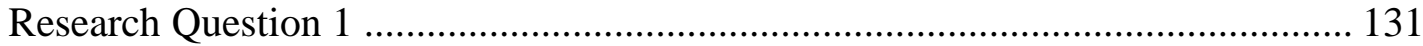

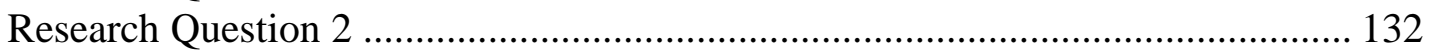

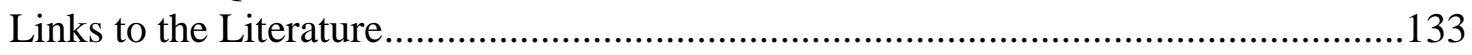

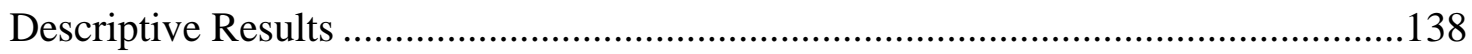

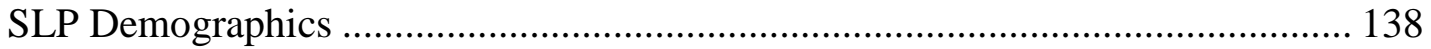

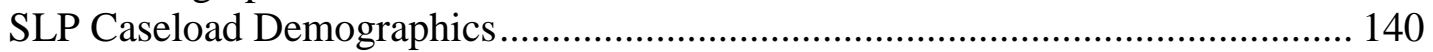

Specific EAC Demographics ......................................................................... 145

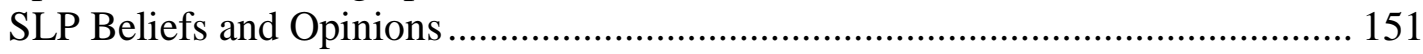

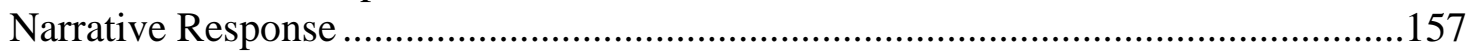

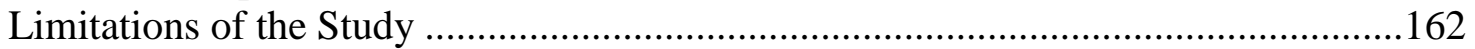

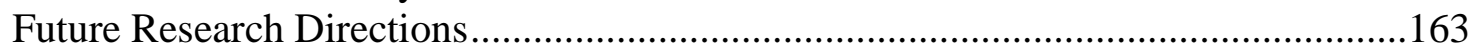

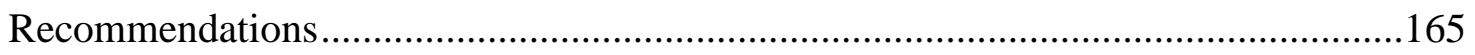

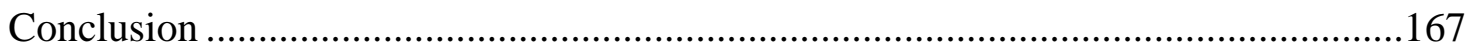

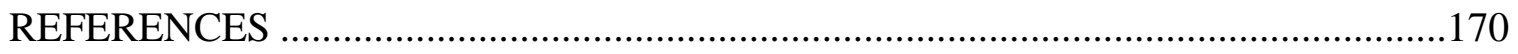

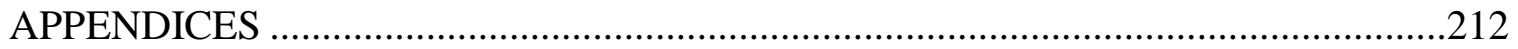




\section{LIST OF TABLES}

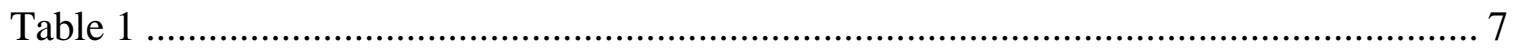

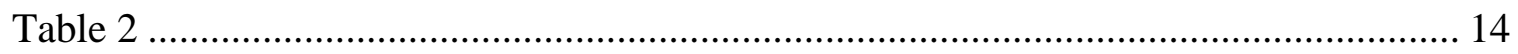

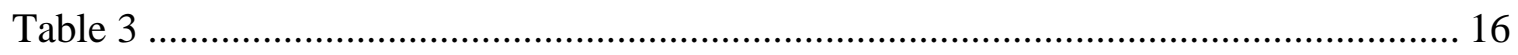

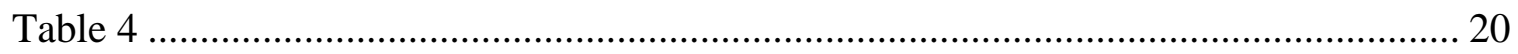

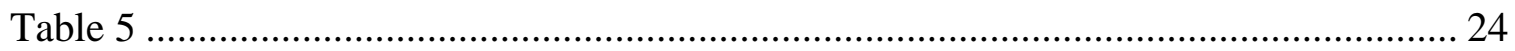

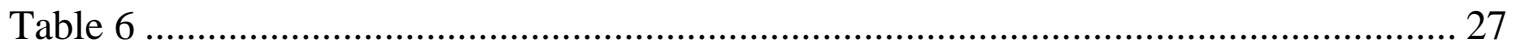

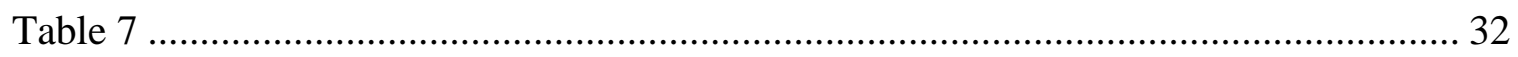

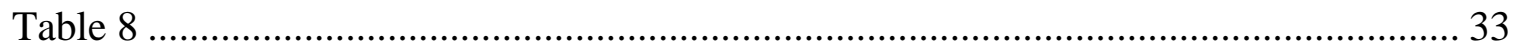

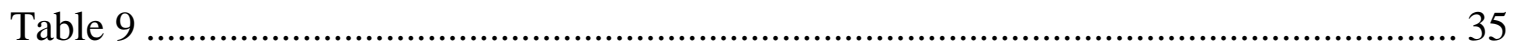

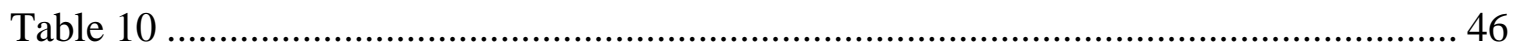

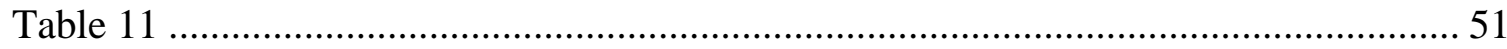

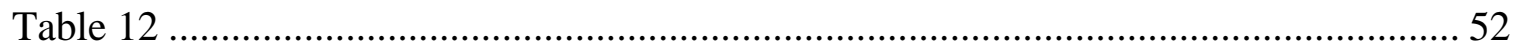

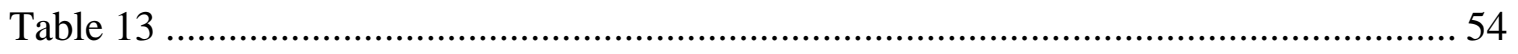

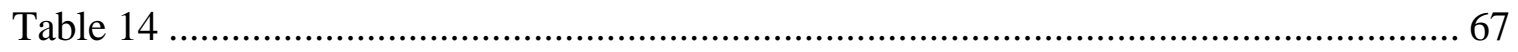

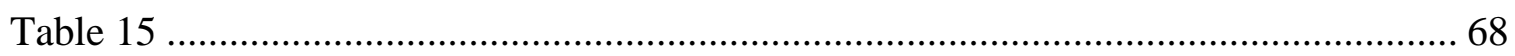

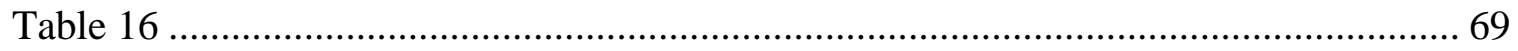

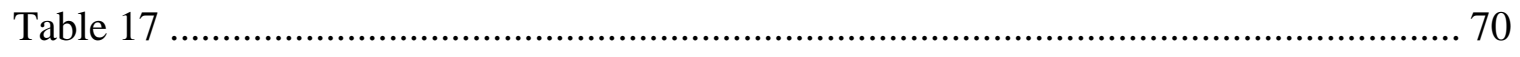

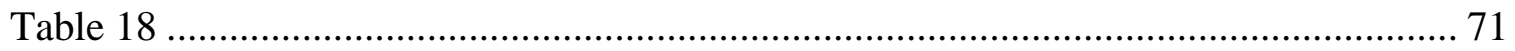




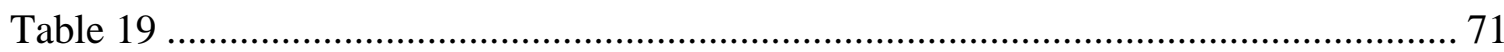

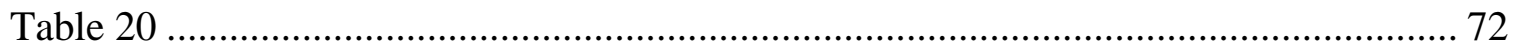

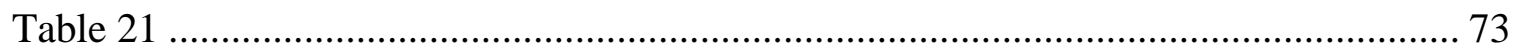

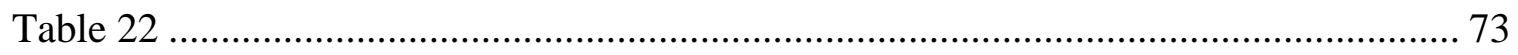

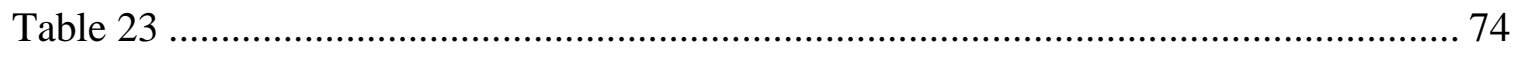

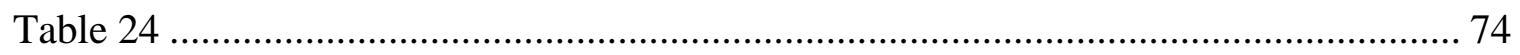

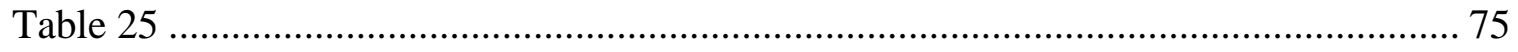

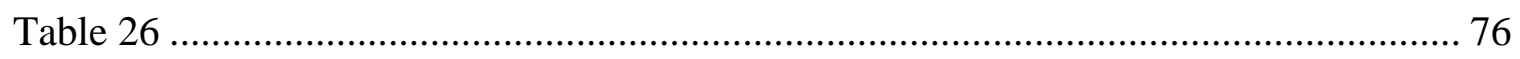

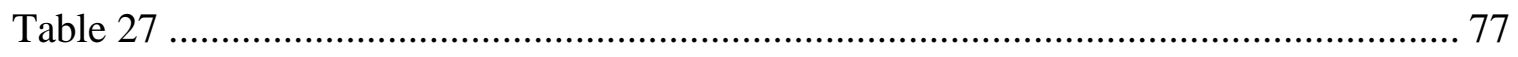

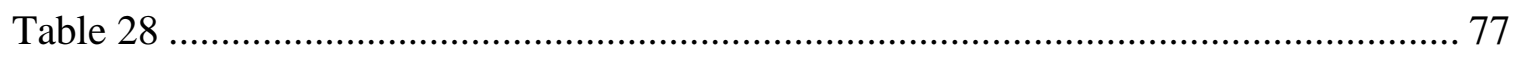

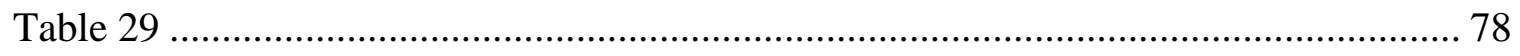

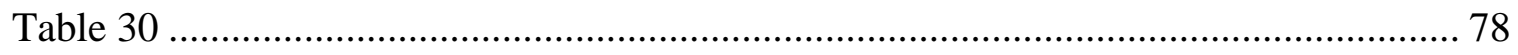

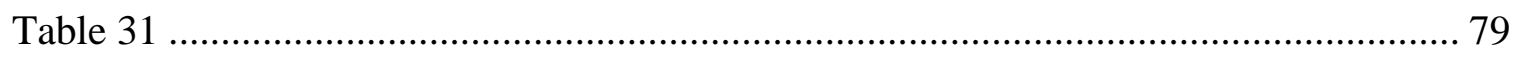

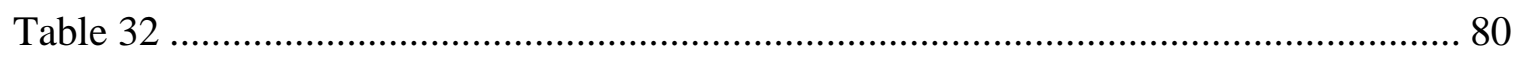

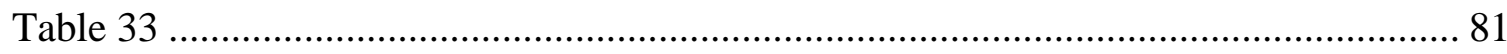

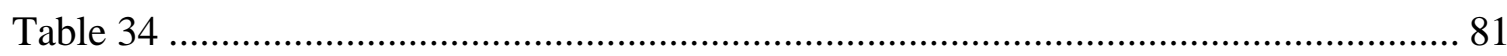

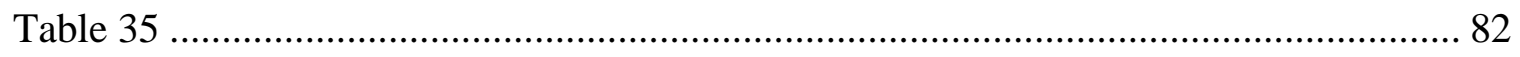

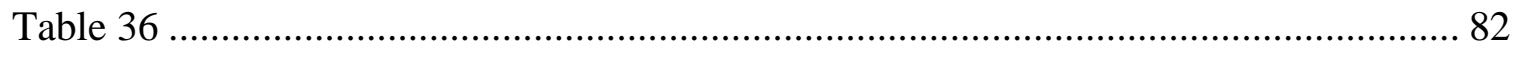

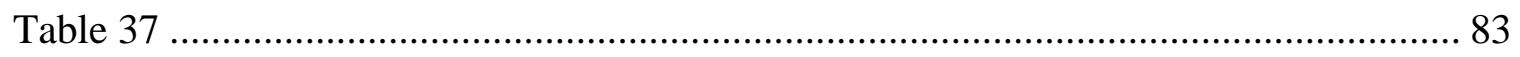




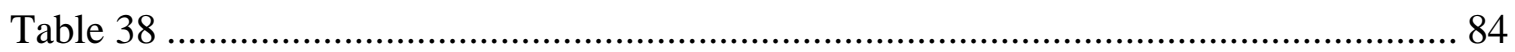

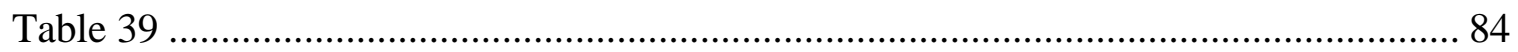

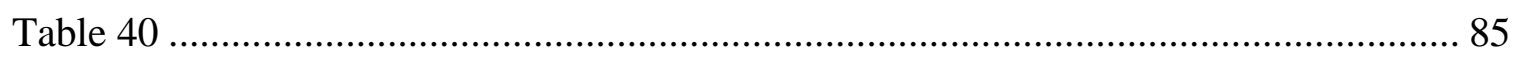

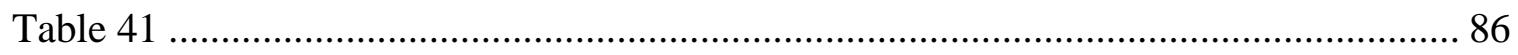

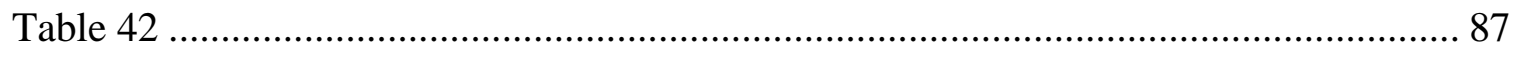

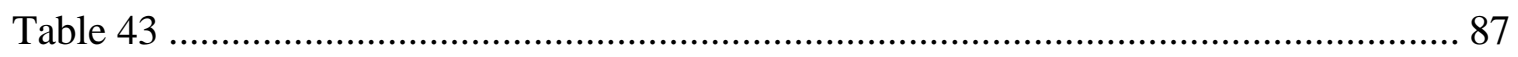

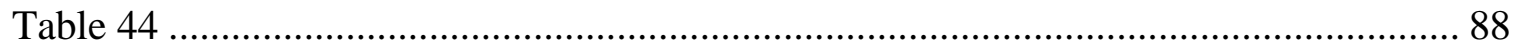

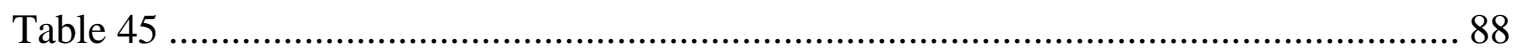

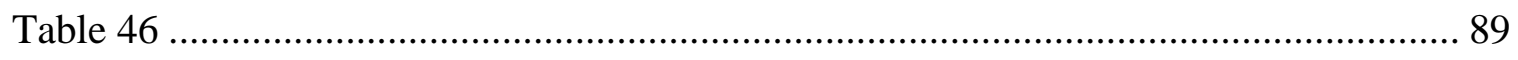

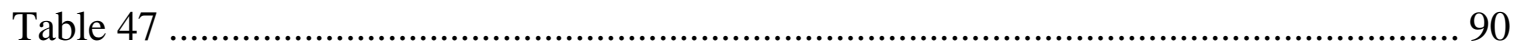

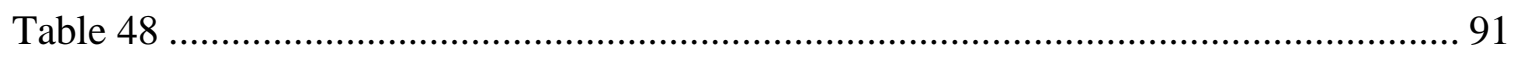

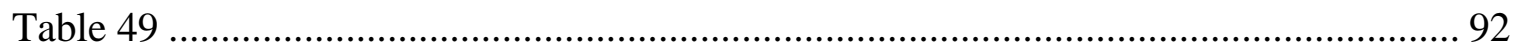

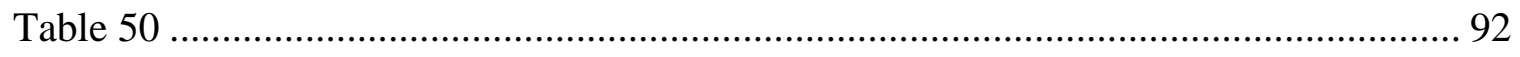

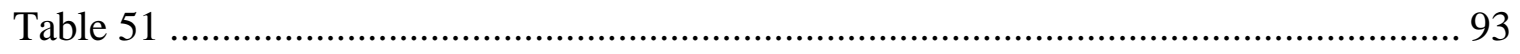

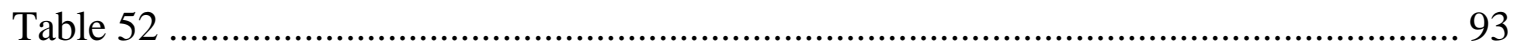

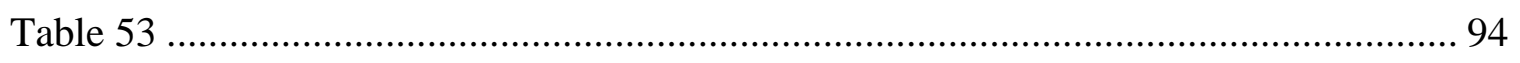

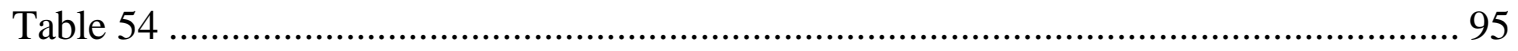

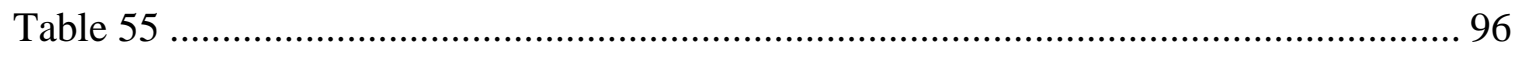

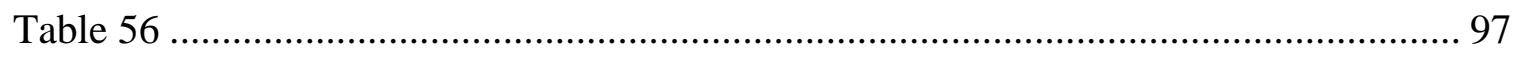


Table 57

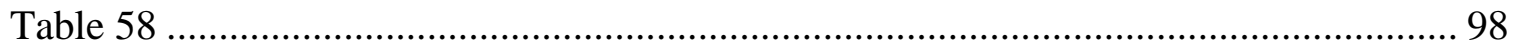

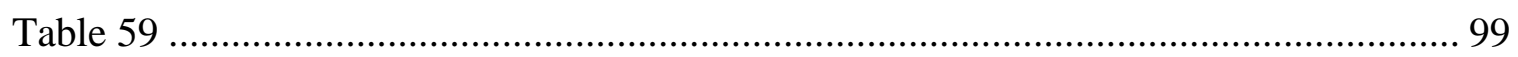

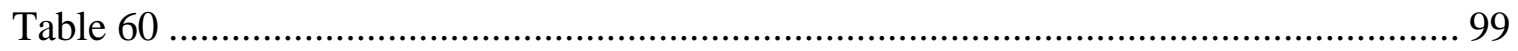

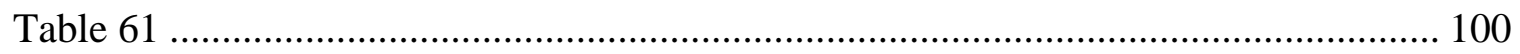

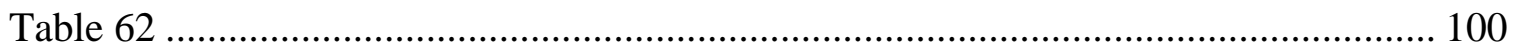

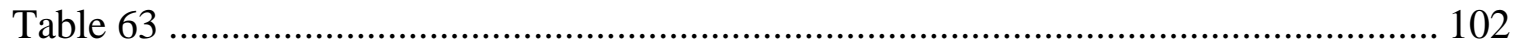

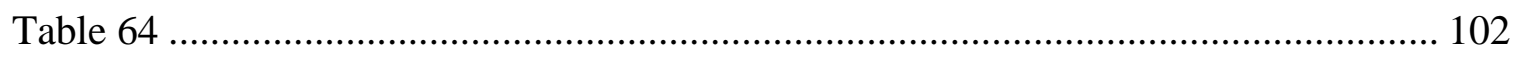

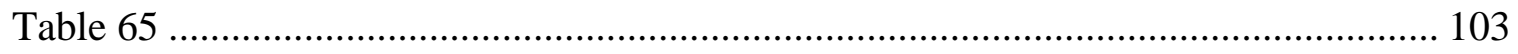

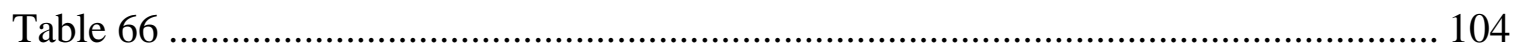

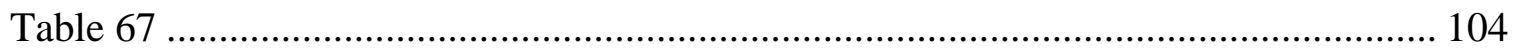

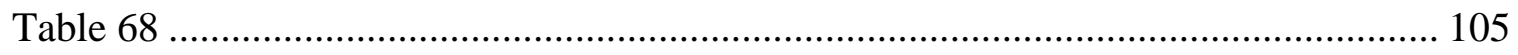

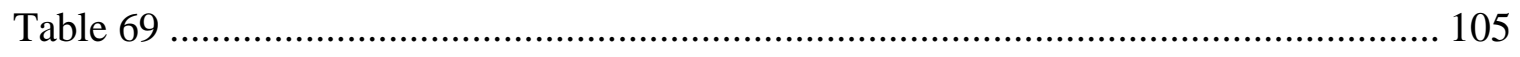

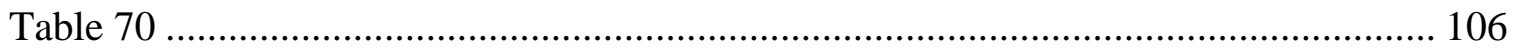

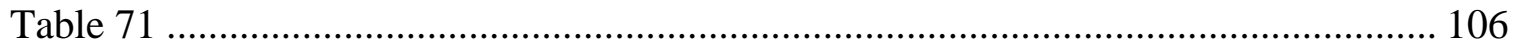

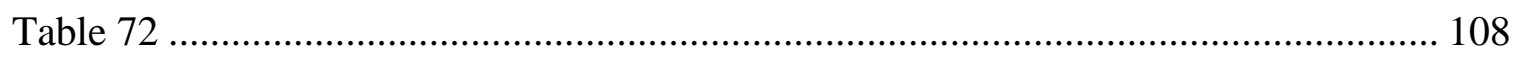

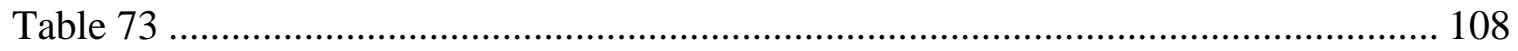

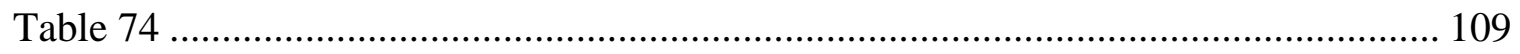

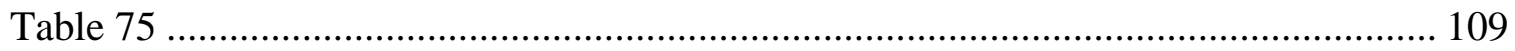




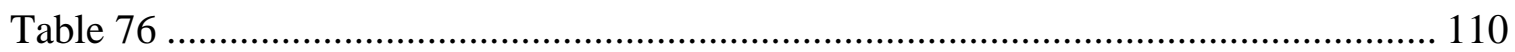

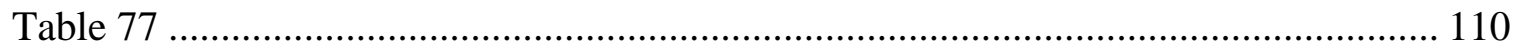

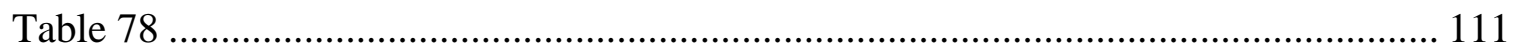

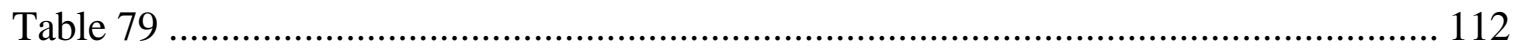

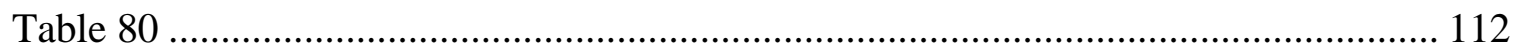

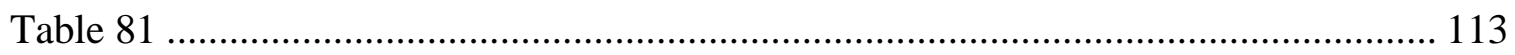

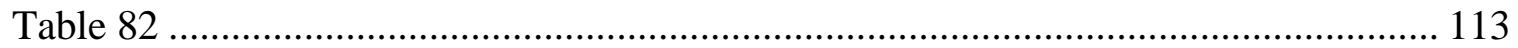

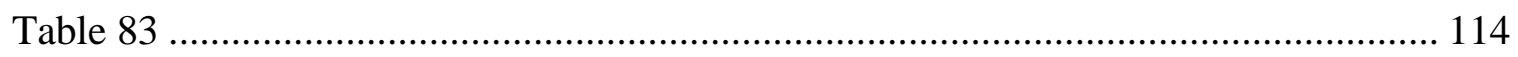

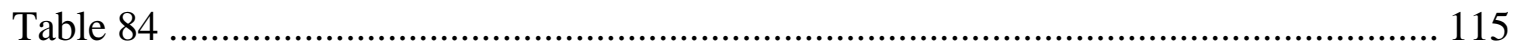

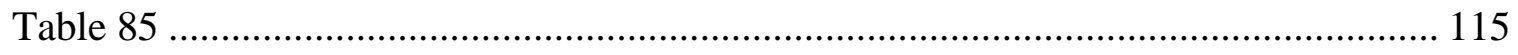

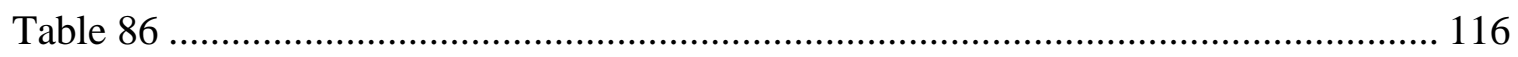

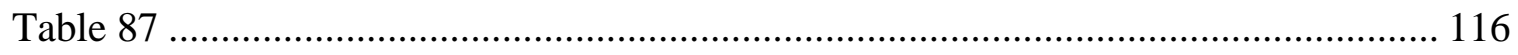

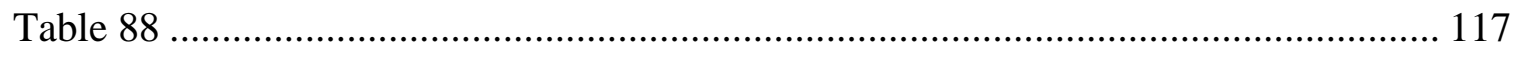

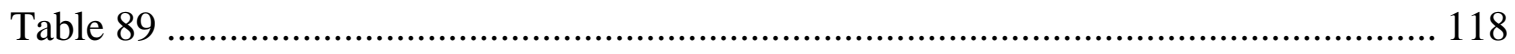

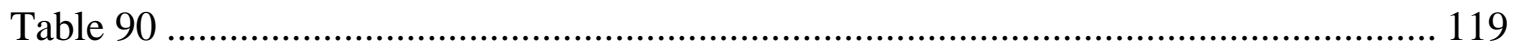

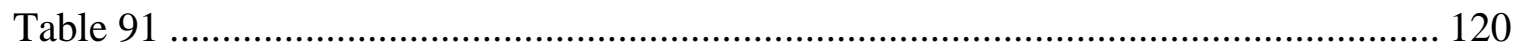

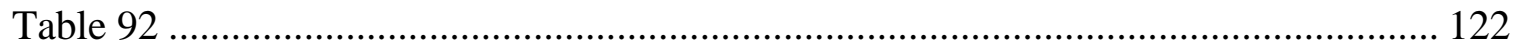

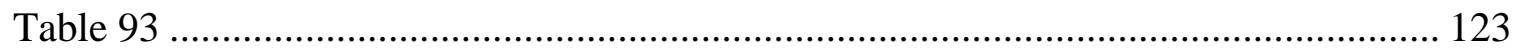

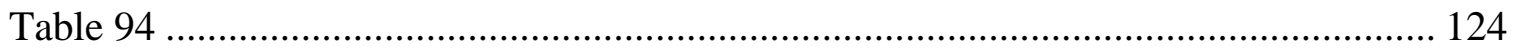


Table 95

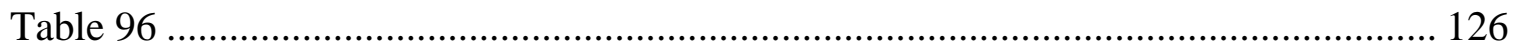

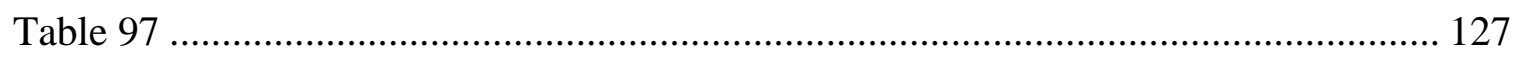

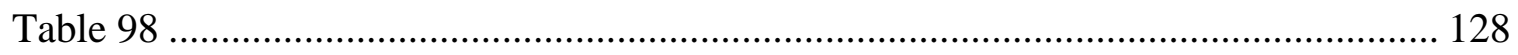

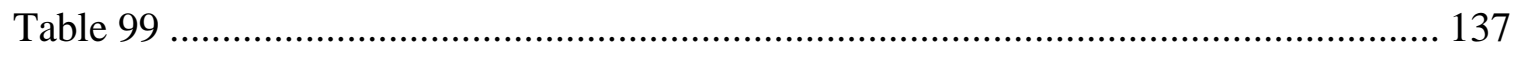

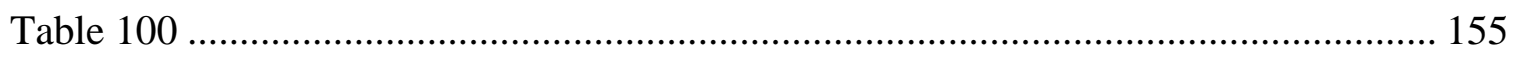




\section{LIST OF FIGURES}

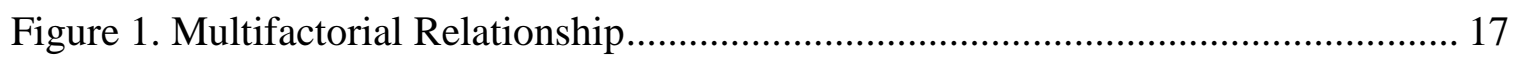

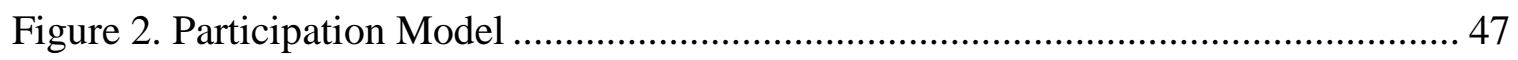

Figure 3. Results of Friedman's Test......................................................................... 98

Figure 4. Factors Affecting Workloads of School-Based SLPs ..................................... 141 


\section{LIST OF ABBREVIATIONS}

AAC - Augmentative and alternative communication

ASHA - American Speech-Language-Hearing Association

ASL - American Sign Language

$\mathrm{CCN}$ - Complex communication need

EAC - Emerging aided communicator

ICF - International Classification of Functioning

MLU - Mean length of utterance

PCS - Picture Communication Systems

SELPA - Special Education Local Plan Area

SES - Socioeconomic status

SLI - Specific Language Impairment

SLP - Speech-language pathologist

SPED - Special education

SPSS - Statistical Package for the Social Sciences

SVO - Subject + Verb + Object

WHO - World Health Organization 


\section{CHAPTER I: INTRODUCTION}

The human constructs of communication, language, and speech can appear at once distinct, congruent, effortless, and confounding. When all perceptual (e.g., vision, audition), processing (e.g., cognition), and productive (e.g., oral speech mechanisms) systems are intact (Koppenhaver, Foley, \& Williams, 2009), these constructs interact in intricate, transactional processes where meaning is co-constructed between communicative partners across multiple conversational turns (Bates \& Goodman, 1997; Blackstone, Williams, \& Wilkins, 2007; Emmorey, 2002; Hickok, 2009; Smith \& Grove, 2003). However, when disruptions occur in one or more of these systems, the distinct manifestations among the constructs reveal themselves.

Prime examples of populations exhibiting system disruptions that illustrate these distinctions include individuals with aphasia and children with congenital deafness (Damasio, 2008; Emmorey, 2002; Hallowell \& Chapey, 2008; Hickok, 2009; Hough \& Johnson, 2009; Mayberry \& Lock, 2003; Pinker, 1994). Aphasia varies considerably across populations, and is highly dependent on type (e.g., fluent, non-fluent) and factors affecting severity (i.e., lesion laterality, location, and size) (Damasio, 2008; Duffy, 2013; Goldin-Meadow, 2014; Hallowell \& Chapey, 2008). Specifically, individuals with aphasia can demonstrate critical disruptions in their ability to produce fluent, coherent speech, and yet maintain relatively intact language comprehension abilities, as seen in Broca's Aphasia. Conversely, in Wernicke's Aphasia, there can be significant deficits in language comprehension far exceeding an individual's ability to produce fluent speech (Damasio, 2008; Duffy, 2013; Hallowell \& Chapey, 2008). 
The linguistic profiles of congenitally deaf children provide a second example of system disruptions (Bishop, 1983). This population demonstrates intact receptive and expressive language abilities with a complete absence of speech that can be caused by lack of perception of the speech signal (Emmorey, 2002; Lillo-Martin, 1999; Mayberry \& Lock, 2003). When congenitally deaf children are born to deaf parents who are fluent in a signed language, their linguistic system develops along similar lines of hearing children, through exposure and access to this language in a visual modality (Emmorey, 2002; Goldin-Meadow, 2014; Mayberry \& Lock, 2003; Pinker, 1994; Vermeerbergen, 2006). However, in spite of their predisposition to develop language, the linguistic and communicative systems of congenitally deaf children can become disrupted when they are born to hearing parents who do not sign, and thus do not provide exposure and access to ambient language (Emmorey, 2002; Goldin-Meadow, 2014; Lillo-Martin, 1999; Mayberry \& Lock, 2003; Pinker, 1994; Vermeerbergen, 2006).

A third population that clearly delineates the ways in which communication, speech, and language can individuate is non- to minimally-verbal children with complex communication needs (CCNs) who use alternate modalities to communicate (Brady, Thiemann-Bourque, Fleming, \& Matthews, 2013; Light et al., 2004; Smith, 2015). Complex communication needs are evidenced across the age span and arise due to motoric, linguistic, sensory (e.g., vision, hearing), cognitive, physical, or neurological impairments of varying levels, in isolation or in combination (American SpeechLanguage-Hearing Association [ASHA], 2005). In children, CCNs are associated with a constellation of physical disabilities, such as cerebral palsy and severe apraxia of speech, which can significantly and negatively affect the motor speech mechanisms (Duffy, 2013; 
Light \& McNaughton, 2013). Further contributors to CCNs include autism spectrum disorder (ASD), and intellectual impairments (American Speech-Language-Hearing Association [ASHA], 2004, 2005; Brignell et al., 2018). Children with CCNs typically do not demonstrate spoken language, or they exhibit impairments to such an extent that intelligible speech is precluded (ASHA, 2004; Beukelman \& Mirenda, 2013). For children experiencing these $\mathrm{CCNs}$, the acquisition of a native language increases in complexity without the ability to produce the spoken word (Blockberger \& Johnston, 2003; Drager \& Light, 2010; Drager, Light, Speltz, Fallon \& Jeffries, 2003; Light \& McNaughton, 2012a; Light et al., 2004; Paul, 1997; Smith \& Grove, 2003; Sutton \& Morford, 1998; Sutton, Soto, \& Blockberger, 2002; Sutton, Trudeau, Morford, Rios, \& Poirier, 2010).

These populations provide a window into the nuances among the constructs of communication, language, and speech, which will be further detailed in this section. Speech is defined as the specific sounds and sound patterns of a language. It is composed of phonetics, the speech sounds as physical and psychological events, and phonology, the abstract representations that underlie speech in both perception and production within and across human languages (Bates, 2003). Language uses established symbols to transmit messages; it is iterative, recursive, systematic, and rule-governed. Language is composed of three domains that are distinctly different from those of speech. These domains consist of syntax (i.e., the rules of sentence formation), semantics (i.e., the relationship between symbols and referents), phonology (i.e., the organization of sounds within a language), morphology (i.e., the structure and content of word forms), and pragmatics (i.e., the use of language in social contexts; Brown, 1973; Chomsky, 1965; Pinker, 1994, 
1996). Communication is the act of message transmission that builds a shared understanding between a sender and a receiver (ASHA, 2004; Blackstone et al., 2007). Language and linguistic output (e.g., spoken words, and sigs) are intrinsically connected and have been shown to influence the development of one another, in that the production, use, and manipulation of linguistic symbols support further language development (Bates \& Goodman, 1997; Blockberger \& Johnston, 2003; Brady et al., 2013; Paul, 1997; Smith, 2015).

Because of the multifaceted nature of speech, language, and communication, and because of the intrinsic constraints associated with CCNs, children with CCNs often acquire their native language while simultaneously learning the use of aided augmentative and alternative communication (AAC) systems (Binger, Maguire-Marshall, \& Kent-Walsh, 2011; Trudeau, Sutton, Dagenais, de Broeck, \& Morford, 2007; Zangari \& Van Tatenhove, 2009). These systems represent words with graphic symbols that can be combined to form utterances that replace impaired or nonexistent speech (Smith, 2015; Sutton et al., 2010). Additionally, because the constraints are often demonstrated in the early stages of language development, these AAC systems are typically introduced before the children gain mastery of the alphabet and develop literacy (Trudeau et al., 2007). As such, the use and manipulation of these graphic symbols become pivotal to children's language acquisition and development (Barker et al., 2013; Blackstone et al., 2007; Davidoff, 2017; Smith, 2015; Sturm \& Clendon, 2004; Sutton et al., 2002; Sutton et al., 2010).

Aided AAC systems offer a means of communicating emotional status and basic wants and needs, such as physical comfort and hunger or thirst through the use of graphic 
symbols (Davidoff, 2017; Light \& McNaughton, 2013). They afford a path to functional communication, communicative competence, and language development (Light, 1989; Light \& Drager, 2007; Locke, 1997; Trudeau et al., 2007). Further, they support a cohesive emergence of the three constructs of speech, language, and communication. Unfortunately, research has shown that many children who use aided AAC, further referred to as emerging aided communicators (EACs), demonstrate atypical form and structure of their native languages (Binger et al., 2011; Smith \& Grove, 2003; Sutton \& Morford, 1998). Specifically, research has demonstrated that EACs often exhibit limited competency in semantics, morphology, and syntax (Blockberger \& Johnston, 2003; Drager et al., 2003; Light et al., 2004; Sutton \& Morford, 1998; Sutton et al., 2002; Sutton et al., 2010), all of which have the potential to reduce agency and exert depressive influences across communicative and linguistic competence (Lund \& Light, 2003), literacy (Davidoff, 2007; Light \& McNaughton, 2012a; Snowling, 2000; Sturm \& Clendon, 2004), education (Kent-Walsh \& Light, 2003), vocation (McNaughton \& Bryen, 2002), and relationships (Light, Parsons, \& Drager, 2002).

The need to address these issues, and to reveal heretofore unexplored contributing factors to these issues provided the genesis for this dissertation. This effort echoes the words of Lillo-Martin (1999) who stated, with respect to children who use American Sign Language (ASL), “....if the acquisition of ASL is significantly different from the acquisition of spoken language, linguistic theory should well wonder why" (p. 532). In the world of AAC, language acquisition does indeed look different for EACs, and it is up to clinicians and researchers not just to wonder well, but find out precisely why. 


\section{Framing the Question}

Research on this subject is complex and challenging based on the small numbers of researchers with expertise in this area, the heterogeneity of the population, and the low prevalence (ASHA, 2004; Calculator \& Black, 2009; Light \& Drager, 2007; Thistle \& Wilkinson, 2015). However, this research strand is a justifiable pursuit based on the relevant and timely factors described in Table 1. 
Table 1

Relevant Rationales for Research Study

\begin{tabular}{|c|c|c|}
\hline Factor & Definition & Supporting Research \\
\hline $\begin{array}{l}\text { Recognized } \\
\text { Need }\end{array}$ & $\begin{array}{l}\text { The majority of individuals with } \\
\text { CCNs do not have access to AAC } \\
\text { systems. }\end{array}$ & National Core Indicators, 2012 \\
\hline $\begin{array}{l}\text { Clinical } \\
\text { Relevance }\end{array}$ & $\begin{array}{l}\text { SLPs are highly likely to } \\
\text { encounter children with CCNs in } \\
\text { their practice. }\end{array}$ & $\begin{array}{l}\text { ASHA, 2016; Kent-Walsh, Stark, } \\
\text { \& Binger, } 2008\end{array}$ \\
\hline Training & $\begin{array}{l}\text { Research has revealed a high level } \\
\text { of concern regarding SLP } \\
\text { preservice training and SLP } \\
\text { knowledge of evidence-based } \\
\text { intervention principles. }\end{array}$ & $\begin{array}{l}\text { Costigan \& Light, 2010; Dietz, } \\
\text { Quach, Lund, \& McKelevey, } \\
\text { 2012; Douglas, Light, \& } \\
\text { McNaughton, 2012; Kent-Walsh } \\
\text { \& Binger, 2009; Kent-Walsh, } \\
\text { Stark, \& Binger, 2008; Ratcliff, } \\
\text { Koul, \& Lloyd, 2008; Thistle \& } \\
\text { Wilkinson, 2015; Schlosser \& } \\
\text { Raghavendra, 2004 }\end{array}$ \\
\hline $\begin{array}{l}\text { Educational } \\
\text { Relevance }\end{array}$ & $\begin{array}{l}\text { Mandates by the United States } \\
\text { Department of Education to give } \\
\text { students access to the curriculum, } \\
\text { regardless of eligibility category. }\end{array}$ & Soto \& Zangari, 2009 \\
\hline $\begin{array}{l}\text { Broad } \\
\text { AAC } \\
\text { Issues }\end{array}$ & $\begin{array}{l}\text { Increases in: (a) awareness of } \\
\text { AAC by professionals and public, } \\
\text { (b) awareness of communication } \\
\text { rights, (c) educational inclusion } \\
\text { practices, (d) AAC use across } \\
\text { multiple populations, and (e) } \\
\text { numbers of individuals who use } \\
\text { AAC. }\end{array}$ & $\begin{array}{l}\text { ASHA, 2004; Kent-Walsh \& } \\
\text { Binger, 2018; Light \& } \\
\text { McNaughton, 2012a, 2012b; } \\
\text { Rowland \& Schweigert, 2003; } \\
\text { Smith, } 2015\end{array}$ \\
\hline
\end{tabular}

Further contributing to the justification of this inquiry are the following legislative acts:

- Individuals with Disabilities Education Act (IDEA; P.L. 94-142)

necessitating intervention supported by data-driven research (IDEA, 2004) 
- Technology-Related Assistance for Individuals with Disabilities Act (P.L. 108-364) mandating the availability of and funding for assistive technology (Assistive Technology Act, 2004)

- Every Student Succeeds Act (ESSA; P.L. 114-95) requiring academic instruction to be based on content standards and made available to all students, regardless of disability extent (ESSA, 2015)

Additional validating factors for this research include: (1) broadening and sharpening linguistic theory by studying language that develops through alternate modalities and in populations that reside outside of normative frameworks (GoldinMeadow, 2014; Lillo-Martin, 1999; Loncke, 2008), (2) increasing theoretical and pragmatic knowledge of efficient and efficacious intervention (Treweek \& Zwarenstein, 2009), and (3) driving future research directions for EACs.

\section{CHAPTER II: LITERATURE REVIEW}

The purpose of this literature review was four-fold: (1) to describe the linguistic patterns of EACs, (2) to discuss language acquisition parallels to this population that provide insight into this specialized acquisition process, (3) to review factors contributing to the linguistic outcomes of emerging aided communicators (EACs), and (4) to identify potential contributing factors not previously identified. This quadriad provides a framework from which to review the corpora of the language acquisition process as it relates to EACs. 


\section{Search Methodology}

\section{Inclusion and Exclusion Methodology}

As a mean of generating the widest search possible while maintaining fidelity to the goals of this dissertation, the following were identified as appropriate search criteria:

1. Primary scholarly articles published in peer-reviewed journals or textbook chapters.

2. Scholarly articles relating to:

a. Augmentative and alternative communication (AAC) and language acquisition and/or development,

b. AAC and morphosyntax,

c. AAC and morphological/syntactic acquisition and/or development,

d. Early language characteristics of AAC users with and without CCNs,

e. AAC system constraints and language development,

f. Language acquisition theories,

g. Language acquisition and development in special populations, and

h. SLP practices and beliefs.

The year 1985 was used as the starting point in the systematic search for AACbased articles. This decision was based on research by Binger and Light (2008) identifying that year as the point in time when research on AAC became available. Both qualitative and quantitative research designs were included in the search, and within these designs, the following types of research were considered: descriptive, surveys, experimental, quasi-experimental, historical, observational, case study, and reviews. 


\section{Search Parameters}

The following databases were accessed in this literature review:

1. Academic Search Complete,

2. Cinhal Plus with Full Text,

3. Comdisdome,

4. ERIC (via ProQuest),

5. Eric (via EBSCO),

6. Linguistics and Language Behavior Abstracts,

7. PsychINFO, and

8. PubMed.

Additional searches were conducted via the ASHA website database.

Specifically, searches were undertaken in the ASHA journals Perspectives on Augmentative and Alternative Communication and Augmentative and Alternative Communication, which have limited availability on general academic databases. Finally, journal-specific searches were conducted on the following journals due to limited access in academic databases: Linguistics, Child Language, Folia Phonatricia, Topics in Language Disorders, and International Journal of Speech and Language. The following search terms were used in various permutations: $A A C$, language acquisition, language development, syntax, morphology, AAC systems, language constraints, sign language, and language acquisition theories. In addition to scholarly articles culled from research databases, articles were identified through the ancestral method.

Studies were deemed appropriate if they included examinations and/or discussions of (a) language acquisition patterns of EACs, (b) various constraints of AAC 
systems, (c) language acquisition theories and their relationship to AAC, (d) the morphosyntactic patterns of EACs, (e) language acquisition in special populations, (f), subcategories of languages, (g) AAC system designs, and (h) SLP practices and beliefs.

\section{Results of the Review}

\section{Augmentative and Alternative Communication}

Augmentative and alternative communication is defined as a communication system used to compensate for temporary or permanent severe expressive and receptive speech-language impairments (ASHA, 2004; Branson \& Demchak, 2009; Davidoff, 2017) and decrease barriers to successful communication (Barker et al., 2013; Johnston, Reichle, \& Jones, 2010; Light \& McNaughton, 2012a). As an area of practice, AAC demonstrates a growing body of evidence supporting the effectiveness of technologies and strategies across a highly heterogeneous spectrum (e.g., disability type, language, culture, socio-economic status) (Brignell et al., 2018; Blackstone et al., 2007; Ganz et al., 2011; Kent-Walsh \& Binger, 2018; Morin et al., 2018; O’Neill, Light, \& Pope, 2018; Wilkinson \& Hennig, 2009). Rather than a narrow range of high-tech speech-generating devices or low-tech communication books, AAC systems offer an additional modality through an integrated and broad set of techniques, tools, and strategies that can be used across communication partners, settings, and contexts (Barker et al., 2013; Blackstone et al., 2007; Calculator \& Black, 2009).

Augmentative and alternative communication can be further conceptualized as a communication continuum ranging from unaided systems incorporating recognized and idiosyncratic gestures, facial expressions, vocalizations, and manual signs produced by the communicator, to low-tech aided systems such as alphabet boards, communication 
books, and Picture Exchange Communication System (PECS) boards, to high-tech systems such as dedicated AAC devices (e.g., Essence Pro ${ }^{\mathrm{TM}}$, Light Writer ${ }^{\mathrm{TM}}$ ) and AAC computer or tablet applications (e.g., Words for Life ${ }^{\mathrm{TM}}$, Proloquo2Go ${ }^{\mathrm{TM}}$ ) (Ganz et al., 2011; Light \& McNaughton, 2012a).

Individuals who use AAC can be differentiated broadly into two categories: those who are introduced to AAC while acquiring their native language and before they are able to use the alphabet (Trudeau et al., 2007), and those who are introduced to AAC after attaining fluency in their native language. As discussed above briefly, this timing has critical implications on the language development of young children, as research has demonstrated that the linguistic patterns of EACs do not reflect those of children with intact speech and language systems (Drager et al., 2003; Drager \& Light, 2010; Light \& McNaughton, 2012a; Light et al., 2004; Smith \& Grove, 2003; Sutton, 2008; Sutton et al., 2010; Sutton \& Morford, 1998).

\section{Language Acquisition and Development}

In order to provide a meaningful point of departure to discuss factors contributing to the linguistic outcomes of EACs, a brief summary of the language acquisition models of typically developing, English-speaking children is provided.

\section{Models of Typical Language Development}

Language acquisition is a contingent and hierarchical process involving multiple domains and stages that allow children to deduce meaning from the language used around them and map this meaning onto the formal phonological, semantic, morphological, and syntactic structures used for expression (Bates \& Goodman, 1997; Brown, 1973;

Chomsky, 2005; Locke, 1997; Pinker, 1979, 1994; Smith, 2015; Smith \& Grove, 2003). 
From birth to preschool, typically developing English-speaking children progress through a language acquisition hierarchy culminating in the use of symbolic language that allows them to engage in complex and sophisticated communication with others (Bates \& Goodman, 1997; Davidoff, 2017; Light, 1997). These children move through this acquisition hierarchy based on individual intrinsic characteristics and extrinsic factors (Light, 1997) that influence their ability to manipulate, comprehend, construct, and produce language; by the time they are 30 months old, they are producing approximately 500 words that are being combined into meaningful two-word phrases (Bates \& Goodman, 1997; Blockberger \& Johnston, 2003; Brown, 1973).

Semantics. Semantics encompasses both the vocabulary and the concepts that are represented by these words (Bates, 2003; Soto \& Zangari, 2009). Words are learned through: (a) inductive and deductive processes; (b) complex interactions between genetic and environmental factors; and (c) conceptualization, socialization, and linguistic capacities (L. Bloom, 2000; P. Bloom, 2000; Dale \& Goodman, 2005). In English, early words include a high ratio of nouns to verbs and encompass categories that include people, animals, mid-sized objects, and actions (Gentner \& Boroditsky, 2001; Pinker, 1994). These words are produced initially in specific and ritualized contexts (nonreferential), and later, as development continues, words are produced in a symbolic or referential way as a means of anticipating or evoking absent referents (Dale \& Goodman, 2005; Rowland, \& Schweigert, 2003; Volterra, Caselli, Caprici, \& Pizzuto, 2005).

Morphology. Morphology refers to the principles governing the construction of complex words (Bates, 2003; Pinker, 1994). The morphological development of 
typically developing children has been studied extensively and follows a very stable hierarchy first identified by Brown in 1973 (see Table 2).

Table 2

Five Stages of Morphological Structural Development in Children with Examples

\begin{tabular}{|c|c|c|c|}
\hline Stage & Age $^{a}$ & Morphological Structure & Example \\
\hline I & $15-30$ & One or two true words & "mama," "bottle" \\
\hline II & $28-36$ & $\begin{array}{l}\text { Present progressive } \\
\text { Articles "in" and "out" } \\
\text {-s Plurals }\end{array}$ & $\begin{array}{l}\text { “ing" } \\
\text { "dogs" }\end{array}$ \\
\hline III & $36-42$ & $\begin{array}{l}\text { Irregular past tense } \\
\text { 's Possessive } \\
\text { Uncontractible copula }\end{array}$ & $\begin{array}{l}\text { "swept" } \\
\text { "Bill's book" } \\
\text { "is it ready?" }\end{array}$ \\
\hline IV & $40-46$ & $\begin{array}{l}\text { Articles } \\
\text { Regular past tense } \\
\text { Third person regular, present tense }\end{array}$ & $\begin{array}{l}\text { "a," "the" } \\
\text { "walked" } \\
\text { "Phoebe takes it" }\end{array}$ \\
\hline $\mathrm{V}$ & $42-52+$ & $\begin{array}{l}3^{\text {rd }} \text { Person Irregular } \\
\text { Uncontractible auxiliary } \\
\text { Contractible copula } \\
\text { Contractible auxiliary } \\
\end{array}$ & $\begin{array}{l}\text { "Riley does" } \\
\text { "are they winning?" } \\
\text { "she's smart" } \\
\text { "they're coming" }\end{array}$ \\
\hline
\end{tabular}

Note. Adapted from A First Language: The Early Stages, by R. Brown, 1973. Copyright 1973 by George Allen \& Unwin; and Language Disorders From Infancy Through Adolescence: Listening, Speaking, Reading, Writing, and Communicating (4th ed.), by R. Paul and C. Norbury, 2012. Copyright 2012 by Elsevier.

${ }^{\mathrm{a} A g e}$ of acquisition by month

This developmental hierarchy reflects the emerging morphological awareness of children who begin to understand that new word meanings can be generated by adding linguistic pieces to familiar words (Bates \& Goodman, 1997; McBride-Chang, Wagner, Muse, Chow, \& Shu, 2005).

Although speaking children initially use uninflected words free of morphological markers (Behrens, 2006), by the time typically developing English-speaking children are approximately $4 \frac{1}{2}$ years old, they are incorporating the majority of the obligatory markers in their language that have been modeled for them by the adults in their environment (Bates \& Goodman, 1997; Behrens, 2006). During these early years, as children's 
morphology advances, they demonstrate a concomitant development in syntax as they begin to combine words meaningfully (Bates \& Goodman, 1997; Gard, Gillman, \& Gorman, 1993; Paul, 1997; Paul \& Norbury, 2012). A final comment regarding morphology is research revealing that morphological development is correlated with semantic and syntactic complexity (Bates, Bretherton, \& Snyder, 1988; Brown, 1973).

Syntax. Syntax is the study of the rules governing sentence structure and acceptable sentential word order (Bates, 2003; Lasnik, 1995). It is considered a second order language skill (Smith, 2015). Word order varies across languages and in English, acceptable sentential word order consists of subject + verb + object (SVO). As with morphology, syntax acquisition follows a stable acquisition hierarchy and by the time English-speaking children are approximately 5 years old, they are demonstrating complex sentence forms, consistent sentence word order of SVO, and a full range of verb forms (see Table 3). 
Table 3

Syntactic Development in Children by Age and Associated Characteristics

\begin{tabular}{|c|c|}
\hline Age & Syntactic Characteristics \\
\hline \multirow[t]{2}{*}{$12-18$} & First true words emerge \\
\hline & Nouns account for $50 \%$ of all utterances \\
\hline \multirow[t]{6}{*}{$18-24$} & Two words are combined \\
\hline & Mean length of utterance (MLU) is 1.8 \\
\hline & Nouns account for $33 \%$ of all utterances \\
\hline & Consistent $\mathrm{S}+\mathrm{V}+\mathrm{O}$ word order \\
\hline & Few grammatical markers are present \\
\hline & $\begin{array}{l}\text { Utterances are telegraphic (e.g., "want up") and contain few } \\
\text { grammatical markers }\end{array}$ \\
\hline \multirow[t]{4}{*}{$24-36$} & Three to four words are combined \\
\hline & Mean length of utterance is 3.1 \\
\hline & Nouns account for $25 \%$ of words \\
\hline & Verbs account for $25 \%$ of words \\
\hline \multirow[t]{4}{*}{$36-48$} & Four- to five-word phrases are produced \\
\hline & Mean length of utterance is 4.3 to 4.4 \\
\hline & Early complex sentence forms appear (i.e., prepositional clauses, \\
\hline & $\begin{array}{l}\text { wh-clauses, simple intinitives, conjoined sentences) } \\
\text { Auxiliary verbs are used correctly in questions and negatives }\end{array}$ \\
\hline \multirow[t]{6}{*}{$48-60$} & Sentences of four to eight words are produced \\
\hline & Mean length of utterance is 4.6 to 4.7 \\
\hline & Stable acquisition of basic sentence forms \\
\hline & $\begin{array}{l}\text { Later complex sentences form appear (i.e., relative clauses, } \\
\text { infinitive clauses with multiple subjects, gerund clauses, wh- } \\
\text { infinitive clauses) }\end{array}$ \\
\hline & Subject-verb agreement errors persist \\
\hline & Emergence of passive sentence structure \\
\hline
\end{tabular}

Note. Adapted from Speech and Language Development Chart (2nd ed.), by A. Gard, L. Gillman, and J. Gorman, 1993. Copyright 1993 by Pro-Ed; and Language Disorders From Infancy Through Adolescence: Listening, Speaking, Reading, Writing, and Communicating (4th ed.), by R. Paul and C. Norbury, 2012. Copyright 2012 by Elsevier.

${ }^{\mathrm{a}} \mathrm{Age}$ of acquisition is in months.

Further, by this age they are well on their way toward linguistic mastery, with productive control over the sounds and grammar of their language, and with a vocabulary 
of more than 6000 words (Bates, 2003). Figure 1 represents the multifactorial relationship among the constructs defined above.

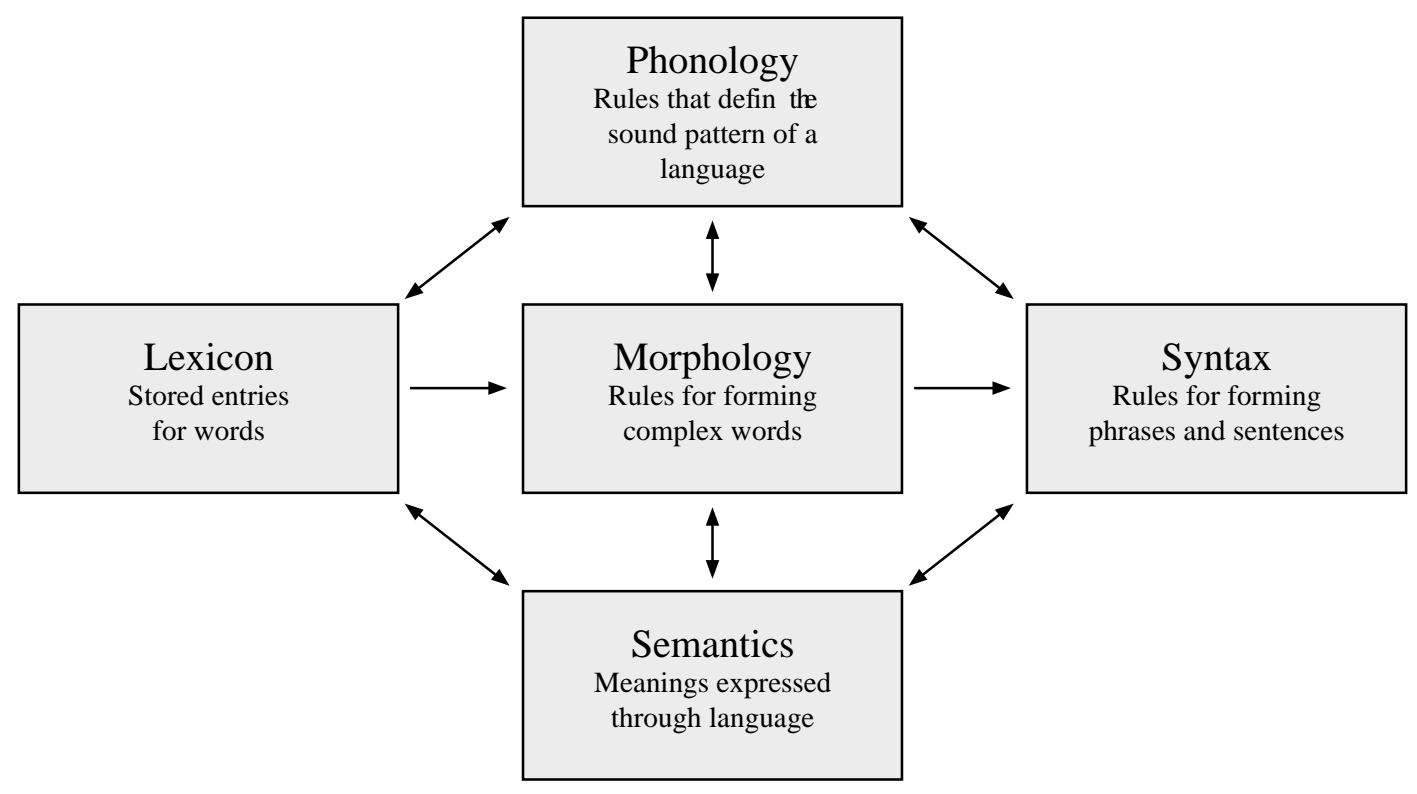

Figure 1. Multifactorial Relationship. Adapted from Words and Rules: The Ingredients of Language, by S. Pinker, 1999, p. 23. Copyright 1999 by Basic Books. The relationships are reflective of those between the various constructs and building blocks of language.

\section{Grammatical Morphology and Syntax of EACs}

Speaking children hear their native language spoken in their environment and use this model to develop linguistic schemata about the form and content of their language (Bates \& Goodman, 1997; Pinker, 1994). These linguistic hypotheses are tested by their language use, from which they receive feedback that supports their continued development (Light, 1997; Tomasello, 2003). For EACs however, the ability to test out their linguistic hypotheses is diminished due to the temporal asynchrony between their exposure to ambient language and their ability to produce that language (Smith, personal communication, October 5, 2017), as well as the lack of access to a reliable method of communication (Light, 2014; Loncke, 2008; Smith \& Grove, 2003; Sutton et al., 2002). 
At the same time, EACs experience demands across all domains that exceed those of speaking children (Trudeau et al., 2007), as evidenced in Plag's (2008) research on language processing which states:

Linguistic structure is gradually built up while conceptualisation [sic] is still going on. On top of that...subsequent processing procedures often have to work with the still-incomplete output of the previous process, which necessitates that incomplete intermediate output has to be kept available in short-term memory. (p. 119)

In addition to the complexity of language processing, EACs have to develop meanings, determine relationships between meanings and spoken words, and identify how these internal meanings interact with their external aided symbols (Smith, 2015). Emerging aided communicators approach these tasks with recognized vocabulary limitations (Boenisch \& Soto, 2015; Light et al., 2004), morphological errors and omissions (Blockberger \& Johnston, 2003; Smith \& Grove, 2003; Sutton, 2008; Sutton \& Morford, 1998), violations in acceptable word order (Blockberger \& Sutton, 2003; Smith \& Grove, 2003; Sutton, 2008; Trudeau et al., 2007), use of telegraphic utterances (e.g., “vacation go airplane") (Binger \& Light, 2008; Sutton \& Morford, 1998), and reduced phrase length (Smith, 2015).

\section{Structural Analysis of the Language of EACs}

The extensive body of evidence describing the linguistic characteristics of EACs as detailed above presents an opportunity to locate the structural patterns within a larger frame of reference and to identify parallels in the linguistic community that may inform this inquiry. Two linguistic parallels that have emerged in the review of literature are 
pidgins and interlanguages. Establishing similarities among these three constructs assists in building a better understanding of whether the linguistic patterns are manifestations of an intermediate step in language development or universal processes (Jung, 2004), grammar building or restructuring (Winford, 2006), or an alternate system of language with a separate syntax or word order-as seen in American Sign Language (ASL) which mandates a reconceptualization of the requisite faithfulness between form and meaning (Lillo-Martin, 2016). Alternatively, this line of questioning may ascertain if the linguistic patterns reflect imperfect learning, inadequate practice (Roberts \& Bresnan, 2008), obligatory errors enforced by the discrepancies between the speaker and the linguistic output form available, or the manner in which language acquisition develops in a modality that dictates an alternate hierarchy and final product (Pichler, 2011).

Pidgins. Pidgins are defined as isolated exceptions to universal patterns of language acquisition, serving as a conventionalized means of communication between speakers of separate languages when no single group adopts the language of the other (Holm, 1988; Roberts \& Bresnan, 2008; Winford, 2006). They have been further defined as reduced or makeshift languages (Holm, 1988). Research indicates that pidgins employ parataxis (i.e., short, unmarked word combinations lacking complements, cohesion, embeddedness), rather than syntax, as well as reduced lexicality and minimal to no inflectional morphology (Holm, 1988; Jourdan, 1991; Winford, 2006). Additional grammatical structures typically absent in pidgins are seen in Table 4 . 
Table 4

Grammatical Structures Typically Absent in Pidgins

\begin{tabular}{lll}
\hline Structure & Definition & Example \\
\hline Case & $\begin{array}{l}\text { The grammatical relationship } \\
\text { of nouns and pronouns to other } \\
\text { words in a sentence }\end{array}$ & $\begin{array}{l}\text { Nominative/Subjective (we, he, I) } \\
\text { Oblique/Objective (us, her, me) } \\
\text { Genitive/Possessive (ours, hers, mine) }\end{array}$ \\
Tense & $\begin{array}{l}\text { The expression of time with } \\
\text { reference to the moment of } \\
\text { speaking }\end{array}$ & $\begin{array}{l}\text { Present (walk) } \\
\text { Past tense (walked) } \\
\text { Future (will walk) }\end{array}$ \\
Aspect & $\begin{array}{l}\text { A verb form indicating time- } \\
\text { related characteristics, such as } \\
\text { the completion, duration, or } \\
\text { repetition of an action }\end{array}$ & $\begin{array}{l}\text { Simple (present: walk) } \\
\text { Continuous (present: am walking) }\end{array}$ \\
Porfect (present: has walked) \\
Perfect Continuous (has been walking)
\end{tabular}

Note. Per Jourdan (1991) and Winford (2006), grammatical structures as provided are typically absent in pidgins.

These patterns are found across all pidgins regardless of their typology (structural and functional features) or source language (Bresnan, 2000; Jourdan, 1991; Roberts \& Bresnan, 2008; Winford, 2006). A final but relevant assertion by researchers is that speakers of pidgins rarely achieve a level of fluency and facility with the language (Tarone, 2013). 
While those structures align with the concept of a corrupted version of traditional languages, there is research suggesting that this perspective presents a simplistic view of pidgins (Bickerton, 2008; Bresnan, 2000; Roberts \& Bresnan, 2008) and that “...pidgins... are not wrong versions of other languages, but rather, new languages” (Holm, 1988, p. 1).

Interlanguages. Interlanguages are often discussed with respect to adult learners of a second language. According to Selinker (1972), interlanguages are separate linguistic systems emerging as a result of attempts to express meaning in a language that is in the process of being learned. Interlanguages occur at the level of the individual and are not conventionalized (Plag, 2008). Central to the definition of an interlanguage is the concept of fossilization, whereby the learner's language ceases to develop, most often permanently, and falls short of a full identity with the targeted language (Tarone, 2013). According to Anderson (1984), interlanguages are constructed in such a way as to allow individuals to express underlying meanings with a clear invariant surface form. In this paradigm, there is a mapping of one form to one meaning and one function to one form, which naturally imposes limits on the message complexity. However, in spite of this limitation, providing a one-to-one mapping of meaning onto form is an appropriate method of communication considering how the brain perceives, processes, stores, and produces linguistically encoded information. This perspective draws attention to language universals (what a possible language is), perceptual strategies (constraints on learnability), and natural processes (constraints on expressibility) (Anderson, 1984).

Research has suggested that interlanguages reflect a syntactic accent of a speaker's first language (MacWhinney, 2005). Two important aspects of a syntactic 
accent are that the experience forces item-based mapping of concept to form, which is not conductive to productive syntax, and that there may be age-related effects or maturational constraints that impact learnability (Henner, Caldwell-Harris, Novogrodsky, \& Hoffmeister, 2016; MacWhinney, 2005; Mayberry \& Lock, 2003). What remains of controversy in the field of linguistics is whether pidgins and interlanguages reflect initial states of language development, imperfect learning, universal simplification processes, or universal constraints on predication (Anderson, 1984; Tarone, 2013; Winford, 2006).

Proposed explanations for the linguistic patterns observed in pidgins and interlanguages can be found in viewing language acquisition through the lens of the competition model (MacWhinney, 2005). This model suggests that linguistic forms compete to express functions or underlying intentions, which forces the most important issue to take precedence, with an expected influence on word order. This pattern is analogous to topic prominence versus subject prominence, or to languages with a pragmatic word order, as seen in Turkish and in individuals acquiring a second language (Jung, 2004). When the linguistic forms available in one language are more limited than another, acquisition becomes more complex. An example of this complexity can be seen in the challenge of translating colors from a language with a system of eight colors into a language with a color system of two (MacWhinney, 2005). This context also suggests that speakers identify the universally least marked properties of the language they are exposed to and generate nonsentential language as a consequence (Winford, 2006). As would be expected when using language where there are absent forms, the form-function correspondence, or meaning, must often be determined by pragmatics and discourse context (Winford, 2006). In each of the constructs discussed above, linguistic structure is 
dominated by a pragmatic style of communication where the function remains communicative rather than linguistic. This structure is characterized by a topic-comment structure, slow delivery, low noun-verb ratio, and no grammatical morphology (Smith \& Grove, 2003). This structure reflects a semantic-syntactic asymmetry that further confounds linguistic development.

Research on pidgins and interlanguages conflicts as to whether they can be considered natural languages (Anderson, 1984; Holm, 1988; Tarone, 2013; Winford, 2006), and this question can be appropriately applied to the language observed in emerging aided communication. Continuing, although there are many sides to a discussion of pidgins and interlanguages, what can be reliably stated is that they are linguistic constructs with permeable rule systems (Tarone, 2013), a conceptualization that can be readily applied to the linguistic patterns observed in EACs.

\section{Shared Traits}

The parallels between the syntax of EACs and that of pidgins and interlanguages are compelling. In addition to the structural similarities detailed above, all three constructs are frequently discussed within a deficit paradigm: reduced, simplified, impoverished, and degraded (Anderson, 1984; Bresnan, 2000; Holm, 1988; Plag, 2008). Continuing, all three constructs demonstrate a lexicon-syntax interface that is relatively transparent (Plag, 2008) because of the imperfect imposition of a semantic representation onto a limited linguistic form, and the fossilization of language and limited fluency by experienced speakers (Tarone, 2013). Table 5 captures the homogeneity of the three constructs of pidgins, interlanguages, and the syntax of EACs. 
Table 5

Shared Traits of Pidgins, Interlanguages, and the Syntax of EACs

\begin{tabular}{lccc}
\hline Characteristic & Pidgins & Interlanguages & Syntax of EACs \\
\hline Atypical or reduced morphology & $\mathrm{X}$ & $\mathrm{X}$ & $\mathrm{X}$ \\
Reduced lexicon & $\mathrm{X}$ & $\mathrm{X}$ & $\mathrm{X}$ \\
Atypical or reduced syntax & $\mathrm{X}$ & $\mathrm{X}$ & $\mathrm{X}$ \\
Pragmatic and contextual word order & $\mathrm{X}$ & $\mathrm{X}$ & $\mathrm{X}$ \\
Absent grammatical forms & $\mathrm{X}$ & $\mathrm{X}$ & $\mathrm{X}$ \\
Unmarked verb forms & $\mathrm{X}$ & $\mathrm{X}$ & $\mathrm{X}$ \\
Lack of complex sentence forms & $\mathrm{X}$ & $\mathrm{X}$ & $\mathrm{X}$ \\
Overgeneralizations of language rules & & $\mathrm{X}$ & $\mathrm{X}$ \\
Use of communication strategies to & $\mathrm{X}$ & $\mathrm{X}$ & $\mathrm{X}$ \\
overcome absent words or forms & & $\mathrm{X}$ & $\mathrm{X}^{\mathrm{a}}$ \\
Fossilization & & $\mathrm{y}$ &
\end{tabular}

Note. Shared traits between pidgins, interlanguages, and syntax of EACs (Anderson, 1984; Blockberger \& Johnston, 2003; Bresnan, 2000; Drager et al., 2003; Light et al., 2004; Plag, 2008; Jourdan, 1991; Roberts \& Bresnan, 2008; Tarone, 2013; Sutton \& Morford, 1998; Sutton et al., 2002; Sutton et al., 2010; Winford, 2006). Examples of absent grammatical forms include case, tense, aspect, mood, copulas, articles. Lack of complex sentence forms include embedding, subordination, passivization, and question inversion.

a. This is a theory being put forth in this dissertation.

\section{Language Samples}

One clear difference between the literature on pidgins and interlanguages and the syntax of EACs is the availability of a corpus of language samples. Because there is a large corpus of pidgin and interlanguage samples, researchers have been able to probe the variations among the native language and target language, and the structure of pidgins and interlanguages. However, there is a crucial need to establish a broad corpus of language samples for EACs to provide greater insight into this population. Access to such a corpus would support greater understanding of the patterns of EACs.

The analysis of language samples is a critical component of evidence-based practices and clinical decision-making (Kovacs \& Hill, 2015). Access to a broad corpus of language samples allows clinicians to identify stages of language development of 
specific populations and to measure change over time (Pavelko, Owens, Ireland, \& HahsVaughn, 2016). Access also provides valuable clinical insight as it allows researchers and clinicians alike to compare a child's production to a known adult grammar model and differentiate between typical and disordered language development (Kovacs \& Stickney, 2012; Rice \& Wexler, 1996). For example, one morphological marker that has proved clinically useful in identifying specific language impairment (SLI) is the use of grammatical morphemes reflecting tense and agreement (i.e., third person singular $-s$, past tense -ed, auxiliary forms, copula) (Kamhi, 2014; Rice, Wexler, \& Cleave, 1995). Without access to grammatical structures that can be used to mark tense or agreement, EACs cannot be differentiated into those who remain in the early stages of language development and those who may be demonstrating SLI. Further, without access to the information that can be gleaned from analyzing the psycholinguistic factors revealed in a language sample, measures of sensitivity (true positives) and specificity (true negatives) cannot be identified (Shamahmood, Jalaie, Soleymani, Haresabadi, \& Nemati, 2016). While this point may give the appearance of being mired in minutia, this differentiation informs intervention decisions that may influence ultimate linguistic outcomes (Rice \& Wexler, 1996).

At the level of the subpopulation of EACs, the absence of a corpus of language samples prevents clinicians from identifying systematized patterns of language acquisition and development or measuring change over time, especially when changes are incremental as is often the case in EACs (Beukelman \& Mirenda, 2013). Additionally, it prevents clinicians from identifying larger, language acquisition patterns in special populations, such as EACs, that may differentiate from spoken language, as is seen in the 
acquisition and developmental patterns of ASL (Lillo-Martin, 2016; Mayberry \& Squires, 2006). While AAC as a research field is growing, and while the use of automated language sampling methods are increasing (Kovacs \& Hill, 2015), limited access to a corpus of language samples of EACs continues to persist.

The Child Language Data Exchange System (CHILDES), supported by National Institute of Health grants (R01-HD23998 and R01-HD051698), is a component of the TalkBank system (CHILDES, n.d.). This is an open-source site designed to share and study conversational interactions. This site contains an extensive collection of language samples across language, disorder, and age span, but does not currently include one for $\mathrm{AAC}$ users, nor is there an expectation for an AAC database in the foreseeable future (MacWhinney, email, July 8, 2017). Gallaudet University and the University of Connecticut maintain the Sign Linguistics and Language Acquisition Lab that contains video taped sessions of conversations between researchers and children who are deaf (Sign Linguistics and Language Acquisition Lab, n.d.). This project provides a potential model for the collection and storage of the language acquisition process in special cases. A search of the literature for peer-reviewed articles containing language samples of EACs revealed six articles with language samples included, as seen in Table 6. These samples have been modified to reflect the use of "E" for examiner and "C" for children, regardless of the names and abbreviations used in the original sample. 
Table 6

Journal Articles Containing Language Samples of Aided Communicators

\begin{tabular}{|c|c|c|c|c|}
\hline Year & Author/Title & $\begin{array}{l}\text { Participant } \\
\text { Characteristics }\end{array}$ & AAC System & Language Sample \\
\hline \multirow[t]{3}{*}{1997} & \multirow[t]{3}{*}{$\begin{array}{l}\text { Bedrosian: } \\
\text { Language acquisition in young AAC } \\
\text { system users: Issues and directions for } \\
\text { future research. Augmentative and } \\
\text { Alternative Communication, 13(3), 179- } \\
185 \text {. }\end{array}$} & $\begin{array}{l}\text { Chronological } \\
\text { Age: Not } \\
\text { specified } \\
\text { Diagnosis: } \\
\text { Severe speech } \\
\text { impairment/ } \\
\text { Not specified }\end{array}$ & $\begin{array}{l}\text { AAC Type: } \\
\text { Unaided AAC }\end{array}$ & $\begin{array}{l}\text { C: (Request for attention) } \\
\text { E: COMES OVER AND LOOKS AT } \\
\text { CHILD } \\
\text { C: TOUCHES ADULT'S HAND } \\
\text { (Request for action) } \\
\text { E: What do you want me to do? } \\
\text { C: DIRECTS EYE GAZE TO A } \\
\text { STORYBOOK (Response) } \\
\text { E: Oh, you want me to read this } \\
\text { storybook to you? } \\
\text { C: SMILES (Response) }\end{array}$ \\
\hline & & & $\begin{array}{l}\text { AAC Type: } \\
\text { Low-Tech } \\
\text { (ETRAN } \\
\text { Board w/ PCS } \\
\text { symbols) }\end{array}$ & $\begin{array}{l}\text { C: (Request for attention) } \\
\text { E: COMES OVER AND LOOKS AT } \\
\text { CHILD } \\
\text { C: DIRECTS EYE GAZE TO PCS } \\
\text { SYMBOL FOR "HELP” (Request for } \\
\text { action) } \\
\text { E: What do you want me to do? } \\
\text { C: DIRECTS EYE GAZE TO PCS } \\
\text { SYMBOL FOR "STORYBOOK" } \\
\text { (Response) } \\
\text { E: Oh, you want me to read this } \\
\text { storybook to you? } \\
\text { C: SMILES (Response) }\end{array}$ \\
\hline & & $\begin{array}{l}\text { Chronological } \\
\text { Age: Not } \\
\text { specified } \\
\text { Diagnosis: } \\
\text { Severe speech } \\
\text { impairment/ } \\
\text { Not specified }\end{array}$ & $\begin{array}{l}\text { AAC Type: } \\
\text { High-Tech } \\
\text { Voice output } \\
\text { communication } \\
\text { aid (VOCA) }\end{array}$ & $\begin{array}{l}\text { C: ACTIVATES PCS SYMBOL FOR } \\
\text { "TURN,' RESULTING IN THE } \\
\text { SPOKEN MESSAGE: Can I have a turn, } \\
\text { please? } \\
\text { E: COMES OVER AND LOOKS AT } \\
\text { CHILD } \\
\text { C: DIRECTS EYE GAZE AND } \\
\text { POINTS TO THE HAMSTER CAGE } \\
\text { E: Oh, do you want a turn to pet the } \\
\text { hamster? } \\
\text { C: SMILES }\end{array}$ \\
\hline \multirow[t]{2}{*}{2011} & \multirow[t]{2}{*}{$\begin{array}{l}\text { Binger, Maguire-Marshall, \& Kent- } \\
\text { Walsh: } \\
\text { Using aided AAC models, recasts, and } \\
\text { contrastive targets to teach grammatical } \\
\text { morphemes to children who use AAC. } \\
\text { Journal of Speech, Language, and } \\
\text { Hearing Research, 54(1), 160-176. }\end{array}$} & $\begin{array}{l}\text { Participant 1 } \\
\text { Chronological } \\
\text { Age: } 11: 0 \\
\text { Diagnosis: } \\
\text { Cerebral palsy }\end{array}$ & $\begin{array}{l}\text { AAC Type: } \\
\text { High-Tech } \\
\text { Vantage or } \\
\text { Vanguard SGD } \\
\text { (Unity } \\
\text { software } \\
\text { vocabulary) }\end{array}$ & $\begin{array}{l}\text { C: I building. } \\
\text { C: He crawl. } \\
\text { C: He dancing. } \\
\text { C: Grandma racing. } \\
\text { C: They jumping. } \\
\text { C: They stealing. } \\
\text { C: They singing. } \\
\text { C: He roll's. } \\
\text { C: He eat's. } \\
\text { C: The drink's. } \\
\text { C: They swimming's. } \\
\text { C: She going's. } \\
\text { C: I am going's. }\end{array}$ \\
\hline & & $\begin{array}{l}\text { Participant } 2 \\
\text { Chronological } \\
\text { Age: } 6: 0 \\
\text { Diagnosis: } \\
\text { Childhood } \\
\text { apraxia of } \\
\text { speech }\end{array}$ & $\begin{array}{l}\text { AAC Type: } \\
\text { High-Tech } \\
\text { Vantage or } \\
\text { Vanguard SGD } \\
\text { (Unity } \\
\text { software } \\
\text { vocabulary) }\end{array}$ & $\begin{array}{l}\text { C: Horse apple. } \\
\text { C: Girl banana. } \\
\text { C: Girl dishes. } \\
\text { C: Cat sleep. } \\
\text { C: Men. } \\
\text { C: Cat spaghetti. } \\
\text { C: Dog bowl. } \\
\text { C: Women. } \\
\text { C: Grandfather glasses. }\end{array}$ \\
\hline
\end{tabular}




\begin{tabular}{|c|c|c|c|c|}
\hline Year & Author/Title & $\begin{array}{l}\text { Participant } \\
\text { Characteristics }\end{array}$ & AAC System & Language Sample \\
\hline & & & & $\begin{array}{l}\text { C: Cow bell. } \\
\text { C: Cat's sleeped } \\
\text { C: Dog's bowled } \\
\text { C: Cat's spaghettied. } \\
\text { C: He talks dog. } \\
\text { C: He looks. } \\
\text { C: He laugheds. }\end{array}$ \\
\hline & & $\begin{array}{l}\text { Participant } 3 \\
\text { Chronological } \\
\text { Age: 9:0 } \\
\text { Diagnosis: } \\
\text { Cerebral palsy }\end{array}$ & $\begin{array}{l}\text { AAC Type: } \\
\text { High-Tech } \\
\text { Vantage or } \\
\text { Vanguard SGD } \\
\text { (Unity } \\
\text { software } \\
\text { vocabulary) }\end{array}$ & $\begin{array}{l}\text { C: He cat kick the ball. } \\
\text { C: She talk to a dog. } \\
\text { C: He the look monkey's. } \\
\text { C: He the walk freeway. } \\
\text { C: She bake the cake's } \\
\text { C: He play the's. } \\
\text { C: She kiss's. } \\
\text { C: She dry's. } \\
\text { C: He cook's. } \\
\text { C: He turn's. }\end{array}$ \\
\hline \multirow[t]{2}{*}{2003} & \multirow[t]{2}{*}{$\begin{array}{l}\text { Lund \& Light: } \\
\text { The effectiveness of grammar } \\
\text { instruction for individuals who use } \\
\text { augmentative and alternative } \\
\text { communication systems: A preliminary } \\
\text { study. Journal of Speech, Language, } \\
\text { and Hearing Research, 46(5), 1110- } \\
1123 \text {. }\end{array}$} & $\begin{array}{l}\text { Participant } 1 \\
\text { Chronological } \\
\text { Age: } 30.0 \\
\text { Diagnosis: } \\
\text { Cerebral palsy; } \\
\text { severe speech } \\
\text { impairments } \\
\text { (i.e., less than } \\
10 \text { spoken } \\
\text { words were } \\
\text { intelligible to } \\
\text { unfamiliar } \\
\text { partners). }\end{array}$ & $\begin{array}{l}\text { AAC Type: } \\
\text { High-Tech } \\
\text { (VOCA); } \\
\text { Liberator with } \\
\text { Unity }\end{array}$ & $\begin{array}{l}\text { C: Please drop me off at the store cards. } \\
\text { C: When you go to the mall? }\end{array}$ \\
\hline & & $\begin{array}{l}\text { Participant } 2 \\
\text { Chronological } \\
\text { Age: } 29.0 \\
\text { Diagnosis: } \\
\text { Severe athetoid } \\
\text { cerebral palsy; } \\
\text { severe speech } \\
\text { impairments } \\
\text { (i.e., less than } \\
10 \text { spoken } \\
\text { words were } \\
\text { intelligible to } \\
\text { unfamiliar } \\
\text { partners). }\end{array}$ & $\begin{array}{l}\text { AAC Type: } \\
\text { High-Tech } \\
\text { (VOCA); } \\
\text { Liberator with } \\
\text { Word Strategy }\end{array}$ & $\begin{array}{l}\mathrm{C}: \text { That } \mathrm{CD} \text { is my. } \\
\text { C: Do you want watch TV with me? }\end{array}$ \\
\hline \multirow[t]{2}{*}{2010} & \multirow[t]{2}{*}{$\begin{array}{l}\text { Romski, Sevcik, Adamson, Cheslock, } \\
\text { Smith, Barker, \& Bakeman: } \\
\text { Randomized comparison of augmented } \\
\text { and nonaugmented language } \\
\text { interventions for toddlers with } \\
\text { developmental delays and their parents. } \\
\text { Journal of Speech, Language, and } \\
\text { Hearing Research, 53(2), 350-364. }\end{array}$} & $\begin{array}{l}\text { Group 1: } \\
\text { Chronological } \\
\text { Age: 2:5 (avg.) } \\
\text { Diagnosis: } \\
\text { Genetic } \\
\text { syndromes } \\
\text { (e.g., Down } \\
\text { syndrome), } \\
\text { seizure } \\
\text { disorders, } \\
\text { cerebral palsy, } \\
\text { or unknown } \\
\text { conditions. }\end{array}$ & $\begin{array}{l}\text { AAC Type: } \\
\text { High-Tech } \\
\text { (SGD) using } \\
\text { Picture } \\
\text { Communication } \\
\text { Symbols }\end{array}$ & $\begin{array}{l}\text { E: Mmm. (while eating snack) } \\
\text { E: Now what do you want? } \\
\text { E: Cookie or cracker? } \\
\text { C: VOCALIZES UNINTELLIGIBLE } \\
\text { AND HOLDS OUT HAND } \\
\text { E: Cookie or cracker? } \\
\text { C: Cracker. } \\
\text { E: Good. } \\
\text { E: You want a cracker. } \\
\text { E: Ok. GIVES CHILD CRACKER } \\
\text { E: That tastes good. }\end{array}$ \\
\hline & & $\begin{array}{l}\text { Group 2: } \\
\text { Chronological } \\
\text { Age: } 2: 6 \text { (avg.) } \\
\text { Diagnosis: } \\
\begin{array}{l}\text { Genetic } \\
\text { syndromes }\end{array}\end{array}$ & $\begin{array}{l}\text { AAC Type: } \\
\text { High-Tech } \\
\text { (SGD) using } \\
\text { Picture } \\
\text { Communication } \\
\text { Symbols }\end{array}$ & $\begin{array}{l}\text { E: Look Johnny. } \\
\text { E: Here are the blocks. } \\
\text { E: Tell mama build. } \\
\text { C: Play. } \\
\text { E: Yep, we're playin'. } \\
\text { E: Tell mama build. TAPS ON SCD }\end{array}$ \\
\hline
\end{tabular}




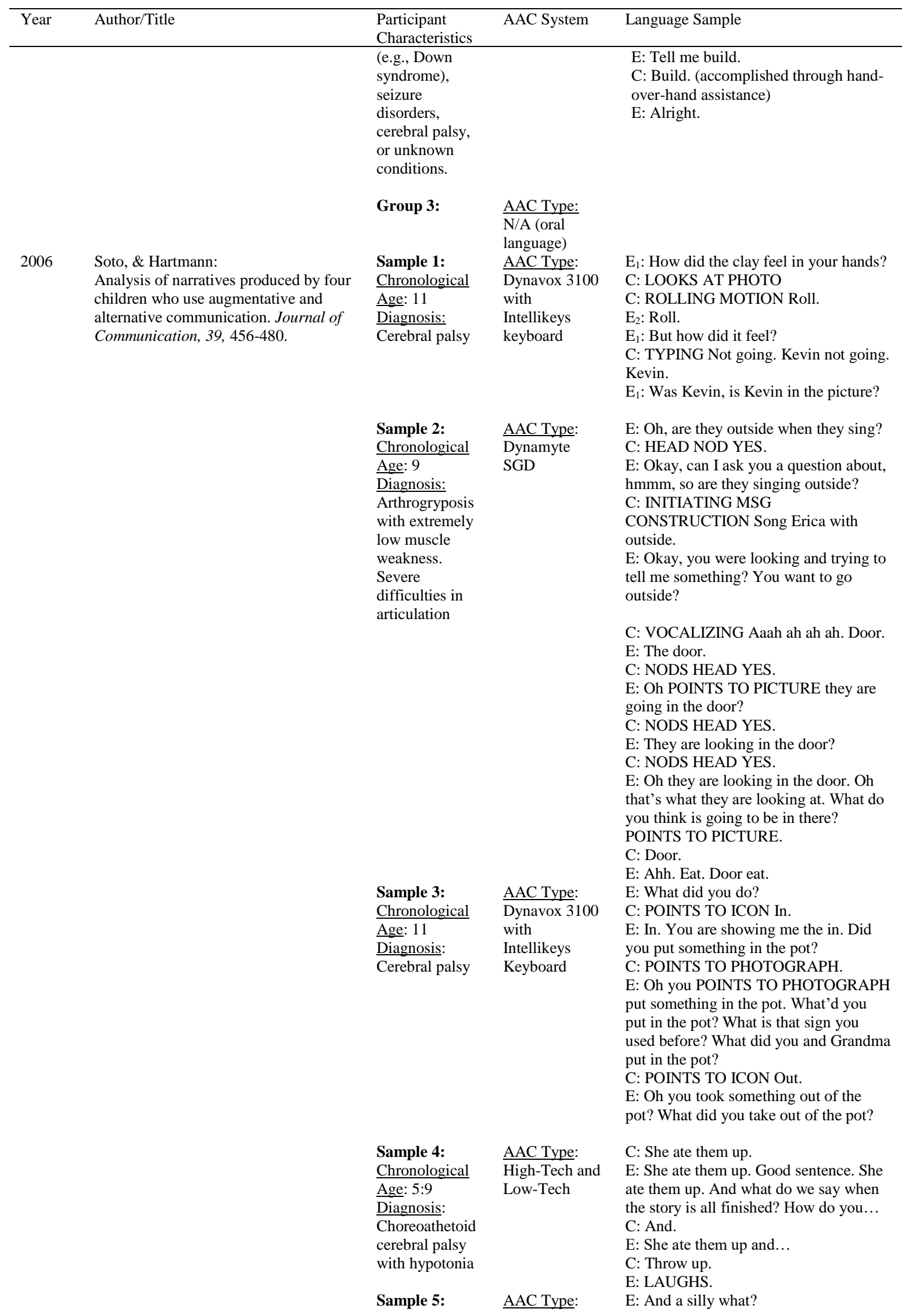




\begin{tabular}{|c|c|c|c|c|}
\hline Year & Author/Title & $\begin{array}{l}\text { Participant } \\
\text { Characteristics }\end{array}$ & AAC System & Language Sample \\
\hline & & $\begin{array}{l}\text { Chronological } \\
\text { Age: } 5: 9 \\
\text { Diagnosis: } \\
\text { Choreoathetoid } \\
\text { cerebral palsy } \\
\text { with hypotonia }\end{array}$ & $\begin{array}{l}\text { High-Tech and } \\
\text { Low-Tech }\end{array}$ & $\begin{array}{l}\text { C: Cap. The bunny has her dress and } \\
\text { blouse and a silly cap. } \\
\text { E: Oh, I want to add something. } \\
\text { C: And. } \\
\text { E: Oh, you want to add it. Okay. }\end{array}$ \\
\hline \multirow[t]{3}{*}{2015} & $\begin{array}{l}\text { von Tetzchner: } \\
\text { The semiotics of aided language } \\
\text { development. Cognitive Development, } \\
\text { 36, 180-190. }\end{array}$ & $\begin{array}{l}\text { Sample 1: } \\
\text { Chronological } \\
\text { Age: } 8: 4 \\
\text { Disorder: Not } \\
\text { identified }\end{array}$ & $\begin{array}{l}\text { AAC Type: } \\
\text { Low-Tech } \\
\text { Communication } \\
\text { Book with } \\
\text { Pictograms }\end{array}$ & $\begin{array}{l}\text { E: Is there anything more you want to } \\
\text { tell about this page? } \\
\text { C: Ball. } \\
\text { E: Yes, ball, yes. What do you want with } \\
\text { the ball Henry? Let's see if we can find } \\
\text { something here that we used it for } \\
\text { TURNS PAGE. Do we use the ball for } \\
\text { anything here? What can we use the ball } \\
\text { for? } \\
\text { C: Foot. } \\
\text { C: Doll } \\
\text { E: Did you bring this along to aunt Kari? } \\
\text { The doll? } \\
\text { C: NODS HEAD Yes. Read. } \\
\text { E: The doll went along to aunt Kari? } \\
\text { Hm? } \\
\text { C: Duplo } \\
\text { E: And you like to play with Duplo. } \\
\text { C: SHAKES HEAD. No. } \\
\text { E: No. } \\
\text { C: Train. } \\
\text { E: What can you do at aunt Kari's? } \\
\text { C : Read. } \\
\text { M: Can you read there? } \\
\text { E: NODS HEAD. Yes. } \\
\text { M: Hm. What else can you do? }\end{array}$ \\
\hline & & $\begin{array}{l}\text { Sample 3: } \\
\text { Chronological } \\
\text { Age: Teenager } \\
\text { Disorder: Not } \\
\text { identified }\end{array}$ & $\begin{array}{l}\text { AAC Type: } \\
\text { Communicatio } \\
\text { n Board with } \\
\text { Blissymbols }\end{array}$ & $\begin{array}{l}\text { C: Museum. } \\
\text { E: Is there something you want to tell } \\
\text { about what you have experienced? } \\
\text { C: Fish. } \\
\text { E: About fish. } \\
\text { E: House. } \\
\text { E: A house. } \\
\text { C: God. } \\
\text { E: God, God's house, is that what you } \\
\text { want to tell me about? } \\
\text { C: Fish. } \\
\text { E: Was there fish? } \\
\text { C: LOOKS AT MOTHER. } \\
\text { E: In the church? } \\
\text { C: 'Yes' NODS. } \\
\text { E: Do you mean last Sunday? Were } \\
\text { there fish in that church in Smalltown? } \\
\text { C: 'No' MIMICS. } \\
\text { E: No, is there something else? } \\
\text { C: Bus. } \\
\text { E: Bus. } \\
\text { C: Fish. } \\
\text { E: Did you go by bus to look at fish? } \\
\text { C: Museum. } \\
\text { E: At a museum? } \\
\text { C: Big. } \\
\text { E: Big. } \\
\text { C: Fish. } \\
\text { E: Big fish. }\end{array}$ \\
\hline & & $\begin{array}{l}\text { Sample 4: } \\
\text { Chronological } \\
\text { Age: } 5: 10 \\
\text { Disorder: Not }\end{array}$ & $\begin{array}{l}\text { AAC Type: } \\
\text { Communicatio } \\
\text { n Board with } \\
\text { Pictograms }\end{array}$ & $\begin{array}{l}\text { C: Bring the communication board (uses } \\
\text { the caller). } \\
\text { E: BRING } \\
\text { BOARD. }\end{array}$ \\
\hline
\end{tabular}




\begin{tabular}{|c|c|c|}
\hline Year Author/Title & $\begin{array}{ll}\text { Participant } & \text { AAC System } \\
\text { Characteristics } & \\
\end{array}$ & Language Sample \\
\hline & identified & 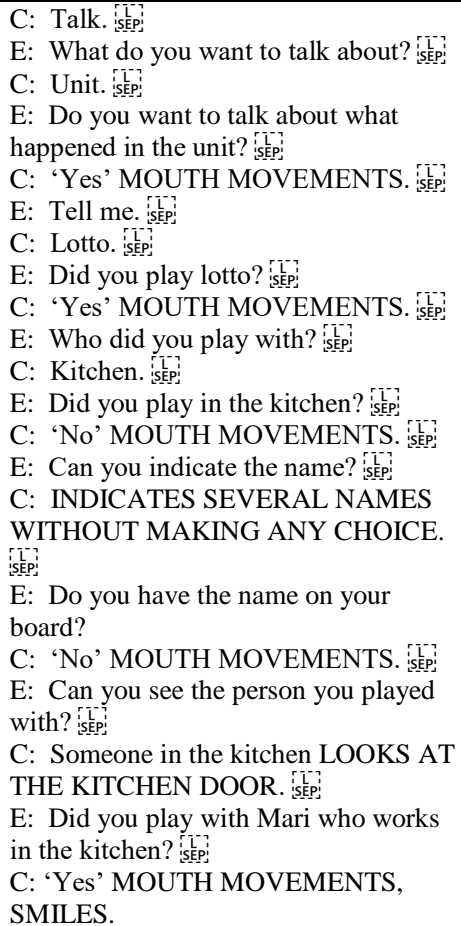 \\
\hline
\end{tabular}

Note. "E" represents "examiner" or "adult" and " $C$ " represents the child

Analysis of the language samples allows for broad generalizations about several

developmental markers, phrase length, and lexical diversity. Table 7 contains a summary

of the linguistic structural characteristics observed in Table 6. 
Table 7

Linguistic Structures of Aided AAC Users in Table 6

\begin{tabular}{ll}
\hline Structure & Exemplar \\
\hline Unmarked verbs & "He crawl" \\
Short phrase length & "Help storybook" \\
Missing syntactic structures (copula) & "I building" \\
Missing syntactic structures (prepositions, articles) & "He talks dog" \\
Pragmatic word order & "Horse apple" \\
Word order violations & "He the look monkey's" \\
Short utterance length & "Cracker; Play; Unit" \\
Use of extra-sentential devices & $\begin{array}{l}\text { Touches adult's hand as request } \\
\text { for action }\end{array}$ \\
Atypical morphological operations & "Cat's spaghettied." \\
Reduced lexical diversity & Throughout \\
\hline
\end{tabular}

Note. The samples also reveal overgeneralizations of grammatical rules (i.e., use of the possessive), the emergence of marked verbs (i.e., third person regular, present progressive), and the use of pronouns (i.e., subjective).

Table 7 supports the parallels between the three constructs of pidgins, interlanguages, and the syntax of EACs detailed in Table 5. However, because of the limited scope of these language samples, it is remains unclear whether these patterns suggest true linguistic deficits or atypical developmental patterns.

A final discussion in this section is the parallel between children with SLI and the linguistic characteristics of EACs. Table 8 contains a summary of the linguistic characteristics of SLI. 
Table 8

Linguistic Characteristics of Specific Language Impairment

Characteristic Reference

Verb morphology errors: bare verb stems

Finite verb morphology errors

Reduced phrase length (word and morpheme)

Reduced competence in the use of mental state verbs

Exclusion of the conjunction "that" in obligatory contexts

Late onset of first words, reduced vocabulary, expressive and receptive vocabulary delays

Higher number of repetitions to learn new words

Decreased maintenance and generalizations of new words

Passive participant in conversational contexts
Leonard, Miller, \& Gerber, 1999;

Norbury, Bishop, \& Briscoe, 2001

Owen \& Leonard, 2002; Rice \& Wexler, 1996

Owen \& Leonard, 2002

Johnston, Miller, \& Tallal, 2001

Schuele \& Tolbert, 2001

Schwartz, 2009

Rice, Oetting, Marquis, Bode, \& Pae, 1994

Rice, Oetting, Marquis, Bode, \& Pae, 1994

Hart, Fujiki, Brinton, \& Hart, 2004

Table 8 illustrates the parallels to the language of EACs and their verbal peers with SLI. It further highlights the challenges in differentiating between the two populations without access to examples of the language patterns of EACs. What remains unknown is whether the manifestations observed in the patterns of pidgins, interlanguages, or the syntax of EACs reflect poor learning, errors in the generation of a linguistic representation when identifying grammatical features, or lack of internal or external access to the linguistic representation (Bishop, 2014). As can be inferred from the preceding discussion, this line of inquiry offers an opportunity to call attention in the 
field of speech-language pathology to the fossilization, maturational constraints, or language impairments that can impinge on the language acquisition and development of EACs.

\section{Guiding Principles}

Given the empirically validated body of evidence demonstrating the reduced linguistic outcomes of EACs (Barker et al., 2013; Binger \& Light, 2008; Light et al., 2004; Trudeau et al., 2007; Wilkinson, \& Hennig, 2009), the persistence of these outcomes presents an opportunity to delve more deeply into contributing factors (Loncke, 2008). As such, it is appropriate to define the set of guiding principles that have lead to the identification of the hypothesis for this dissertation.

\section{Language Acquisition}

The first guiding principle to be discussed is the universality and robustness of the language acquisition process evidenced in typical and exceptional children (Bates, Bretherton, \& Snyder, 1988; Bates \& Goodman, 1997; Goldin-Meadow, 2014; Pinker, 1994), which runs counter intuitive to the reduced linguistic outcomes of EACs. While there is significant controversy regarding a unified theory of language acquisition, a nexus among all the theories is that children encounter language with a readiness that allows for acquisition (Goldin-Meadow, 2014). Of controversy throughout the language acquisition world is with what exactly the child is equipped: (a) a generalized understanding of what language is, (b) language acquisition-specific processes, or (c) general learning processes (Bates \& Goodman, 1997; Chomsky, 1965; Pinker, 1994; Marchman \& Thal, 2005; Tomasello, 2003; Volterra et al., 2005). Table 9 provides a broad overview of language acquisition theories and conceptualizations. 
Table 9

Theories of Language Acquisition

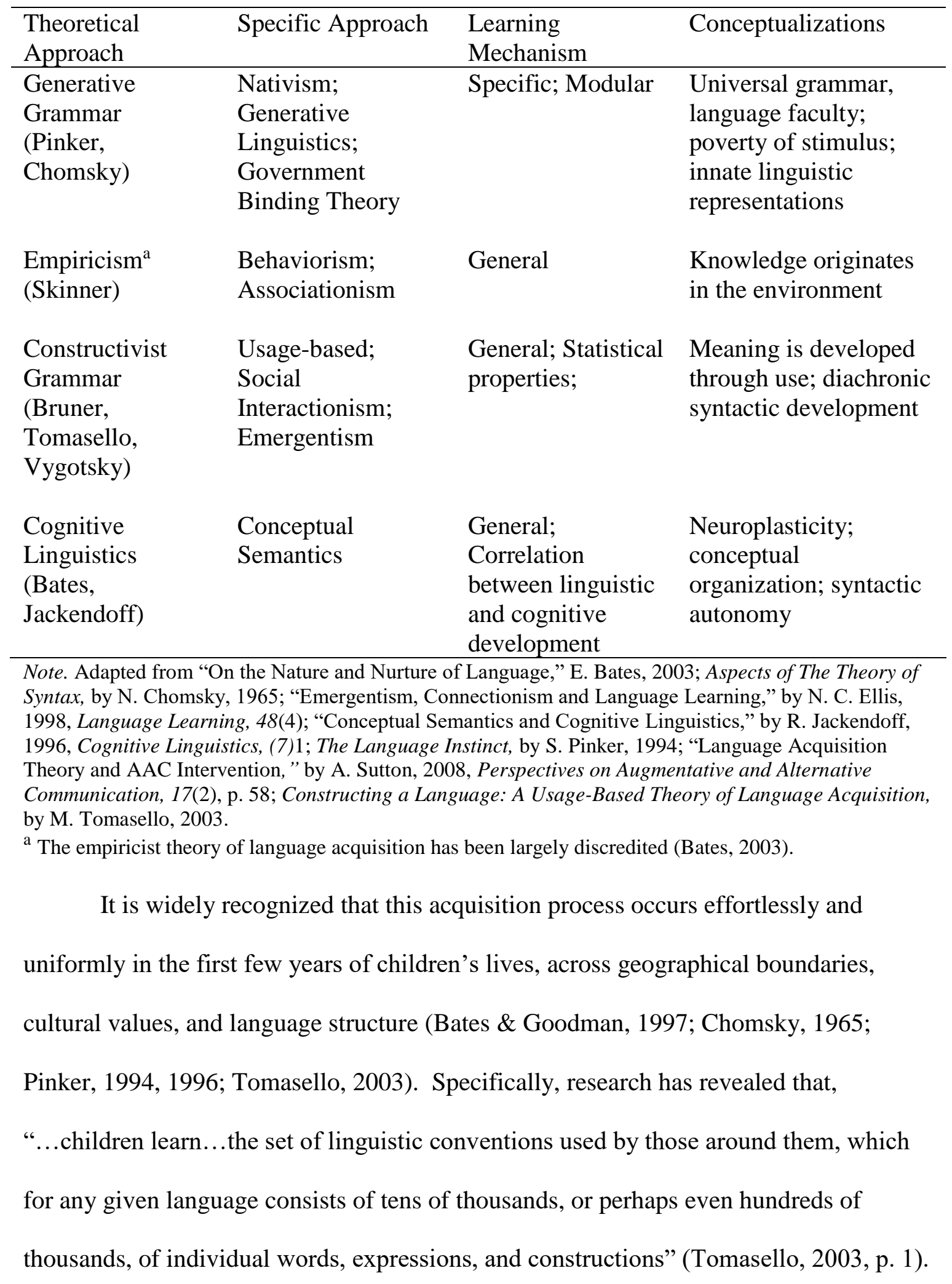


Examples of this universal learning process include the transition from sounds to words to grammar (Bates \& Goodman, 1997), the development of language-specific word order (i.e., subject-verb-object [SVO], SOV, VSO, VOS, OSV, OVS; Pinker, 1994; 1996; 1999), and the culturally-bound rules for how, where, when, and with whom language can and cannot be used (Craig, 1995; Hoag, Bedrosian, McCoy, \& Johnson, 2008; Light \& McNaughton, 2015). These findings are in line with the notion of universality as a feature of language acquisition and development (Pinker, 1994; 1996).

As discussed by multiple researchers (Marchman \& Thal, 2005; Smith, 2015; Sutton, 2008), there are theoretical constructs that have implications for EACs, which include generative, constructivist, and cognitivist. Within generative grammar, there is an assumption that children possess an innate underlying grammatical knowledge, which is acutely linked to comprehension. Within the constructivist view, there is an assumption that grammatical knowledge requires specific input to be acquired. This viewpoint posits that comprehension and production can dissociate to a degree, but comprehension alone is insufficient for language development (Bates \& Goodman, 1997). The third construct, cognitivist, implies that grammatical knowledge cannot exceed conceptual development, and the production of grammar drives cognitive development. An even broader perspective can be viewed from a comprehension versus a production context (Loncke, 2008; Sutton, 2008). If comprehension alone is sufficient for the development of language, children need only be exposed to language to break the linguistic code, and the necessity of an AAC system would not inherently inhibit the process. If the primary force were determined to be production, this would imply that language is shaped through use, and it would be a logical assumption that the intrusion of 
an AAC system into the process would be an inhibiting factor (Loncke, 2008; Sutton, 2008).

Central to this differentiation is: (a) whether graphic symbol use is defined as linguistic or metalinguistic (Sutton, 2008; Trudeau et al., 2007), (b) when and where the interface between the mental representation of the concept and the symbol occurs, (c) whether the graphic symbols behave as linguistic structures or if the underlying linguistic structure is recoded or transposed onto the graphic symbol (Trudeau et al., 2007), or (d) whether there is a distinction or a continuity between prelinguistic and linguistic development (Volterra et al., 2005). While discussions of theoretical constructs can appear far removed from practical application, they have value as described by Sutton (2008):

Theory underlies...interventions, whether or not we acknowledge this openly, and the theory one adopts reflects what is believed to be important. One should be aware that approaches to intervention entail certain underlying theoretical assumptions, and theory and action should be consistent with each other. (p. 60)

\section{Special Cases}

A second guiding principle is the language acquisition of children who veer from typical language development models. This research allows for an analysis of linguistic structures that are more or less fragile, and those that are more or less resilient to disruption. This differentiation is accomplished by analyzing the variability of a language property across learner and environment; if there is no impact on the property with respect to either the learner or the environment, that property is deemed to be overdetermined or resilient (Goldin-Meadow, 2014). Longitudinal research on two groups of 
children (i.e., typically developing and brain injured) (Goldin-Meadow, 2014), and research on deaf children who use homesign (i.e., an idiosyncratic, gesture-based communication method) indicated that: (a) language learning is unlikely to be affected by alterations in language input modality; (b) acquisition of word order is unlikely to be affected by age variance, and (c) language function (i.e., making requests, commenting, engaging in inner dialogue, talking about language) is unlikely to be affected by access to a conventional language model. Conversely, this same research (Goldin-Meadow, 2014) suggested that: (a) morphological marking is likely to be affected by age of exposure; (b) vocabulary and syntax are likely to be affected by parental language behavior; (c) language complexity is likely to be affected by age of exposure; and (d) language systematicity is likely to be affected by actively producing language in and receiving language from a linguistic community.

Further evidence of the resiliency of the language acquisition process is found in research on the language acquisition process in children in both typical and exceptional circumstances (e.g., Williams Syndrome, congenital deafness, intellectual impairment, blindness). Smith and Grove (2003) indicated that both populations evince similar abilities to either recognize or seek structural patterns, which suggests that the structureseeking capacity is both robust and amodal. It was also reported that children with varied cultures, input modalities, and cognitive profiles demonstrate highly analogous prelinguistic and linguistic development patterns (Volterra et al., 2005). Further, research on linguistic recovery from acquired aphasia in children reveals fully functional recovery of language in cases of left frontal subcortical infarction (Lauterbach et al., 2010). This resilience has been attributed to the plasticity and equipotentiality of an immature brain 
(Chilosi et al., 2008). Factors that influence this recovery include size, site, and side of lesion, age of injury, and stage of language development at occurrence (Chilosi et al., 2008). Of specific importance is whether the infart occurs pre- or post-pubertal (Chilosi et al., 2008). A final population demonstrating relevant findings is that of internationally adopted children who acquire a new language in their new county. These children demonstrate initial acquisition of a greater number of nouns than verbs, which suggests that this acquisition pattern may not be related to conceptual limitations (GoldinMeadow, 2014), but may be a function of the superimposition of a new linguistic schema onto an existing one. Taken together, these findings demonstrate the complexity of language acquisition universals in that the recognized resiliency and fragility of language constructs are multifactorial and are difficult to isolate.

Vocabulary acquisition is an additional aspect of language that is considered resilient. In an analysis of the research on how words are learned, P. Bloom (2000) reported that vocabulary acquisition rate is extraordinarily robust across language and culture and there may not be a strict temporal or spatial relationship necessary to learn the words of a native language. He further detailed research indicating that children born blind and deaf who are exposed to ambient signed or spoken language evince remarkably similar vocabulary levels to those of their sighted and hearing peers. These patterns suggest that children do not need the full range of senses or a consistent input modality, findings that have been validated by other researchers (Lillo-Martin, 1999; Meier \& Newport, 1990; Volterra et al., 2005).

Research on special cases demonstrates that multiple factors compete, converge, and conspire to determine language outcomes (Devoscovi \& D'Amico, 2005). This 
research further lends credence to the theory that many properties of language are overdetermined and can be relatively unaffected by manipulation to the learner and the environment. Based on the information detailed above, it can clearly be inferred that within a system as complex as language, as the magnitude of the manipulation increases to the learner or the environment, the potential for an altered outcome becomes greater (Dale \& Goodman, 2005); however, the resiliency of many language properties bodes well for atypical learners. As would be implied by the descriptive term complex communication needs, the children discussed in this paper encounter language with one or more issues that adversely affect their linguistic potential; however, the language that does emerge from these children is indicative of the human imperative to use the tool of language and is suggestive that alternate outcomes may be possible:

Human beings have evolved capabilities to learn a vast array of complex skills and information....these capabilities are biased toward certain types of information and patterns and they include the ability to devise and use symbolic and material tools to support and extend intelligent action. (Gauvain, 2009, p.

\section{Constraints}

The discussion supports the argument that language is a very robust construct across a multiplicity of populations. However, what cannot be overlooked are the very real and formidable constraints that present roadblocks to the language development of EACs. These are the final guiding principles to be discussed. 


\section{Intrinsic Constraints}

Intrinsic constraints are those that can be considered to reside within the individual (Sutton \& Morford, 1998). Examples of intrinsic constraints that have the potential to interfere with processing and production (MacWhinney, 2005) include factors that negatively impinge upon the senses, cognition, motoric abilities, and linguistic abilities (Beukelman \& Mirenda, 2013). Research has further identified the underlying vocabulary, morphological, and syntactic knowledge of the user (Blockberger \& Johnston, 2003; Sutton \& Morford, 1998), and passivity and low rates of initiation as additional intrinsic constraints (Kent-Walsh \& McNaughton, 2005). Additionally, children with a variety of disorders (e.g., cerebral palsy, Down syndrome, intellectual disability, ASD, childhood apraxia of speech) can demonstrate reduced joint attention, indexicality, object manipulation, and play (Bruner, 1983; Gauvain, 2009), all of which are central to the process of language acquisition (Bates \& Dick, 2002; P. Bloom, 2000). A final constraining factor to be discussed is the trade off between effort and outcome in that the generation of multi-word phrases and marking of lexemes adds cognitive, linguistic, motoric, and memory loads to a system that may already be compromised (Loncke, 2008). These findings suggest that the cognitive-linguistic and operational demands may vary across aided AAC system layout and language organization techniques, and may present challenges when learning and using certain types of aided AAC systems (Drager \& Light, 2010; Light, 1997; Light \& McNaughton, 2012a).

\section{Extrinsic Constraints}

Extrinsic factors are defined as those that are external to the individual using the system (Sutton \& Morford, 1998) and have been identified as potentially limiting the 
language development of EACs. Frequently cited extrinsic factors include: (a) AAC system layout (e.g., grid format, integrated scene format, fixed, dynamic) (Drager et al., 2003; Drager \& Light, 2010; Light et al., 2004; Sutton \& Morford, 1998); (b) symbol organization (e.g., iconic encoding, iconic prediction) (Binger et al., 2011; Drager et al., 2003; Drager \& Light, 2010); (c) symbolic representation complexities (e.g., concreteness, abstraction, opacity, transparency) (Blockberger \& Johnston, 2003; Light et al., 2004; Light \& McNaughton, 2012a; Sutton et al., 2010); and (d) the motoric demands of AAC system navigation (Binger et al., 2011; Light, 1997).

Additionally, the real estate of AAC systems is finite, which adds a layer of complexity that extends beyond those discussed above and the domain-specific challenges of aided AAC users (i.e., motoric, sensory, cognitive, linguistic; Zangari \& Van Tatenhove, 2009). This restriction mandates a series of cost-benefit tradeoffs involving decisions as to how and which concepts are included in the array of choices (Devoscovi, \& D'Amico, 2005; Zangari \& Van Tatenhove, 2009). Specific constraints related to space allocation can result in: (a) an unbalanced ratio of nouns and other parts of speech, (b) a reduced range of morphological markers, (c) a lack of words/icons that support a range of communicative functions extending beyond the early appearing function of requesting, and (d) a reduced number of function words providing inter-word and inter-sentential connections (ASHA, 2001, 2002, 2004; Behrens, 2006; Blackstone et al., 2007; Blockberger \& Johnston, 2003; Boenisch \& Soto, 2015; Calculator \& Black, 2009; Johnson, Inglebret, Jones, \& Ray, 2006; Light \& McNaughton, 2015; Lund \& Light, 2007; Murray \& Goldbart, 2009; Sutton et al., 2010; Sturm \& Clendon, 2004; Wilkinson \& Hennig, 2009). Even in a best-case scenario, with a dedicated device with 
thousands of vocabulary items, this external vocabulary is likely to be only a subset of an individual's internal vocabulary (Smith, 2015).

Modality asymmetry. One of the most appreciable differences in the language acquisition and production patterns between speaking children and EACs is modality asymmetry, which is manifested in the relationship between their receptive and expressive language modalities (Binger et al., 2011; Blockberger \& Johnston, 2003; Light, 1997; Smith \& Grove, 2003; Sutton et al., 2010; Sutton \& Morford, 1998; Trudeau et al., 2007). Speaking children with intact receptive and expressive language abilities produce their native language in the same modality they are exposed to by the speakers in their environments. Conversely, EACs are exposed to and comprehend spoken language, but produce a graphic, symbol-based visual language (Sutton et al., 2010; Sutton \& Morford, 1998; Trudeau et al., 2007). Further, EACs analyze linguistic principles based on their language of comprehension, but must realize their communicative intent within the confines of a very limited and different modality (Smith \& Grove, 2003).

Modality asymmetry is a significant constraint and distinguishes EACs from other populations of special cases in language acquisition. However, children across populations of special cases demonstrate a high level of variability in developmental patterns (Bishop, 1983; Goldin-Meadow, 2014; Smith \& Grove, 2003) and use early cross-modal communication, as evidenced when diectic gestures are combined with words in early semantic relations (Goldin-Meadow, 2014; Rowland, \& Schweigert, 2003; Smith \& Grove, 2003; Volterra et al., 2005). Further, these children produce utterances composed of concepts represented symbolically with varying levels of abstraction (Dietz et al., 2012), which may not affect the developmental progression of language acquisition 
(Lillo-Martin, 1999). These findings suggest that utterance construction through the use of graphic symbols may contribute to a different acquisition process (Smith \& Grove, 2003; Sutton et al., 2002), but there is no evidence to suggest that this asymmetry precludes the development of syntactically correct language that extends beyond the communicative function of requesting.

AAC system design. In 1997, Janice Light suggested the need for a Velcro solution to AAC, or a surprisingly simple solution to a complex problem, but that solution has yet to come to fruition (Treviranus, \& Roberts, 2003). Currently, AAC systems are labor intensive, training demands are high, and mastery of them has proven to be elusive (Treviranus \& Roberts, 2003). Further, research on AAC system design has been minimal (Light \& McNaughton, 2012a). However, longitudinal and extensive research on AAC system design is underway by recognized experts in the field, including David Beukelman, Susan Fager, Melanie Fried-Oken, Janice Light, and David McNaughton, at the Rehabilitation Engineering Research Center on Augmentative and Alternative Communication (RERC on AAC) (Light \& McNaughton, 2012a, 2012b). This research is funded through the National Institute on Disability, Independent Living, and Rehabilitation Research (NIDILRR grant \#90RE5017; RERC on AAC , n.d.). Much of this research focuses on questioning underlying assumptions about AAC systems and designing AAC systems that support a better match between the AAC user and the AAC system (Light \& McNaughton, 2013; Treviranus, \& Roberts, 2003; Wilkinson \& Hennig, 2009). These researchers have recommended involving principles of universal design to account for the multiplicity of variables that accompany individuals with CCNs, 
maintaining a focus on the people who use AAC, and ensuring "an appropriate persontechnology fit” (Light \& McNaughton, 2013, p. 302).

\section{Clinician-Related Factors}

For EACs, language development is contingent upon both the process of linguistic experience and the process of direct instruction, which is typically provided by speechlanguage pathologists (SLPs) (Dietz et al, 2012). The role of the SLP within AAC-based intervention is to identify and leverage available language acquisition mechanisms to support further language development (Sutton, 2008). As such, the clinical skills of SLPs are crucial to language development in EACs (ASHA, 2004). These clinical skills are related to multiple elements, including the relationships between clinical practices, clinician familiarity with established evidence-based practices, professional consensus, and policies of governing bodies (Schlosser \& Raghavendra, 2004). However, a review of the literature has validated the issues outlined in Table 10 relating to SLP intervention practices that negatively impact intervention and may contribute to the reduced linguistic outcomes. 
Table 10

Potential Impacting Factors in the Reduced Linguistic Outcomes for EACs

Issue Supporting Research

Level of preparation of SLPs for this population

Costigan \& Light, 2010; Dietz et al., 2012; Douglas, Light, \& McNaughton, 2012; Kent-Walsh \& Binger, 2009; Kent-Walsh et al., 2008; Ratcliff et al., 2008; Schlosser \& Raghavendra, 2004; Thistle \&

Wilkinson, 2015

Risk of inadequate services

Lack of well-trained AAC assessors

Flawed decisions regarding the match between the AAC user and AAC system

Lack of language modeling by clinicians

Use of the candidacy model as a qualifier for intervention

Lack of inclusion of AAC peer language models in intervention or in educational placement

Increased demands on SLP time to maintain an AAC system that accurately reflects the developing needs of the AAC user
Costigan \& Light, 2010

Dietz et al., 2012

Light \& McNaughton, 2013

Cress \& Marvin, 2003; Elder \& Goossens', 1994; Romski \& Sevcik, 2003; Smith, 2015

Romski \& Sevcik, 2005; Wilkinson \& Henning, 2009

Barker et al., 2013; Drager et al., 2003

Boenisch \& Soto, 2015; Light \& McNaughton, 2012a

Lack of a well-established evidence base for intervention

Note. Issues and supporting research of deficits in the skill, practices, and knowledge of SLPs with respect to AAC, all of which relate to external evidence (Schlosser \& Raghavendra, 2004).

In 1988 Beukelman and Mirenda developed the, which has since been expanded on in its current version (Figure 2) (Beukelman \& Mirenda, 2013). 


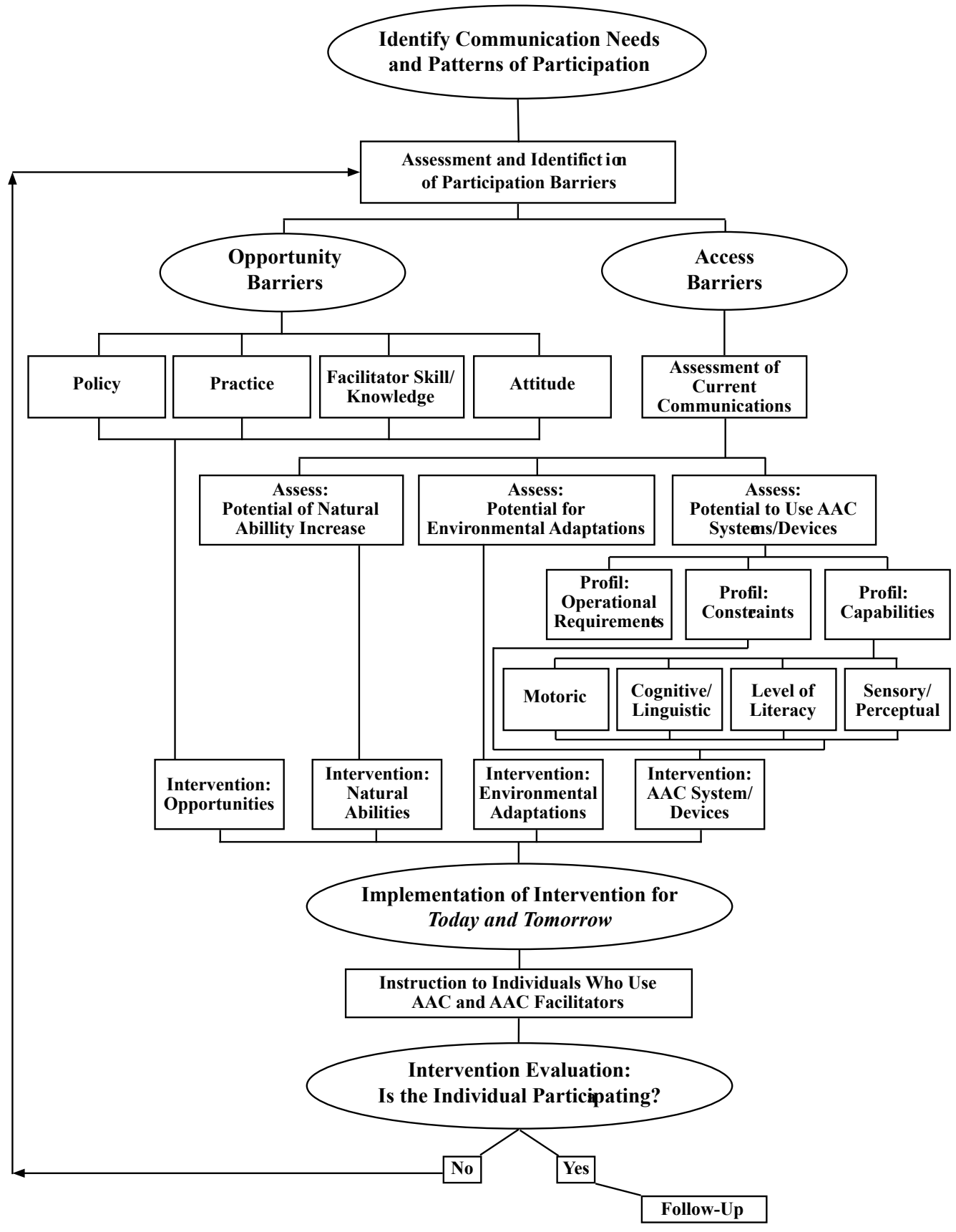

Figure 2. Participation Model.

The Participation Model from Beukelman and Mirenda (2013) identifies

participation barriers to individuals who use AAC related to opportunities and access (p. 109). Two opportunity barriers are Facilitator Skill/Knowledge and Attitude, which can 
be compelling factors in AAC intervention, but this model does not identify the latent beliefs that may be exerting influence in SLPs theoretical frameworks.

What Table 10 and Figure 2 do not reveal is the internal evidence that SLPs use in their intervention that can include opinions, values, and beliefs (Schlosser \& Raghavendra, 2004), nor does it reveal the personal perspectives, philosophies, or biases of SLPs in their intervention with EACs. It is this narrow area that has been identified as a gap in the literature. As such, it appears a worthy endeavor to quantify and describe internal factors that shape SLPs' intervention with EACs and to identify patterns and relationships that interact in this intervention. It is hypothesized that the quantification and description of these factors may support a greater understanding of specific elements that support the language acquisition and development in EACs that more closely aligns with their speaking peers, and to isolate those elements that exert a deleterious effect.

\section{Summary}

The discussions above reveal two opposing forces in the language acquisition and development process for EACs: universal principles of language acquisition that suggest a robust imperative toward the development of a linguistic system in multiple populations, and mainfold factors that exert constraints on this process. The research examined has demonstrated that (a) children approach language with a readiness to learn, (b) there are universal patterns to language acquisition, (c) there are aspects of language that are more and less resilient to insult, and (d) language acquisition and development occurs in special cases where there are alterations in input and output modalities. This research has also discussed the clinician-specific factors that may be negatively impacting the language acquisition and development of EACs. 
While it can be stated that there are no true equivalents to EACs in the populations discussed, there are compelling similarities among them, and it is prudent to question whether there may be additional, underlying factors beyond the intrinsic constraints of EACs and the extrinsic constraints of the AAC system that negatively impact language acquisition and development. 


\section{CHAPTER III: METHODS}

Survey research is a non-experimental method of research involving gathering information systematically from a sample to construct descriptions of characteristics or experiences of a population (Coughlin, Cronin, \& Ryan, 2009; Creswell, 2014; Fowler, 2014; Groves et al., 2009). Surveys play a critical role when researching human subjects (Dillman, Smyth, \& Christian, 2014; Maeda, 2015; Nicholls, Orr, Okubo, \& Loftus, 2006) and offer opportunities to measure unobservable conceptual variables with observable indicators of those variables (Maeda, 2015). In recent years, this methodology has been recognized as a rigorous approach with established strategies that can produce high-quality outcomes and address a range of research aims (Ponto, 2015). According to Groves et al. (2009), surveys "use information obtained imperfectly to describe a more abstract, larger entity" (p. 40). Surveys are used in both qualitative and quantitative research; however, when employed in quantitative research, surveys must meet the rigors of probability sampling, question design, standardized measurement, and data analysis (Fowler, 2014). Although surveys can take many forms (Groves et al., 2009; Ponto, 2015), they typically entail gathering information through the use of questionnaires (DeVellis, 2017, Dillman et al., 2014), which can include existing scales or instruments or special purpose surveys designed to fulfill the need for unique data (DeVellis, 2017; Fowler, 2014).

\section{Previous Research on AAC and Language Development}

Augmentative and alternative communication (AAC) is an area of practice and research in the field of speech-language pathology with an increasing evidence base since 1995 (ASHA, n.d.b., 2004, 2005). Research in this area has a broad scope because AAC 
has the potential to encompass life span, disability type and severity, setting, and term of use (ASHA, 2004, 2005). A large body of research has developed regarding the relationship between AAC system constraints and the reduced syntactic development of emerging aided communicators (EACs). Table 11 outlines the research on AAC system constraints that are linked to the linguistic outcomes of EACS.

Table 11

AAC System Constraints Linked to the Linguistic Outcomes of EACs

\begin{tabular}{ll}
\hline AAC Constraints & Supporting Research \\
\hline AAC system layout & $\begin{array}{l}\text { Drager \& Light, 2010; Drager, Light, Speltz, } \\
\text { Fallon, \& Jeffries, 2003; Light et al., 2004 }\end{array}$ \\
$\begin{array}{l}\text { Light et al, 2004; Sutton, Trudeau, Morford, Rios, } \\
\text { \&ymbolic representation } \\
\text { complexities }\end{array}$ & Behrens, 2006; Binger, Maguire-Marshall, \& \\
Vocabulary constraints & $\begin{array}{l}\text { Kent-Walsh, 2011; Blockberger \& Johnston, } \\
\text { 2003; Lund \& Light, 2007 }\end{array}$ \\
& Smith \& Grove, 2003; Sutton et al, 2010 \\
\hline
\end{tabular}

A primary finding of this research is that the transposition or translation of linguistic concepts into graphic symbols may be linked to alterations in the language structure observed in EACs.

Another area of research in AAC with a robust body of evidence is the impact of intrinsic and extrinsic factors on the linguistic outcomes of EACs. A summative analysis of these findings suggests that there are formidable intrinsic and extrinsic factors that may be contributing to the linguistic outcomes of EACs, as seen in Table 12. 
Table 12

Contributing Factors to the Linguistic Outcomes of EACs

Contributing Factors $\quad$ Supporting Research

Cognitive-linguistic, motoric, and Blockberger \& Johnston, 2003; Sutton \& sensory abilities of user $\quad$ Morford, 1998

Memory capacity Hetzroni, 2004; Light, McNaughton, Weyer, \& Karg, 2008

Communication rate limitations $\quad$ Smith \& Grove, 2003

Lack of education, training, and ASHA, 2016; Kent-Walsh, Stark, \& Binger, 2008 professional expertise in AAC of SLPs

Low incidence and heterogeneity of the population

Opportunity and access barriers
Kent-Walsh, Stark, \& Binger, 2008; Light \& Drager, 2007; Smith, 2005

Light \& Drager, 2007

\section{Practice-Based Research}

Speech-language pathology is an applied field with a critical need for resultsdriven research (ASHA, 2014; Crooke \& Olswang, 2011; Glogowska, 2011; Light \& McNaughton, 2012a, 2012b; Olswang \& Prelock, 2015). In light of this need, the use of practice-based research has been recommended by multiple researchers (ASHA, 2014; Crooke \& Olswang, 2011; Epstein, 2001; Olswang \& Prelock, 2015). Practice-based research employs evidenced-based principles, designs, and data collection methods within established research practices (Epstein, 2001). It is designed to examine practice questions of clinical importance that (a) extend beyond a specific individual, (b) impact a discipline, and (c) offer knowledge that can be generalized to a broader population (Crooke \& Olswang, 2015). It is precisely this generalization piece that supported the use of a quantitative design for the present inquiry. This design allowed for the 
examination of relationships between and among variables as a means of testing objective theories, while protecting against bias and controlling for alternative explanations (Creswell, 2014).

\section{Perceptual Research in the Field of Speech-Language Pathology}

A growing area of research involves examinations of SLP practices and perceptual factors, such as attitudes, beliefs, and opinions. Survey research that includes perceptual measures allows for an investigation into hypotheses about the way respondents interpret and organize information (Lavrakas, 2008). Further, it allows the researcher to measure the extent to which human behavior is affected by expectations, past experiences, or goals (Nelson, 2008). It has been used reliably in the behavioral sciences for decades (Ponto, 2015), and more recently in the field of speech-language pathology. A search in the academic databases revealed multiple articles that used survey methodology to capture attitudes, perceptions, and opinions of a variety of stakeholders (i.e., families, AAC users, caregivers, teachers, SLPs) related to AAC and emerging aided communicators. A list of these articles is presented in Table 13. 
Table 13

List of Research Articles Regarding Attitudes, Perceptions, and Opinions

Summary of Related Research

$\underline{\text { Attitudes, Opinions, Perceptions }}$

AAC Users $\quad$ Beck, Thompson, Kosuwan, \& Prochnow, 2010; Hidecker, 2010;

McCarthy \& Light, 2005; Lilienfeld \& Alant, 2001; Murchland \& Kernot, 2011; Styles, 2008*; Weiss, Seligman-Wine, Lebel, Arzi, \& Yalon-Chamovitz, 2005

Caregivers Anderson, Balandin, \& Stancliffe, 2015*; Anderson, Balandin, \& Stancliffe, 2014; Anderson, Balandin, Stancliffe, \& Layfield, 2014; Angelo, 2000; Angelo, Kokoska, \& Jones, 1995; Bailey, Parette, Stoner, Angell, \& Carroll, 2006; Calculator, 2014; Calculator \& Black, 2010; Cockerill et al., 2014; Hetzroni, 2002; Jonsson, Kristoffersson, Ferm \& Thunberg, 2011; McNaughton, Rackensperger, Benedek-Wood, Krezman, Williams, \& Light, 2008; Meder \& Wegner, 2015; Mesko, Eliades, et al., 2011; Newton, Clarke, Donlan, Wright, Lister, \& Cherguit, 2007;

Parette, et al., 2000; Ryan et al., 2018; Senner, 2011

Peers Dada, Horn, Samuels, \& Schlosser, 2016; Hyppa-Martin, Collins, Chen, Amundson, Timinski, \& Mizuko 2016

Teachers Barker, Akaba, Brady, Thiemann-Bourque, 2013; Kent-Walsh \& Light, 2003; Lorah, 2016*; Pickl, 2011*; Soto, 1997; Tönsing \& Dada, 2016

SLPs

Finke \& Quinn, 2012; Iacono \& Cameron, 2009; Johnson, Inglebret, Jones, \& Ray, 2006; Simpson, Beukelman, \& Bird, 1998; Sutherland, Gillon, \& Yoder, 2005; Simpson, Beukelman, \& Bird, 1998; Siu et al., 2010; Thistle \& Wilkinson, 2015; Wormnæ \& Malek, 2004*

Support Staff $\quad$ Norburn, Levin, Morgan, \& Harding, 2016; Rombouts, Maes, \& Zink, 2016

Note. An asterisk after a list of authors indicates that the article has a secondary focus; however, the author list only appears under the category of the primary focus. 
These studies offer valuable insight into various challenges facing SLPs working with EACs and have potential to inform practices; however, they do not address broader SLP-specific practice perceptions, decisions, and beliefs that may be impacting the longterm language outcomes of EACs.

\section{Strengths and Limitations of Survey Methodology}

There are numerous advantages to using surveys as a research methodology (Coughlin et al., 2009; Dillman et al., 2014; Fowler, 2014; Ponto, 2015). Surveys are an efficient method for learning about a population and the distribution of characteristics (Creswell, 2014). They allow for widespread dissemination to a carefully selected sample, a relatively fast turn around time, and an economical means for data collection (Creswell, 2014; Dillman et al., 2014; Groves et al., 2009). Further, the recent shift in survey research to computer-based delivery has allowed for greater efficiency in delivery, respondent convenience, and ease of data management (Coughlin et al., 2009; Dillman et al., 2014). Dillman et al. (2014) reported on the use of internet-based surveys and suggested that approximately $70 \%$ of adults have access to the Internet at their homes and many of the remaining $30 \%$ have access to mobile phones.

While survey research is used widely in social and psychological research to describe and explore human behavior, it has potential for error and limitations (Nelson, 2008; Ponto, 2015). The $70 \%$ figure referred to above implies a $30 \%$ gap in available respondents due to access to the Internet. This gap reflects population differences that have the potential to skew results. Research has demonstrated that people without access to the internet are more likely to live in rural areas, be over 65 years of age, and have lower levels of education and income (Dillman et al., 2014). Whereas research has 
suggested that access to mobile phones has helped to reduce this gap, it cannot be entirely erased. Additional weaknesses are revealed in the errors associated with surveys (i.e., coverage, non-response, sampling, measurement) and the subjective nature of perceptual questions (Nelson, 2008). Finally, further limitations of survey research include the limited view that is shaped by the a priori theory of the researcher (Fowler, 2014), response selection bias (Maeda, 2015; Nicholls et al., 2006), and the imposition of social desirability onto responses (Callegaro, 2008; Jo, Nelson, \& Kiecker, 1997), all of which will be addressed in following sections.

\section{The Present Study}

The purpose of the dissertation was to examine: (1) perceptions of practices, (2) beliefs of and attitudes about language acquisition and development, and (3) perceptions of various language constructs of elementary-school-based SLPs in their work with EACs. This inquiry has its origins in the atypical language use demonstrated by EACs, when compared to their speaking peers (Binger \& Light, 2008; Drager et al., 2003; Drager \& Light, 2010; Light et al., 2004; Light \& McNaughton, 2012a, 2012b; Smith \& Grove, 2003; Sutton, 2008; Sutton et al., 2010; Sutton \& Morford, 1998). It was grounded in the ideals of improving the language outcomes of these children and supporting their ability to negotiate the inherently linguistic demands of independence and agency. It was further grounded in empiricism (Webb, 2007), within a post-positivist and pragmatist theoretical perspective (Creswell, 2014; Crotty, 1998; Glowgowska, 2011; Webb, 2007), which emphasizes the link between knowledge and action (Baudelaire, Ulysse, \& Ulysse, 2013). 


\section{Research Questions}

This dissertation was designed to address the following two primary research questions:

Research Question 1: Do SLPs perceive differences in their beliefs between their practices with emerging oral communicators with language impairments and EACs?

Research Question 1a: If variances do exist, are those variances significant and what is the relationship?

Research Question 2: Do SLPs report differences between their practices with emerging oral communicators with language impairments and EACs?

Research Question 2a: If variances do exist, are those variances significant and what is the relationship?

\section{Participants}

The targeted population for this research project was SLPs who met the following criteria: (a) current licensed practitioners in a California public elementary school who have had at least one emerging aided communicator on their caseload in the past two

years, and (b) fluent readers and writers of English. Potential participants were identified through the following process:

1. Conducting an Internet search of all California Special Education Local Plan Areas (SELPAs).

2. Identifying all SLPs and their email addresses through the publically available lists on school district websites.

3. Generating a self-managed list of all email addresses.

See Appendices A and B to review the Chapman University required documents related to the participant invitation protocol. 


\section{Instrumentation}

\section{Survey Instrument}

A review of the literature revealed no articles examining constructs similar to the constructs being studied in this research. Further, there were no existing scales or questionnaires identified that could be used for the purposes of this research. As such, a special purpose questionnaire was developed to quantify the specific phenomenon targeted in this research inquiry. This questionnaire was designed to examine demographics, perceptual variables, general practices, specific practices, and professional opinions. There were a total of thirty-seven, close-ended questions and one short narrative response (See Appendix $\mathrm{C}$ for the survey). The question number and scope were delimited based on a maximum 15-minute time frame for completion.

Demographic data were included to identify to whom findings could be generalized, to allow for cross-study replication, and to support future research synthesis (Beins, 2009; Hammer, 2011). Questions addressing perceptual variables were designed to identify links among the theoretical constructs being studied (Hinkin, 1998).

Questions were included based on the assumption that an individual's beliefs and assumptions can cause variations in behaviors, and would thus influence intervention patterns of SLPs (Sutton, 2008). Questions addressing practices were included to gain greater insight into specific factors that contribute to language acquisition and development for EACs. A final requirement for questions and variables included in the survey was a nexus between the specific construct and a specific reference in the literature. 
Questions addressing perceptual variables were measured with a 5-point, unipolar Likert scale to ensure sufficient variance among respondents and to allow for statistical analysis (Kerlinger \& Lee, 2000; Vagias, 2006). Additional response methods included rankings, forced choices (e.g., 1-3; 4-7; 8-10; 11-15), matrices, and a single short narrative response (Dillman et al., 2014; Fowler, 2014; Vagias, 2006; Visser, Krosnick, \& Lavrakas, 2000). The survey included a statement of approval by the Chapman University Institutional Review Board, an informed consent document, and an invitation to participate.

\section{Instrument Development}

The development of this survey followed a multi-step procedure based on the tailored design method described by Dillman et al. (2014). Upon completion of the literature review, primary research questions were formulated to address the atypical language demonstrated by EACs. This process involved developing a theoretical framework of influencing variables and identifying those that needed to be controlled and included to increase the likelihood of valid and reliable results (Coughlin et al., 2009). This step was followed by the generation of question sets that addressed a range of demographic characteristics of SLPs based in California, public elementary schools and their caseloads, and the measurement of: (1) multiple latent constructs relating to language and practices, (2) levels of language performance of both emerging oral communicators and EACs, (3) SLP practices with both populations, and (4) SLP opinions on the language demonstrated by EACs.

In order to increase the content validity of the survey (Litwin, 1995), this questionnaire was discussed and analyzed with a focus group of ten SLPs with 
demonstrated expertise in AAC. The SLPs represented diversity in years in practice, practice setting, population served, and job title. This expert analysis provided greater validation that the underlying construct (e.g., relevance, importance) was captured accurately. During the focus group, each question was analyzed for structure, intent, and format. This step was crucially important due to the inherent challenges in measuring latent constructs, which are theoretical in nature and are highly sensitive to interpretation (Creswell, 2014). Changes to individual items were negotiated by the group, and a final version was generated by consensus. Formal notes and an audio recording were taken during the meeting. Changes made to the questionnaire were confirmed by reviewing the notes and listening to the recording on two separate occasions.

Upon completion of these changes, a Microsoft Word version of the questionnaire was sent out to twenty SLPs via email who responded to a request on two ASHAsponsored special interest groups-SIG 12 with a focus on AAC, and SIG 16 with a focus on school-based issues - for further review. A total of ten surveys were returned. The process of sending out questionnaires was discontinued when no further changes or edits were suggested from three sequential responders. A final control step involved five SLPs previewing the survey to identify potential platform-based interface issues, overall survey ease of use, and overall comprehensibility. With each response, changes were made as appropriate and sent out to to be reviewed again until no further edits were suggested. See Appendix C for the survey. 


\section{Variables}

\section{Control Variables}

Coverage. The survey was designed to examine multiple factors that shape SLPs' practices with EACs. In order to accomplish this task and develop valid and generalizable theories about these practices, it was necessary to identify an appropriate target population, and from that population, develop a sample frame that reflected the full heterogeneity of the targeted population (Dillman et al., 2014; Visser et al., 2000). The targeted population for this study included all California, public elementary-school-based SLPs with a published email address on a SELPA, district, or school website. The selfmanaged list of SLPs may have included those who do not work with EACs. That portion of SLPs was eliminated from the sample through the initial contact, which asked potential respondents if they are currently working with an EAC on their caseload. A further elimination step occurred within the survey via the first question (i.e., 1C1.2), wherein each participant confirmed his/her status as a currently practicing SLP in an elementary school in California with at least one aided EAC on his/her caseload in the past two years. Those SLPs not meeting this qualification were asked not to participate in the survey or were exited from the survey, thereby eliminating that portion of the lists.

Sampling. The sample was the population (Dillman et al., 2014).

Nonresponse. The potential for nonresponse error, which occurs when respondent characteristics are different from non-responders in relevant aspects (Coughlin et al., 2009; Dillman et al., 2014; Fowler, 2014; Ponto, 2015), was mitigated by:

1. Having a clearly stated purpose for the research, 
2. Using an established survey tool (i.e., Qualtrics) that could be used across platforms (e.g., Apple OSX, Windows, Linux) and devices (e.g., desk top computers, lap top computer, tablets, cell phones),

3. Sending an email announcing the pending survey,

4. Allowing a multiple-week time frame for respondents to access and respond to the survey,

5. Sending three reminder emails about the survey spaced two weeks apart, and

6. Ensuring anonymity.

In addition to these measures, a further means of mitigating nonresponse was the inclusion of a token incentive (Dillman et al., 2014) in the form of a donation for each completed survey. On December 20, 2018, a donation of $\$ 400.00$ was made to The Orange County Childhood Language Center, a community outreach program of the California Scottish Rite, located in Santa Ana, California. This organization is a nonprofit charitable 501(c)(3) agency providing free diagnostic and therapeutic services for children with disabilities, aged 2 to 16 years of age (The Orange County Childhood Language Center, n.d.).

Measurement. Errors related to measurement were addressed with multiple controls. The first was the development of an instrument with careful attention to question formation, question order, and the need to include multiple measures of the same construct (Dillman et al., 2014; Trochim, 2006). Further steps to reduce measurement error included piloting the questionnaire with experts who provided feedback with respect to question intent, question comprehensibility, question order effects (i.e., primacy versus recency); response formation and options (i.e., scaled, forced 
choice, dichotomous); and salient issues that may have been omitted unintentionally (Dillman et al., 2014; Visser et al., 2000). In addition to these factors, the survey instrument reflected considerations pertaining to anonymity.

\section{Biases}

Bias has been identified as a potential confound in research design (Kaufman \& Kaufman, 2005; Treweek \& Zwarenstein, 2009). Consideration of bias supports participants' ability to respond to survey items free from distortions. Acknowledgement of bias supports a researcher's ability to interpret findings more accurately (Kaufman \& Kaufman, 2005). The two biases of selection and social desirability were determined to be the most appropriate to be addressed in this dissertation.

Selection bias. Selection bias has been shown to skew results of survey research using Likert scales (Maeda, 2015). This bias involves acquiescence, scale directionality, and left-to-right orientation, (Maeda, 2015; Nicholls et al., 2006). Acquiescence bias, which is the tendency for respondents to agree with survey items regardless of their opinion, has been shown to be attenuated by the use of dimension-specific language (Holbrook, 2008). As such, scaled items in the survey contained the use of specific constructs in the question stem, such as levels of confidence, importance, likelihood, similarity, qualification, and frequency where appropriate. Further, when possible, agree/disagree items were modified into rankings, and either multiple choice, matrices, or

dichotomous questions. Scale directionality relates to the use of unipolar (i.e., extremely likely, very likely, moderately likely, slightly likely, not at all likely) or bipolar scale items (i.e., strongly agree, agree, somewhat agree, somewhat disagree, disagree, strongly disagree; Dillman et al., 2014). Orientation involves the presentation of the scaled items, 
such as left to right, ascending, or descending (Maeda, 2015). The issues of directionality and orientation were addressed in recent research by Maeda (2015), which validated unipolar scaling and vertical response placement as having the lowest selection bias, either ascending or descending, for online surveys. In light of these findings, the survey developed for this inquiry incorporated both unipolar scales and ascending vertical response placement as a means of reducing these biases. A final factor considered with respect to selection bias was response-order effects, where survey respondents are more likely to select an earlier or later occurring answer were controlled by randomizing item presentation when possible (Dillman et al., 2014).

Social desirability. Social desirability is the tendency for participants to respond to questions in a manner they believe represents a favorable projection of themselves with regards to social norms (Jo et al., 1997). It has been shown to distort results and is most likely to occur in responses to sensitive questions (van de Mortel, 2008). Responses involving social desirability can cause scalar poling (i.e., "extremely confident" or "not at all confident"), an overrepresentation of socially desirable responses, and an underrepresentation of socially undesirable traits (Callegaro, 2008). As such, this bias poses a threat to construct validity (Jo et al., 1997). There are four characteristics associated with social desirability: culture, personality, mode of data collection, and item. Methods to control for this bias included being aware of cultural values, using neutral wording of items, including direct and indirect questions, offering forgiving response options (i.e., "I don’t know”), and using self-administered questionnaires (Callegaro, 2008; Jo et al., 1997), all of were incorporated into this instrument. 


\section{Data Procedures}

\section{Data Collection Procedures}

Data collection was accomplished through the use of a self-administered questionnaire (Coughlin et al., 2009; Dillman et al., 2014; Fowler, 2014) via the webbased survey tool, Qualtrics.

\section{Data Analysis}

Data analysis involved the transfer of the raw data from Qualtrics into Statistical Package for the Social Sciences, version 24 (SPSS 24.). Initial statistical analysis involved plotting the data and running basic descriptive statistics and frequencies (Pallant, 2013; Urdan, 2010). The short narrative responses were coded for themes.

\section{Summary}

This chapter served to describe the use of survey methodology within a postpositivist and pragmatist paradigm, and quantitative principles (Creswell, 2014; Crotty, 1998; Webb, 2007). This methodology was used to address two primary research questions involving the identification of factors that may be contributing to the reduced linguistic outcomes of EACs. The factors examined in this study included the demographics, beliefs, opinions, and practices of SLPs who work with EACs. Toward this end, a special purpose questionnaire was developed, containing thirty-seven closedended questions and one short narrative response. Statistical analyses included frequencies, means comparisons, and group differences. Based on the focus of this dissertation, the structure of the questions, and the assumptions met by these data, it was determined that paired samples t-tests were the appropriate statistical test (Pallant, 2013). 


\section{CHAPTER IV: RESULTS}

This dissertation sought to answer research questions regarding the relationship between speech-language pathologist (SLP) practices, philosophies, and beliefs and the linguistic patterns observed in emerging aided communicators (EACs). This inquiry is timely and relevant based on the following factors:

1. The acquisition and development of language has been shown to be highly robust across typical, atypical, and special populations and input and output modalities (P. Bloom, 2000; Devoscovi \& D’Amico, 2005; Goldin-Meadow et al., 2014; Lillo-Martin, 1999; Meier \& Newport, 1990; Smith \& Grove, 2003; Volterra et al., 2005).

2. Research has demonstrated reduced linguistic outcomes in emerging aided communicators (Blockberger \& Johnston, 2003; Drager \& Light, 2010; Drager, Light, Speltz, Fallon \& Jeffries, 2003; Light et al., 2004; Light \& McNaughton, 2012a; Paul, 1997; Smith \& Grove, 2003; Sutton, Soto, \& Blockberger, 2002; Sutton, Trudeau, Morford, Rios, \& Poirier, 2010).

3. Speech-language pathologists are integral to the use of AAC systems by emerging aided communicators (ASHA, 2001, 2002, 2004, 2005; Dietz et al, 2012; Sutton, 2008).

4. Practices by SLPs are influenced by their beliefs and philosophies (Schlosser \& Raghavendra, 2004).

The two primary research questions posed in this dissertation follow:

Research Question 1: Do SLPs perceive differences in their beliefs between their practices with emerging oral communicators with language impairments and EACs? 
Research Question 1a: If variances do exist, are those variances significant and what is the relationship?

Research Question 2: Do SLPs report differences between their practices with emerging oral communicators with language impairments and EACs?

Research Question 2a: If variances do exist, are those variances significant and what is the relationship?

\section{Survey Return}

Table 14 contains specific information on the surveys returned in response to the invitation.

Table 14

Survey Response Summary

\begin{tabular}{lrr}
\hline Survey Information & Number & Percentage \\
\hline Contact Emails & 2549 & N/A \\
Surveys Sent & 2514 & $98.62 \%$ \\
Surveys Bounced via Server & 326 & $12.96 \%$ \\
Surveys Started & 250 & $9.95 \%$ \\
Recorded Responses & 184 & $7.31 \%$ \\
Days Survey Was Open & 36 & N/A \\
\hline
\end{tabular}

\section{Data Preparation}

The current chapter will detail the results of the data revealed by the special purpose survey designed for this dissertation. The first stage in the analysis involved a three step cleaning process entailing evaluating the raw data, cleaning the data, and summarizing the data (Osborne, 2013). These three steps were necessary to ensure a valid and reliable data set, which further supported proper analysis. An additional step involved confirming assumptions met as a means of minimizing Type I and Type II errors, as well as supporting accurate determinations of power and effect sizes (Osborne, 
2013). This first stage was followed by preliminary analysis, which was followed up by the final analysis. Each stage is described in this chapter, and a full interpretation and discussion of the findings are found in the final chapter of this dissertation.

\section{Cleaning the Data}

Cleaning up the data involved multiple filtration steps (see Table 14 for details). The initial data set included 184 responses as identified by those who read the Informed Consent Form (Appendix B) and consented to participate in the survey (See Question IC1.1 in Appendix C). The 184 responses were further filtered down to 124 based on the presence of at least one EAC on the participants' caseload for at least two years and an appropriate level of certification/licensure (See Question IC1.2 in Appendix C). A final filtration step involved removing responses missing values prior to Question 3.1.2 (See Appendix C). Although the remaining 102 responses contained missing values within the 60 questions, it was determined that the integrity of these responses was sufficiently robust as to support reliable and valid analysis. As a result of this missing data, there are inconsistent numbers of responses to questions. As such, the number of responses to each question is listed in Table 15 for each response.

Table 15

Survey Response Specification

\begin{tabular}{lrr}
\hline Response Specification & Number & Percentage \\
\hline Surveys Started & 250 & N/A \\
Surveys with Responses to Question IC1.1 & 184 & $73.60 \%$ \\
Surveys with Responses to Question IC1.2 & 124 & $49.60 \%$ \\
Surveys with Responses to Questions IC1.1 through Q3.1.2 & 102 & $40.80 \%$ \\
\hline
\end{tabular}




\section{Descriptive Results}

Prior to performing statistical analysis of the research questions, preliminary analysis was conducted to capture the demographic information of SLPs, SLPs' caseloads, and the EACs on their caseloads. Response options included 5-point Likert scales, multiple choice, and rankings. Unless otherwise specified, the descriptive statistics were generated through the use of frequencies.

\section{SLP Demographics}

In order to analyze the data from an integrated perspective, the demographic data from the survey were examined and each construct is presented individually.

Coursework. In response to the question regarding coursework specific to augmentative and alternative communication (AAC) (Q1.3), the majority of SLPs reported taking their AAC-specific coursework at either the undergraduate $(6 / 5.9 \%)$ or graduate $(62 / 60.8 \%)$ level, with $6(5.9 \%)$ having this coursework at both levels. However, it is noteworthy that almost one quarter of SLPs $(24 / 23.5 \%)$ did not have any AAC-specific coursework (see Table 16).

Table 16

SLP AAC-Specific Coursework

\begin{tabular}{lrrr}
\hline Education Level & Frequency & Percent & Valid Percent \\
\hline Undergraduate Level & 6 & 5.9 & 5.9 \\
Graduate Level & 62 & 60.8 & 60.8 \\
Both Levels & 6 & 5.9 & 100 \\
No AAC-Specific Coursework & 24 & 23.5 & 23.5 \\
Unsure & 4 & 3.9 & 3.9 \\
Total Responses & 102 & 100.0 & 100.0 \\
Missing & 0 & 0 & \\
\hline
\end{tabular}


Preparation. In response to the question regarding opinions on preparation (Q1.4), the majority of SLPs surveyed did not feel that their university program prepared them sufficiently to work with EACs (73/71.6\%). See Table 17 for results.

Table 17

SLP Opinions on the Sufficiency of University Program Preparation for Work with EACs

\begin{tabular}{lrrr}
\hline Preparation & Frequency & Percent & Valid Percent \\
\hline Yes & 25 & 24.5 & 2.45 \\
No & 73 & 71.6 & 71.6 \\
& & & \\
I don't know & 4 & 3.9 & 3.9 \\
Total Responses & 102 & 100.0 & 100.0 \\
Missing & 0 & 0 & \\
\hline
\end{tabular}

Certification. In response to the question regarding certification (Q1.1), nearly all SLPs reported having been certified by ASHA (92/90.2\%) or licensed by the State of California (99/97.1\%), or both. A small number of SLPs surveyed selected, working on a waiver as their credential (6/5.9\%). As seen in Table 18, a discrepancy exists in these data in that in the category of waiver is mutually exclusive of the other two categories. It is unclear in which category the error occurred. 
Table 18

SLP Certification

\begin{tabular}{lrrr}
\hline Certification & Frequency & Percent & Valid Percent \\
\hline ASHA Certificate of Clinical Competence & 92 & 90.2 & 100 \\
Missing & 10 & 9.8 & \\
Total Responses & 102 & 100.0 & \\
Missing & 0 & 0 & \\
& & & \\
California State Licensure & 99 & 97.1 & 100 \\
Missing & 3 & 2.9 & \\
Total Responses & 102 & 100.0 & \\
Missing & 0 & 0 & 100 \\
& & & \\
Waiver & 6 & 5.9 & \\
Missing & 96 & 94.1 & \\
Total Responses & 102 & 100.0 & \\
Missing & 0 & 0 & \\
\hline
\end{tabular}

Years of practice. In response to the question regarding years in practice (Q1.2), results revealed a relatively equal spread between the three categories of 1 to 5 years, 6 to 10 years, and 11 or more years $(29 / 28.4 \% ; 31 / 30.4 \% ; 42 / 41.2 \%)$, respectively, with a slight skew toward SLPs with more experience (see Table 19).

Table 19

SLP Practice Years

\begin{tabular}{lrrr}
\hline Years in Practice & Frequency & Percent & Valid Percent \\
\hline 1 to 5 & 29 & 28.4 & 28.4 \\
6 to 10 & 31 & 30.4 & 30.4 \\
11 or more & 42 & 41.2 & 41.2 \\
Total Responses & 102 & 100 & 100.0 \\
Missing & 0 & 0 & \\
\hline
\end{tabular}




\section{Caseload Demographics}

For the following three questions, SLPs were instructed to respond based on the elementary school at which they had most recently completed an Individualized Education Program (IEP). This instruction for recency was provided because many SLPs work at more than one school location.

Special-education program. In response to the question regarding programs (Q1.5), results revealed a relatively similar spread between the two program types of Categorical (44/43.6\%) and Non-Categorical (54/52.5\%). See Table 20 for results.

Table 20

Special Education Program

\begin{tabular}{lrrr}
\hline Program & Frequency & Percent & Valid Percent \\
\hline Categorical: Disability Specific & 44 & 43.1 & 43.6 \\
Non-Categorical: Non-specified Disability & 54 & 52.9 & 53.5 \\
Other & 3 & 2.9 & 3.0 \\
Total Responses & 101 & 99.0 & 100.0 \\
Missing & 1 & 1 & \\
\hline
\end{tabular}

Special-education population. In response to the question regarding population (Q1.6), results revealed that the majority of SLPs work with children in the Mild-toModerate (22/22.0\%) and Moderate-to-Severe (46/46.0\%) range, with very few SLPs working with children in the Severely Handicapped (9/9.0\%) range. See Table 21. 
Table 21

Special Education Population

\begin{tabular}{lrrr}
\hline Population & Frequency & Percent & Valid Percent \\
\hline Learning Center & 6 & 5.9 & 6.0 \\
Mild-to-Moderate & 22 & 21.6 & 22.0 \\
Moderate-to-Severe & 46 & 45.1 & 46.0 \\
Severely Handicapped & 9 & 8.8 & 9.0 \\
Other & 17 & 16.7 & 17.0 \\
Total Responses & 100 & 98.0 & 100.0 \\
Missing & 2 & 2.0 & \\
\hline
\end{tabular}

School socioeconomic status. In response to the question regarding socioeconomic status (Q1.7), results indicated that the socioeconomic status (SES) of the majority of SLPs' primary workplace setting was Medium-to-Low (34/35.8\%) to Low $(25 / 26.3 \%)$. Results can be seen in Table 22 .

Table 22

Reported SES of the Students at the SLPS' School of Primary Employment

\begin{tabular}{lrrr}
\hline SES & Frequency & Percent & Valid Percent \\
\hline Low & 25 & 24.5 & 26.3 \\
Medium-to-Low & 34 & 33.3 & 35.8 \\
Medium & 13 & 12.7 & 13.7 \\
Medium-to-High & 16 & 15.7 & 16.8 \\
High & 7 & 6.9 & 7.4 \\
Total Responses & 95 & 93.1 & 100.0 \\
Missing & 7 & 6.9 & \\
\hline
\end{tabular}

Caseload size. In response to the question regarding caseload size (Q2.1), results reveal a direct relationship between the number of children on a caseload and the number of SLPs with that caseload size. Specifically, as the number of children on a caseload decreases, so do the number of SLPs with that caseload size. For example, two (2\%) of 
the SLPs reported having a caseload of 19 or fewer and 52 (51\%) SLPs surveyed reported having a caseload of 50 or greater. Results can be seen in Table 23.

Table 23

Caseload Size

\begin{tabular}{lrrr}
\hline Caseload Size & Frequency & Percent & Valid Percent \\
\hline 19 or fewer & 2 & 2.0 & 2.0 \\
20 to 29 & 2 & 2.0 & 2.0 \\
30 to 39 & 19 & 18.6 & 18.6 \\
40 to 49 & 27 & 26.5 & 26.5 \\
$50+$ & 52 & 51.0 & 51.0 \\
Total Responses & 102 & 100.0 & 100.0 \\
Missing & 0 & 0 & \\
\hline
\end{tabular}

Number of aided AAC users. In response to the question regarding number of aided AAC users (Q2.2), results reveal a fairly equal split between SLPs with 1 to 4 EACs on their caseload (53/52.5\%) and those with 5 or more (29/28.4\%). Table 24 provides the results.

Table 24

Number of EACs on SLPS' caseloads

\begin{tabular}{lrrr}
\hline Number of EACs & Frequency & Percent & Valid Percent \\
\hline 1 to 4 & 53 & 52.0 & 52.5 \\
5 to 8 & 29 & 28.4 & 28.7 \\
9 or more & 19 & 18.6 & 18.6 \\
Total Responses & 101 & 99.0 & 100.0 \\
Missing & 1.0 & 1.0 & \\
\hline
\end{tabular}

Time spent on AAC-related tasks. Responses to the question about time spent on AAC-related tasks (Q2.5) are detailed in the following sections.

Direct intervention. When asked about how their time per week is spent on AAC-related tasks (Q2.5), the majority of SLPs reported spending between 1 to 4 hours $(82 / 80.4 \%)$. A minority reported spending 9 or more hours $(3 / 5.9 \%)$. Two participants 
reported spending None (2/2.0\%), which may reflect the use of related professional, such as a speech-language pathologist assistant (SLPA) or a paraprofessional, may provide the direct intervention under the supervision of the SLP, as specified by No Child Left Behind Act of 2001(PL 107-110; 20 U.S.C. $§ 6319(g))$ (NCLB, 2001). An alternate explanation for this response may be a misunderstanding of the question. See Table 25 for results.

Table 25

Number of Hours Spent Weekly in Direct Intervention With an EAC

\begin{tabular}{lrrr}
\hline Direct Intervention & Frequency & Percent & Valid Percent \\
\hline None & 2 & 2.0 & 2.0 \\
1 to 4 hours & 82 & 80.4 & 80.4 \\
5 to 8 hours & 12 & 11.8 & 11.8 \\
9 or more hours & 3 & 5.9 & 5.9 \\
Total Responses & 102 & 100.0 & 100.0 \\
Missing & 0 & 0 & \\
\hline
\end{tabular}

Programming high-tech devices. When asked about the number of hours per week spent programming high-tech AAC devices, the majority of SLPs reported between 1 to 4 hours (64/66.0\%). Almost one third of participants (31/32.0\%) reported spending None. For these 31 SLPs, it remains unclear whether this work is accomplished by a related professional (e.g., SLPA, paraprofessional), or if no time is allocated to this task (see Table 26 for results). 
Table 26

Number of Hours Spent Weekly Programming High-Tech AAC Devices

\begin{tabular}{lrrr}
\hline Programming & Frequency & Percent & Valid Percent \\
\hline None & 31 & 30.4 & 32.0 \\
1 to 4 hours & 64 & 62.7 & 66.0 \\
5 to 8 hours & 2 & 2.0 & 2.1 \\
9 or more & 0 & 0 & 0 \\
Total Responses & 97 & 95.1 & 100.0 \\
Missing & 5 & 4.9 & \\
\hline
\end{tabular}

Making low-tech materials. When asked about the number of hours spent weekly making materials for low-tech AAC devices, the majority of SLPs reported between 1 to 8 hours (82/81.2\%). Approximately one fifth of SLPs reported spending None (19/18.8\%). As with the programming of high-tech devices described above, it remains unclear whether this work is accomplished by a related professional (i.e., SLPA, paraprofessional), or if no time is allocated to this task. See Table 27 for results. 
Table 27

Number of Hours Spent Weekly Making Materials for Low-Tech AAC System

\begin{tabular}{lrrr}
\hline Making Materials & Frequency & Percent & Valid Percent \\
\hline None & 19 & 18.6 & 18.8 \\
1 to 4 hours & 80 & 78.4 & 79.2 \\
5 to 8 hours & 2 & 2.0 & 2.0 \\
9 or more & 0 & 0 & 0 \\
Total Responses & 101 & 99 & 100.0 \\
Missing & 1 & 1.0 & \\
\hline
\end{tabular}

Collaboration with AAC stakeholders. When asked about the number of hours spent weekly collaborating with AAC stakeholders, the majority of SLPs (95/93.1\%) reported spending between 1 to 8 hours collaborating with teachers, allied professionals, or family members (see Table 28).

Table 28

Number of Hours Spent Weekly Collaborating with Allied Professionals or Families

\begin{tabular}{lrrr}
\hline Collaboration & Frequency & Percent & Valid Percent \\
\hline None & 6 & 5.9 & 5.9 \\
1 to 4 hours & 91 & 89.2 & 89.2 \\
5 to 8 hours & 4 & 3.9 & 3.9 \\
9 or more & 1 & 1.0 & 1.0 \\
Total Responses & 102 & 100 & 100.0 \\
Missing & 0 & 0 & \\
\hline
\end{tabular}

Summary. Results from this section can also be analyzed by examining the number of None responses in Table 29. 
Table 29

Number of "None" Responses to Question 2.5

\begin{tabular}{llr}
\hline Task & Descriptor & $\begin{array}{r}\text { Number of Responses/ } \\
\text { Percentage of Responses }\end{array}$ \\
\hline $\begin{array}{l}\text { Direct Intervention } \\
\text { Programming High-Tech Devices }\end{array}$ & None & $2 / 2.0 \%$ \\
Making Low-Tech Materials & None & $31 / 30.4 \%$ \\
Collaboration with AAC Stakeholders & None & $19 / 18.6 \%$ \\
& & $6 / 5.9 \%$
\end{tabular}

The results indicate that $31(30.4 \%)$ of SLP do not spend time programming hightech devices or making materials for low-tech systems (19/18.6\%).

Selection method. In order to allow for a holistic perspective on the EACs on the SLPs' caseloads, statistics regarding selection method (Q2.3) are coupled in the table below. Table 30 indicates that a minority of EACs (22/28.2\%) access their device with indirect select and the majority of EACs (74/94.9\%) access their device with direct select.

Table 30

Number of EACs by Selection Method

\begin{tabular}{|c|c|c|c|}
\hline \multicolumn{4}{|c|}{ Indirect Select } \\
\hline Number of EACs & Frequency & Percent & Valid Percent \\
\hline None & 56 & 54.9 & 71.8 \\
\hline 1 to 4 & 19 & 18.6 & 24.4 \\
\hline 5 to 8 & 1 & 1.0 & 1.3 \\
\hline 9 or more & 2 & 2.0 & 2.6 \\
\hline Total Responses & 78 & 76.5 & 100.0 \\
\hline Missing & 24 & 23.5 & \\
\hline \multicolumn{4}{|c|}{ Direct Select } \\
\hline Number of EACs & Frequency & Percent & Valid Percent \\
\hline None & 13 & 12.7 & 14.9 \\
\hline 1 to 4 & 45 & 44.1 & 51.7 \\
\hline 5 to 8 & 21 & 20.6 & 24.1 \\
\hline 9 or more & 8 & 7.8 & 9.2 \\
\hline Total Responses & 87 & 85.3 & 100.0 \\
\hline Missing & 15 & 14.7 & \\
\hline
\end{tabular}


AAC access method. As with the question regarding selection methods, in order to allow for a holistic perspective of the EACs on the SLPs' caseloads, statistics regarding level of technology $(\mathrm{Q} 2.3)$ are coupled. In Table 31, the data demonstrate a relatively parallel split between the two levels of technology. With respect to low-tech, $80(88.8 \%)$ SLPs reported having EACs on their caseload who use this level of technology. With respect to high-tech, 90 (93.8\%) SLPs reported having EACs on their caseload who use this level of technology.

Table 31

Number of Users of AAC by Selection Method

\section{$\underline{\text { Low-Tech Aided AAC }}$}

\begin{tabular}{lrrr} 
Number of Users & Frequency & Percent & Valid Percent \\
\hline None & 10 & 9.8 & 11.1 \\
1 to 4 & 60 & 58.8 & 66.7 \\
5 to 8 & 16 & 15.7 & 17.8 \\
9 or more & 4 & 3.9 & 4.4 \\
Total Responses & 90 & 88.2 & 100.0 \\
Missing & 12 & 11.8 & \\
\hline
\end{tabular}

High-Tech Aided AAC

\begin{tabular}{lrrr} 
Number of Users & Frequency & Percent & Valid Percent \\
\hline None & 6 & 5.9 & 6.3 \\
1 to 4 & 66 & 64.7 & 68.8 \\
5 to 8 & 19 & 18.9 & 19.8 \\
9 or more & 5 & 4.9 & 5.2 \\
Total Responses & 96 & 94.1 & 100.0 \\
Missing & 6 & 5.9 & \\
\hline
\end{tabular}

Contexts of aided AAC use. Question 2.4 addressed contexts of use by EACs.

Four of the five contexts are presented in sets: (a) pull-out and push-in speech-language therapy session aided AAC use, and (b) classroom and non-classroom-based aided AAC use. The fifth context, in the home, resides independently. The three contexts parallel a 
continuum of naturalness, as defined by Dunst, Raab, and Trivette (2012), with pull-out speech-language therapy sessions being the least natural, the in the home being the most natural.

Analysis of the results revealed a pattern in the uniformity of responses. As is evident when reviewing the responses to Question 2.4, the question stem referred to usage on a daily basis, which may have skewed the results. The consistent pattern of responses may have been confounded by the use of that phrase as a qualifier because very few EACs receive daily speech-language services (ASHA, 2016b). Alternative possibilities may include the bias imposed by social desirability (Callegaro, 2008), or a more generalized misunderstanding of the question. Detailed results are found in the paragraphs below.

Pull-out speech-language therapy sessions. As detailed in Table 32, 86 (88.7\%) EACs on the SLPs caseloads use their device in pull-out therapy sessions, but $11(11.3 \%)$ do not use them in this context.

Table 32

Contexts of Daily AAC Use: Pull-Out Speech-Language-Therapy Sessions

\begin{tabular}{lrrr}
\hline Descriptor & Frequency & Percent & Valid Percent \\
\hline None & 11 & 10.8 & 11.3 \\
1 to 4 & 57 & 55.9 & 58.8 \\
5 to 8 & 20 & 19.6 & 20.6 \\
9 or more & 9 & 8.8 & 9.3 \\
Total Responses & 97 & 95.1 & 100.0 \\
Missing & 5 & 4.9 & \\
\hline
\end{tabular}

Push-in speech-language therapy sessions. As detailed in Table 33, 87 (86.1\%) of the EACs on SLPs caseloads use their aided AAC system in push-in therapy sessions, but $14(13.9 \%)$ do not use them in this context. 
Table 33

Contexts of Daily AAC Use: Push-In Speech-Language Therapy Sessions

\begin{tabular}{lrrr}
\hline Number of EACs & Frequency & Percent & Valid Percent \\
\hline None & 14 & 13.7 & 13.9 \\
1 to 4 & 55 & 53.9 & 54.5 \\
5 to 8 & 25 & 24.5 & 24.8 \\
9 or more & 7 & 6.9 & 6.9 \\
Total Responses & 101 & 99 & 100.0 \\
Missing & 1 & 1 & \\
\hline
\end{tabular}

Classroom-based academic activities. As seen in Table 34, 87 (88.8\%) EACs on

SLPs caseloads use their aided AAC system for classroom-based activities, but 11

$(11.2 \%)$ do not use them in this context.

Table 34

Contexts of Daily AAC Use: In the Classroom for Academic Tasks

\begin{tabular}{lrrr}
\hline Number of EACs & Frequency & Percent & Valid Percent \\
\hline None & & & \\
1 to 4 & 11 & 10.8 & 11.2 \\
5 to 8 & 64 & 62.7 & 54.5 \\
9 or more & 19 & 18.6 & 93.1 \\
Total Responses & 4 & 3.9 & 6.9 \\
Missing & 98 & 96.1 & 100.0 \\
\hline
\end{tabular}

Non-classroom-based activities. As seen in Table 35, 57 (58.8\%) EACs on SLPs caseloads use their aided AAC system for non-classroom-based activities, such as at the lunch tables, during recess, or in the library, but $40(41.2 \%)$ do not use them in this context. 
Table 35

Contexts of Daily AAC Use: For Non-Classroom-Based Activities

\begin{tabular}{lrrr}
\hline Number of EACs & Frequency & Percent & Valid Percent \\
& & & \\
\hline None & 40 & 39.2 & 41.2 \\
1 to 4 & 44 & 43.1 & 45.6 \\
5 to 8 & 9 & 8.8 & 9.3 \\
9 or more & 4 & 3.9 & 4.1 \\
Total Responses & 97 & 95.1 & 100.0 \\
Missing & 5 & 4.9 & \\
\hline
\end{tabular}

In the home. As seen in Table 36, 74 (76.2\%) EACs on SLPs' caseloads use their aided AAC system in the home, but 23 (23.7\%) do not use them in this context. Table 36

Contexts of Daily AAC Use: In the Home

\begin{tabular}{lrrr}
\hline Number of EACs & Frequency & Percent & Valid Percent \\
& & & \\
\hline None & 23 & 22.5 & 23.7 \\
1 to 4 & 64 & 62.7 & 66.0 \\
5 to 8 & 6 & 5.9 & 6.2 \\
9 or more & 4 & 3.9 & 4.1 \\
Total Responses & 97 & 95.1 & 100.0 \\
Missing & 5 & 4.9 & \\
\hline
\end{tabular}

Summary of aided AAC contexts. Table 37 demonstrates a distinct pattern in Contexts, which is most aptly captured in the response category of None. As can be seen, in the first two sets, the reported number of EACs who do not use their aided AAC system increased as the context in which they are used becomes less naturalistic. This pattern is demonstrated in that fewer EACs use their aided AAC systems in push-in than in pull-out speech-language therapy sessions, and fewer EACs use their aided AAC systems in classroom-based academic activities than in non-classroom-based tasks. In the most naturalistic context of the three sets, the home, use of the aided AAC system is 
absent in almost one-quarter of the EACs. What remains unclear is if the EACs have access to their aided AAC systems in these contexts and do not use them, or if aided AAC systems are not made available to them.

Table 37

Daily Use by Context

\begin{tabular}{llr}
\hline Context & Descriptor & $\begin{array}{r}\text { Number of Responses/ } \\
\text { Percentage of Responses }\end{array}$ \\
\hline $\begin{array}{l}\text { Pull-out speech-language therapy sessions } \\
\text { Push-in speech-language therapy sessions }\end{array}$ & None & $11 / 11.3 \%$ \\
Classroom-based academic tasks & None & $14 / 13.9 \%$ \\
Non-classroom-based activities & None & $11 / 11.2 \%$ \\
In-home & None & $40 / 41.2 \%$ \\
\hline
\end{tabular}

\section{Specific EAC Demographics}

In addition to the details about SLPs' caseloads in the general, participants were asked to describe a specific EAC on their caseload. Participants were instructed to describe the EAC whose IEP they had most recently completed. This instruction for recency was included as a means of reducing selection bias toward specific EACs on SLPs' caseloads, which may have skewed the sample away from a more neutral representation.

Length of time on SLPs' caseloads. Participants were asked to indicate the length of time the specific EAC has been on their caseloads (Q6.1). As can be seen in Table 38, the majority of SLPs (56/60.9\%) have had the specified EAC on their caseload for a full academic year or more. 
Table 38

Length of Time on Caseload

\begin{tabular}{lrrr}
\hline Length of Time & Frequency & Percent & Valid Percent \\
\hline$<1 / 2$ of an Academic Year & 21 & 20.6 & 22.8 \\
$\approx 1 / 2$ of an Academic Year & 7 & 6.9 & 7.6 \\
$\approx 3 / 4$ of an Academic Year & 8 & 7.8 & 8.7 \\
Full Academic Year & 19 & 18.6 & 20.7 \\
$>$ A Full Academic Year & 37 & 36.3 & 40.2 \\
Total & 92 & 90.2 & 100.0 \\
Missing & 10 & 9.8 & \\
\hline
\end{tabular}

Grade level of EACs. Participants were asked to indicate the grade level of the specific EAC on the their caseloads (Q6.2). As can be seen in the Table 39 in the first three years in the public education system, there was an increase in the number of SLPs describing their EAC as being in preschool (16/15.7\%) and first grade (19/18.6\%).

However, the data also reveal that as EACs progress through the elementary school years, they become less likely to be on SLPs' caseloads. For example, only 6 (6.5\%) SLPs reported having an EAC on their caseload by fifth grade, whereas 19 (20.7\%) reported having a first grader on their caseload.

Table 39

Grade Level of EACs

\begin{tabular}{lrrr}
\hline Length of Time & Frequency & Percent & Valid Percent \\
& & & \\
\hline Preschool & 16 & 15.7 & 17.4 \\
Kindergarten & 14 & 13.7 & 15.2 \\
First Grade & 19 & 18.6 & 20.7 \\
Second Grade & 14 & 13.7 & 15.2 \\
Third Grade & 11 & 10.8 & 12.0 \\
Fourth Grade & 8 & 7.8 & 8.7 \\
Fifth Grade & 6 & 5.9 & 6.5 \\
Sixth Grade & 4 & 3.9 & 4.3 \\
Total & 92 & 90.2 & 100.0 \\
Missing & 10 & 9.8 & \\
\hline
\end{tabular}


While Table 39 includes these data collected from preschool through sixth grade, many elementary schools end at $5^{\text {th }}$ grade. As such, for purposes of further analysis, only the data up to $5^{\text {th }}$ grade was included. When analyzing these results from the perspective of primary (preschool through $\left.3^{\text {rd }}\right)$ versus upper grade $\left(4^{\text {th }}\right.$ and $\left.5^{\text {th }}\right)$ elementary school students, these data indicate that EACs in the upper grades are disproportionally underrepresented. Assuming similar-sized grades, based on the 88 responses considered in this analysis (up through $5^{\text {th }}$ grade), the two grades that make up the upper grades $\left(4^{\text {th }}\right.$ and $\left.5^{\text {th }}\right)$, should represent approximately $2 / 6(33.3 \%)$, or approximately 29 students of the EACs on caseloads. However, these data demonstrate only $14(15.9 \%)$ of EACs in the $5^{\text {th }}$ grade are on SLPs' caseloads. Possible factors skewing these data may include decreased need for aided AAC by the EACs as they progress through elementary school, or a greater number of participants who work solely with EACs in the early grades.

Primary educational placement. Question 6.3 asked participants to identify the primary educational placement of the specified ECA. As is evident, the majority of EACs have a primary placement in special education (76/82.6\%). These data also indicate that $16(17.4 \%)$ EACs have a primary placement in a general education classroom. See Table 40 for results.

Table 40

Primary Educational Placement of the Specified EAC

\begin{tabular}{lrrr}
\hline Placement & Frequency & Percent & Valid Percent \\
& & & \\
\hline General Education & 16 & 15.7 & 17.4 \\
Special Education & 76 & 74.5 & 82.6 \\
Total Responses & 92 & 90.2 & 100.0 \\
Missing & 10 & 9.8 & \\
\hline
\end{tabular}


Primary special education eligibility category. As a means of obtaining a complete profile of the specified EAC, SLPs were asked to select the special education eligibility (Q6.4) of the EAC, as defined by the California Department of Education (n.d.). As seen in Table 41, the single eligibility category of Autism represents 40 (43.0\%) EACs on SLPs' caseloads. Of note is that $9(9.7 \% \%)$ EACs have a primary eligibility of Specific Learning Impairment, which is the only category that is solely language-based.

Table 41

Primary Special Education Eligibility of the Specified EAC

\begin{tabular}{lrrr}
\hline Length of Time & Frequency & Percent & Valid Percent \\
\hline Autism & 40 & 39.2 & 43.0 \\
Intellectual Disability & 17 & 16.7 & 18.3 \\
Multiple Disabilities & 8 & 7.8 & 8.6 \\
Other Health Impairment & 10 & 9.8 & 10.8 \\
Orthopedic Impairment & 8 & 7.8 & 8.6 \\
Specific Learning Impairment & 9 & 8.8 & 9.7 \\
Specific Learning Disability & 1 & 1.0 & 1.1 \\
Total & 93 & 91.2 & 100.0 \\
Missing & 9 & 8.8 & \\
\hline
\end{tabular}

Language development levels. The participants were asked to identify the linguistic characteristics of the specified EAC. The characteristics included the levels of symbolism and commonly observed utterance types. These two characteristics demonstrate a corollary relationship (Bates \& Goodman, 1997), and provide valuable insight regarding intervention directions.

Level of symbolism. Question 6.5 addressed the level of language development of the specified EAC. As seen in Table 42, the majority of SLPs described the specific 
EAC as either Intentional/Symbolic (59/63.4\%) or Linguistic (19/20.4\%). This finding is linked to the majority opinion demonstrated in Question 4.1.e (Table 65).

Table 42

Language Development of Specified EAC

\begin{tabular}{lrrr}
\hline Descriptor & Frequency & Percent & Valid Percent \\
& & & \\
\hline Non-Intentional/Non-Symbolic & 3 & 2.9 & 3.2 \\
Intentional/Non-Symbolic & 3 & 2.9 & 3.2 \\
Intentional/Symbolic & 59 & 57.8 & 63.4 \\
Linguistic & 19 & 18.6 & 20.4 \\
I do not know & 9 & 8.8 & 9.7 \\
Total & 93 & 91.2 & 100.0 \\
Missing & 9 & 8.8 & \\
\hline
\end{tabular}

Utterance type. Participants were asked to describe the language development level of the specified EAC on their caseload with three sub-Questions, 6.10.a, 6.10.b and 6.10.c. For this question, a bipolar Likert-scale was used and responses were grouped by various levels.

As seen in Table 43, the majority of SLPs (56/60.9\%) described their specified EAC as responding with a single icon by selecting the frequencies of Often and Almost Always.

Table 43

Frequency of Single Icon Response

\begin{tabular}{lrrr}
\hline Frequency & Frequency & Percent & Valid Percent \\
& & & 0 \\
Never & 0 & 0 & 6.0 \\
Rarely & 6 & 7.0 & 34.8 \\
Sometimes & 32 & 31.4 & 43.5 \\
Often & 40 & 39.2 & 15.2 \\
Almost Always & 14 & 13.7 & 100.00 \\
Total & 92 & 90.2 & \\
Missing & 10 & 9.8 & \\
\hline
\end{tabular}


As seen in Table 44, 39 SLPs (42.9\%) described their specified EAC as responding with a telegraphic or agrammatical utterance by selecting the frequencies of Often and Almost Always.

Table 44

Frequency of Telegraphic or Agrammatical Utterance

\begin{tabular}{lrrr}
\hline Frequency & Frequency & Percent & Valid Percent \\
\hline Never & 14 & 13.7 & 15.4 \\
Rarely & 14 & 13.7 & 15.4 \\
Sometimes & 24 & 23.5 & 26.4 \\
Often & 21 & 20.6 & 23.1 \\
Almost Always & 18 & 17.6 & 19.8 \\
Total & 91 & 89.2 & 100.00 \\
Missing & 11 & 10.8 & \\
\hline
\end{tabular}

As seen in Table 45, 4 SLPs (4.3\%) described their specified EAC as responding with typical English syntax (SVO) by selecting the frequencies of Often and Almost Always.

Table 45

Frequency of SVO Response

\begin{tabular}{lrrr}
\hline Frequency & Frequency & Percent & Valid Percent \\
& & & 32.4 \\
Never & 33 & 34.3 & 38.9 \\
Rarely & 35 & 19.6 & 21.7 \\
Sometimes & 20 & 2.0 & 2.2 \\
Often & 2 & 2.0 & 2.2 \\
Almost Always & 2 & 90.2 & 100.00 \\
Total & 92 & 9.8 & \\
Missing & 10 & & \\
\hline
\end{tabular}

Level of aided AAC technology. Participants were asked to describe the type of aided AAC used primarily by the specified EAC (Q6.6). The qualifier primarily was included in the wording based on research indicating that AAC users may use a 
combination of AAC methods and systems (Barker et al., 2013; Blackstone et al., 2007; Calculator \& Black, 2009). For this question, examples of low-tech aided AAC include communication books, picture communication symbols (PCS), and Big Macs. Examples of high-tech aided AAC include dedicated devices, computer applications on a tablet, and keyboards. As can be seen in Table 46, approximately half of SLPs (48/51.6\%) described their specified EAC as using a high-tech AAC system.

Table 46

Primary AAC System Used by Specified EAC

\begin{tabular}{lrrr}
\hline AAC System & Frequency & Percent & Valid Percent \\
& & & \\
\hline Low-Tech & 22 & 21.6 & 23.7 \\
High-Tech & 48 & 47.1 & 51.6 \\
Combination of Both & 23 & 22.5 & 24.7 \\
Total & 93 & 91.2 & 100.0 \\
Missing & 9 & 8.8 & \\
\hline
\end{tabular}

Selection method. Participants were asked to describe the method of selection by the specified EAC (Q6.7). The qualifier primarily was included in the wording based on research indicating that $\mathrm{AAC}$ users may use a combination of $\mathrm{AAC}$ methods and systems (Barker et al., 2013; Blackstone et al., 2007; Calculator \& Black, 2009). As can be seen in Table 47, the majority of SLPs $(65 / 71.4 \%)$ described their specified EAC as using primarily direct selection. 
Table 47

Primary Selection Method Used by Specified EAC

\begin{tabular}{lrrr}
\hline Method of Selection & Frequency & Percent & Valid Percent \\
\hline Direct Select & & & 71.4 \\
Indirect Select & 05 & 63.7 & 0 \\
Other & 1 & 1 & 1.1 \\
Combination of Both & 25 & 24.5 & 27.4 \\
Total & 91 & 89.2 & 100.0 \\
Missing & 11 & 10.8 & \\
\hline
\end{tabular}

A follow-up question (Q6.8) to previous question asked participants to describe any aided AAC systems categorized as Other. These descriptions are contained in Table 48. The response detailed in the second line item provides an example of the multimodality nature of aided AAC as is seen in the description that included two types of low-tech AAC and a single type of high-tech AAC. Further, as can be seen, the response in the first line item describes an EAC well outside the elementary school range. There is a possibility that the SLP providing this response described the student whose IEP had just been completed at a high school, which was likely a secondary site of employment. This response may have occurred due to the instruction in the question stem, "When answering these questions, please consider the recent emerging aided communicator for whom you completed an IEP" without the inclusion of "at the elementary school where you work." 
Table 48

Descriptions of "Other" AAC Systems

Number Description

1. Student is 19 and in vocational transition program.

2. She uses a combination of low tech (Big Mac), PECS, tablet (visual field of 2).

3. TD Compass on an iPad with Picture Word Power 100; no keyboard.

4. The student currently uses Proloquo2go on an iPad device. He uses it to respond to questions and is emerging with making comments.

5. My student has Retts [sic] and is using a Tobii.

\section{Specific Intervention Practices}

Intervention techniques. Participants were asked to report frequencies of use of specific intervention techniques to support the development of morphosyntax with the specified EAC (Q6.11). Detailed results for each specific intervention techniques are found below.

Recasts. The first intervention technique detailed by the participants was Recasts. As can be seen in Table 49, the majority of SLPs reported implementing this technique Often or Almost Always (64/67.0\%). An interesting finding that emerged from this question is that $11(12.1 \%)$ of SLPs reported either Never or I am not familiar with this technique. What remains unclear is if these SLPs were unfamiliar with this clinically established intervention technique as a whole, or if they were unfamiliar with how to use Recasts with EACs. 
Table 49

Use of Recasts as an Intervention Technique

\begin{tabular}{lrrr}
\hline Descriptor: Recasts & Frequency & Percent & Valid Percent \\
\hline Never & & & \\
Rarely & 2 & 2.0 & 2.2 \\
Sometimes & 12 & 3.9 & 4.4 \\
Often & 33 & 32.4 & 13.2 \\
Almost Always & 31 & 30.4 & 36.3 \\
I am not familiar with this technique & 9 & 8.8 & 34.1 \\
Total & 91 & 89.2 & 100.0 \\
Missing & 11 & 10.8 & \\
& & & \\
\hline
\end{tabular}

Expansions. The next intervention technique detailed by the participants was Expansions. As can be seen in Table 50, the majority of SLPs reported implementing this technique Often or Almost Always (78/86.7\%).

Table 50

Use of Expansions as an Intervention Technique

\begin{tabular}{lrrr}
\hline Descriptor: Expansions & Frequency & Percent & Valid Percent \\
\hline Never & 3 & 2.9 & 3.3 \\
Rarely & 3 & 2.9 & 3.3 \\
Sometimes & 5 & 4.9 & 5.6 \\
Often & 35 & 34.3 & 38.9 \\
Almost Always & 43 & 42.2 & 47.8 \\
I am not familiar with this technique & 1 & 1.0 & 1.1 \\
Total & 90 & 88.2 & 100.0 \\
Missing & 12 & 11.8 & \\
& & & \\
\end{tabular}

Time Delay/Slowed Rate. The next intervention technique detailed by the participants was Time Delay/Slowed Rate. As can be seen in Table 51, the majority of SLPs reported implementing this technique Often or Almost Always (58/63.0\%).

Similarly to the results seen in Recasts, an interesting finding that emerged from this 
question is that $9(10 \%)$ of SLPs reported Never or I am not familiar with this technique. What remains unclear is if these SLPs were unfamiliar with this clinically established intervention technique as a whole, or if they were unfamiliar with how to use Time Delay/Slowed Rate with EACs.

Table 51

Use of Time Delay/Slowed Rate as an Intervention Technique

\begin{tabular}{lrrr}
\hline Descriptor: Time Delay/Slowed Rate & Frequency & Percent & Valid Percent \\
\hline Never & 1 & 1.0 & 1.1 \\
Rarely & 9 & 8.8 & 9.8 \\
Sometimes & 16 & 15.7 & 17.4 \\
Often & 34 & 33.3 & 37.0 \\
Almost Always & 24 & 23.5 & 26.1 \\
I am not familiar with this technique & 8 & 7.8 & 8.7 \\
Total & 92 & 90.2 & 100.0 \\
Missing & 10 & 9.8 & \\
& & & \\
\hline
\end{tabular}

Imitation. The next intervention technique detailed by the participants was Imitation. As seen in Table 52, the majority of SLPs reported implementing this technique Often or Almost Always (67/72.8\%).

Table 52

Use of Imitation as an Intervention Technique

\begin{tabular}{lrrr}
\hline Descriptor: Imitation & Frequency & Percent & Valid Percent \\
\hline Never & 1 & 1.0 & 1.1 \\
Rarely & 6 & 5.9 & 6.5 \\
Sometimes & 17 & 16.7 & 18.5 \\
Often & 35 & 34.3 & 38.0 \\
Almost Always & 32 & 31.4 & 34.8 \\
I am not familiar with this technique & 1 & 1.0 & 1.1 \\
Total & 92 & 90.2 & 100.0 \\
Missing & 10 & 9.8 & \\
\hline
\end{tabular}


Explicit/Direct instruction. The final intervention technique detailed by the participants was Explicit/Direct Instruction. As seen in Table 53, the majority of SLPs reported implementing this technique Often or Almost Always (70/76.1\%).

Table 53

Use of Explicit/Direct Instruction as an Intervention Technique

\begin{tabular}{lrrr}
\hline Descriptor: Imitation & Frequency & Percent & Valid Percent \\
\hline Never & 1 & 1.0 & 1.1 \\
Rarely & 7 & 6.9 & 7.6 \\
Sometimes & 14 & 13.7 & 15.2 \\
Often & 33 & 32.4 & 35.9 \\
Almost Always & 37 & 36.3 & 40.2 \\
I am not familiar with this technique & 0 & 0 & 0 \\
Total & 92 & 90.2 & 100.0 \\
Missing & 10 & 9.8 & \\
\hline
\end{tabular}

Summary of Intervention Techniques. An overview of the above-described results indicates that SLPs are most familiar with Expansions, Imitations, and Explicit/Direct Instruction, and least familiar with Recasts and Time Delayed/Slowed Rate. As stated earlier, it remains unclear if these levels of familiarity are related to the intervention technique itself or to the use of these clinically established techniques with EACs.

Aided language modeling. Participants were asked to identify the frequency with which they used an established intervention called Aided Language Modeling with their specified EAC. As seen in Table 54, the majority of SLPs (73/79.3\%) use aided language modeling in speech-language therapy sessions with their specified EAC as indicated by the number of SLPs selecting the frequencies of Often and Almost Always. 
Table 54

Use of Aided Language Modeling

\begin{tabular}{lrrr}
\hline Frequency & Frequency & Percent & Valid Percent \\
& & & \\
\hline Never & 1 & 1.0 & 1.1 \\
Rarely & 3 & 2.9 & 3.3 \\
Sometimes & 15 & 14.7 & 16.3 \\
Often & 36 & 35.3 & 39.1 \\
Almost Always & 37 & 36.3 & 40.2 \\
Total & 92 & 90.2 & 100.0 \\
Missing & 10 & 9.8 & \\
\hline
\end{tabular}

\section{SLP Opinions and Beliefs}

The next section provides the results to questions regarding SLPs' opinions and beliefs about various language constructs and intervention. The data for this construct were obtained through a combination of scales, rankings, and dichotomous responses.

\section{Factors Impacting Language Acquisition and Development}

A series of questions were asked to identify factors influencing language acquisition and development for EACs. Results to each question are discussed in the following sections.

Primary influences on language acquisition and development. Question Q3.1 asked SLPs to differentiate between language comprehension and the combination of language comprehension and production as primary influences on language acquisition and development. As displayed in Table 55, SLPs indicated a greater level of agreement, as defined by the number of responses in the Agree, and Strongly Agree categories, to the statement that language acquisition and development are primarily influenced by production (69/68.3\%), rather than by comprehension $(41 / 40.6 \%)$. 
Table 55

Primary Influences on Language Acquisition and Development

\begin{tabular}{lrrr}
\hline & Language Comprehension & & \\
\cline { 2 - 4 } Descriptor & Frequency & Percent & Valid Percent \\
\hline Do not Agree at All & 8 & 7.8 & 7.9 \\
Only Slightly Agree & 19 & 18.6 & 18.4 \\
Somewhat Agree & 27 & 26.5 & 26.7 \\
Agree & 24 & 23.5 & 23.8 \\
Strongly Agree & 17 & 16.7 & 16.8 \\
I am not sure & 6 & 5.9 & 5.9 \\
Total Responses & 101 & 99.0 & 100.0 \\
Missing & 1 & 1.0 & \\
\hline & & & \\
Descriptor & Language Production & \\
\hline Do not Agree at All & & & \\
Only Slightly Agree & 2 & 2.0 & 2.0 \\
Somewhat Agree & 6 & 5.9 & 5.9 \\
Agree & 23 & 22.5 & 22.8 \\
Strongly Agree & 35 & 34.3 & 34.7 \\
I am not sure & 34 & 33.3 & 33.7 \\
Total Responses & 1 & 1.0 & 1.0 \\
Missing & 101 & 99.0 & 100.0 \\
\hline
\end{tabular}

Impediments to language acquisition. Question Q3.2 asked SLPs to select four issues that most impede the language acquisition and development of EACs. As seen in Table 56, 90 SLPs selected lack of fidelity across communicative contexts and partners, which implicates the environments of and demands placed on EACs. The next two factors, lack of access to communication opportunities (66) and lack of access to language models (52), reflect the EACs' ability to engage in communicative interaction. The fourth most frequently selected factor was cognitive demands of aided AAC system layouts (48). 
Table 56

Impediments to Language Acquisition

Factor

Frequency

Lack of Fidelity Across Communicative Contexts and Partners 90

Lack of Access to Communication Opportunities 66

Lack of Access to Language Models

Cognitive Demands of aided AAC system layouts $\quad 48$

Deficits in Symbolic Representation Abilities $\quad 45$

Lack of Access to Appropriate Vocabulary $\quad 39$

Programming Burdens on the SLP $\quad 34$

Motoric Demands of aided AAC System Layouts 19

The Mismatch Between and Oral Modality and a Graphic Symbol-based modality

Access to morphology. Question 4.5 asked SLPs to indicate their level of agreement regarding access to morphological markers (e.g., $-s,-i n g$ ) and marked words (e.g., cats, singing) on the devices of EACs. With respect to access to morphological markers, fewer than half of SLPs (39/39.0\%) selected Agree, or Strongly Agree. With respect to access to marked words, almost half of the SLPs $(49 / 49.0 \%)$ selected those same levels. These results are seen in Tables 57 and 58 .

Table 57

Levels of Agreement on the Inclusion of Morphologial Markers

\begin{tabular}{lrrr}
\hline Descriptor & Frequency & Percent & Valid Percent \\
\hline Do Not Agree At All & 5 & 4.9 & 5.0 \\
Only Slightly Agree & 18 & 17.6 & 18.0 \\
Somewhat Agree & 38 & 31.7 & 38.0 \\
Agree & 29 & 28.4 & 29.0 \\
Strongly Agree & 10 & 9.8 & 10.0 \\
Total & 100 & 98.0 & 100.0 \\
Missing & 2 & 2.0 & \\
\hline
\end{tabular}


Table 58

Levels of Agreement on the Inclusion of Morphologically Marked Words

\begin{tabular}{lrrr}
\hline Descriptor & Frequency & Percent & Valid Percent \\
& & & \\
\hline Do Not Agree At All & 3 & 2.9 & 3.0 \\
Only Slightly Agree & 18 & 17.6 & 18.0 \\
Somewhat Agree & 30 & 31.7 & 38.0 \\
Agree & 36 & 28.4 & 29.0 \\
Strongly Agree & 13 & 9.8 & 10.0 \\
Total & 100 & 98.0 & 100.0 \\
Missing & 2 & 2.0 & \\
\hline
\end{tabular}

Influence of communication partners. Question 3.3 addressed factors affecting language acquisition and development for EACs. For this question, SLPs were asked to rank the influence of common communication partners on the language acquisition and development of EACs. For this ranking question, it was determined that a Friedman Test was the appropriate statistic to determine results. The analysis indicated that individual rankings were statistically different for all factors, $\mathrm{X}^{2}(4)=100.202, p<.0005$.

\begin{tabular}{l|l}
\hline Total N & 99 \\
Missing & 3 \\
Test Statistic & 102.202 \\
Degrees of Freedom & 4 \\
Asymptotic Sig. (2-sided test) & .0000 \\
\hline
\end{tabular}

Figure 3. Results of Friedman's Test. 
Table 59

Ranked Order of Communication Partner Influence on Language Acquisition and Development

\begin{tabular}{ll}
\hline Ranked Order & Communication Partner \\
\hline 1 & Family members \\
2 & Teachers \\
3 & SLPs \\
4 & Paraeducators/Educational Aides \\
5 & Peers \\
\hline
\end{tabular}

Factors Influencing Intervention

Intervention focus. Participants were asked to indicate the differentiation in their intervention focus between Basic Wants and Needs and Language Acquisition and Development (Q6.9) for the EACs on their caseloads. As seen in Table 60, participants reported a greater focus on Basic Wants and Needs, with a mean of 59.23, than on Language Acquisition and Development, with a mean of 40.76 .

Table 60

Intervention Focus

\begin{tabular}{lll}
\hline \multirow{2}{*}{$\mathrm{N}$} & Basic Wants and Needs & $\begin{array}{l}\text { Language Acquisition and } \\
\text { Development }\end{array}$ \\
\cline { 2 - 3 } & Valid & 93 \\
Missing & 09 \\
\hline & & \\
Mean & 59.24 & 40.76 \\
Median & 60.00 & 40.00 \\
Standard Deviation & 22.16 & 22.16 \\
\hline
\end{tabular}

Intervention design. Participants were asked to select the factor that is more informative when designing intervention (Q4.6). As seen in Table 61, the majority of SLPs selected The language development stage of the communicator (53/52.0\%), with 40 (39.2\%) selecting They are equally informative. 
Table 61

Most Important Factor in Intervention Design

\begin{tabular}{lrrr}
\hline Descriptor & Frequency & Percent & Valid Percent \\
\hline $\begin{array}{l}\text { The language development stage of the } \\
\text { communicator }\end{array}$ & 53 & 52.0 & 55.8 \\
The aided AAC system/device (hardware & 2 & 2.0 & 2.1 \\
of software) & & & \\
They are equally informative & 40 & 39.2 & 42.1 \\
Total & 95 & 93.1 & 100.0 \\
Missing & 7 & 6.9 & \\
\hline
\end{tabular}

\section{Primary Statistical Analysis}

The following section details the results of the survey items addressing the primary questions addressed in this dissertation:

Research Question 1: Do SLPs perceive differences in their beliefs between their practices with emerging oral communicators with language impairments and EACs?

Research Question 1a: If variances do exist, are those variances significant and what is the relationship?

Research Question 2: Do SLPs report differences between their practices with emerging oral communicators with language impairments and EACs?

Research Question 2a: If variances do exist, are those variances significant and what is the relationship?

\section{Perceptions of Differences in Beliefs}

In order to address Research Question 1, results from the following survey items were compared using multiples statistical measures as specified in each subsection (see Table 62 for specific comparisons).

Table 62 
Comparisons Made for Analysis for Research Question 1

\section{EACs}

Q4.1: Indicate your level of agreement with general statements relating to assessment and intervention with the EACs currently on your caseload

Q4.2: Indicate your level of agreement with specific statements relating to intervention with EACs currently on your caseload

Q4.3: Frequency of use of specific intervention techniques with EACs currently on your caseload

Q4.4: Presence or absence of specific assessment practices with EACs currently on your caseload

\section{Emerging Oral Communicators}

Q5.1: Indicate your level of agreement with general statements relating to assessment and intervention with the emerging oral communicators currently on your caseload

Q5.2: Indicate your level of agreement with specific statements relating to intervention with emerging oral communicators currently on your caseload

Q5.3: Frequency of use of specific intervention techniques with emerging oral communicators on your caseload

Q5.4: Presence or absence of specific assessment practices with emerging oral communicators currently on your caseload

\section{SLPs' Beliefs}

Language acquisition and development. Question 4.1 contained five subquestions regarding beliefs about intervention and assessment. Sub-Questions 4.1.a and 4.1.e reflect SLPs' beliefs about overall language acquisition and development in EACs. Sub-Question 5.1.a addressed the same construct for emerging oral communicators. Analysis of correlations between these two constructs (i.e., Spearman's) revealed no relationship, and as such, frequencies are detailed in the following sections.

EACs. As seen in Table 63, when asked about the likelihood of EACs developing standard English syntax (SVO) with effective intervention by the end of elementary school (Q4.1.a), 46 (46.0\%) SLPs reported Agree to Strongly Agree, with only 3 (3.0\%) participants reporting Do Not Agree at All. 
Table 63

Likelihood of EACs Developing Standard English Syntax by End of Elementary School

\begin{tabular}{lrrr}
\hline Descriptor & Frequency & Percent & Valid Percent \\
\hline Do Not Agree At All & 3 & 2.9 & 3.0 \\
Only Slightly Agree & 22 & 21.6 & 22.0 \\
Somewhat Agree & 29 & 28.4 & 29.0 \\
Agree & 33 & 32.4 & 33.0 \\
Strongly Agree & 13 & 12.7 & 13.0 \\
Total & 100 & 98.0 & 100.0 \\
Missing & 2 & 2.0 & \\
\hline
\end{tabular}

Emerging oral communicators. As seen in Table 64, when asked about the likelihood of emerging oral communicators developing standard English syntax (SVO) with effective intervention by the end of elementary school (Q5.1.a), 57 (62.0\%) SLPs reported Agree through Strongly Agree, with one (1.1\%) SLP reporting Do Not Agree at All.

Table 64

Likelihood of Emerging Oral Communicators Developing Standard English Syntax by End of Elementary School

\begin{tabular}{lrrr}
\hline Descriptor & Frequency & Percent & Valid Percent \\
\hline Do Not Agree At All & 1 & 1.0 & 1.1 \\
Only Slightly Agree & 10 & 9.8 & 10.9 \\
Somewhat Agree & 24 & 23.5 & 26.1 \\
Agree & 40 & 39.2 & 43.5 \\
Strongly Agree & 17 & 16.7 & 18.5 \\
Total & 92 & 9.8 & 100.0 \\
Missing & 10 & 9.8 & \\
\hline
\end{tabular}

Summary. Tables 63 and 64 reveal that a greater number of SLPs believe that standard English syntax can be achieved by emerging oral communicators than by EACs.

EACs. As seen in Table 65, when asked about the likelihood of EACs being able to acquire and develop language while learning to use aided AAC (Q4.1.e), there was 
almost complete agreement (96/95.0\%) that this outcome is possible, as evidenced by the number of selections of Agree through Strongly Agree, with no SLPs indicating any level of disagreement.

Table 65

Likelihood of EACs Being Able to Acquire and Develop Language While Learning to use Aided AAC

\begin{tabular}{lrrr}
\hline Descriptor & Frequency & Percent & Valid Percent \\
\hline Do Not Agree At All & 0 & 0 & 0 \\
Only Slightly Agree & 1 & 1.0 & 1.0 \\
Somewhat Agree & 4 & 3.9 & 4.0 \\
Agree & 39 & 38.2 & 38.6 \\
Strongly Agree & 57 & 55.9 & 56.4 \\
Total & 101 & 99.0 & 100.0 \\
Missing & 1 & 1.0 & \\
\hline
\end{tabular}

Assessment and intervention. Analysis of beliefs with respect to assessment and intervention involved multiple questions and multiple statistical tests. An initial approach to the sub-Questions of 4.1 and 5.1 involved testing for scale reliability. Results to this test revealed an insufficient level of Cronbach's Alpha (Urdan, 2010). As such, Questions 4.1 and 5.1 were analyzed with the use of frequency tables.

Language development hierarchies. When asked about their belief that language development hierarchies (e.g., stages of language development) are important components of intervention with EACs (Q4.1.b), 74 SLPs (73.3\%) reported a level of agreement of Agree through Strongly Agree, with no SLPs indicating Do Not Agree at All. These results are demonstrated in Table 66. 
Table 66

Belief that Language Development Hierarchies are an Important Component of Intervention with EACs

\begin{tabular}{lrrr}
\hline Descriptor & Frequency & Percent & Valid Percent \\
\hline Do Not Agree At All & 0 & 0 & 0 \\
Only Slightly Agree & 5 & 4.9 & 5.0 \\
Somewhat Agree & 22 & 21.6 & 21.8 \\
Agree & 46 & 45.1 & 45.5 \\
Strongly Agree & 28 & 27.5 & 27.7 \\
Total & 101 & 99.0 & 100.0 \\
Missing & 1 & 1.0 & \\
\hline
\end{tabular}

When asked about their belief that language development hierarchies (e.g., stages of language development) are important components of intervention with emerging oral communicators (Q5.1.b), 83 participants (100.0\%) reported a level of agreement of Agree through Strongly Agree, with no participants indicating any level of disagreement. The results are demonstrated in Table 67.

Table 67

Belief that Language Development Hierarchies are an Important Component of Intervention with Emerging Oral Communicators

\begin{tabular}{lrrr}
\hline Descriptor & Frequency & Percent & Valid Percent \\
& & & 0 \\
\hline Do Not Agree At All & 0 & 0 & 0 \\
Only Slightly Agree & 0 & 0 & 8.8 \\
Somewhat Agree & 8 & 7.8 & 68.1 \\
Agree & 62 & 60.8 & 23.1 \\
Strongly Agree & 21 & 20.6 & 100.0 \\
Total & 91 & 89.2 & \\
Missing & 11 & 10.8 & \\
\hline
\end{tabular}

Criterion-referenced norms. When asked about their belief that it is important to consider criterion-referenced norms (e.g., mean length of utterance [MLU], Brown's Stages) when analyzing the language acquisition and development of EACs (Q4.1.c), a 
majority of participants, (46/45.5\%), reported a level of agreement of Agree or Strongly Agree, with 7 (6.9\%) participants indicating Do Not Agree at All. These results are demonstrated in Table 68.

Table 68

Belief in the Importance of Considering Criterion-Referenced Norms when Analyzing the Language Acquisition and Development of EACs

\begin{tabular}{lrrr}
\hline Descriptor & Frequency & Percent & Valid Percent \\
\hline Do Not Agree At All & 7 & 6.9 & 6.9 \\
Only Slightly Agree & 24 & 23.5 & 23.8 \\
Somewhat Agree & 24 & 23.5 & 23.8 \\
Agree & 36 & 35.3 & 35.6 \\
Strongly Agree & 10 & 9.8 & 9.9 \\
Total & 101 & 99.0 & 100.0 \\
Missing & 1 & 1.0 & \\
\hline
\end{tabular}

When asked about their belief that it is important to consider criterion-referenced norms (e.g., MLU, Brown's Stages) when analyzing the language acquisition and development of emerging oral communicators (Q5.1.c), 73 SLPs (79.3\%) reported a level of agreement of Agree or Strongly Agree, with no participants indicating Do Not Agree at All. These results are demonstrated in Table 69.

Table 69

Belief in the Importance of Considering Criterion-Referenced Norms when Analyzing the Language Acquisition and Development of Emerging Oral Communicators

\begin{tabular}{lrrr}
\hline Descriptor & Frequency & Percent & Valid Percent \\
& & & 0 \\
\hline Do Not Agree At All & 0 & 0 & 4.3 \\
Only Slightly Agree & 4 & 3.9 & 16.3 \\
Somewhat Agree & 15 & 14.7 & 63.0 \\
Agree & 58 & 56.9 & 16. \\
Strongly Agree & 15 & 14.7 & 100.0 \\
Total & 92 & 90.2 & \\
Missing & 10 & 9.8 & \\
\hline
\end{tabular}


Language samples. When asked about their agreement that it is important to include language samples in assessments with EACs (Q4.1.d), SLPs demonstrated an overall high level of agreement, with 59 (58.4\%) selecting a level of agreement of Agree or Strongly Agree, with 1 SLP selecting Do Not Agree at All (see Table 70 for results).

Table 70

Belief in the Importance of Including a Language Sample in Assessments of EACs

\begin{tabular}{lrrr}
\hline Descriptor & Frequency & Percent & Valid Percent \\
& & & \\
\hline Do Not Agree At All & 1 & 1.0 & 1.0 \\
Only Slightly Agree & 11 & 10.8 & 10.9 \\
Somewhat Agree & 16 & 15.7 & 15.8 \\
Agree & 43 & 42.2 & 42.6 \\
Strongly Agree & 30 & 29.4 & 29.7 \\
Total & 101 & 99 & 100.0 \\
Missing & 1 & 1.0 & \\
\hline
\end{tabular}

When asked about their agreement that it is important to include language samples in assessments with emerging oral communicators (Q5.1.d), participants demonstrated an overall high level of agreement, with 74 (79.5\%) selecting a level of agreement of Agree to Strongly Agree, with no SLPs selecting Do Not Agree at All (see Table 71 for results).

Table 71

Belief in the Importance of Including a Language Sample in Assessments of Emerging Oral Communicators

\begin{tabular}{lrrr}
\hline Descriptor & Frequency & Percent & Valid Percent \\
\hline Do Not Agree At All & 0 & 0 & 0 \\
Only Slightly Agree & 2 & 2.0 & 2.2 \\
Somewhat Agree & 17 & 16.7 & 18.3 \\
Agree & 48 & 47.1 & 51.6 \\
Strongly Agree & 26 & 25.5 & 28.0 \\
Total & 93 & 91.2 & 100.0 \\
Missing & 9 & 8.8 & \\
\hline
\end{tabular}


Summary. When comparing the data with the two populations (i.e, EAC, emerging oral communicators) side by side, a descriptive trend for each construct arises. In each pair, there were greater levels of agreement when the question addressed emerging oral communicators than when the question addressed EACs.

Specifically, for emerging oral communicators and with respect to the importance of including language development hierarchies, $100 \%$ of the responses were categorized as a level of agreement of Agree and Strongly Agree, whereas this same category of agreement was selected by $73.3 \%$ of respondents for EACs.

With respect to the importance of considering criterion-referenced norms when analyzing language acquisition and development for emerging oral communicators, the same level of agreement was expressed by $79.3 \%$ of respondents, whereas this same level of agreement was expressed by $45.5 \%$ of respondents for EACs.

Finally, with respect to the importance of including a language sample in assessments of emerging oral communicators, $79.5 \%$ selected the same level of agreement (Agree to Strongly Agree), whereas 58.4\% of respondents indicated this same level of agreement for EACs.

Although statistically significant differences cannot be determined, the descriptive trend suggests a greater consensus among SLPs that these three constructs are more appropriately applied to emerging oral communicators than to EACs (detailed in Table 72). 
Table 72

Comparison of Descriptive Trends on the Belief in the Importance of the Inclusion of Assessment Constructs

\begin{tabular}{lcr}
\hline Construct & EACs & $\begin{array}{r}\text { Emerging Oral } \\
\text { Communicators }\end{array}$ \\
\hline $\begin{array}{l}\text { Language Development } \\
\text { Hierarchies }\end{array}$ & $73.3 \%$ & $100.0 \%$ \\
Criterion-Referenced & $45.5 \%$ & $79.3 \%$ \\
Norms & & $79.5 \%$ \\
Language Samples & $58.4 \%$ & \\
\hline
\end{tabular}

Perceptions of confidence and qualification. This next section details SLPs' perceived levels of confidence and qualification to work with EACs and emerging oral communicators. These perceived differences are central to the primary questions addressed in this dissertation because of the link between theory and action (Sutton, 2008).

EACs. Question 4.2, with three sub-questions (a,b,c), asked SLPs to indicate their perceived levels of confidence and qualification relating to intervention principles with EACs. These questions were collapsed into a scale, which was determined to have an acceptable level of consistency as determined by a Cronbach's Alpha level of .765 (Urdan, 2010). Results are presented in Table 73.

Table 73

Cronbach's Alpha

\begin{tabular}{ll}
\hline Cronbach's Alpha & Number of Items \\
\hline .765 & 3 \\
\hline
\end{tabular}

Emerging oral communicators. Question 5.2, with three sub-questions (a,b,c), asked participants to indicate their perceived levels of confidence and qualification relating to intervention principles with emerging oral communicators. These questions 
were collapsed into a scale, which was concluded to have a good level of consistency as determined by a Cronbach's Alpha of .857 (Urdan, 2010). Table 74 shows the detailed result.

Table 74

Cronbach's Alpha

\begin{tabular}{ll}
\hline Cronbach's Alpha & Number of Items \\
\hline .857 & 3 \\
\hline
\end{tabular}

Based on these findings for scale reliability, confirmations of assumption were accomplished by checking for outliers and normal distribution. Analysis of boxplots indicated that there were no outliers in the data for EACs; however, there were three outliers more than 1.5 box-lengths from the edge of the box in the boxplot for emerging oral communicators. Inspection of their values did not reveal them to be extreme and they were kept in the analysis. As assessed by Shapiro-Wilk's test for EACs (i.e., $p=$ $.045)$ and emerging oral communicators (i.e., $p=.000$ ), the data were not normally distributed as seen in Table 75 .

Table 75

Results of Test of Normality

\begin{tabular}{|c|c|c|c|c|c|c|}
\hline \multicolumn{7}{|c|}{ Tests of Normality } \\
\hline & \multicolumn{3}{|c|}{ Kolmogorov-Smirnov $^{\mathrm{a}}$} & \multicolumn{3}{|c|}{ Shapiro-Wilk } \\
\hline $\begin{array}{l}\text { EACs } \\
\text { Emerging Oral Communicators }\end{array}$ & $\begin{array}{l}\text { Statistic } \\
.112 \\
.150\end{array}$ & $\begin{array}{l}\text { df } \\
92 \\
92\end{array}$ & $\begin{array}{l}\text { Sig. } \\
.006 \\
.000\end{array}$ & $\begin{array}{l}\text { Statistic } \\
.972 \\
.939\end{array}$ & $\begin{array}{l}\text { df } \\
92 \\
92\end{array}$ & $\begin{array}{l}\text { Sig. } \\
.045 \\
.000\end{array}$ \\
\hline
\end{tabular}

Because paired samples $t$-tests are fairly robust to deviations from normality (Osborn, 2013), it was determined an appropriate course to continue with the test.

Based on the findings of the scale reliability test, a paired samples $t$-test was run to determine whether there was a statistically significant mean difference between SLPs 
perceived levels of confidence and qualification relating to intervention principles for the two populations of EACs and emerging oral communicators. Results demonstrated that perceived levels of confidence and qualification were higher for SLPs with respect to emerging oral communicators (EOCs) $(M=11.7609, S D=2.30322)$ as opposed to EACs $(M=10.1413, S D=2.34676)$, a statistically different mean increase of $1.6196,95 \%$ CI [2.087 to -1.152$],=t(-6.882), p<.001 . d=.72$. Data supporting this statement can be found in Tables 76 and 77.

Table 76

Paired Samples Statistics

\section{Paired Samples Statistics}

\begin{tabular}{ll|llll}
\hline \multirow{3}{*}{ Pair 1 } & & Mean & N & Std. Deviation & St. Error Mean \\
\cline { 3 - 6 } & EACs Totals & 10.1413 & 92 & 2.34676 & .24467 \\
\cline { 2 - 5 } & EOCs Totals & 11.7609 & 92 & 2.30322 & .24013 \\
\hline
\end{tabular}

Table 77

Paired Samples Test

\section{Paired Samples Test}

\begin{tabular}{|c|c|c|c|c|c|c|c|c|c|}
\hline & & & & Paired Di & ferences & & & & \\
\hline & & & & & $\begin{array}{l}95 \% \mathrm{Cc} \\
\text { Interval } \\
\text { Differe }\end{array}$ & $\begin{array}{l}\text { fidence } \\
\text { f the } \\
\text { e }\end{array}$ & & & \\
\hline & & Mean & $\begin{array}{l}\text { Std. } \\
\text { Dev. }\end{array}$ & $\begin{array}{l}\text { St. Error } \\
\text { Mean }\end{array}$ & Lower & Upper & $t$ & $d f$ & $\begin{array}{l}\text { Sig } \\
\text { (2- } \\
\text { tailed) }\end{array}$ \\
\hline Pair 1 & $\begin{array}{l}\text { EACot - } \\
\text { EOCot }\end{array}$ & -1.620 & 2.257 & .234 & -2.087 & -1.152 & -6.88 & 91 & .000 \\
\hline
\end{tabular}




\section{Perceptions of Differences in Practices}

In order to answer Research Question 2, results from the following survey items were compared using multiple statistical measures as specified in each subsection (see Table 78 for comparisons).

Table 78

Comparisons Made for Analysis for Research Question 2

\begin{tabular}{ll}
\hline EACs & Emerging Oral Communicators
\end{tabular}

Q4.3: Indicate the frequency level of your use of specific intervention techniques with the EACs currently on your caseload

Q4.4: Indicate the inclusion of specific assessment practices with the EACs currently on your caseload
Q5.3: Indicate the frequency level of your use of specific intervention techniques with the emerging oral communicators currently on your caseload Q5.4: Indicate the inclusion of specific assessment practices with the emerging oral communicators currently on your caseload

The following sections provide results for each set of questions.

\section{Frequency of Specific Practices}

Questions 4.3 and 5.3 asked participants to indicate the frequency with which they use specific intervention techniques (i.e., recasts, expansions, time delay/slow rate, imitation, explicit/direct instruction), using a 7-point Likert scale ranging from Never to Most of the Time, with an option for I am not familiar with this intervention. See the following sections for detailed discussions of results.

Recasts. When asked about the frequency of use of Recasts to support the development of morphosyntax with EACs (Q4.3), the majority of SLPs (72/72.0\%) reported using this technique of Often to Almost Always. A total of 12 (12\%) SLPs reported never using it or not being familiar with this technique. It is unclear if this lack 
of familiarity is related to the technique itself or use of the technique with EACs (results in Table 79).

Table 79

Frequency of Recast Used in Intervention with EACs

\begin{tabular}{lrrr}
\hline Descriptor & Frequency & Percent & Valid Percent \\
& & & 4.0 \\
\hline Never & 4 & 3.9 & 4.0 \\
Rarely & 4 & 3.9 & 12.0 \\
Sometimes & 12 & 11.8 & 38.0 \\
Often & 38 & 37.3 & 34.0 \\
Almost Always & 34 & 33.3 & 8.0 \\
I am not familiar with this technique & 8 & 7.8 & 100.0 \\
Total & 100 & 98.0 & \\
Missing & 2 & 2.0 & \\
\hline
\end{tabular}

When asked about the frequency of use of Recasts to support the development of morphosyntax with emerging oral communicators (Q5.3), the majority of SLPs (74/81.3\%) reported using this technique of Often or Almost Always. A total of $9(9.8 \%)$ SLPs reported never using it or not being familiar with this technique. It is unclear if this lack of familiarity is related to the technique itself or use of the technique with emerging oral communicators (results seen in Table 80).

Table 80

Frequency of Recast Used in Intervention with Emerging Oral Communicators

\begin{tabular}{lrrr}
\hline Descriptor & Frequency & Percent & Valid Percent \\
\hline Never & 1 & 1.0 & 1.1 \\
Rarely & 2 & 2.0 & 2.2 \\
Sometimes & 6 & 5.9 & 6.6 \\
Often & 29 & 28.4 & 31.9 \\
Almost Always & 45 & 44.1 & 49.5 \\
I am not familiar with this technique & 8 & 7.8 & 8.0 \\
Total & 91 & 89.2 & 100.0 \\
Missing & 11 & 10.8 & \\
\hline
\end{tabular}


Expansions. When asked about the frequency of use of Expansions to support the development of morphosyntax with EACs (Q4.3), the majority of SLPs (85/85.0\%) reported using this technique of Often or Almost Always (see Table 81 for resulting frequencies).

Table 81

Frequency of Expansions Used in Intervention with EACs

\begin{tabular}{lrrr}
\hline Descriptor & Frequency & Percent & Valid Percent \\
\hline Never & 3 & 2.9 & 3.0 \\
Rarely & 0 & 0 & 0 \\
Sometimes & 11 & 10.8 & 11.0 \\
Often & 36 & 35.3 & 36.0 \\
Almost Always & 49 & 48.0 & 49.0 \\
I am not familiar with this technique & 1 & 1.0 & 1.0 \\
Total & 100 & 98.0 & 100.0 \\
Missing & 2 & 2.0 & \\
\hline
\end{tabular}

When asked about the frequency of use of Expansions to support the development of morphosyntax with emerging oral communicators (Q5.3), the majority of SLPs $(85 / 92.4 \%)$ reported using this technique of Often or Almost Always (as seen in Table 82).

Table 82

Frequency of Expansions Used in Intervention with Emerging Oral Communicators

\begin{tabular}{lrrr}
\hline Descriptor & Frequency & Percent & Valid Percent \\
& & & 0 \\
Never & 0 & 1.0 & 1.1 \\
Rarely & 1 & 4.9 & 5.4 \\
Sometimes & 5 & 31.4 & 34.8 \\
Often & 32 & 52.0 & 57.6 \\
Almost Always & 53 & 1.0 & 1.1 \\
I am not familiar with this technique & 1 & 90.2 & 100.0 \\
Total & 92 & 9.8 & \\
Missing & 10 & & \\
\hline
\end{tabular}


Time Delay/Slow Rate. When asked about the frequency of use of Time Delay/Slow Rate to support the development of morphosyntax with EACs (Q4.3), the majority of SLPs (63/63.0\%) reported using this technique of Often or Almost Always. A total of 13 (13\%) SLPs reported never using it or not being familiar with this technique. It is unclear if this lack of familiarity is related to the technique itself or use of the technique with EACs (see Table 83 for results).

Table 83

Frequency of Time Delay/Slow Rate Used in Intervention with EACs

\begin{tabular}{lrrr}
\hline Descriptor & Frequency & Percent & Valid Percent \\
\hline Never & 5 & 4.9 & 5.0 \\
Rarely & 2 & 2.0 & 2.0 \\
Sometimes & 22 & 21.6 & 22.0 \\
Often & 38 & 37.3 & 38.0 \\
Almost Always & 25 & 24.5 & 25.0 \\
I am not familiar with this technique & 8 & 7.8 & 8.0 \\
Total & 100 & 98.0 & 100.0 \\
Missing & 2 & 2.0 & \\
\hline
\end{tabular}

When asked about the frequency of use of Time Delay/Slow Rate to support the development of morphosyntax with emerging oral communicators (Q5.3), the majority of SLPs (70/76.1\%) reported using this technique between Often or Almost Always (see results in Table 84). 
Table 84

Frequency of Time Delay/Slow Rate Used in Intervention with Emerging Oral Communicators

\begin{tabular}{lrrr}
\hline Descriptor & Frequency & Percent & Valid Percent \\
\hline Never & & & 0 \\
Rarely & 0 & 0 & 4.3 \\
Sometimes & 4 & 3.9 & 13.0 \\
Often & 12 & 11.8 & 45.7 \\
Almost Always & 42 & 41.2 & 30.4 \\
I am not familiar with this technique & 28 & 27.5 & 6.5 \\
Total & 6 & 5.9 & 100.0 \\
Missing & 92 & 90.2 & \\
\hline
\end{tabular}

Imitation. When asked about the frequency of use of Imitation to support the development of morphosyntax with EACs (Q4.3), the majority of SLPs (80/80.0\%) reported using this technique either Often or Almost Always (see Table 85 for resulting frequencies).

Table 85

Frequency of Imitation Used in Intervention with EACs

\begin{tabular}{lrrr}
\hline Descriptor & Frequency & Percent & Valid Percent \\
\hline Never & 2 & 2.0 & 2.0 \\
Rarely & 4 & 3.9 & 4.0 \\
Sometimes & 14 & 13.7 & 14.0 \\
Often & 40 & 39.2 & 40.0 \\
Almost Always & 40 & 39.2 & 40 \\
I am not familiar with this technique & 0 & 0 & 0 \\
Total & 100 & 98.0 & 100.0 \\
Missing & 2 & 2.0 & \\
\hline
\end{tabular}

When asked about the frequency of use of Imitation to support the development of morphosyntax with emerging oral communicators (Q5.3), more than three-quarters of SLPs (76/83.5\%) reported using this technique either Often or Almost Always (see Table 86 for results). 
Table 86

Frequency of Imitation Used in Intervention With Emerging Oral Communicators

\begin{tabular}{lrrr}
\hline Descriptor & Frequency & Percent & Valid Percent \\
\hline Never & 1 & 1.0 & 1.1 \\
Rarely & 2 & 2.0 & 2.2 \\
Sometimes & 12 & 11.8 & 13.2 \\
Often & 37 & 36.3 & 40.7 \\
Almost Always & 39 & 38.2 & 42.9 \\
I am not familiar with this technique & 0 & 0 & 0 \\
Total & 91 & 89.2 & 100.0 \\
Missing & 11 & 10.8 & \\
\hline
\end{tabular}

Explicit/Direct instruction. When asked about the frequency of use of Explicit/Direct Instruction to support the development of morphosyntax with EACs (Q4.3), a majority of SLPs (83/83.0\%) reported using this technique either Often or Almost Always (results in Table 87).

Table 87

Frequency of Explicit/Direct Instruction Used in Intervention with EACs

\begin{tabular}{lrrr}
\hline Descriptor & Frequency & Percent & Valid Percent \\
\hline Never & & & 2.0 \\
Rarely & 4 & 3.9 & 4.0 \\
Sometimes & 11 & 10.8 & 11.0 \\
Often & 39 & 38.2 & 39.0 \\
Almost Always & 44 & 43.1 & 44.0 \\
I am not familiar with this technique & 0 & 0 & 0 \\
Total & 100 & 98.0 & 100.0 \\
Missing & 2 & 2.0 & \\
\hline
\end{tabular}

When asked about the frequency of use of Explicit/Direct Instruction to support the development of morphosyntax with emerging oral communicators (Q5.3), the majority of SLPs (79/85.9\%) reported using this technique either Often or Almost Always. (see Table 88). 
Table 88

Frequency of Explicit/Direct Instruction Used in Intervention with Emerging Oral Communicators

\begin{tabular}{lrrr}
\hline Descriptor & Frequency & Percent & Valid Percent \\
\hline Never & 0 & 0 & 0 \\
Rarely & 2 & 2.0 & 2.2 \\
Sometimes & 11 & 10.8 & 12.0 \\
Often & 37 & 36.3 & 40.2 \\
Almost Always & 42 & 41.2 & 45.7 \\
I am not familiar with this technique & 0 & 0 & 0 \\
Total & 92 & 90.2 & 100.0 \\
Missing & 10 & 9.8 & \\
\hline
\end{tabular}

Summary. When comparing the two populations of EACs and emerging oral communicators side by side for each construct (recasts, expansions, time delay/slow rate, imitation), a descriptive trend arises. In each pair, there were greater levels of frequency when the question addressed emerging oral communicators than when the question addressed EACs.

Specifically, for emerging oral communicators, and with respect to the frequency of use of Recasts to support the development of morphosyntax, $81.3 \%$ of the responses were categorized as Often or Almost Always, whereas this same category of frequency was selected by $72.0 \%$ of respondents for EACs.

With respect to the frequency of use of Expansions to support the development of morphosyntax for emerging oral communicators, $92.4 \%$ of the responses were categorized as Often or Almost Always, whereas this same category of frequency was selected by $85.0 \%$ of respondents for EACs.

With respect to the frequency of use of Time Delay/Slow Rate to support the development of morphosyntax for emerging oral communicators, $76.1 \%$ of the responses 
were categorized as Often or Almost Always, whereas this same category of frequency was selected by $63.0 \%$ of respondents for EACs.

With respect to the frequency of use of Imitation to support the development of morphosyntax for emerging oral communicators, $83.5 \%$ of the responses were categorized as Often or Almost Always, whereas this same category of frequency was selected by $80.0 \%$ of respondents for EACs.

And finally, with respect to the frequency of use of Explicit/Direct Instruction to support the development of morphosyntax for emerging oral communicators, $85.9 \%$ of the responses were categorized as Often or Almost Always, whereas this same category of frequency was selected by $83.0 \%$ of respondents for EACs.

Although it cannot be determined if these scores are significantly different statistically, the descriptive trend suggests higher frequency levels of use of these techniques by SLPs to support the development of morphosyntax with emerging oral communicators than with EACs (results in Table 89).

Table 89

Comparison of Descriptive Trends on the Inclusion of Intervention Constructs

\begin{tabular}{lcr}
\hline Technique & EACs & $\begin{array}{r}\text { Emerging Oral } \\
\text { Communicators }\end{array}$ \\
\hline Recasts & $72.0 \%$ & $81.3 \%$ \\
Expansions & $85.0 \%$ & $92.4 \%$ \\
Time Delay/Slow Rate & $63.0 \%$ & $76.1 \%$ \\
Imitation & $80.0 \%$ & $83.5 \%$ \\
Explicit/Direct Instruction & $83.0 \%$ & $85.9 \%$ \\
\hline
\end{tabular}




\section{Assessment Practices}

Participants were asked to identify assessment practices with both EACs and emerging oral communicators (Q4.4 and Q5.4). Frequencies were run for each population and results are discussed in the following sections.

EACs. Analysis of assessment practices was obtained through a series of statements responded to by the participants. As seen in Table 90, in the most recent speech-language assessment conducted by SLPs for an EAC, 55.9\% (57) included a language sample, $48 \%$ (49) analyzed a language sample, and 48\% (49) included a criterion-referenced norm. Further data indicated that $16.7 \%$ (17) of SLPs have not found it necessary to include language samples in their speech-language assessments, and the same number have not conducted a speech-language assessment for EACs.

Table 90

Assessment Practices by SLPs with EACs

\begin{tabular}{|c|c|c|c|}
\hline \multicolumn{4}{|c|}{$\underline{\mathrm{EACs}}$} \\
\hline Assessment Construct & Frequency & Percent & Valid Percent \\
\hline Inclusion of a Language Sample & 57 & 55.9 & 100.0 \\
\hline Missing & 45 & 44.1 & \\
\hline Total & 102 & 100 & \\
\hline Analysis of a Language Sample & 49 & 48.0 & 100.0 \\
\hline Missing & 53 & 52.0 & \\
\hline Total & 102 & 100.0 & \\
\hline Inclusion of a Criterion-Referenced Norm & 49 & 48.0 & 100.0 \\
\hline Missing & 53 & 52.0 & \\
\hline Total & 102 & 100.0 & \\
\hline I have not found it necessary to include & 17 & 16.7 & 100.0 \\
\hline language samples for assessments for EACs & & & \\
\hline Missing & 85 & 83.3 & \\
\hline Total & 102 & 100 & \\
\hline I have not conducted a speech-language & 17 & 16.7 & 100.0 \\
\hline assessment for an EAC & & & \\
\hline Missing & 85 & 83.3 & \\
\hline Total & 102 & 100.0 & \\
\hline
\end{tabular}


Emerging oral communicators. Analysis of assessment practices was obtained through a series of statements responded to by the participants. As seen in Table 91, the most recent speech-language assessment conducted by SLPs for an emerging oral communicator, $70.6 \%$ (72) included a language sample, $62.7 \%$ (64) analyzed a language sample, and $70.6 \%$ (72) included a criterion-referenced norm. Further data indicated that $6.9 \%$ (7) of SLPs have not found it necessary to include language samples in their assessments and 3.9\% (4) have not conducted a speech-language assessment for emerging oral communicators.

Table 91

Assessment Practices by SLPs with Emerging Oral Communicators

\begin{tabular}{|c|c|c|c|}
\hline \multicolumn{4}{|c|}{ Emerging Oral Communicators } \\
\hline Construct & Frequency & Percent & Valid Percent \\
\hline Inclusion of a Language Sample & 72 & 70.6 & 100 \\
\hline Missing & 30 & 29.4 & \\
\hline Total & 102 & & \\
\hline Analysis of a Language Sample & 64 & 62.7 & 100 \\
\hline Missing & 38 & 37.3 & \\
\hline Total & 102 & 100.0 & \\
\hline Inclusion of a Criterion-Referenced Norm & 72 & 70.6 & 100.0 \\
\hline Missing & 30 & 29.4 & \\
\hline Total & 102 & 100.0 & \\
\hline $\begin{array}{l}\text { I have not found it necessary to include } \\
\text { language samples for assessments for emerging } \\
\text { oral communicators }\end{array}$ & 7 & 6.9 & 100 \\
\hline Missing & 95 & 93.1 & \\
\hline Total & 102 & 100.0 & \\
\hline $\begin{array}{l}\text { I have not conducted a speech-language } \\
\text { assessment for an emerging oral communicator }\end{array}$ & 4 & 3.9 & 100.0 \\
\hline Missing & 98 & 96.1 & \\
\hline Total & 102 & 100.0 & \\
\hline
\end{tabular}


Summary. For the first three constructs (e.g., inclusion of a language sample, analysis of a language sample, inclusion of a criterion-referenced norm), when comparing the populations of EACs and emerging oral communicators, a descriptive trend arises as seen in Table 91. In each pair, there appear to be more SLPs who include the specified constructs in their assessments of speech and language, as recommended by ASHA (n.d.a.), for emerging oral communicators than for EACs.

Specifically, with respect to the inclusion of language samples in speech-language assessments, $70.6 \%$ of the participants do so with emerging oral communicators, whereas 55.9\% do so with EACs. With respect to the analysis of language samples in their speech-language assessments, $62.7 \%$ do so with emerging oral communicators, whereas $48 \%$ of SLPs do so with EACs. Continuing, with respect to the inclusion of a criterionreferenced norm in their speech-language assessments, $70.6 \%$ do so with emerging oral communicators, whereas $55.9 \%$ of SLPs do so with EACs.

The fourth construct involved SLPs' opinions about the necessity of including language samples for the two populations. As seen in Table 92, SLPs are more likely to make this determination with EACs (16.7\%) than with emerging oral communicators (6.9\%). The fifth construct reflected SLPs' statements that they have not conducted speech-language assessments for the two populations, regardless of the stated authority to do so by ASHA (ASHA, 2016c). As seen in Table 92, 3.9\% of SLPs have not conducted a speech-language assessment for emerging oral communicators, whereas $16.7 \%$ have not conducted a speech-language assessment for EACs. 
Table 92

Comparison of Descriptive Trends on the Inclusion of Assessment Constructs

\begin{tabular}{lrr}
\hline Construct & EACs & $\begin{array}{r}\text { Emerging Oral } \\
\text { Communicators }\end{array}$ \\
\hline Inclusion of Language Sample & $55.9 \%$ & $70.6 \%$ \\
Analysis of Language Sample & $48.0 \%$ & $62.7 \%$ \\
Inclusion of Criterion-Referenced Norm & $48.0 \%$ & $70.6 \%$ \\
\hline I have not found it necessary to include & & $6.9 \%$ \\
language samples for assessments for the & & \\
population & $16.7 \%$ & $3.9 \%$ \\
$\begin{array}{l}\text { I have not conducted a speech-language } \\
\text { assessment for the population }\end{array}$ & $16.7 \%$ & \\
\hline
\end{tabular}

\section{Narrative Response}

Upon completion of the structured questions in the survey, SLPs were asked to share their perspective on the high frequency of atypical word order and reduced phrase length in the language of EACs (Q7.1) in a short narrative response. A total of 61 (59.8\%) SLPs responded to this question and the individual responses can be found in Appendix D. In this Appendix, responses were transferred from SPSS (V. 25) to the table without any corrections for spelling or syntax.

Analysis of the 61 narrative responses included an in-depth reading of each response, identifying recurring concepts, establishing broader themes, collapsing those broader themes into subthemes, and selecting representative responses to support the validity of the themes (Creswell, 2014). A total of five major themes were identified (i.e., Environment, Expectations, Constraints, SLPs, Language), with 11 corresponding subthemes. Each theme, subtheme, and specific exemplars can be found in Table 93 through 97. 
Table 93

Environment-Related Factors

Theme: Environment-Related Factors

\begin{tabular}{llr}
\hline Subtheme & Exemplar & $\begin{array}{c}\text { Exemplar } \\
\text { Number }\end{array}$ \\
\hline Models of Language & $\begin{array}{l}\text { I believe that the productions of students using } \\
\text { aided AAC devices are largely a result of the } \\
\text { modeling or lack of modeling provided to the } \\
\text { student. }\end{array}$ & 12 \\
& $\begin{array}{l}\text { The children must also see consistent modeling of } \\
\text { using their AAC so that they can improve their } \\
\text { understanding and context of using longer phrases. }\end{array}$ \\
& $\begin{array}{l}\text { Telegraphic speech is often modeled for the student } \\
\text { at home and in the classroom }\end{array}$ \\
& $\begin{array}{l}\text { Emerging aided communicators benefit from } \\
\text { language models from adults around them and } \\
\text { direct/explicit instruction of syntax/word order. }\end{array}$ \\
& $\begin{array}{l}\text { Causes are multifactorial and include: lack of } \\
\text { language models, cognitive deficits, motor planning } \\
\text { deficits, consistency. }\end{array}$ \\
Consistency Across \\
Communicative \\
Contexts
\end{tabular}


Table 94

Expectation Related Factors

Theme: Expectation-Related Factors

\begin{tabular}{|c|c|c|}
\hline Subtheme & Exemplar & $\begin{array}{l}\text { Exemplar } \\
\text { Number }\end{array}$ \\
\hline \multirow[t]{2}{*}{$\begin{array}{l}\text { Emphasis of Language } \\
\text { Content over } \\
\text { Language Form }\end{array}$} & $\begin{array}{l}\text { For my students who use AAC, I find it more } \\
\text { important for them to have the ability to get a } \\
\text { message out at all, regardless of grammatical forms. }\end{array}$ & 13 \\
\hline & $\begin{array}{l}\text { I have found that the content of the message is more } \\
\text { important than incorrect word order or reduced } \\
\text { phrase length. As long as the message is expressed } \\
\text { and conveyed, the intent is known and met. }\end{array}$ & 6 \\
\hline \multirow[t]{2}{*}{$\begin{array}{l}\text { Emphasis of } \\
\text { Functional } \\
\text { Communication over } \\
\text { Language } \\
\text { Development }\end{array}$} & $\begin{array}{l}\text { It is my perspective that the main purpose of using } \\
\text { AAC devices/systems for young students (or } \\
\text { emerging communicators) who have severe speech- } \\
\text { language needs is for functional communication. }\end{array}$ & 49 \\
\hline & $\begin{array}{l}\text { I am most concerned with the functionality of the } \\
\text { communication. }\end{array}$ & 60 \\
\hline \multirow[t]{2}{*}{ Reduced Expectations } & $\begin{array}{l}\text { For convenience and efficiency, reduced phrase } \\
\text { length is common and acceptable. }\end{array}$ & 6 \\
\hline & $\begin{array}{l}\text { To me, atypical word order is not as important as a } \\
\text { listener/communication partner being able to } \\
\text { understand the overall message. }\end{array}$ & 36 \\
\hline
\end{tabular}


Table 95

Constraints-Related Factors

Theme: Constraints-Related Factors

\begin{tabular}{llr}
\hline Subtheme & Exemplar & $\begin{array}{r}\text { Exemplar } \\
\text { Number }\end{array}$ \\
\hline $\begin{array}{l}\text { Extrinsic Constraints } \\
\text { of AAC system }\end{array}$ & $\begin{array}{l}\text { Depending on the device or app if using high tech } \\
\text { AAC, there are certain limitations in editing and } \\
\text { selection of icons and order. }\end{array}$ & 6 \\
& $\begin{array}{l}\text { I think that navigating devices pose a problem with } \\
\text { morphological markers. }\end{array}$ \\
& $\begin{array}{l}\text { I do think that reduced phrase length can be } \\
\text { dependent on the AAC systems we create for these } \\
\text { children. }\end{array}$ \\
\cline { 2 - 3 } Intrinsic Constraints of & $\begin{array}{l}\text { The increased time and effort it takes to generate } \\
\text { language through AAC. When motoric demands are } \\
\text { high, linguistic output is low. }\end{array}$ \\
& $\begin{array}{l}\text { Imitation skills - social, motor, and verbal - are } \\
\text { frequently impaired. Their comprehension of time } \\
\text { is often restricted to the "here and now." }\end{array}$ \\
& $\begin{array}{l}\text { The biggest problem I see with my student's } \\
\text { abilities to use AAC to communicate is their } \\
\text { personal motivation. }\end{array}$ \\
& 13 \\
\hline
\end{tabular}


Table 96

SLP-Related Factors

Theme: SLP-Related Factors

\begin{tabular}{|c|c|c|}
\hline Subtheme & Exemplar & $\begin{array}{l}\text { Exemplar } \\
\text { Number }\end{array}$ \\
\hline \multirow[t]{5}{*}{ SLP Beliefs } & $\begin{array}{l}\text { I believe that often people only expect children who } \\
\text { use AAC devices/systems to use the content words } \\
\text { and they don't expect them to use appropriate word } \\
\text { order or an expanded utterance beyond just their } \\
\text { basic wants and needs. }\end{array}$ & 30 \\
\hline & $\begin{array}{l}\text { Due to the nature of the disorder, many children are } \\
\text { not interested in communicating beyond requesting. } \\
\text { They want their needs and wants met first. }\end{array}$ & 32 \\
\hline & $\begin{array}{l}\text { I find that adults tend to simplify their language } \\
\text { when speaking to these students, likely because of } \\
\text { the limited comprehension skills that these children } \\
\text { have. }\end{array}$ & 44 \\
\hline & $\begin{array}{l}\text { I consider word order and phrase length to be } \\
\text { comparable with a student's developmental level. }\end{array}$ & 57 \\
\hline & $\begin{array}{l}\text { I teach functional multi modality communication. I } \\
\text { feel functional communication should be in place } \\
\text { before working on word order and phrase length. }\end{array}$ & 18 \\
\hline \multirow[t]{2}{*}{ SLP Practices } & $\begin{array}{l}\text { I also think sometimes SLP's don't do a good job } \\
\text { varying the language/allowing for one word } \\
\text { responses. }\end{array}$ & 8 \\
\hline & $\begin{array}{l}\text { Another important factor is the intervention being } \\
\text { utilized by the SLP. It is critical that SLPs go } \\
\text { beyond teaching these children how to request. } \\
\text { SLPs need to provide solid, evidence-based, } \\
\text { language intervention. }\end{array}$ & 20 \\
\hline
\end{tabular}


Table 97

Language-Related Factors

Language-Related Factors

\begin{tabular}{|c|c|c|}
\hline Subtheme & Exemplar & $\begin{array}{r}\text { Exemplar } \\
\text { Number }\end{array}$ \\
\hline \multirow[t]{2}{*}{$\begin{array}{l}\text { Language } \\
\text { Development Process }\end{array}$} & $\begin{array}{l}\text { Language learning for emerging aided } \\
\text { communicators is a slow process. Teaching these } \\
\text { students their first } 50 \text { core words is so important } \\
\text { and may take years depending on the rate of } \\
\text { learning. }\end{array}$ & 26 \\
\hline & $\begin{array}{l}\text { I believe that many of the "errors" I encounter in the } \\
\text { language of my AAC users are a stage in } \\
\text { developing competence. }\end{array}$ & 40 \\
\hline \multirow[t]{2}{*}{$\begin{array}{l}\text { Access to Appropriate } \\
\text { Vocabulary }\end{array}$} & $\begin{array}{l}\text { I believe that the word order is dependent on what } \\
\text { vocabulary the child is exposed. The variety and } \\
\text { diversity of the words that the child has also affects } \\
\text { their ability to create phrases. }\end{array}$ & 47 \\
\hline & $\begin{array}{l}\text {..lack of access to vocabulary/morphological } \\
\text { components on the device... }\end{array}$ & 15 \\
\hline \multirow[t]{2}{*}{$\begin{array}{l}\text { Effects of } \\
\text { Bilingualism }\end{array}$} & $\begin{array}{l}\text { In addition, many of my students are dual language } \\
\text { learners and their word order follows Spanish first } \\
\text { and since they have grammatical differences, they } \\
\text { tend to omit function words even more }\end{array}$ & 37 \\
\hline & $\begin{array}{l}\text { A lot of these children live in multicultural families } \\
\text { that either do not speak English (when they get to } \\
\text { school-this is what is spoken to them) or they do } \\
\text { not speak to them at all. }\end{array}$ & 38 \\
\hline
\end{tabular}


In order to determine the frequency with which these themes occurred, each response was read carefully for specific words and partial or full phrases. Analysis revealed that a single narrative response could be categorized in multiple themes, as well as the reverse, where multiple narrative responses could be categorized within a single theme. The frequencies of occurrence for each subtheme are demonstrated in Table 98.

Table 98

Frequencies of Subthemes

\begin{tabular}{lr}
\hline Theme & $\begin{array}{r}\text { Frequency of } \\
\text { Occurrence }\end{array}$ \\
\hline Lack of Language Models & 11 \\
Consistency Across Communicative Contexts & 6 \\
Emphasis of Language Content over Language Form & 10 \\
Emphasis of Functional Communication over Language Development & 9 \\
Reduced Expectations & 14 \\
Extrinsic Constraints of AAC system & 10 \\
Intrinsic Constraints of EAC & 17 \\
SLP Beliefs & 13 \\
SLP Practices & 10 \\
Language Development Process & 9 \\
Access to Appropriate Vocabulary & 6 \\
\hline
\end{tabular}

\section{Summary}

The purpose of this Chapter was to present the results to each question or question set from the special purpose survey designed for this dissertation. As stated in the Introduction, the purpose of this dissertation was to: (1) broaden and sharpen linguistic theory by studying language that develops through alternate modalities and in populations that reside outside of normative frameworks (Goldin-Meadow, 2014; LilloMartin, 1999; Loncke, 2008), (2) increase theoretical and pragmatic knowledge of efficient and efficacious intervention (Treweek \& Zwarenstein, 2009), and (3) drive future research directions for EACs. The results discussed in this chapter provide a solid 
springboard from which approach these goals, and identify factors that may support improved outcomes for EACs. 


\section{CHAPTER V: DISCUSSION}

As reiterated throughout this dissertation, the purpose of this research was to examine the intersection of speech-language pathologists' (SLPs') beliefs, practices, and philosophies and the language acquisition and development of emerging aided communicators (EACs). A further purpose was to identify potential differences in the ways SLPs perceive the two populations of EACs and emerging oral communicators. Toward this end, the following two primary research questions were put forth:

Research Question 1: Do SLPs perceive differences in their beliefs between their practices with emerging oral communicators with language impairments and EACs?

Research Question 1a: If variances do exist, are those variances significant and what is the relationship?

Research Question 2: Do SLPs report differences between their practices with emerging oral communicators with language impairments and EACs?

Research Question 2a: If variances do exist, are those variances significant and what is the relationship?

The process of answering these questions involved the use of survey methodology, with a special purpose survey, as detailed in Chapter III. The survey participants included SLPs working in a public elementary school in the state of California. Responding SLPs were required to have at least one EAC on their caseload for the past two years. Of the 250 surveys started, there were a total of 102 responses determined to be sufficiently robust for analysis. 


\section{Primary Statistical Analysis}

\section{Research Question 1}

As described previously, Question 1 addressed SLP-perceived differences in beliefs about language development, reported levels of agreement about the importance of the inclusion of specific assessment and intervention constructs, and reported levels of confidence and qualification between the two populations of EACs and emerging oral communicators (Q4.1/5.1; Q4.2/5.2).

When the questions are analyzed as a whole, the levels of agreement regarding the likelihood of the acquisition of Standard English syntax and the importance of specific intervention (i.e., recasts, expansions, time delay/slow rate, imitation, explicit/direct instruction) and assessment practices (i.e., language development hierarchies, criterion-referenced norms, language samples) reveal a descriptive trend with greater numbers of SLPs reporting levels of agreement of Strongly Agree and Agree when the question addressed emerging oral communicators than when EACs were the specified population. An example of the results supporting this descriptive trend include $100 \%$ of SLPs selecting these levels of agreement on the importance of the inclusion of language development hierarchies in intervention and assessment with emerging oral communicators, compared to $73 \%$ for EACS, as evidenced in Table 72 .

Analysis of the responses of the questions regarding SLP perceptions of confidence and qualification were completed with a paired samples $t$-test, which revealed statistically significant mean differences, as seen in Tables 76 and 77 . These differences demonstrated that SLPs reported higher levels of confidence and qualification with emerging oral communicators than with EACs. When considered side-by-side, the 
descriptive trend observed regarding the number of SLPs' with the specified agreement levels on the constructs described above, and the statistically significant mean differences demonstrated in the responses questions regarding SLPs' reported levels of confidence and qualification suggest that there are discrepancies in SLPs' beliefs regarding the two populations, with greater levels of agreement, confidence, and qualifications demonstrated with emerging oral communicators than with EACs.

\section{Research Question 2}

Research Question 2 addressed perceptions of differences in SLPs' practices with emerging oral communicators and EACs, as measured through questions regarding the frequency of actual use of specific intervention and assessment practices (Q4.3/5.3; Q4.4/5.4). Results of the question responses regarding the frequency of actual use of specific intervention practices (i.e., recasts, expansions, time delay/slow rate, imitation, explicit/direct instruction) revealed a consistent descriptive trend in that SLPs reported higher levels of frequencies (i.e., often, almost always) with emerging oral communicators than with EACs, as seen in Table 89. Examples of this trend can be seen in the number of SLPs who use time delay/slow rate with emerging oral communicators (76.1\%) and EACs (63.0\%).

A similar descriptive trend was demonstrated in the questions addressing the frequency of actual use of specific assessment practices (i.e., inclusion of a language sample, analysis of a language sample, inclusion of a criterion-referenced norm) with emerging oral communicators and EACs. Results demonstrated that there were more SLPs who reported higher levels of frequency (i.e., often, almost always) of actual use of specific constructs (i.e., inclusion of language sample, analysis of language sample, 
inclusion of criterion-referenced norm) in their assessments with emerging oral communicators than with EACs, as seen in Table 91. Examples of these differences are seen in the number of SLPs who reported analyzing a language sample of emerging oral communicators (62.7\%) and EACs (48.0\%). Further, the number of SLPs who reported not finding it necessary to include language sample analysis for emerging oral communicators and EACs, $6.9 \%$ and $16.7 \%$ respectively supports evidence of the descriptive trend.

These descriptive trends observed across all the specified assessment and intervention constructs suggest that there may be contrasts in SLPs' beliefs regarding their practices with the two populations, with greater numbers of SLPs reporting higher levels of frequencies with emerging oral communicators than with EACs. As discussed in Chapter IV, these results could not be determined to be statistically significant, and so conclusions must be interpreted with caution. However, because of the consistency of the differences across all the measured constructs, it appears a prudent course of action would be to establish methods with greater rigor that can examine these constructs further, as posited by Kent-Walsh and Binger (2018).

\section{Links to the Literature}

The survey questions, designed to address the primary research questions, focused on the beliefs and perceptions of SLPs in their work with emerging oral communicators and EACs. This was appropriate based on the importance of internal influences on individuals' intervention theories (Argyris, 1970), evidence suggesting that SLPs are influenced by their beliefs and philosophies (Schlosser \& Raghavendra, 2004), and the large body of literature documenting the reduced linguistic outcomes of EACs 
(Blockberger \& Johnston, 2003; Drager \& Light, 2010; Drager, Light, Speltz, Fallon, \& Jeffries, 2003; Light et al., 2004; Light \& McNaughton, 2012a; Paul, 1997; Smith \& Grove, 2003; Sutton \& Morford, 1998; Sutton, Soto, \& Blockberger, 2002; Sutton, Trudeau, Morford, Rios, \& Poirier, 2010). The lower levels of agreement reported for EACs on the statement about the likelihood of EACs achieving standard English syntax by the end of elementary school corresponds to research demonstrating absent grammar forms, shorter phrases, lack of morphology, and pragmatic word order in the language of EACs (Anderson, 1984; Blockberger \& Johnston, 2003; Bresnan, 2000; Drager et al., 2003; Jourdan, 1991; Light et al., 2004; Plag, 2008; Roberts \& Bresnan, 2008; Sutton \& Morford, 1998; Sutton et al., 2002; Sutton et al., 2010; Tarone, 2013; Winford, 2006).

The results from Research Question 1 may point to lack of SLP knowledge of and experience with AAC assessment (Dietz et al., 2012) and decreased levels of academic preparation and training (Costigan \& Light, 2010; Dietz et al., 2012; Douglas, Light, \& McNaughton, 2012; Kent-Walsh et al., 2008; Kent-Walsh \& Binger, 2009; Ratcliff et al., 2008; Schlosser \& Raghavendra, 2004; Thistle \& Wilkinson, 2015), which have been acknowledged in the literature and are consistent with this dissertation. However, these lower levels of agreement may also suggest that SLPs have developed separate assessment and intervention frameworks for the two populations.

It appears there may be a link between the questions regarding the acquisition of Standard English syntax and SLPs' agreement levels and rates of frequencies about the various assessment and intervention practices with EACs. The information gained through the responses to these questions about language development hierarchies, criterion-referenced norms, and language samples revealed lower levels of agreement and 
frequencies for the EACs on the SLPs' caseloads. While research has validated greater numbers of children with CCNs who show meaningful differences in communicative behaviors (Beukelman \& Mirenda, 2013; Kent-Walsh \& Binger, 2009) when compared to their oral peers, language development hierarchies are not limited to spoken communication. In addition to well-known hierarchies based on oral language such as Brown's Morphemes (Brown, 1973), there are established hierarchies of the many precursive skills that precede spoken language (Bates, Camaioni, \& Volterra, 1975; Bates \& Dick, 2002; L. Bloom \& Beckwith, 1989; Volterr et al., 2005) that can be applied to EACs in a prelinguistic state. These include pre-intentional behaviors, proto-imperatives, gestures, and the combination of gestures and vocalizations. According to multiple researchers and ASHA, evidence-based practices suggest that assessment of and intervention with individuals who use AAC should incorporate all AAC communicative competencies, including linguistic, operational, social, and strategic (ASHA, 2001; 2002; 2005; n.d.a.; n.d.f.; Beukelman \& Mirenda, 2013; Blackstone et al., 2007; Brady et al., 2016; Dietz et al., 2012; Light \&McNaughton, 2014; Light \& McNaughton, 2015; Smith, 2015), regardless of any perceived level of language competency.

Another issue to be discussed here is the difference in the frequency of inclusion of language samples in the assessment of emerging oral communicators and EACs. Language sample analysis has been validated as evidence based and has been defined as "the cornerstone of any clinical assessment protocol" (Evans, 1996, p. 207), which would logically apply to assessment with EACs. As indicated in Chapter II, there remains a crucial need for a corpus of language samples for EACs, and this need extends at the micro and mezzo levels. Language sample analysis for each EAC assists in shaping 
intervention decisions and language sample analysis conducted across a broad corpus assists in identifying the language development process of EACs. This analysis may also help define an adult grammar model and determine what can be called typical versus disordered development for EACs (Kovacs \& Stickney, 2012; Rice \& Wexler, 1996).

An analysis of the results on questions regarding actual use of intervention techniques revealed overall high numbers of SLPs who use the evidence-based techniques (i.e., recasts, expansions, time delay/slow rate, imitation, and explicit/direct instruction). These findings suggest that SLPs are following best practices to support the development of morphosyntax with EACs. This finding may also implicate the established constraints of aided language use by individuals with CCNs (see Table 99).

However, an additional explanation for these results may be found in the syntactic structural analogy between the linguistic patterns observed in EACs and those documented in interlanguages, as seen in Tables 6 and 8. In addition to calling for a reevaluation of the requisite faithfulness between form and meaning (Lilo-Martin, 2016), these results support future research aimed at determining whether the utterances of EACs reported by the SLPs reflect initial states of language development, imperfect learning, insufficient training, universal simplification processes, or universal constraints on predication (Anderson, 1984; Tarone, 2013; Winford, 2006). There is currently no research in the corpus on this topic. 
Table 99

Intrinsic and Extrinsic Constraints of Aided Language Use

Intrinsic Constraints

Constraint Citations

Foundational vocabulary, morphological, Blockberger \& Johnston, 2003; Sutton \& and syntactic grasp of the EAC Morford, 1998

Passivity and low rates of initiation

Kent-Walsh \& McNaughton, 2005

Reduced joint attention, indexicality, object Bates \& Dick, 2002; P. Bloom, 2000 manipulation, and play

Trade-off between effort and outcome in Loncke, 2008 the generation of multi-word phrases

Compromised cognitive, linguistic, motoric, and memory abilities

Beukelman \& Mirenda, 2013; Loncke, 2008

\section{Extrinsic Constraints}

Constraint Citations

AAC system layout

Symbolic representation complexities

Motoric demands of selection methods

AAC layout space limitations
Binger et al., 2011; Light, 1997; Drager \& Light, 2010; Drager et al., 2003; Light et al., 2004; Sutton \& Morford, 1998; Zangari \& Van Tatenhove, 2009

Blockberger \& Johnston, 2003; Light \& McNaughton, 2012a; Light et al., 2004; Sutton et al., 2010

Binger et al., 2011; Light, 1997

ASHA, 2001, 2002, 2004; Boenisch \& Soto, 2015; Behrens, 2006; Blackstone et al., 2007; Blockberger \& Johnston, 2003; Calculator \& Black, 2009; Johnson, Inglebret, Jones, \& Ray, 2006; Light \& McNaughton, 2015; Lund \& Light, 2007; Murray \& Goldbart, 2009; Sutton et al., 2010; Sturm \& Clendon, 2004; Wilkinson \& Hennig, 2009

Note. See reference page for further description. 


\section{Descriptive Results}

Analysis of the Descriptive Results revealed multiple connections to Research Questions 1 and 2. Descriptive results were segmented into the demographics, caseloads, and opinions and beliefs of the SLPs. Questions relevant to the primary research questions will be discussed in the following sections.

\section{SLP Demographics}

Demographic questions relevant to the primary research questions included years in practice, AAC-specific university coursework, and sufficiency of preparation.

Results from the questions concerning SLP years of practice revealed a relatively equal spread across the year span (i.e., 1 to 5, 6 to 10, 11 or more), with a very slight skew toward those with more than 11 years of experience. These data are important in relation to the question regarding the number of SLPs who had taken AAC-specific coursework during their university education. Responses to this question indicate more than half of the participants $(60.8 \%)$ had taken AAC-specific coursework at the graduate level. This figure demonstrates a level of preparation across the majority of participants that meets the ASHA standards for Certificate of Clinical Competence originally published in 2005, and revised in 2014 and 2016.

Although these data suggest an overall confidence in the knowledge and skill of the participants, the results of this question also revealed that almost one-quarter of the participants had taken no AAC-specific coursework at either the undergraduate or graduate level $(23.5 \%)$. This finding indicates that almost one in four SLPs likely began their career without the theoretical underpinnings to support effective clinical practices in 
their work with EACs. These findings are surprising based on ASHA's inclusion of specific knowledge of “...communication modalities (including oral, manual, augmentative, and alternative communication techniques and assistive technologies)" in their academic certification (Standard III-C) since 2005 (personal correspondence, January 20, 2019). What remains unclear is whether the SLPs who received no AACspecific coursework graduated from their program before Standard III-C included knowledge of alternative modalities. If these participants have been practicing for 11 or more years, then this outcome is not unexpected.

When asked their opinion about the sufficiency of their university program's preparation for work with EACs, a compelling majority of SLPs responded that they did not feel sufficiently prepared by their university to work with this population $(71.6 \%)$. When considered alongside the findings on AAC-specific coursework, these data suggest that the AAC-specific coursework taken by over half of the participants was either ineffective or irrelevant to their work with this population. As would be inferred, there is a likely relationship between these demographic findings and the results of Research Questions 1 and 2.

These results provide important feedback about university programs and AACspecific coursework, regardless of ASHA's specified requirements in their Standards and Implementation document (2016). With such a large number of SLPs having reported feeling unprepared to work with EACs across a wide span of years in practice, it appears a prudent course of action for universities to evaluate course content, clinical practicum experience, and instructor qualifications for AAC-specific coursework. This finding aligns with previous research confirming lack of education (ASHA, 2016, 2018; Kent- 
Walsh et al., 2008) as a factor impacting intervention with individuals with CCN who use AAC as discussed in Chapter II.

\section{SLP Caseload Demographics}

Demographics specific to SLP caseloads were gathered through questions regarding: caseload size; number of aided AAC users on their caseload; time spent on AAC-related tasks; AAC access and selection methods; and contexts of aided AAC use. Responses to the question about caseload size revealed that more than half of the SLPs had caseload sizes of 50 or more students (51.0\%). Although the survey did not capture actual caseload size, this descriptor (50 or more) stands in contrast to recommendations by ASHA that caseloads should not exceed 55 students for elementary schools (ASHA, 2018). However, it must be noted that ASHA specifically does not recommend a maximum number for caseloads because of the heterogeneity of children with speechlanguage impairments (ASHA, 2018). This finding regarding the caseload size of the SLPs is worthy of further analysis based on research suggesting a probable relationship between measurable progress on functional goals and caseload size (Schooling, 2003). The issue of caseload size is further linked to the notion of de minimis, which was the focus of the Supreme Court decision on Endrew v. Douglas County (2017). This decision highlighted the necessity of supporting a child's ability to meet challenging goals, rather than a minimum level of progress, which evinces a clear link to caseload size.

This finding on caseload size is interesting based on the documented increases in the roles and responsibilities of SLPs in the schools over the past decade without any appreciable change in caseload size as identified by ASHA in 2016. These data support a 
paradigm shift in the field of speech-language pathology from caseload to workload (ASHA, n.d.d.). Caseload commonly refers to the number of students served by SLPs, regardless of the type of service or special education eligibility category. The term workload refers to all the duties performed by the SLP, including direct and indirect services, and incorporates a system of weighting by special education eligibility category (ASHA, n.d.e.). Figure 4 presents a detailed representation of the many factors affecting overall workloads of school-based SLPs.

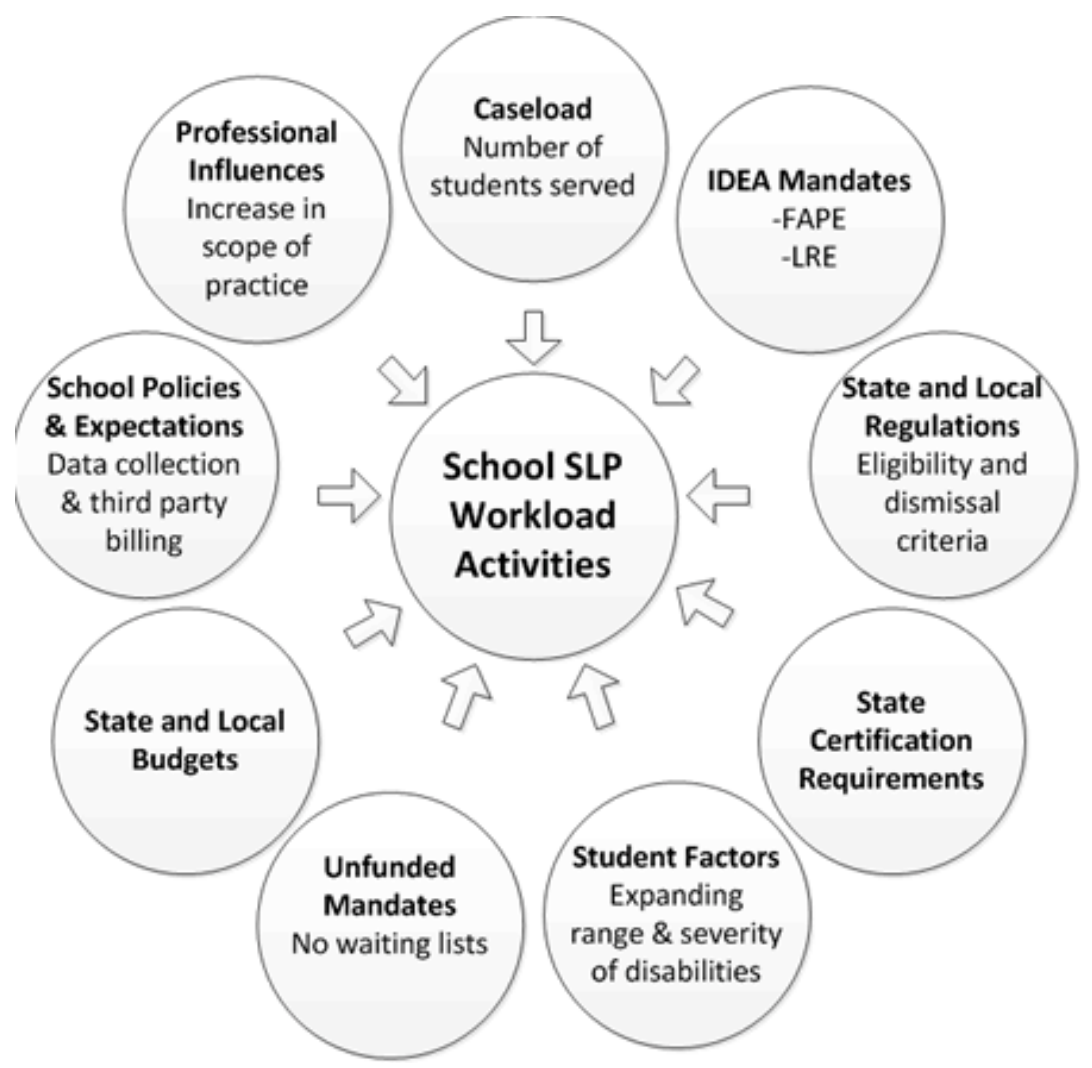

Figure 4. Factors Affecting Workloads of School-Based SLPs (ASHA, n.d.d. para. 3).

Workload also takes into account differences in services based on the individualized needs inherent in specific impairments (Carlin, 2015). While this paradigm shift recognizes that the intensity and frequency of services differ from student to student, the most commonly used calculator to determine weighted workloads does not 
differentiate between students who use oral language and those who use alternative modalities to communicate (Carlin, 2015). This recommendation is validated by research indicating that EACs have to develop understandings of words, identify the relationships between meanings and spoken words, and figure out how these internal meanings interact with their AAC system (Smith, 2015), which must also be mastered simultaneously. Due to the complex nature of aided communication and the multifaceted factors involved in intervention with EACs, it appears a reasonable course of action to include modality differences in the caseload or workload analysis as means of supporting more efficacious intervention and improved outcomes.

An additional survey question defined the number of EACs within this caseload size. The majority of participants reported having between 1 and 4 EACs on their caseloads (52.0\%). This finding is in line with the 2018 ASHA Schools Survey, which reported an average of 4.5 non-verbal children who use AAC on SLPs' caseloads. Within this population of EACs, SLPs were asked to describe the amount of time allocated to specific, AAC-related tasks: direct intervention, high-tech device programming, low-tech material making, and collaboration with AAC stakeholders. The most striking findings were that direct intervention and collaborating with allied professionals or families were the two tasks that the greatest number of SLPs reported spending between 1 and 8 hours on weekly. This finding supports recommendations by ASHA (n.d.b., n.d.g., 2001, 2002, 2005) and other researchers (Bailey et al., 2006; Beukelmen \& Mirenda, 2013; Brady et al., 2016; Calculator, 2009; Douglas et al., 2012; Johnson et al., 2006; Kent-Walsh et al., 2008; Light \& McNaughton, 2012a, 2014; Loncke, 2008; McNaughton et al., 2008; Newton et al., 2007; Parette et al, 2000; Ruppar 
et al., 2011) that intervention including stakeholders, such as teachers, instructional aides, paraprofessionals, and family members, is most efficacious. This finding also suggests that SLPs place a high priority on their direct work with the EACs on their caseloads.

Not far behind these tasks were making low-tech materials and programming high-tech devices. These results can clearly be linked to the earlier discussion of the differentiation between caseload and workload. As can be inferred, there are tasks outside of direct intervention that must be addressed when working with EACs. When looked at as a whole, it can be seen that the nature of intervention with EACs is likely to exceed the intervention-related demands of emerging oral communicators on SLPs' caseloads who require none of these services.

An unexpected outcome observed with respect to AAC-related tasks is that there were participants who responded with the descriptor, None, in each category. One possible contributing factor for these responses may be that the tasks have been delegated to an allied professional, such as an SLPA or a paraprofessional. While all these tasks are within the scope of practice for SLPAs as specified by ASHA (2013, n.d.f.) and No Child Left Behind Act of 2001(PL 107-110; 20 U.S.C. $§ 6319(\mathrm{~g})$ ) (NCLB, 2001), and as described under the description of paraprofessionals by Title I of Elementary and Secondary Education Act (1966), these allied professionals must be supervised directly and indirectly (ASHA, 2013), which again places additional demands on SLPs' time.

In describing the general characteristics of the EACs on SLPs' caseloads, results revealed an approximate parity between low-tech and high-tech aided device use. These data correspond to the descriptions of hours spent weekly on making materials for lowtech devices and programming high-tech devices. Participants also provided descriptions 
of the method of selection for the EACs on their caseloads. The data for this question revealed a greater number of EACs who use direct select than indirect select, which is the ways symbols or messages are accessed by aided AAC communicators (ASHA, n.d.g.). These data are in line with the responses to the question asking the SLPs to identify the special education population with whom they worked. The majority of participants reported working with children in the Mild-to-Moderate (22/22.0\%) and Moderate-toSevere (68/68.0\%) range. Children categorized in these ranges typically posess motoric and perceptual abilities that support their ability to access icons directly with a finger or other body part (ASHA, n.d.g.).

Participants were also asked a series of questions about the contexts of aided AAC use by the EACs on their caseloads. This was a key question in this survey. Regardless of levels of agreement on the primary force in language acquisition and development (i.e., language production versus language comprehension), use of the AAC system is based on childrens' ability to access it. The contexts were presented along a continuum of naturalness, ranging from pull-out and push-in sessions, to classroom and non-classroom-based sessions, both of which occur on the school campus, and to aided AAC use in the home. Examples of non-classroom based contexts include the nurse's office, the library, the lunch tables, and in assemblies. As discussed in Chapter IV, because of the pattern of the responses to these questions, the results may have been skewed by question-stem wording, which included the descriptor on a daily basis. However, an overall analysis of the data revealed an inverse relationship between the naturalness of the setting (i.e., pull-out, push-in, classroom-based, non-classroom based, in the home) and the number of EACs who use their AAC systems in that setting. These 
data lie in juxtaposition to recommendations by researchers (Beukelman \& Mirenda, 2013; Light, 1988) that intervention for individuals with CCNs should support them in their abilities to use communication for the expression of basic wants and needs, information transfer, social closeness, social etiquette, and internal dialogue in natural contexts. Although the full range of communication purposes (Beukelman \& Mirenda, 2013) may be demonstrated in the confines of a structured, pull-out speech-language therapy session, their value is enhanced when targeted in unstructured, natural settings and contexts across communication partners with naturalistic, real-time demands (Blackstone et al., 2007; Light \& McNaughton, 2014).

\section{Specific EAC Demographics}

A series of questions was asked as a means of developing an overall profile of the specific EACs on the SLPs' caseloads at their primary place of employment. As described earlier, SLPs were directed to consider the EAC for whom they had most recently completed an IEP. The questions relevant to the primary research questions included: length of time on the SLP's caseload; grade level of the EAC; primary educational placement; language development level; and level of aided AAC technology. All of which will be discussed in the following section.

The majority of SLPs reported having the specified EAC on their caseload for a full academic year or more (54.9\%). This result is important because this time frame suggests an understanding of the EACs' level of development and knowledge of language use. It is further relevant based on research suggesting that progress gained by EACs can be incremental (Beukelman \& Mirenda, 2013) and can be identified more accurately over time. Results to the question regarding the grade level of the specified EAC revealed an 
interesting pattern. These data revealed an overall inverse relationship between grade level and number of EACs on the SLPs' caseloads. As explained in Chapter IV, 19 SLPs reported having an EAC in $1^{\text {st }}$ grade, while only 6 SLPs reported having an EAC in the $5^{\text {th }}$ grade. These data suggest a disproportionate underrepresentation of EACs in the upper elementary school years.

These data present multiple points of discussion. The first point meriting attention is the increase in the numbers of SLPs reporting having EACs on their caseloads in the first three years of public education (i.e., preschool through $1^{\text {st }}$ grade). This was an expected result based on documented language milestone delays that would theoretically emerge in the early years of children's educational experience. Over time, these delays would contribute to the differentiation between children who demonstrate use of oral language at delayed rates and those will require AAC to support communication and language development (Branson \& Demchak, 2009). The second point to be addressed is the drop in numbers of SLPs reporting EACs on their caseloads between the primary grade and upper grade years. This survey did not contain any questions about reasons for exiting EACs on the SLPs caseloads; however, because of the clear decline in the number of SLPs reporting the presence of EACs on their caseloads over the grade span, it would be highly beneficial to examine this phenomenon.

The next question to be discussed pertains to the primary educational placement. As would be expected, a compelling majority of EACs had primary placement in a special education classroom (74.5\%), which falls in line with the commonly observed motoric, linguistic, cognitive, and perceptual profiles of EACs. However, almost one in five of the specified EACs were described as having their primary educational placement 
in a general education classroom. This finding on placement was particularly striking and may be indicative of a trend toward more inclusive educational practices for students who use AAC (Soto, Müller, Hunt, \& Goetz, 2001). It further implicates the need for AAC-specific training and professional development for general and special education teachers (Soto et al., 2001), and analyses of the opportunity (i.e., policy, practice, facilitator skill/knowledge, attitude) and access (i.e., current communication status) barriers experienced by EACs in the general education setting (Buekelman \& Mirenda, 2013). And finally, this finding supports the premise put forth by Calculator (2009) that inclusive education is more than placement, it is about meaningful contexts where education occurs.

Participants were asked to identify the language development levels of the specified EACs on their caseloads through two questions. The first question involved levels of symbolic understanding based on a hierarchy moving from NonIntentional/Non-Symbolic to Intentional/Non-Symbolic, to Intentional/Symbolic, to Linguistic. This question was an important inclusion to this dissertation as this categorization is highly likely to be a factor that drives assessment and intervention decisions, AAC device complexity, and vocabulary selection. Results demonstrated that a large majority of the SLPs identified their specified EAC as being either Intentional/Symbolic or Linguistic (76.4\%). These data suggest that the SLPs acknowledge that the specified EAC has mastered the prerequisite skills that support the use and comprehension of linguistic symbols. These data further support the results in a series of questions addressing utterance types of these EACs and the frequency with which language sample analysis is used in assessment. These data are also important 
because they may suggest that part of the challenge in working with EACs is finding a way to allow this language to emerge from EACs through this alternative modality.

The participants were asked to select the frequency of specific utterance types that included single icon responses, telegraphic or agrammatical responses, and responses that follow Standard English syntax. These utterances follow a general shift from single to multi-word productions, which parallel typical language acquisition models (Bates, Bretherton, \& Snyder, 1988; Brown, 1973). Results indicated that a majority of EACs were reported to produce a single icon response Often or Almost Always (52.9\%), with a smaller number who produce a telegraphic or agrammatical utterance Often or Almost Always (44.1\%), and a small minority who produce utterances that follow Standard English syntax Often or Almost Always (4\%). An additional perspective on these data can be gained when looking at the numbers of EACs who were reported to produce these utterance types Never or Rarely, which dropped precipitously between Standard English syntax and single-word utterances.

When the population was examined as a whole, findings revealed minimal growth in mean length of utterance (MLU) for EACs from preschool to $5^{\text {th }}$ grade. Results indicate that there is a shift over time from an initial one-word stage into a stage of telegraphic utterances, which may include early and later semantic relations (e.g., agent + action; entity + location; demonstrative + entity) and later semantic relations (e.g., agent + action + object; action + object + locative) (Brown, 1973; Kaderavek, 2015), and early morphosyntax (Kaderavek, 2015). Factors contributing to this relatively static MLU may include endogenous factors discussed in Chapter II, such as the cognitive, motoric, linguistic, or perceptual profiles of the EACs, or exogenous factors, such as reduced 
access to appropriate vocabulary, morphological markers and language models, lack of explicit instruction across the AAC competencies (i.e., operational, linguistic, social, strategic) as identified by Light (1997), or modality asymmetry. However, this static MLU may also be linked to intervention practices and underlying frameworks that may differentiate between the immediate needs of communication or long-term language development (Binger \& Light, 2008).

Results to this question demonstrate an association to the question regarding SLPs' beliefs about the likelihood of EACs developing Standard English syntax by the end of elementary school. Clearly, the specified EACs described in this question have not developed this level of language competency. This question can also be linked to the question addressing SLPs beliefs that EACs can develop language while simultaneously learning the use of aided AAC, on which the majority of SLPs reported either Agree or Strongly Agree (94.1\%). As stated earlier, best practices suggest focusing on the communicative competencies (i.e., linguistic, operational, strategic, social) (Light, 1989) in intervention. This dissertation did not investigate how SLPs divide their intervention time between the four competencies and as such, it is not clear if SLPs were focusing on the development of operational and strategic competencies. However, it is important to note that these four constructs are interrelated and work on one competency supports the further development of the others (Beukelman \& Mirenda, 2013).

These data were examined alongside results regarding number of EACs on SLPs' caseloads, where there was an inverse relationship demonstrated between the number of EACs on SLPs' caseloads and grade levels, and the data on utterance type. This examination revealed that EACs are not attaining fluency in their native language over 
the course of their elementary school experience. Results from this question validate findings indicating that EACs demonstrate language with a forced topic prominence or pragmatic word order, where word order remains communicative rather than linguistic (Jung, 2004). As discussed in Chapter II, it can be inferred that a semantic-syntactic asymmetry can exert a depressive force in further linguistic development. These findings lend credence to the observation discussed in this dissertation, which is that the language observed in EACs can be viewed as an interlanguage rather than a language, which will be discussed in a later section.

Specific intervention practices. The participants were asked to report the frequencies with which they used six evidence-based intervention practices (i.e., recasts, expansions, time delay/slowed rate, imitation, explicit/direct instruction, aided language modeling) with their specified EAC. This question revealed that the majority of SLPs reported using these intervention practices with the specified EACs on their caseloads Often or Almost Always (see Tables 49 through 54). The results on the reported use of recasts, expansions, imitation, and aided language modeling align with the results demonstrating that the majority of SLPs identified their specified EAC as being Intentional/Symbolic or Linguistic. The results on time delay/slowed rate and explicit/direct instruction also fall in line with those findings; however, because these practices can be used across all levels of language development, they would be appropriate practices with the minority of EACs described as being Non-Intentional/NonSymbolic and Intentional/Non-Symbolic.

An interesting finding is seen in the results for all but two of the intervention practices (i.e., explicit/direct instruction, aided language modeling), where there were 
SLPs who selected I am not familiar with this technique. It was unclear if the SLPs intended to convey that they were not familiar with this technique at all or if they were unfamiliar with how to use these techniques with EACs. Regardless of their intent, these responses suggest that additional education and training would be beneficial for SLPs working with this population, as discussed in the question regarding perceived levels of confidence and qualification. A final point to be considered is the link between foundational principles of language development. Although the six intervention techniques are considered valid, evidence-based practices (ASHA, n.d.g.; Fey, Long, \& Finestack, 2003; Proctor-Williams \& Fey, 2007), what remains unknown is whether the underlying principles of the SLPs reflect a linguistic/developmental or functional/immediate needs intervention framework (Binger \& Light, 2008) as discussed in Chapter II.

\section{SLP Beliefs and Opinions}

The next set of questions required the participants to step back from an individual EAC and shift to the group of EACs on their caseloads. This series of questions was used to capture SLPs' opinions about factors impacting language acquisition and development of EACs including: primary influences on language acquisition and development; impediments to language acquisition and development; access to morphology, the influence of communication partners; and factors influencing intervention.

The question regarding primary influences of language acquisition and development targeted the two interrelated constructs of language comprehension and language production. The results indicated that the majority of SLPs reported their

agreement to align with language production (68.3\%) (Loncke, 2008; Sutton, 2008). This 
finding suggests that SLPs recognize the importance of EACs using their devices in expressive communicative contexts in the process of language acquisition, as well as its relevance in continued language development.

When asked to identify four factors that most impede language acquisition and development, the SLPs identified: (1) lack of fidelity across communicative contexts and partners, (2) lack of access to communication opportunities, (3) lack of access to language models, and (4) cognitive demands of AAC system layouts. The first three factors correspond to the SLPs' opinions on the question regarding the perceived importance of language production as a primary force in language acquisition and development (Loncke, 2008; Sutton, 2008). The last factor identified by the SLPs mirrors findings by multiple researchers (Drager \& Light, 2010; Drager, Light, Speltz, Fallon, \& Jeffries, 2003; Light, 1997; Light et al., 2004; Light \& McNaughton, 2012a, 2012b; Light \& McNaughton, 2013; Treviranus, \& Roberts, 2003; Wilkinson \& Hennig, 2009), suggesting that a contributing factor to the reduced linguistic outcomes of EACs is AAC system design (Light \& McNaughton, 2012a). What the identification of this factor does not reveal is whether the cognitive load of the AAC system is truly inappropriate for EACs, or if EACs do not receive sufficient training with sufficient opportunities to master both the device and their native language, especially considering the complex challenges of aided communication (Smith, 2015) and the incremental progress observed in EACs (Beukelman \& Mirenda, 2013). This perceived high level of cognitive demands of the AAC system may be confounded by the concept of competing demands (Smith, 2015; Wallach, 2008; Wallach \& Butler, 1994), which implicate the overall challenges of 
using an alternate modality as a primary method of communication and the necessity of carefully crafted intervention.

A final comment regarding the results from this question relates to the identification of lack of access to language models as an impediment to language acquisition and development. As would be inferred from data demonstrating that the majority of SLPs reported having between one and four EACs on their caseload, it is not surprising that these children do not have access to language models via peers who use aided communication (Cress \& Marvin, 2003; Elder \& Goossens, 1994; Light \& Drager, 2007; Romski \& Sevcik, 2003; Smith, 2015). This is an important issue in light of research identifying modality asymmetry as a factor influencing language acquisition and development (Smith \& Grove, 2003; Sutton et al., 2002). Because of the lack of peers who use aided AAC, language models must be identified and invited by the adults in their environs (e.g., SLPs, teachers, allied professionals, family) through aided language modeling, which was recently validated as an empirically-based intervention in a metaanalysis (O’Neill, Light, \& Pope, 2018).

Participants were also asked to rank the influence of various communication partners on the language acquisition and development of EACs. Results from this question revealed family members as being the most influential, followed by teachers, SLPs, paraprofessionals/educational aides, and peers, respectively. This result validates research recommendations that "because the goals of AAC are value-laden...outcomes for children should be made in the context of the family," (Ryan \& Renzoni, 2015, p. 348 ) and, thus, should reflect priorities of both children and their families (Ryan et al., 2018). This finding supports the use of the Family Impact of Assistive Technology Scale 
for AAC (FIATS-AAC), a measure designed to gather information about the functional effects of AAC interventions with respect to families and children (Delarosa et al., 2012; Ryan \& Renzoni, 2015). In research conducted by Ryan et al. (2018), the use of this measure supported improved functional gains in the use of speech-generating devices and communicative competency. This finding further supports the validity of family advocacy and its focus on the participation of families in the design of service provision (U.S. Department of Health and Human Services, n.d.). A final comment on this finding is its alignment with the World Health Organization (WHO) International Classification Functioning (ICF) framework adapted for children (WHO, 2018). This framework merges the concepts of disability and functionality into a single construct reflecting environmental and personal factors. This demonstrates an evidential link to the technology of AAC and the valuable role of families.

This question also revealed that $S L P S$, with high levels of knowledge of and experience with AAC, were listed behind family members and teachers. While it is clear that family members and teachers spend more time with EACs, these communication partners may or may not have training in AAC (McNaughton et al., 2008). As such, the value of a holistic approach to AAC intervention and training cannot be overstated. When trained in AAC, and with on-going interprofessional collaboration between the SLP and the teacher, as well as paraprofessionals/educational aides, this time differential has the potential to enhance language acquisition and development (ASHA, n.d.i.). A further comment on this ranking is that when identifying families as the primary communication partners supporting language acquisition and development, SLPs may have been referring to the development of communication within the family, where 
multiple modes of communication are likely to be used (Hidecker, 2010), rather than the development of a true linguistic system.

Of note is the juxtaposition of these finding with those of the earlier question regarding factors that most impede language acquisition and development. When placed side-by-side, as seen in Table 100, the data suggest that family members, teachers, and paraeducators/instructional aides would benefit from additional training and education (Norburn, Levin, Morgan, \& Harding, 2016; Rombouts, Maes, \& Zink, 2016).

Table 100

Factors Affecting Language Association and Development

\begin{tabular}{ll}
\hline Impediments to Language Acquisition and & Ranked Order of Communication Partner \\
Development & Influence of Language Acquisition and \\
& Development
\end{tabular}

Lack of fidelity across communicative Family Members

contexts and partners

Lack of access to communication

Teachers

opportunities

Lack of access to language models

SLPs

Cognitive demands of aided AAC system Paraeducators/Educational Aides layouts

Peers

Note. Each of the factors identified as impediments to language acquisition and development correspond to the four partners identified in the previous question.

The next two questions in this section dealt with SLPs' agreement of the importance of access to morphological markers and marked words on aided AAC systems for EACs. On both of these questions, fewer than half of the SLPs reported either Agree or Strongly Agree, with slightly more agreeing with the statement regarding access to marked words than morphological markers. These responses appear to 
contradict the SLPs' opinions indicating that language production is the primary influence on language acquisition and development. As would be expected when examining the process of language acquisition as detailed in the first two chapters, language production is severely limited without access to morphological markers or marked words. This lack of access prevents EACs from incorporating the obligatory markers used by adults in their environs (Bates \& Goodman, 1997; Behrens, 2006), a factor that exacerbates the temporal asymmetry between when EACs become aware of the marking and their ability to do so (Smith, 2017).

Without access to inflectional or derivational morphemes, sentences remain uninflected, which increases the likelihood of topic-prominent language or pragmatic word order and decreases the likelihood of a shift from messages that are communicative in nature to language that is linguistic in nature. This finding suggests that the language patterns observed in EACs may be influenced by the vocabulary and morphological constraints of their AAC device. This issue is particularly relevant as SLPs are most often the professionals who work in concert with EACs and allied stakeholders to select and prioritize specific vocabulary decisions on the aided AAC system (Ryan et al, 2018).

The final two questions in this section addressed factors influencing intervention. With respect to focus, SLPs reported a greater focus on Basic Wants and Needs than on Language Acquisition and Development. When considered alongside the number of SLPs who agree with the importance of access to morphologically marked words and morphological markers, this suggests that SLPs may be focusing of the development of communication rather than a linguistic system. A final comment is that this dissertation did not investigate how SLPs divide their intervention time between the four 
competencies and, as such, it is not clear if SLPs were focusing on the development of operational, social, and strategic competencies. However, it bears restating that these four constructs are interrelated and work on one competency supports the further development of the others (Beukelman \& Mirenda, 2013).

\section{Narrative Response}

Participants were asked to respond to the following question with a narrative response: As an SLP who works with children who use aided AAC devices/systems, your opinions have a deep and unique value to the world of research. Because of your experience with the language acquisition and development of emerging aided communicators, please describe your perspective on the high frequency of atypical word order and reduced phrase length in the language produced by these children.

A total of 61 SLPs provided an answer. After coding and analysis, the responses were collapsed into five major themes and 11 subthemes, as seen in Tables 93 through 97. For purposes of this discussion, narrative responses specifically relating to the primary research questions will be discussed. Please note that the comments were taken directly from the survey and not corrected for spelling and grammar.

The major themes that emerged in the narrative responses included factors relating to: (a) environment, (b) expectations, (c) constraints, (d) SLP beliefs and practices, and (e) language. Although these categories are distinct, it was very clear that the boundaries between each are very permeable and many of the items categorized into one subtheme were often closely associated with another. The responses with explicit reference to differences between emerging oral communicator and EACs were 
represented across the five major themes. These associations were not unexpected as the participants would obviously been influenced by the process of the survey, but they appear to validate an uncertainty in the field about the linguistic outcomes of EACs.

The first theme to emerge from the narrative responses was Environment-Related Factors, as seen in the following statement:

One of the barriers I run up against most often is lack of use of the AAC device when the child is outside of a speech therapy session. The AAC user is given a fraction of the communication opportunities that verbal children are given and I believe that is often reflected in their ability to generate appropriate word order/appropriate phrase length. I also think that many educators and parents view devices as a quick miracle fix (if I had a dollar for every time a parent demanded an iPad..) and don't understand that aided communicators need to learn language on their device or program the same way that children learn oral language. It takes time and modeling, and I believe there's a general lack of understanding of how children learn to communicate using AAC. Education on the topic is often refuted or ignored by educators and parents. (Comment 4)

This theme was echoed in another comment, "Typical developing children practice a variety of grammatical structures throughout the day, all day, every day, with peers and adults, at school and home" (Comment 34). In these comments, the SLPs identify language modeling and communicative interaction as possible reasons for the atypical syntax seen in EACs. These comments are particularly insightful based on a recent metaanalysis validating language modeling as a valid evidence-based intervention ( $\mathrm{O}^{\prime} \mathrm{Neil}$ et al., 2018). This is also insightful based on well-known language development theories 
indicating that children learn to speak the language spoken to and around them (Bates \& Goodman, 1997; Behrens, 2006). With the established link between ambient language and aided language modeling, it is not surprising that this was a factor identified in the atypical syntax observed in EACs.

Within the theme of Expectation-Related Factors, one participant observed the following:

It seems difficult to make the jump between single words and teo word phrases, then again the jump to multiple word ohrases and then again to integrating grammatical morphemes. It's almost as if a kiddo using aac is up against a much lower expectation. It seems people only ever expect single words (even in classrooms where aac systems are always out and encouraged or they want full lengthy sentences the moment the child receives aac. They have trouble gradually expecting more. (Comment 33)

This response is interesting because it identifies expectations that are both too low and too high. Although this response does not specifically identify SLPs as being part of the expectations, it validates the relevance of expectations in work with EACs. A second response that reflects this theme follows:

I believe part of the issue is that these emerging aided communicators are not spoken to with the same frequency or in the same manner as emerging oral communicators. So much time and energy is consumed focusing on behavior, compliance, and fulfilling basic needs that they do not receive the same models (either oral or with AAC) as emerging oral communicators. (Comment 61) 
What is notable here is the explicit link between language and behavior. However, equally notable is that this SLP does not differentiate between the maladaptive behaviors observed in EACs and emerging oral communicators.

Within the theme of Constraints-Related Factors, one comment put forth by a participant was, "Most students respond using less words than an oral communicator as it takes more time and effort to communicate their wants/needs" (Comment 19). This comment validates research on AAC devices suggesting that navigation and use are formidable issues in aided language (Light \& McNaughton, 2012a; Treviranus \& Roberts, 2003). Another comment included under this theme reflects intrinsic constraints, as follows:

The students I work with primarily have autism. Children with autism (particularly mod-severe) tend to rely on visuals to support their language acquisition that are not consistently available across all environments (home included). Imitation skills - social, motor, and verbal - are frequently impaired. Their comprehension of time is often restricted to the "here and now." Given these considerations and their impact on "typical" language development, students with mod-severe autism who use oral communication also often use atypical word order and reduced phrase length. I cannot speak for other populations, but the unique way that a student with autism processes language and produces it is often reflected in the use of AAC. (Comment 27)

This comment is noteworthy because Autism was the most frequently selected special education eligibility category (40.0\%) by the SLPs. As with the comment about extrinsic constraints, this response validates the language acquisition challenges faced by EACs. 
However, research has not demonstrated that these constraints validate the reduced linguistic outcomes for EACs. As discussed at length in Chapter II, the large body of evidence regarding language acquisition and development in special cases supports continued efforts to suss out the nuanced factors involved in this process.

With respect to $S L P$-related factors, the following comment deftly captures the influence of beliefs on practices:

I definitely notice that these students frequently use telegraphic speech, which results in shorter phrase length. Since language acquisition and use doesn't come "naturally" to these students, I always assume as they learn language, they find more use for the content words as they more clearly represent items to be discussed. Function words, on the hand, are less "visible" to them and thus less important to them (or so it seems to me). (Comment 4)

The use of the term naturally demonstrates a compelling differentiation in the way this SLP regards the two populations. This response calls into question how SLPs view not just language acquisition, but how they view the cognition involved in symbolic representation and manipulation.

Of further relevance is the perceived importance of content versus function words. This perspective may inadvertently support the production the parataxis observed in EACs, where words and phrases are unmarked (Holm, 1988; Jourdan, 1991; Winford, 2006). As stated earlier, the conveyance of intent without productive syntax forces the item-based mapping of content onto form, which parallels the linguistic structures of interlanguages (MacWhinney, 2005; Mayberry \& Lock, 2003). 
The theme of Language-Related Factors was revealed in the following comment about errors:

I believe that many of the "errors" I encounter in the language of my AAC users are a stage in developing competence. Many children acquiring oral communication "play" with their words, produce incorrect syntax and we respond to the message, expand, recast and teach the correct syntax. I believe that we must apply the same principle to the aided students. We must respond and reinforce the attempts to use language rather than over correct the form. (Comment 40)

This comment supports the suggested theory that the language of EACs may develop with a previously undefined hierarchy that varies from spoken English. It further supports the evidence that the language of EACs develops incrementally (Beukelman \& Mirenda, 2013). The narrative responses provided by the SLPs supported the findings of this dissertation and served to support this topic as an area worthy of future research.

\section{Limitations of the Study}

The limitations of this dissertation include the use of a special purpose survey that was not tested for validity and reliability, captured data taken at a single point in time, and was distributed to a convenience sample (Coughlin et al., 2009; Dillman et al., 2014; Fowler, 2014). As the presence of EACs on the participants' caseloads was a requirement for inclusion in this study, the sample may have been skewed toward SLPs with specific interest and expertise in augmentative and alternative communication (AAC) and may not represent the population of SLPs in public elementary schools in California as a whole. Further, when considering the number of surveys started versus the number of surveys completed, there may have been SLPs who met the requirements 
of the survey and whose opinions would have been informative, but exited the survey due to survey fatigue (Dillman et al., 2014). These characteristics limit the generalizability of the study.

Participants may also have felt the need to tailor their answers based on their perceived interpretation of the survey intent, thereby introducing the potential for the Hawthorne Effect (McCambridge, Witton, \& Elbourne, 2014). As such, it is unclear whether the participants' responses accurately reflected their practices or beliefs.

However, the use of anonymity and self-administration of the survey may have mitigated the likelihood of this bias. An additional limitation is the potential for participants to misunderstand questions. Attempts at attenuating this limitation were addressed in the multi-step process of survey development as detailed in Chapter III. A final comment regarding study limitations relates to asking the participants to reflect on their entire caseload, the subset of EACs, and a specific EAC. As such, the data are based on the participants' recall, which may limit the accuracy of their responses. Because of these factors, caution must be exercised when interpreting the data discussed herein.

\section{Future Research Directions}

As with all good inquiry, this dissertation has assisted in identifying opportunities for future research. One area that will be pursued is the relationship between specific SLP characteristics, such as years in practice, AAC-specific course work at both levels of education, caseload size, school SES, and specific responses to questions. This analysis may reveal correlations among factors that inform future policies, effective intervention, and clinical decision-making. 
Of particular importance is research examining factors involved in the decrease in the number of EACs on SLPs' caseloads over the course of the elementary school years. This survey did not contain any questions about reasons for exiting EACs on the SLPs caseloads; however, because of the clear decline in the number of SLPs reporting the presence of EACs on their caseloads over the grade span, it would be highly beneficial to examine this phenomenon. This research should consider: (a) specific recommendations by ASHA regarding the Participation Gap (Beukelman \& Mirenda, 2013); (b) zeroexclusion policies that align with the National Joint Committee (NJC) for the Communication Needs of Persons with Severe Disabilities (Brady et al., 2016, NJC, 1992); (c) the Participation Model (Beukelman \& Mirenda, 2013); (d) the WHO-ICF Framework for children (WHO, 2018); and (e) discrepancies between communication abilities and communication needs. Research on this topic would be well augmented with the use of a Disabilities Studies paradigm, which calls into question the hierarchical relations employed in exclusion (Reid \& Knight, 2006). It further supports a move away from the medical model of disability, where a specified impairment is viewed as a defect or failure that is inherently pathological and abnormal (Goodley, 2011). This shift away from the medical model supports analysis of the relational factors affecting policies, accessibility to services, and broad systemic changes (Goodley, 2011), all of which are clearly linked to the inclusion of EACs on the caseloads of SLPs.

This line of research demonstrates a clear link to the caseload versus workload issue. Because of the inherent link between the increased demands on SLPs over the past decade and the documented additional intervention work associated with EACs, this area of research becomes a call to action on the part of SLPs to advocate for themselves as a 
means of providing improved clinical practices not just for the EACs on their caseloads, but for all the children with whom they work. Additional areas of recommended future research include analyzing initial and triennial speech-language assessment reports, reviewing actual IEP goals for EACs, and gaining access to the actual vocabularies available to EACs.

A final area of research is further identifying parallels with alternative linguistic constructs, such as interlanguages and pidgins. With greater access to language samples and triennial speech-language assessment reports, these parallels may be drawn more definitively. In addition to calling for a re-evaluation of the requisite faithfulness between form and meaning (Lilo-Martin, 2016), future research should attempt to determine whether language reported by the SLPs reflects initial states of language development, imperfect learning, insufficient training, universal simplification processes, or universal constraints on predication (Anderson, 1984; Tarone, 2013; Winford, 2006). This may lead to new insight into alternate syntactic structural definitions for an alternative modality that may be more closely aligned with linguistic structures such as signed languages (Henner, Nobogrodsky, Caldwell-Harris, \& Hoffmeister, 2019).

\section{Recommendations}

The findings revealed in this dissertation lend credence to the following recommendations. The first is for universities to examine policies on the required qualifications for professors or instructors in AAC-specific coursework and whether AAC-specific coursework should be offered at the undergraduate or graduate level or at both levels. This is a theme that has been discussed over time by multiple researchers and has not resulted in appreciable changes to the participants of this dissertation. It may 
be beneficial for universities to further consider infusing aspects of AAC into other required courses, such as those covering assessment, case management, language development, and adult language disorders. This concept of content infusion across coursework could follow the model established by initial instruction in cultural and linguistic diversity. Further, it may be useful to develop a collection of AAC-specific syllabi in a clearinghouse through ASHA's SIG-12 as a means of allowing professors or instructors to share ideas on pedagogy. This shared information may support a reconceptualization of AAC for EACs, in which language acquisition and development is the primary focus, and the technological component of AAC is the secondary focus. This leads to the recommendation for ASHA to continue to move forward with approving AAC as a Clinical Specialty Area of Practice (ASHA, n.d.h.), which is currently in the second and final stage. The establishment of AAC as a clinical area of specialty will support greater access to knowledge, skills, and clinical experience for SLPs. Additionally, this allows parents and family members to locate and seek contact with ASHA identified AAC experts.

A further recommendation is for SLPs to evaluate their decision making process in their intervention with EACs. The choice to implement intervention with a communicative versus a linguistic focus may be an appropriate course of action based on the unique profile of a specific EAC; however, this choice should be made intentionally, be based on evidence-based principles, reflect the opinions of the EAC and allied stakeholders, and take into consideration recognized theories of language acquisition. Further, SLPs should carefully evaluate their decisions on the type of vocabulary included on aided AAC systems. The use of prestored phrases or rote utterances is not 
conducive to the development of a true linguistic system. However, access to individual bound and free morphemes allows EACs opportunities to build words from parts and sentences from words in a similar manner to their oral peers.

A final recommendation is to move toward greater provision of the least restrictive environment for EACs, with a priority on inclusion that extends beyond mere legal compliance to practices that ensure access to meaningful and quality educational and social experiences. Toward this end, SLPs, teachers, and other stakeholders may benefit from a review of The Design to Learn IEP Development Guide for children with CCNs (Rowland, Quinn, \& Steiner, 2015).

\section{Conclusion}

This dissertation sought to answer the following two primary research questions:

Research Question 1: Do SLPs perceive differences between their practices with emerging oral communicators with language impairments and EACs?

Research Question 1a: If variances do exist, are those variances significant and what is the relationship?

Research Question 2: Do SLPs report differences between their practices with emerging oral communicators with language impairments and EACs?

Research Question 2a: If variances do exist, are those variances significant and what is the relationship?

Results from the two questions revealed descriptive trends across all constructs measured, as well as statistically significant mean differences between SLPs' perceived levels of confidence and qualification relating to intervention principles for the two populations of EACs and emerging oral communicators. In reporting different levels of 
perceived confidence and qualification in their work with EACs, this population of SLPs may be indicating that they view the two populations as separate and distinct. When this finding is paired with the descriptive trends, it appears there may be an association between SLPs practices and beliefs and the linguistic outcomes observed in EACs.

This dissertation further broadened and sharpened linguistic theory by examining language that develops through alternate modalities and in populations that reside outside of normative frameworks (Goldin-Meadow, 2014; Lillo-Martin, 1999; Loncke, 2008), identifying parallels to the language observed in EACs, and increasing theoretical and pragmatic knowledge of efficient and efficacious intervention (Treweek \& Zwarenstein, 2009).

It is important to note that the findings of this dissertation do not diminish the impact of the constraints associated with aided language identified in the literature; those are very real and formidable, and require further research to identify methods of overcoming these challenges. However, they should mandate a call to action on the part of ASHA in requiring AAC coursework for all accredited programs, on universities to better prepare students with theoretical and practical knowledge specific to aided AAC users, on researchers to continue to develop better AAC interfaces and AAC systems, and on SLPs to maintain parity between their standards for intervention practices for speaking children and aided communicators of all ages.

The process of this dissertation revealed broad links to the existing literature base, answered the primary research questions, and identified possible contributing factors to linguistic outcomes for EACs. It further suggested potential analogs between the linguistic characteristics of EACs and the construct of interlanguages. Additionally, it 
provided a means for the primary researcher to develop an understanding of the methods of survey research and rigorous academic writing. However, as important as these factors are, of greater relevance are the outcomes of these children who use alternate modalities for the development of language. As professionals who work in the realm of language and are fortunate enough to play a role in the acquisition of this profoundly human construct, we must remain mindful of the words of Wittgenstein in our work with children, "Die grenzen meiner sprache sind die grenzen meiner welt" (1922, section 5.6), which translates into "the limits of my language are the limits of my world." 


\section{REFERENCES}

Ahlgrim-Delzell, L., Browder, D., \& Wood, L. (2014). Effects of systematic instruction and an augmentative communication device on phonics skills acquisition for students with moderate intellectual disability who are nonverbal. Education and Training in Autism and Developmental Disabilities, 49(4), 517-532.

Ahlgrim-Delzell, L., Browder, D., Wood, L., Stranger, C., Preston, A. I., \& Kemp-Inman, A. (2015). Systematic instruction of phonics skills using an iPad for students with developmental disabilities who are AAC users. The Journal of Special Education, 50(2), 86-97. doi:10.1177/0022466915622140.

American Speech-Language-Hearing Association [ASHA]. (2001). Competencies for speech-language pathologists providing services in augmentative communication. ASHA, 31(3), 107-110.

ASHA. (2002). Augmentative and alternative communication: Knowledge and skills for service delivery. ASHA Supplement 22, 97-106.

ASHA. (2004). Roles and responsibilities of speech-language pathologists with respect to augmentative and alternative communication: Technical report. Retrieved from https://www.asha.org/policy/tr2004-00262/

ASHA. (2005). Roles and responsibilities of speech-language pathologists with respect to augmentative and alternative communication: Position statement. Retrieved from https://www.asha.org/policy/tr2004-00262/

ASHA. (2005). Standards and implementation of procedures for the certificate of clinical competence in speech-language pathology. Retrieved via email January 28, 2019, Lisa Wolf, Certification Department, ASHA. 
ASHA. (2013). Speech-language pathology assistant scope of practice [Scope of Practice]. Retrieved from https://www.asha.org/policy/sp2013-00337/

ASHA. (2014). 2014 Standards and implementation procedures for the certification of clinical competence in speech-language pathology. Retrieved from https://www.asha.org/certification/2014-speech-language-pathology-certificationstandards/

ASHA. (2016a). 2016 Schools survey report: SLP caseload characteristics. Retrieved from www.asha.org/research/memberdata/schoolsurvey/

ASHA. (2016b). 2016 Schools survey. Survey summary report: Numbers and types of responses. Retrieved from http://www.asha.org/uploadedFiles/2016-SchoolsSummary-Report.pdf

ASHA. (2016c). Scope of practice in speech-language pathology. Retrieved from https://www.asha.org/policy/sp2016-00343/

ASHA. (2018). 2018 State-issued guidance for caseload chart. Retrieved from https://www.asha.org/uploadedFiles/ASHA/Practice_Portal/Professional_Issues/C aseload_and_Workload/State-Caseload-Chart.pdf

ASHA. (n.d.a.). Assessment and evaluation of speech-language disorders in schools.

Retrieved from https://www.asha.org/slp/assessment-and-evaluation-of-speechlanguage-disorders-in-schools/

ASHA. (n.d.b.). Evidence maps/augmentative and alternative communication. http://www.asha.org/EvidenceMapLanding.aspx?id=8589942945\&recentarticles= false $\&$ year=undefined $\&$ tab $=$ all 
ASHA. (n.d.d.). Caseload and workload. Retrieved from https://www.asha.org/PRPSpecificTopic.aspx?folderid=8589934681\&section=Re ferences

ASHA. (n.d.e.). Implementation guide: A workload analysis approach for establishing speech-language caseload standards in schools. Retrieved from https://www.asha.org/slp/schools/implementation-guide/

ASHA. (n.d.f.). Speech-language pathology assistants. Retrieved from https://www.asha.org/Practice-Portal/Professional-Issues/Speech-LanguagePathology- Assistants

ASHA. (n.d.g.). Augmentative and alternative communication. Retrieved from https://www.asha.org/PRPSpecificTopic.aspx?folderid=8589942773\&section=Ke y_Issues

ASHA. (n.d.h.). Maintaining your certification. Retrieved from https://www.asha.org/Certification/maintain-ccc/

ASHA. (n.d.i.). Collaboration and teaming. Retrieved from https://www.asha.org/Practice-Portal/Clinical-Topics/IntellectualDisability/Collaboration-and-Teaming/

American Speech-Language-Hearing Foundation. (2014, March). Implementation Science Summit: Integrating Research into Practice in Communication Sciences and Disorders. Retrieved from www.ashfoundation.org/news/ImplementationScience- Summit 
Anderson, K., Balandin, S., \& Stancliffe, R. (2014). Australian parents' experiences of speech generating device (SGD) service delivery. Developmental Neurorehabilitation, 17(2), 75-83. doi:10.3109/17518423.2013.857735

Anderson, K. L., Balandin, S., \& Stancliffe, R. J. (2015). Alternative service delivery models for families with a new speech generating device: Perspectives of parents and therapists. International Journal of Speech-Language Pathology, 17(2), 185195. doi:10.3109/17549507.2014.979876

Anderson, K., Balandin, S., Stancliffe, R. J., \& Layfield, C. (2014). Parents' perspectives on tele-AAC support for families with a new speech generating device: Results from an Australian pilot study. SIG 18 Perspectives on Telepractice, 4(2), 52-60. doi:10.3109/17549507.2014.979876

Anderson, R. W. (1984). The one to one principle of interlanguage construction. Language Learning, 34(4), 77-95. doi:10.1111/j.1467-1770.1984.tb00353.x

Angelo, D. (2000). Impact of augmentative and alternative communication devices on families. Augmentative and Alternative Communication, 16(1), 37-47. doi:10.1080/07434610012331278894

Angelo, D. H., Jones, S. D., \& Kokoska, S. M. (1995). Family perspective on augmentative and alternative communication: Families of young children. Augmentative and Alternative Communication, 11, 193-201. doi:10.1080/07434619512331277319

Argyris, C. (1970). Intervention theory \& method: A behavioral science view. Reading, MA: Addison-Wesley. 
Artiles, A. J., Kozleski, E. B., \& Trent, S. C. (2010). Justifying and explaining disproportionality, 1968-2008: A critique of underlying views of culture. Council for Exceptional Children, 76(3), 279-299. doi:10.1177/0014402910076300303

Assistive Technology Act of 2004. 29 USC 3001 note. Retrieved from: https://www.gpo.gov/fdsys/pkg/STATUTE-118/pdf/STATUTE-118-Pg1707.pdf

Bailey, R. L., Parette, H. P., Jr., Stoner, J. B., Angell, M. E., \& Carroll, K. (2006). Family members' perceptions of augmentative and alternative communication device use. Language, Speech, and Hearing Services in Schools, 37, 50-60. doi:10.1044/0161-1461(2006/006)

Barker, R. M., Akaba, S., Brady, N. C., \& Thiemann-Bourque, K. (2013). Support for AAC use in preschool, and growth in language skills, for young children with developmental disabilities. Augmentative and Alternative Communication, 29(4), 334-346. doi:10.3109/07434618.2013.848933

Bates, E. (2003). On the nature and nurture of language. In R. Levi-Montalcini, D. Baltimore, R. Dulbecco, F. Jacob, F., E. Bizzi, P. Calissano, \& V. Volterra (Eds.), Frontiers of biology: The brain of homo sapiens (pp. 241-265). Rome, Italy: Istituto della Enciclopedia Italiana Fondata de Giovanni Trecanni.

Bates, E., Bretherton, I., \& Snyder, L. (1988). From first words to grammar: Individual differences and dissociable mechanisms. New York, NY: Cambridge University Press.

Bates, E., Camaioni, L., \& Volterra, V. (1975). The acquisition of performatives prior to speech. Merrill-Palmer Quarterly, 21(3), 205-226. 
Bates, E., \& Dick, F. (2002). Language, gesture, and the developing brain. Developmental Psychobiology, 40, 203-310. doi:10.1002/dev.10034

Bates, E., \& Goodman, J. C. (1997). On the inseparability of grammar and the lexicon: Evidence from acquisition, aphasia, and real-time processing. Language and Cognitive Processes, 12(5/6), 507-584. doi:10.1080/016909697386628

Baudelaire, K., Lukenchuk, U., \& Lukenchuk, A. (2013). Paradigms of research for the $21^{\text {st }}$ century. Perspectives and Examples from Practice, 436, 3-30. doi:10.1080/02607476.2014.957991

Beck, A. R., Thompson, J. R., Kosuwan, K., \& Prochnow, J. M. (2010). The development and utilization of a scale to measure adolescents' attitudes toward peers who use augmentative and alternative communication (AAC) devices. Journal of Speech, Language, and Hearing Research, 53(3), 572-587. doi:10.1044/1092-4388(2009/07-0140)

Behrens, H. (2006). The input-output relationship in first language acquisition. Language and Cognitive Processes, 21(1/2/3), 2-24. doi:10.1080/01690960400001721

Beins, B. (2009). Research methods: A tool for life (2nd ed.). Boston, MA: Pearson.

Beukelman, D. R., \& Mirenda, P. (1988). Communication options for persons who cannot speak: Assessment and evaluation. In C. A. Costin (Ed.), Proceedings of the National Planners Conference on Assistive Device Service Delivery (pp. 151165). Washington, DC: Association for the Advancement of Rehabilitation Technology. 
Beukelman, D. R., \& Mirenda, P. (2013). Augmentative and alternative communication: Supporting children and adults with complex communication needs. Baltimore, MD: Paul H. Brooks.

Bickerton, D. (2008). Bastard tongues: A trailblazing linguist finds clues to our common humanity in the world's lowliest languages. New York, NY: Hill and Wang.

Binger, C., \& Light, J. (2008). The morphology and syntax of individuals who use AAC: Research review and implications for effective practice. Augmentative and Alternative Communication, 24(2), 123-138. doi:10.1080/07434610701830587

Binger, C., Maguire-Marshall, M., \& Kent-Walsh, J. (2011). Using aided AAC models, recasts, and contrastive targets to teach grammatical morphemes to children who use AAC. Journal of Speech, Language, and Hearing Research, 54, 160-176. doi:10.1044/1092-4388(2010/09-0163)

Bishop, D. V. M. (1983). Comprehension of English syntax by profoundly deaf children. Journal of Child Psychology and Psychiatry, 24(3), 415-434. doi:10.1111/j.14697610.1983.tb00118.x

Bishop, D. V. M. (2014). Problems with tense marking in children with specific language impairment: Not how but when. Philosophical Transactions of the Royal Society B: Biological Sciences, 19, 369(1634). doi:10.1098/rstb.2012.0401

Blackstone, S. W., Williams, M. B., \& Wilkins, D. P. (2007). Key principles underlying research and practice in AAC. Augmentative and Alternative Communication, 23(3), 191-203. doi:10.1080/07434610701553684

Blockberger, S., \& Johnston, J. (2003). Grammatical morphology acquisition by children with complex communication needs. Augmentative and Alternative 
Communication, 19(4), 207-221. doi.10.1080/07434610310001598233

Blockberger, S., \& Sutton, A. (2003). Towards linguistic competence: The language experiences and knowledge of children with extremely limited speech. In J. Light, D. Beukelman, \& J. Reichle (Eds.), Communication competence for individuals who use AAC (pp. 63-106). Baltimore, MD: Brookes.

Bloom, L. (2000). The intentionality model of word learning: How to learn a word, any word. In R. M. Golinkoff, K. Hirsh-Pasek, L. Bloom, L. B. Smith, A. L. Woodward, N. Akhtar,...G. Hollich (Eds.), Becoming a word learner: A debate on lexical acquisition (pp. 19-50). Oxford, England: Oxford University Press.

Bloom, L., \& Beckwith, R. (1989). Intentionality and language development. Columbia Academic Commons. Retrieved from https://academiccommons.columbia.edu/catalog/ac:h9w0vt4bb1

Bloom, P. (2000). How children learn the meaning of words. Cambridge, MA: MIT Press.

Boenisch, J., \& Soto, G. (2015). The oral core vocabulary of typically developing English-speaking school-aged children: Implications for AAC practice. Augmentative and Alternative Communication, 31(1), 77-84. doi:10.3109/07434618.2014.1001521

Brady, N., Bruce, S., Goldman, A., Erickson, K., Mineo, B., Ogletree, B., . . Wilkinson, K. (2016). Communication services and supports for individuals with severe disabilities: Guidance for assessment and intervention. American Journal on Intellectual and Developmental Disabilities, 121, 121-138. doi:10.1352/1944$7558-121.2 .121$ 
Brady, N. C., Thiemann-Bourque, K., Fleming, K., \& Matthews, K. (2013). Predicting language outcomes for children learning augmentative and alternative communication: Child and environmental factors. Journal of Speech, Language, and Hearing Research, 56, 1595-1612. doi:10.1044/1092-4388(2013/12-0102)

Branson, C., \& Demchak, M. (2009). The use of augmentative and alternative communication methods with infants and toddlers with disabilities. Augmentative and Alternative Communication, 25(4), 274-286.

doi:10.3109/07434610903384529

Bresnan, J. (2000). Pidgin genesis and optimality theory. In J. Siegel (Ed.), Processes of language contact: Case studies from Australia and the Pacific (pp. 145-173). Montreal, Canada: Les Editions Fides.

Brignell, A., Chenausky, K. V., Song, H., Zhu, J., Suo, C., \& Morgan, A. T. (2018). Communication interventions for autism spectrum disorder in minimally verbal children. Cochrane Database of Systematic Reviews, 11(CD012324). doi:10.1002/14651858.CD0123424.pub2

Bronfenbrenner, U., \& Morris, P. A. (2006). The biological model of human development. In R. M. Lerner (Ed.). Volume 1 of Handbook of child psychology (6th ed.; pp. 792-828). Editors-in-chief: W. Damon \& R. M. Lerner. Hoboken, NJ: Wiley.

Brown, R. (1973). A first language: The early stages. London, England: George Allen \& Unwin.

Bruner, J. (1983). Play, thought, and language. Peabody Journal of Education, 60(3), 6069. Retrieved from http//dx.doi.org:0.1080/01619568309538407 
Calculator, S. N. (2009). Augmentative and alternative communication and inclusive education for students with the most severe disabilities. International Journal of Inclusive Education, 13(1), 93-113. doi.10.1080/13603110701284656

Calculator, S. N., \& Black, T. (2009). Validation of an inventory of best practices in the provision of augmentative and alternative communication services to students with severe disabilities in general education classrooms. American Journal of Speech-Language Pathology, 18, 329-342. doi:10.1044/1058-0360(2009/080065)

Calculator, S. N., \& Black, T. (2010). Parents' priorities for AAC and related instruction for their children with Angelman syndrome. Augmentative \& Alternative Communication, 26(1), 30-40. doi:10.3109/07434610903585406

California Department of Education. (n.d.). California Department of Education: CALPADS primary disability category codes. Retrieved from https://www.cde.ca.gov/ta/tg/ca/disablecodes.asp

Callegaro, M. (2008). Social desirability. In P. J. Lavrakas, (Ed.), Encyclopedia of survey research methods (pp. 1-4). Thousand Oaks, CA: Sage. doi: $10.4135 / 9781412963947$

Carlin, C. H. (2015). Workload guidance. Retrieved from The Ohio Center for Autism and Low Incidence website: http://www.omnie.ocali.org/user_mod.php

CHILDES. (n.d.). Retrieved December 02, 2017 from https://childes.talkbank.org

Chilosi, A., Cipriani, P., Pecini, C., Brizzolara, D., Biagi, L., Montanaro, D., \& ... Cioni, G. (2008). Acquired focal brain lesions in childhood: Effects on development and 
reorganization of language. Brain and Language, 106(3), 211-225.

doi:10.1016/j.bandl.2007.12.010

Chomsky, N. (1965). Aspects of the theory of syntax. Cambridge, MA: MIT Press.

Chomsky, N. (2005). Language and the mind. Cambridge, MA: MIT Press.

Clendon, S. A. (2011). Literacy interventions for students who use aided augmentative and alternative communication: More work to be done. Evidence-based Communication Assessment and Intervention, 5(3), 138-143.

doi:10.1080/17489539.2011.650919

Cockerill, H., Elbourne, D., Allen, E., Scrutton, D., Will, E., McNee, A.... Baird, G. (2014). Speech, communication and use of augmentative communication in young people with cerebral palsy: The SH \& PE population. Child Care, Health, \& Development, 40(2), 149-157. doi:10.1111/cch.12066

Costigan, F. A., \& Light, J. (2010). A review of pre-service training in augmentative and alternative communication for speech- language pathologists, special education teachers, and occupational therapists. Assistive Technology, 22, 200-212. doi:10.1080/10400435.2010.492774

Coughlin, M, Cronin, P., \& Ryan, F. (2009). Survey research: Process and limitations. International Journal of Therapy and Rehabilitation, 16(1), 9-15. Retrieved from http://hdl.handle.net/2262/69916

Craig, H. K. (1995). Pragmatic impairments. In P. Fletcher \& B. MacWhinney, (Eds.), The handbook of child language (pp. 623-640). Oxford, UK: Blackwell. 
Cress, C. J., \& Marvin, C. A. (2003). Common questions about AAC in early intervention. Augmentative and Alternative Communication, 19(4), 254-272. doi:10.1080/07434610310001598242

Creswell, J. W. (2014). Research design: Qualitative, quantitative, and mixed method approaches. Thousand Oaks, CA: Sage.

Crooke, P. J., \& Olswang, L. B. (2015). Practice-based research: Another pathway for closing the research-practice gap. Journal of Speech, Language, and Hearing Research, 58, S1871-S1882. doi:10.1044/2015_JSLHR-L-15-0243

Dada, S., Horn, T., Samuels, A., \& Schlosser, R. W. (2016). Children's attitudes toward interaction with an unfamiliar peer with complex communication needs: Comparing high- and low-technology services. Augmentative and Alternative Communication, 32(4), 305-311. doi:10.1080/07434618.2016.1216597

Dale, P., \& Goodman, J. (2005). Commonality and individual differences in vocabulary growth. In M. Tomasello, \& D. I. Slobin (Eds.), Beyond nature-nurture. Essays in honor of Elizabeth Bates (pp. 41-80). London, UK: Lawrence Erlbaum Associates.

Damasio, H. (2008). Neural basis of language disorders. In R. Chapey (Ed.), Language intervention strategies in aphasia and related neurogenic communication disorders (5th ed.; pp. 20-41). Baltimore: MD: Lippincott Williams \& Wilkins.

Davidoff, B. E. (2017). AAC with energy-Earlier. The ASHA Leader, 22, 48-53. doi:10.1044/leader.FTR2.22012017.48

DeVellis, R. F. (2017). Scale development: Theory and application. Thousand Oaks, CA: Sage. 
Delarosa, L., Horner, S., Eisenberg, C., Ball, L., Renzoni, A., \& Ryan, S.E. (2012). Family Impact of Assistive Technology Scale: Development of a measurement scale for parents of children with complex communi- cation needs. Augmentative and Alternative Communication, 28, 171-180.

doi:10.3109/07434618.2012.704525

Devoscovi, A., \& D’Amico, S. (2005). The competition model: Crosslinguistic studies of online processing. In M. Tomasello \& D. I. Slobin, (Eds.), Beyond naturenurture: Essays in honor of Elizabeth Bates (pp. 165-191). Mahwah, NJ: Lawrence Erlbaum Associates.

Dietz, A., Quach, W., Lund, S. K., \& McKelvey, M. (2012). AAC assessment and clinical-decision making: The impact of experience. Augmentative and Alternative Communication, 28(2), 117-126. doi:10.3109/07434618.2012.704521

Dillman, D. A., Smyth, J. D., \& Christian, L. M. (2014). Internet, phone, mail, and mixed mode surveys: The tailored design method. Los Angeles, CA: John Wiley and Sons.

Dodd, J. L., Y Hagge, D. K. (2014). AAC camp as an alternative school-based service delivery model: A retrospective survey. Communication Disorders Quarterly, 35(3), 123-132. doi:10.1177/1525740113512670

Douglas, S. N., Light, J. C., \& McNaughton, D. B. (2012). Teaching paraeducators to support the communication of young children with complex communication needs. Topics in Early Childhood Special Education, 33, 91-101. doi:10.1177/0271121412467074

Drager, K. D., \& Light, J. C. (2010). A comparison of the performance of typically 
developing 5-year-old children using iconic encoding in AAC systems with and without iconic prediction on a fixed display. Augmentative and Alternative Communication, 26(1), 12-20. doi:10.3109/07434610903561464

Drager, K. D., Light, J. C., Speltz, J. C., Fallon, K. A., \& Jeffries, L. Z. (2003). The performance of typically developing $2 \frac{1}{2}$ year olds on dynamic display AAC technologies with different system layouts and language organizations. Journal of Speech, Language, and Hearing Research, 46(2), 298-312. doi:10.1044/1092$4388(2003 / 024)$

Duffy, J. R. (2013). Motor speech disorders: Substrates, differential diagnosis, and management (3rd ed.). St. Louis, MO: Elsevier Mosby.

Dunst, C. J., Raab, M., \& Trivette, C. M. (2012). Characteristics of naturalistic language intervention strategies. Journal of Speech-Language Pathology and Applied Behavior Analysis, 53(4), 8-16.

Elder, P., \& Goossens, C. (1994). Engineering training environments for interactive augmentative communication: Strategies for adolescents and adults who are moderately/severely developmentally delayed. Birmingham, AL: Southeast Augmentative Communication Conference Publications.

Ellis, N. C. (1998). Emergentism, connectionism and language learning. Language Learning, 48(4), 631-664. doi:10.1111/0023-8333.00063

Emmorey, K. (2002). Language, cognition, and the brain: Insights from sign language research. Mahaw, NJ: Lawrence Erlbaum Associates. 
Enderby, P. (2014). Introducing the therapy outcome measure for AAC services in the context of a review of other measures. Disability and Rehabilitation: Assistive Technology, 9(1), 33-40. doi:10/3109/17483107.2013.823576

Endrew F. v. Douglas County School District RE-1, 580 U.S. (2017). Retrieved fromhttps://www.supremecourt.gov/opinions/16pdf/15-827_0pm1.pdf

Epstein, I. (2001). Using available clinical information in practice-based research. Social Work in Health Care, 33, 15-32. doi:10.1300/J010v33n03_03

Erickson, K. (2003). Reading comprehension in AAC. The ASHA Leader, 6-9. doi:10.1044/leader.FTR1.08122003.6

Evans, J. L. (1996). Plotting the complexities of language sample analysis: Linear and non-linear dynamical models of assessment. In K. Cole, P. Dale, \& D. Thal (Eds.), Assessment of communication and language (pp. 207-256). Baltimore, MD: Brookes.

Every Student Succeeds Act (2015). (2017). In Current events in context. Retrieved from http://www.abc-clio.com/current/

Fallon, K. A., \& Katz, L. A. (2008). Augmentative and alternative communication and literacy teams: Facing the challenges, forging ahead. Seminars in Speech and Language, 29(2), 112-119. doi:10.1055/s-2008-1079125

Fallon, K. A., Light, J., McMaughton, D., Drager, K., \& Hammer, C. (2004). The effects of direct instruction on the single-word reading skills of children who require augmentative and alternative communication. Journal of Speech, Language, and Hearing Research, 47, 1424-1439. doi:10.1044/1092-4388(2004/106) 
Finke, E. H., \& Quinn, E. (2012). Perceptions of communication style and influences on intervention practices for young children with AAC needs. Augmentative and Alternative Communication, 28(2), 117-126. doi:10.3109/07434618.2012.677959

Fowler, F. J. (2014). Survey research methods. Thousand Oaks, CA: Sage.

Ganz, J. B., Earles-Vollrath, T. L., Mason, R. A., Rispoli, M. J., Heath, A. K., \& Parker, R. I. (2011). An aggregate study of single-case research involving aided AAC: Participant characteristics of individuals with autism spectrum disorders. Research in Autism Spectrum Disorders, 5, 1500-1509. doi:10.1016/j.rasd.2011.02.011

Gard, A., Gilman, L., \& Gorman, J. (1993). Speech and language development chart (2nd ed.). Austin, TX: Pro-Ed.

Gauvain, M. (2009). Social and cultural transaction in cognitive development: A crossgenerational view. In A. Sameroff (Ed.), The transactional model of development: How children and contexts shape each other (pp. 163-183). Washington, DC: American Psychological Association. doi.org/10.1037/11877-009

Gentner, D., \& Boroditsky, L. (2001). Individuation, relativity, and early word learning. In M. Bowerman and S. C. Levinson (Eds.), Language acquisition and conceptual development (pp. 215-256). Cambridge, UK: Cambridge University Press.

Goodley, D. (2011). Disability studies: An interdisciplinary introduction. Los Angeles, CA: Sage Publications.

Glogowska, M. (2011). Paradigms, pragmatism, and possibilities: Mixed-methods research in speech and language therapy. International Journal of Communication Disorders, 46(3), 251-260. doi:10.3109/13682822.2010.507614 
Goldin-Meadow, S. (2014). In search of resilient and fragile properties of language. Journal of Child Language, 41, 64-77. doi:10.1017/S030500091400021X

Groves, R. M., Fowler, F. J., Couper, M. P., Lepkowski, J. M., Singer, E., \& Tourangeau, R. (2009). Survey methodology (2nd ed.). Los Angeles, CA: John Wiley \& Sons. Hallowell, B., \& Chapey, R. (2008). Introduction to language intervention strategies in adult aphasia. In R. Chapey (Ed.), Language intervention strategies in aphasia and related neurogenic communication disorders (5th ed.; pp. 3-19). Baltimore: MD: Lippincott Williams \& Wilkins.

Hammer, C. S. (2011). The importance of participant demographics. American Journal of Speech-Language Pathology, 20, 261-366. doi:10.1044/1058-0360(2011/ed-04)

Hart, K. I., Fujiki, M., Brinton, B, \& Hart, C. H. (2004). The relationship between social behavior and severity of language impairment. Journal of Speech, Language and Hearing Research, 47, 647-662. doi:10.1044/1092-4388(2004050/)

Henner, J., Caldwell-Harris, C. L., Novogrodsky, R., \& Hoffmeister, R. (2016). American Sign Language syntax and analogical reasoning skills are influenced by early acquisition and age of entry to signing schools for the Deaf. Frontiers in Psychology, 7, 1982. doi:10.3389/fpsyg.2016.01982

Henner, J., Caldwell-Harris, C. L., Novogrodsky, R., \& Hoffmeister, R. (2019). The development of American Sign Language-based analogical reasoning in signing Deaf children. Journal of Speech, Language, and Hearing Research, 62(1), 93105. doi:10.1044/2018_JSLHR-18-0062 
Hetzroni, O. (2002). Augmentative and alternative communication in Israel: Results from a family survey. Augmentative and Alternative Communication, 18, 255-266. doi:10.1080/07434610212331281341

Hetzroni, O. E. (2004). AAC and literacy. Disability and Rehabilitation. 26(21/22), 1305-1312. doi:10.1080/096382820412331280334

Hickok, G. (2009). The functional neuroanatomy of language. Physics of Life Reviews, 6(3), 121-143. doi:101016/j.plrev.2009.06.001

Hidecker, M. J. C. (2010). AAC use by young children at home. Perspectives on Augmentative and Alternative Communication, 19(1), 5-11. doi:10.1044/aac19.1.5

Hinkin, T. R. (1998). A brief tutorial on the development of measures for use in survey questionnaires. Retrieved from http://scholarship.sha.cornell.edu/articles/521

Hoag, L. A., Bedrosian, J. J., McCoy, K. F., \& Johnson, D. E. (2008). Hierarchy of conversational rule violations involving utterance-based augmentative and alternative communication systems. Augmentative and Alternative Communication, 24(2), 149-161. doi:10.1080/07434610802038288

Holbrook, A. (2008). Acquiescence response bias. In P. J. Lavrakas, (Ed.), Encyclopedia of survey research methods (pp. 1-4). Thousand Oaks, CA: Sage. doi:10.4135/9781412963947

Holm, J. (1988). Pidgins and Creoles: Volume 1 theory and structure. Cambridge, MA: Cambridge Language Survey. 
Hough, M., \& Johnson, R. K. (2009). Use of AAC to enhance linguistic communication skills in an adult with chronic severe aphasia. Aphasiology, 23(7/8), 965-976. doi:10.1080/02687030802698145

Hyppa-Martin, J., Collins, D., Chen, M., Amundson, C., Timinski, K., \& Mizuko, M. (2016). Comparing first graders' attitudes and preferences toward a peer using an iPad-based speech-generating device and a non-electronic AAC system. Augmentative and Alternative Communication, 32(2), 94-104. doi:10.3109/07434618.2016.1146332

Iacono, T., \& Cameron, M. (2009). Australian speech-language pathologists' perceptions and experiences of augmentative and alternative communication in early childhood intervention. Augmentative and Alternative Communication, 25(4), 236-249. doi:10.3109/07434610903322151

Individuals with Disability Education Act. (n.d.). About IDEA. Retrieved from https://sites.ed.gov/idea/about-idea/

Individuals with Disabilities Education Act of 2004. 20 U.S.C. $§ 300.105$, Assistive Technology. Retrieved from http://idea.ed.gov/explore/view/p/\%2Croot\%2Cregs\%2C300\%2CB\%2C300 $\% 252 \mathrm{E} 105 \% 2 \mathrm{C}$

Jackendoff, R. (1996). Conceptual semantics and cognitive linguistics. Cognitive Linguistics 7(1), 93-129. doi:10/1515/cogl.1996.7.1.93.

Jo, M., Nelson, J. M., \& Kiecker, P. (1997). A model for controlling social desirability bias by direct and indirect questioning. Marketing Letters, 8(4), 429-437. doi.10.1023/A:1007951313872 
Johnson, J. M., Inglebret, E., Jones, C., \& Ray, J. (2006). Perspectives of speech language pathologists regarding success versus abandonment of AAC. Augmentative and Alternative Communication, 22(2), 85-99. doi:10.1080/07434610500483588

Johnston, J. R., Miller, J., \& Tallal, P. (2001), Use of cognitive state predicates by language-impaired children. International Journal of Language \& Communication Disorders, 36, 349-370. doi:10.1080/13682820118217

Johnston, S. S., Davenport, L., Kanarowski, B., Rhodehouse, S., \& McDonnel, A. P. (2009). Teaching sound letter correspondence and consonant-vowel-consonant combinations to young children who use augmentative and alternative communication. Augmentative and Alternative Communication, 25(2), 123-135. doi:10.1080/07434610902921409

Johnston, S. S., Reichle, J., \& Jones, E. A. (2010). AAC strategies for individuals with moderate to severe disabilities. Baltimore, MD: Brookes.

Jonsson, A., Kristoffersson, L., Ferm, U., \& Thunberg, G. (2011). The ComAlong communication boards: Parents' use and experiences of aided language stimulation. Augmentative and Alternative Communication, 27(2), 103-116. doi:10.3109/07434618.2011.580780

Jourdan, C. (1991). Pidgins and Creoles: The blurring of categories. Annual Review of Anthropoloty, 20, 187-209. doi:10.1146/annurev.an.20.10091.01155

Jung, E. H. (2004). Topic and subject prominence in interlanguage development. Language Learning, 5(4), 713-738. doi:10.1111/j.1467-9922.2004.00284.x 
Kaderavek, J. N. (2015). Language disorders in children: Fundamental concepts of assessment and intervention (2nd ed.). Upper Saddle River, NJ: Pearson.

Kamhi, A. G. (2014). Improving clinical practices for children with language and learning disorders. Language, Speech, and Hearing Services in Schools, 45, 92103. doi:10.1044/2014_LSHSS-13-0063

Kent-Walsh, J., \& Binger, C. (2009). Addressing the communication demands of the classroom for beginning communicators and early language users. In G. Soto \& C. Zangari (Eds.), Practically speaking: Language, literacy and academic development for students with AAC needs (pp. 143-172). Baltimore, MD: Brookes.

Kent-Walsh, J., \& Binger, C. (2018). Methodological advances, opportunities, and challenges in AAC research. Augmentative and Alternative Communication, 34(2), 93-103. doi:10.1080/07434618.2018.1456560

Kent-Walsh, J., \& Light, J. (2003). General education teachers' experiences with inclusion of students who use augmentative and alternative communication. Augmentative and Alternative Communication, 19(4), 104-124. doi.org/10.1080/0743461031000112043

Kent-Walsh, J., \& McNaughton, D. (2005). Communication partner instruction in AAC: Present practices and future directions. Augmentative and Alternative Communication, 21(3), 195-204. doi:10.1080/07434610400006646

Kent-Walsh, J., Stark, C., \& Binger, C. (2008). Tales from school trenches: AAC servicedelivery and professional expertise. Seminars in Speech and Language, 28(2), 149-154. doi:10.1055/s-2008-1079128 
Kerlinger, F. N., \& Lee, H. (2000). Foundations of behavioral research (4th ed.). New York, NY: Harcourt Press.

Koppenhaver, D. A., Foley, B. E., \& Williams, A. R. (2009). Diagnostic reading assessment for students with AAC needs. In G. Soto \& C. Zangari (Eds.), Practically speaking: Language, literacy and academic development for students with AAC needs (pp. 71-91). Baltimore, MD: Brookes.

Kovacs, T., \& Hill, K. (2015). A tutorial on reliability testing in AAC language sample transcription analysis. Augmentative and Alternative Communication, 31(2), 159169. doi: $10.3109 / 07434618.2015 .1036118$

Kovacs, T., \& Stickney, H. (2012). Acquisition of subject-auxiliary inversion in a child using AAC: A corpus analysis and clinical implications. Proceedings of the 15 Biennial Conference of the International Society for Augmentative and Alternative Communication. Pittsburgh, PA.

Larsson, M., Dahlgren Sandberg, A., \& Smith, M. (2009). Early reading and spelling abilities in children with severe speech and physical impairment: A crosslinguistic comparison. Research in Developmental Disabilities, 30, 77-95. doi:10.1016/j.ridd.2007.11.003

Lasnik, H. (1995). The forms of sentences. In K. R. Gleitman \& M. Liberman (Eds.), An invitation to cognitive science: Language Volume 1 (2nd ed.; pp. 283-310). Cambridge, MA: MIT Press.

Lauterbach, M., Gil de Casta, R., Leal, G., Willmes, K., \& Martins, L. P. (2010). Recovering from acquired childhood aphasia (ACA) - 20 years later, learning 
about the neuroplasticity of language. Behavioral Neurology, 23(4), 195-197. doi:10.3233/BEN-2010-0293

Leonard, L. B., Miller, C., \& Gerber, E. (1999). Grammatical morphology and the lexicon in children with specific language impairment. Journal of Speech, Language, and Hearing Research, 42(3), 678-689.

Light, J. (1988). Interaction involving individuals using augmentative and alternative communication systems: State of the art and future directions. Augmentative and Alternative Communication, 4, 66-72. doi:10.1080/07434618812331274657

Light, J. (1989). Toward a definition of communicative competence for individuals sing augmentative and alternative communication systems. Augmentative and Alternative Communication, 5, 137-144.

Light, J. (1997). Communication is the essence of human life: Reflections on communicative competence. Augmentative and Alternative Communication, 13, 61-70. doi:10.1080/07434619712331277848

Light, J., \& Drager, K. (2007). AAC technologies for young children with complex communication needs: State of the science and future research directions. Augmentative and Alternative Communication, 23(3), $204-216$. doi:10.1080/07434610701553635

Light, J., Drager, K., McCarthy, J., Mellott, S., Millar, D., Parrish, C., ... Welliver, M. (2004). Performance of typically developing four- and five-year-old children with AAC systems using different language organization techniques. Augmentative and Alternative Communication, 20(2), 63-88.

doi:10.1080/07434610410001655553 
Light, J., \& McNaughton, D. (2014). Communicative competence for individuals who require augmentative and alternative communication: A new definition for anew era of communication? Augmentative and Alternative Communicaiton, 30, 1-18. doi:10.3109/07434618.2014.885080

Light, J., \& McNaughton, D. (2012a). Supporting the communication, language, and literacy development of children with complex communication needs: State of the science and future research priorities. Assistive Technology, 24(1), 34-44. doi:10.1080/10400435.2011.648717

Light, J., \& McNaughton, D. (2012b). The changing face of augmentative and alternative communication: Past, present, and future challenges. Augmentative and Alternative Communication, 28(4), 197-204. doi:10.3109/07434618.2012.737024

Light, J., \& McNaughton, D. (2013). Putting people first: Re-thinking the role of technology in augmentative and alternative communication intervention. Augmentative and Alternative Communication, 29(4), 299-309. doi:10.3109/07434618.2013.848935

Light, J., \& McNaughton, D. (2014). Communicative competence for individuals who require augmentative and alternative communication: A new definition for a new era of communication? Augmentative and Alternative Communication, 30(1), 118. doi:10.3109/07434618.2014.885080

Light, J., \& McNaughton, D. (2015). Designing AAC research and intervention to improve outcomes for individuals with complex communication needs. Augmentative and Alternative Communication, 31(2), 85-96. doi:10.3109/07434618.2015.1036458 
Light, J. C., Parsons, A. R., \& Drager, K. (2002). “There's more to life than cookies": Developing interactions for social closeness with beginning communicators who use AAC. In J. Reichle, D. R. Beukelman, \& J. C. Light (Eds.), Exemplary practices for beginning communicators: Implications for AAC (pp. 187-218). Baltimore, MD: Paul H. Brookes.

Lilienfeld, M., \& Alant, E. (2001). Attitudes of children towards augmentative and alternative communication systems. The South African Journal of Communication Disorders, 48, 45-54.

Lillo-Martin, D. (1999). Modality effects and modularity in language acquisition: The acquisition of American Sign Language. In T. Bhatia \& W. Ritchie (Eds.), Handbook of child language acquisition, (pp. 531-567). San Diego, CA: Academic Press. Retrieved from http://www.haskins.yale.edu/Reprints/HL1167.pdf

Lillo-Martin, D. (2016). Sign language acquisition studies. In E. L. Bavin \& L. R. Naigles (Eds.), The Cambridge handbook of child language (2nd Ed.; pp. 504526). Cambridge, MA: Cambridge University Press.

Litwin, M. S. (1995). How to measure survey reliability and validity. Thousand Oaks, CA: Sage.

Locke, J. L. (1997). A theory of neurolinguistic development. Brain and Language, 58(2), 265-326. doi:10.1006/brln.1997.1791

Loncke. F. (2008). Basic principles of language intervention for children who use AAC. SIG 12 Perspectives on Augmentative and Alternative Communication, 17, 50-55. doi:10.1044/aac17.2.50 
Lorah, E. R. (2016). Comparing teacher and student use and preference of two methods of augmentative and alternative communication: Picture exchange and a speechgenerating device. Journal of Developmental and Physical Disabilities, 28(5), 751-767. doi:10.1007/s10881-016-9507-z

Lund, S. K., \& Light, J. (2003). The effectiveness of grammar instruction for individuals who use augmentative and alternative communication systems: A preliminary study. Journal of Speech Language and Hearing Research, 46(5), 1110-1123. doi:10.1044/1092-4388(2003/087)

Lund, S. K., \& Light, K. (2007). Long-term outcomes for individuals who use augmentative and alternative communication: Part II-communicative interaction. Augmentative and Alternative Communication, 23(1), 1-15. doi:10.1080/07434610600720442

MacWhinney, B. (2005). New directions in the competition model. In M. Tomasello \& D. I. Slobin (Eds.), Beyond nature-nurture: Essays in honor of Elizabeth Bates (pp. 81-110). Mahwah, NJ: Lawrence Erlbaum Associates.

Maeda, H. (2015). Response option configuration of online administered likert scales. International Journal of Social Research Methodology, 18(1), 15-26. doi:10.1080/13645579.2014.885159

Marchman, V. A., \& Thal, D. J. (2005). Words and grammar. In M. Tomasello \& D. I. Slobin (Eds.), Beyond nature-nurture: Essays in honor of Elizabeth Bates (pp. 141-164). Mahwah, NJ: Lawrence Erlbaum Associates.

Marchman, V. A., \& Thal, D. J. (2005). Words and grammar. In M. Tomasello \& D. I. Slobin (Eds.), Beyond nature-nurture: Essays in honor of Elizabeth Bates (pp. 
141-164). Mahwah, NJ: Lawrence Erlbaum Associates.

Mayberry, R. I., \& Lock, E. (2003). Age constraints on first versus second language acquisition: Evidence for linguistic plasticity and epigenesis. Brain and Language, 87, 369-384. doi:10.1016/S0093-934X(03)00137-8

Mayberry R., \& Squires B. (2006). Sign language acquisition. In K. Brown (Ed.), Encyclopedia of language \& linguistics (2nd ed.; pp. 291-296). Oxford, UK: Elsevier.

McBride-Chang, C., Wagner, R. K., Muse, A., Chow, B. W. -Y., \& Shu, H. (2005). The role of morphological awareness in children's vocabulary acquisition in English. Applied Psycholinguistics, 26(3), 415-435. doi:10.1017/S014271640505023X

McCambridge, J., Wilton, J., \& Elbourne, D. R. (2014). Systematic review of the Hawthorne effect: New concepts are needed to study research participation effects. Journal of Clinical Epidemiology, 67(3), 246-277. doi:10.1016.j.clinepi.2013.08.015

McCarthy, J., \& Light, J. (2005). Attitudes toward individuals who use augmentative and alternative communication: Research review. Augmentative and Alternative Communication, 21(1), 41-55. doi:10.1080/07434610410001699753

McNaughton, D., \& Bryen, D. N. (2002). Enhancing participation in employment through AAC technologies. Assistive Technology, 14(1), 58-70. doi:10.1080/10400435.2002.10132055

McNaughton, D., Rackensperger, T., Benedek-Wood, E., Krezman, C., Williams, M. B., \& Light, J. (2008). “A child needs to be given a chance to succeed": Parents of 
individuals who use AAC describe the benefits and challenges of learning AAC technologies. Augmentative and Alternative Communication, 24(1), 43-55. doi:10.1080/07434610701421007

Meder, A. M., \& Wegner, J. R. (2015). iPads, mobile technologies, and communication applications: A survey of family wants, needs, and preferences. Augmentative and Alternative Communication, 31(1), 27-36. doi:10.3109/07434618.2014.995223

Meier, R. P., \& Newport, E. L. (1990). Out of the hands of babes: On a possible sign advantage in language acquisition. Language, 66(4), 1-23. doi:10.2307/415277

Mesko, P. J., Eliades, A. B., Christ-Libertin, C. \& Shelestak, D. (2011). Use of picture communication aids to assess pain location in pediatric postoperative patients. Journal of PeriAnesthesia Nursing, 26(6), 395-404.

doi:10.1016/j.jopan.2011.09.006

Morgan, D. L. (2007). Paradigms lost and regained: Methodological implications of combining qualitative and quantitative methods. Journal of Mixed Methods Research, 1(1), 48-76. doi:10.1177/2345678906292462

Morin, K. L., Ganz, J. B., Gregori, E. V., Foster, M. J., Gerow, S. L., Genç-Tosun, D, \& Hong, E. A. (2018). A systematic quality review of high-tech AAC interventions as an evidence-based practice. Augmentative and Alternative Communication, 34(2), 104-117. doi:10.1080/07434618.2018.1458900

Murchland, S., \& Kernot, J., \& Parkyn, H. (2011). Children's satisfaction with assistive technology solutions for schoolwork using the QUEST 2.1: Children's version. Assistive Technology, 23(3), 162-176. doi:10.1080/10400435.2011.588990 
Murray, J., \& Goldbart, J. (2009). Cognitive and language acquisition in typical and aided language learning: A review of recent evidence from an aided communication perspective. Child Language Teaching and Therapy, 25(1), 3158. doi:10.1177/0265659008098660

National Core Indicators. (2012). National core indicators chart generator. Retrieved from http://www.nationalcoreindicators.org/charts/

National Governors Association Center for Best Practices, \& Council of Chief State School Officers. (2010). Common Core State Standards for English language arts: Reading: Foundational skills. Retrieved from http://www.corestandards.org/ELA-Literacy/RF/5/

National Joint Committee for the Communication Needs of Persons With Severe Disabilities. (1992). Guidelines for meeting the communication needs of persons with severe disabilities. Retrieved from www.asha.org/policy or www.asha.org/njc

Nelson, L. M. (2008). Perception question. In P. J. Lavrakas (Ed.), Encyclopedia of survey research methods (pp. 1-4). Thousand Oaks, CA: Sage. doi: $10.4135 / 9781412963947$

Newton, C., Clarke, M., Donlan, C., Wright, J. A., Lister, C., \& Cherguit, J. (2007). Parents' expectations and perceptions concerning the provision of communication aids by the communication aids project (CAP). Child Language Teaching \& Therapy, 23(1), 47-65. doi:10.1177/0265659007072144 
Nicholls, M. E. R., Orr, C. A., Okubo, M., \& Loftus, A. (2006). Satisfaction guaranteed: The effect of spatial biases on responses to Likert scales. Psychological Science, 17, 1027-1028. doi:10.1111/j.1467-9280.2006.01822.x

No Child Left Behind Act. (n.d.). NCLB. Retrieved from https://www2.ed.gov/policy/elsec/leg/esea02/index.html

Norburn, K., Levin, A., Morgan, S., \& Harding, C. (2016). A survey of augmentative and alternative communication used in an inner city special school. British Journal of Special Education, 43(3), 289-306. doi:10.1111/1467-8578.12142

Norbury, C. F., Bishop, D. V. M., \& Briscoe, J. (2001). Production of English finite verb morphology: A comparison of SLI and moderate hearing impairment. Journal of Speech, Language, and Hearing Research, 44, 165-178. doi:1092-4388/01/44010165

Olswang, L. B., \& Prelock, P. A. (2015). Bridging the gap between research and practice: Implementation science. Journal of Speech, Language, and Hearing Research, 58, S1818-S1826. doi:10.1044/2015_JSLHR-L-14-0305

O’Neill, T. O., Light, J., \& Pope, L. (2018). Effects of interventions that included aided augmentative and alternative communication of individuals with complex communication needs: A meta-analysis. Journal of Speech, Language, and Hearing Research, 61, 1743-1765. doi:10.23461.asha.6394364

Orange County Childhood Language Center. (n.d.). Orange County Childhood Language Center. Retrieved from http://www.oclanguagecenter.org

Osborne, J. W. (2013). Best practices in data cleaning: A complete guide to everything you need to do before and after collecting your data. London, UK: Sage. 
Owen, A. J. \& Leonard, L. B. (2002). Lexical diversity in the spontaneous speech of children with specific language impairment: Application of D. Journal of Speech, Language and Hearing Research, 45(5), 927-937. doi:10.1044/1092$4388(2005 / 075)$

Pallant, J. (2013). SPSS survival manual: A step-by-step guide to data analysis using IBM statistics. Berkshire, UK: Open University Press.

Parette, H. P., Brotherson, M. J., \& Huer, M. B. (2000). Giving families a voice in augmentative and alternative communication decision-making. Education and Training in Mental Retardation and Development Disabilities, 35, 177-190.

Paul, R. (1997). Facilitating translations in language development for children using AAC. Augmentative and Alternative Communication, 13, 141-148. doi:10.1080/07434619712331277985

Paul, R., \& Norbury, C. (2012). Language disorders from infancy through adolescence: Listening, speaking, reading, writing, and communicating (4th ed.). St. Louis, MO: Elsevier.

Pavelko, S. L., Owens, Jr., R. E., Ireland, M., \& Hahs-Vaughn, D. L. (2016). Use of language sample analysis by school-based SLPs: Results of a nationwide survey. Language, Speech, and Hearing Services in Schools, 47, 246-258. doi:10.1044/2016_LSHSS-15-0044

Pichler D. C. (2011) Using early ASL word order to shed light on word order variability in sign language. In M. Anderssen, K. Bentzen, \& M. Westergaard, (Eds.), Variation in the input: Studies in theoretical psycholinguistics, 39, (pp. 
157-177). Dordrecht, the Netherlands: Springer. doi.10.1007/978-90-4819207-6_7

Pickl, G. (2011). Communication intervention in children with severe disabilities and multilingual backgrounds: Perceptions of pedagogues and parents. Augmentative and Alternative Communication, 27(4), 229-244. doi:10.3109/07434618.2011.630021

Pinker, S. (1979). Formal models of language learning. Cognition, 7, 217-283.

Pinker, S. (1994). The language instinct. New York, NY: William Morris.

Pinker, S. (1996). Language learnability and language development. Cambridge, MA: Harvard University Press.

Pinker, S. (1999). Words and rules: The ingredients of language. New York, NY: Basic Books.

Plag, I. (2008). Creoles as interlanguages: Inflectional morphology. Journal of Pidgin and Creole Languages, 23(1), 114-135. doi:10.1075/jpc1.23.1.06pla

Ponto, J. (2015). Understanding and evaluating survey research. Journal of the Advanced Practitioner in Oncology, 6(2), 168-191.

Ratcliff, A., Koul, R., \& Lloyd, L. (2008). Preparation in augmentative and alternative communication: An update for speech-language pathology training. American Journal of Speech-Language Pathology, 17, 48-59. doi:10.1044/10580360(2008/005)

Rehabilitation Engineering Research Center. (n.d.). Retrieved from https://rercaac.psu.edu/people/ 
Reid, d. K., \& Knight, M. G. (2006). Disability justifies exclusion of minority students: A critical history grounded in disability studies. Educational Researcher, 35(6), 1823. doi:10.3102/0013189035006018

Rice, M. L., Oetting, J. B., Marquis, J., Bode, J., \& Pae, S. (1994). Frequency of input effects on word comprehension of children with specific language impairment. Journal of Speech, Language, and Hearing Research, 37(1), 106-122.

Rice, M., \& Wexler, K. (1996). Toward tense as a clinical marker of specific language impairment in English-speaking children. Journal of Speech and Hearing Research, 39, 1239-1257.

Rice, M., Wexler, K., \& Cleave, P. (1995). Specific language impairment as a period of optimal infinitive. Journal of Speech and Hearing Research, 38, 850-863.

Roberts, S. J., \& Bresnan, J. (2008). Retained inflectional morphology in pidgins: A typological study. Linguistic Typology, 12, 269-302. doi:10.1515/LITY.2008.039

Rombouts, E., Maes, B., \& Zink, I. (2016). Attitude and key word signing usage in support staff. Research in Developmental Disabilities, 55, 77-87. doi:10.1016/j.ridd 2016.03 .016

Romski, M. A., \& Sevcik, R. A. (2003). Augmented input: Enhancing communication development. In J. C. Light, D. R. Beukelman \& J. Reichle (Eds.), Communicative competence for individuals who use AAC: From research to effective practice (pp. 147-162). Baltimore, MD: Paul H. Brookes.

Romski, M. A., \& Sevcik, R. A. (2005). Augmentative communication and early intervention: Myths and realities. Infants and Young Children, 18, 174-185. doi:10.1097/00001163-200507000-00002 
Rowland, C. M., Quinn, E. D., \& Steiner, S. A. M. (2015). Beyond legal: Crafting highquality IEPs for children with complex communication needs. Communication Disorders Quarterly, 37(1), 53-62. doi:10.1177/1525740114551632

Rowland, C., \& Schweigert, P. D. (2003). Cognitive skills and AAC. In J. C. Light, D. R. Buekelman, \& J. Reichle (Eds.), Communicative competence for individuals who use AAC: From research to effective practice (pp. 199-240). Baltimore, MD: Brookes.

Ruppar, A. L., Dyomond, S. K., \& Gaffney, J. S. (2011). Teachers’ perspectives on literacy instruction for students with severe disabilities who use augmentative and alternative communication. Research \& Practice for Persons with Severe Disabilities, 36(3-4), 100-111. doi:10.2511/027494811800824435

Ryan, S.E., \& Renzoni, A.M. (2015). Family Impact of Assistive Technology Scale for Augmentative and Alternative Communication (FIATS-AAC). [Measurement instrument]. Retrieved from: https://flintbox.com/pub- lic/project/27105/

Ryan, S. E., Sheperd, T. A., Renzoni, A. M., Servais, M., Kingsnorth, S., Laskey, C., Ward, K., \& Bradley, K. (2018). Responsivness of a parent-reported outcome measure to evaluate AAC interventions for children and youth with complex communication needs. Augmentative and Alternative Communication, 34(4), 348358. doi:10.1080/074346182018.1520296

Schlosser, R. W., \& Raghavendra, P. (2004). Evidence-based practice in augmentative and alternative communication. Augmentative and Alternative Communication, 20(1), 1-21. doi:10.1080/07434610310001621083 
Schooling, T. L. (2003). Lessons from the National Outcomes Measurement System (NOMS). Seminars in Speech and Language, 24, 245-256. doi:10.1055/s-200342827

Schuele, C. M., \& Tolbert, L. (2001). Omissions of obligatory relative markers in children with specific language impairment. Clinical Linguistics \& Phonetics, 15(4), 257-274. doi:10.1080/02699200010017805

Schwartz, R. G. (2009). Specific language impairment. In R. G. Schwartz (Ed.), Handbook of child language disorders (pp. 3-43). New York, NY: Psychology Press.

Selinker, L. (1972). Interlanguage. International Review of Applied Linguistics in Language Teaching, 10, 209-231.

Sendak, M. (1963). Where the wild things are. New York, NY: Harper and Row.

Senner, J. E. (2011). Parent perceptions of pragmatic skills in teens and young adults using AAC. Communication Disorders Quarterly, 32(2), 103-108. doi: $10.1177 / 1525740109351570$

Shamahmood, T. M., Jalaie, S., Soleymani, A., Haresabadi, F., \& Nemati, P. (2016). A systematic review on diagnostic procedures for specific language impairment: The sensitivity and specificity issues. Journal of Research in Medical Sciences, 21(1), 1-16. doi:10.4103/1735-1995.189648

Sign Linguistics and Language Acquisition Lab. (n.d.). SLAASh Project. Retrieved from https://slla.lab.uconn.edu/slaaash/

Simpson, K., Beukelman, D., \& Bird, A. (1998). Survey of school speech and language service provision to students with severe communication impairments in 
Nebraska. Augmentative and Alternative Communication, 14(4), 212-221. doi:10.1080/07434619812331278386

Siu, E., Tm, E., Sin, D., Ng, C., Lam, E., Chiu, M., ...Lam, C. (2010). A survey of augmentative and alternative communication service provision in Hong Kong. Augmentative and Alternative Communication, 26(4), 289-298. doi:10.3109/07434618.2010.521894

Smith, M. (2005). Literacy and augmentative and alternative communication. New York, NY: Elsevier.

Smith, M. M. (2015). Language development of individuals who require aided communication: Reflections on state of the science and future research directions. Augmentative and Alternative Communication, 31(3), 215-233. doi:10.3109/07434618.2015.1062553

Smith, M. M., \& Grove, N. C. (2003). Asymmetry in input and output for individuals who use AAC. In J. C. Light, D. R. Beukelman, \& J. Reichle (Eds.), Communicative competence for individuals who use AAC: From research to effective practice (pp. 163-195). Baltimore, MD: Brookes.

Snowling, M., (2000). Language and literacy skills: Who is at risk and why? In D. V. M. Bishop, \& L. B. Leonard (Eds), Speech and Language Impairments in Children (pp. 17-34). East Sussex, UK: Psychology Press.

Soto, G. (1997). Special education teacher attitudes toward AAC: Preliminary survey. Augmentative and Alternative Communication, 13(3), 186-197. doi:10.1080/07434619712331278008 
Soto, G., Müller, E., Junt, P., \& Goetz, L. (2001). Professional skills for serving students who use AAC in general education classrooms: A team perspective. Language, Speech, and Hearing Services in Schools, 32, 51-56. doi:10.1044/0161$1641(2001 / 005)$

Soto, G., \& Zangari, C. (2009). Practically speaking: Language, literacy, \& academic development for student with AAC needs. Baltimore, MD: Paul H. Brooks.

Sturm, J. M., \& Clendon, S. A. (2004). Augmentative and alternative communication, language, and literacy: Fostering the relationship. Topics in Language Disorders, 24(1), 76-91. doi:10.1097/00011363-200401000-00008

Styles, V. (2008). Service users' acceptability of videoconferencing as a form of service delivery. Journal of Telemedicine \& Telecare, 14(8), 415-420. doi:10.1258/jtt.2008.071202

Sutherland, D. E., Gillon, G. G., \& Yoder, D. E. (2005). AAC use and service provision: A survey of New Zealand speech-language therapists. Augmentative and Alternative Communication, 21(4), 295-307. doi:10.1080/074346105000103483

Sutton, A. E. (2008). Language acquisition theory and AAC intervention. Perspectives on Augmentative and Alternative Communication, 17(2), 56-61. Retrieved from http://sig12perspectives.pubs.asha.org/

Sutton, A. E., \& Morford, J. P. (1998). Constituent order in picture pointing sequences produced by speaking children using AAC. Applied Psycholinguistics, 19(4), 525-536. doi:10.1017/S0142716400010341 
Sutton, A. E., Soto, G., \& Blockberger, S. (2002). Grammatical issues in graphic symbol communication. Augmentative and Alternative Communication, 18, 192-204. doi:10.1080/07434610212331281271

Sutton, A. E., Trudeau, N., Morford, J., Rios, M., \& Poirier, M. (2010). Preschool-aged children have difficulty constructing and interpreting simple utterances composed of graphic symbols. Journal of Child Language, 37(1), 1-26. doi:10.1017/S0305000909009477

Tarone, E. (2013). Interlanguage. In C. A. Chapelle (Ed.), The encyclopedia of applied linguistics (pp. 747-752). Oxford, UK: Wiley-Blackwell.

Thistle, J. J., \& Wilkinson, K. M. (2015). Building evidence-based practice in AAC display design for young children: Current practices and future directions. Augmentative and Alternative Communication, 31(2), 124-136. doi:10.3109/07434618.2015.1035798

Tomasello, M. (2003). Constructing a language: A usage-based theory of language acquisition. Cambridge, MA: Harvard University Press.

Tönsing, K. M., \& Dada, S. (2016). Teachers' perspectives of implementation of aided AAC to support expressive communication in South African special schools: A pilot investigation. Augmentative and Alternative Communication, 32(4), 282304. doi:10.1080/07434618.2016.1246609

Treviranus, J., \& Roberts, V. (2003). Supporting competent motor control of AAC systems. In J. C. Light, D. R. Buekelman, \& J. Reichle (Eds.), Communicative competence for individuals who use AAC: From research to effective practice (pp. 199-240). Baltimore, MD: Brookes. 
Treweek, S., \& Zwarenstein, M. (2009). Making trials matter: Pragmatic and explanatory trials and the problem of applicability. Biomedical Central, 10(37). doi:10.1186/1745-6215-10-37

Trochim, W., M., K. (2006). Research methods knowledge base. Retrieved from http://www.socialresearchmethods.net/kb/quesresp.php

Trudeau, N., Sutton, A., Dagenais, E., de Broeck, S., \& Morford, J. (2007). Construction of graphic symbol utterances by children, teenagers, and adults: The effect of structure and task demands. Journal of Speech, Language, and Hearing Research, 50, 1314-1329. doi:10.1044/1092-4388(2007/092)

Truxler, J. E., \& O'Keefe, B. M. (2007). The effects of phonological awareness instruction on beginning word recognition and spelling. Augmentative and Alternative Communication, 23(2), 164-176. doi:10.1080/07434610601151803

United States. (1966). Profile of ESEA: The Elementary and Secondary Education Act of 1965. Titles I, II, III, IV and V. Washington: U.S. Dept. of Health, Education and Welfare.

Urdan, T. C. (2010). Statistics in plain English (3rd ed.). New York, NY: Routledge Taylor \& Francis Group.

U.S. Department of Health \& Human Services (n.d.). Advocating for families. Retrieved from https://www.childwelfare.gov/topics/famcentered/caseworkpractice/advocatingfor-families/ 
Vagias, W. M. (2006). Likert-type scale response anchors. Clemson, SC: Clemson International Institute for Tourism \& Research Development, Department of Parks, Recreation, and Tourism Management, Clemson University.

van de Mortel, T. F. (2008). Faking it: Social desirability response bias in self-report research. Australian Journal of Advanced Nursing, 25(4), 40-48. Retrieved from http://www.ajan.com.au/ajan_25.4.html

Vermeerbergen, M. (2006). Past and present trends in sign language research. Language \& Communication, 26(2), 168-192. doi:10.1016/j.langcom.2005.10.004

Visser, P. S., Krosknick, J. A., \& Lavrakas, P. J. (2000). Survey research. In H. T. Reid \& C. M. Judd (Eds.), Handbook of research methods in social and personality psychology (pp. 223-252). New York, NY: Cambridge University Press.

Volterra, V., Caselli, M. C., Caprici, O., \& Pizzuto, E. (2005). Gesture and the emergence and development of language. In M. Tomasello \& D. I. Slobin (Eds.), Beyond nature-nurture: Essays in honor of Elizabeth Bates (pp. 3-40). Mahwah, NJ: Lawrence Erlbaum Associates.

von Tetzchner, S., \& Jensen, M. H. (1996). Introduction. In S. von Tetzchner, \& M. H. Jensen (Eds.), Augmentative and alternative communication: European perspectives (pp. 1-18). London, UK: Whurr/Wiley.

Wallach, G. P. (2008). Language intervention for school-age students: Setting goals for academic success. St. Louis, MO: Mosby/Elsevier.

Wallach, G. P., \& Butler, K. G. (1994). Language learning disabilities in school-age children and adolescents: Some principles and applications. London, UK: Pearson Education. 
Webb, J. T. (2007). Pragmatisms (plural) part I: Classical pragmatism and some implications for empirical inquiry. Journal of Economic Issues, 41(4), 10631086. doi:10.1080/00213624.2007.11507087

Weiss, P. L., Seligman-Wine, J., Lebel, T., Arzi, N., \& Yalon-Chamovitz, S. (2005). A demographic survey of children and adolescents with complex communication needs in Israel. Augmentative and Alternative Communication, 21(1), 56-66. doi:10.1080/07434610412331272910

Wilkinson, K. M., \& Hennig, S. C. (2009). Considerations of cognitive, attentional, and motivational demands in the construction and use of aided AAC systems. In G. Soto \& C. Zangari (Eds.), Practically speaking: Language, literacy and academic development for students with AAC needs (pp. 313-334). Baltimore, MD: Brookes.

Winford, D. (2006). Reduced syntax in (prototypical) pidgins. In L. Progovac, K. Paesani, E. Casielles, \& E. Barton (Eds.), The syntax of nonessentials: Multidisciplinary perspectives (pp. 283-307). Amsterdam, The Netherlands: John Benjamins.

Wittgenstein, L. (1922). Tractatus logio-philosophicus. London, UK Harcourt, Brace \& Company.

World Health Organization [WHO]. (2007). ICF-CY, International classification of functioning, disability and health: Children \& youth version. Geneva: Author. Wormnæs, S., \& Malek, Y. A. (2004). Egyptian speech therapists want more knowledge about augmentative and alternative communication. Augmentative and Alternative Communication, 20(1), 30-41. doi:10.1080/07434610310001629571 
Zangari, C., \& Van Tatenhove, G. (2009). Supporting more advanced linguistic communicators in the classroom. In G. Soto \& C. Zangari (Eds.), Practically speaking: Language, literacy and academic development for students with AAC needs (pp. 173-193). Baltimore, MD: Brookes. 
APPENDICES 


\section{APPENDIX A}

\section{Invitation to Participate}

Dear Participant,

I invite you to participate in a research study titled, "The Intersection of Speech-Language Pathologists' Beliefs, Perceptions, and Practices and the Language Acquisition of Emerging Aided Communicators."

I am a doctoral student at Chapman University in the Donna Ford Attallah College of Educational Studies. I am also a practicing speech-language pathologist (SLP) in the Southern California area. The purpose of my dissertation is to closely analyze the beliefs, perceptions, and practices of SLPs in their work with young children who use aided AAC as their primary means of communication. As is expressly detailed in the Consent Form, your participation in this research project is completely voluntary. You may decline altogether, you may decline to reply to any specific questions you do not wish to answer, or you may quit at any time.

Your responses will remain anonymous and the data for this research will be kept secure and reported only on the collective and combined total. No one other than my dissertation committee and myself will know any individual answers to the questionnaire. If you agree to participate in this research project, please answer the questions as best as you can. It should take approximately 16 minutes to complete. Please complete the survey as soon as you can.

In the next few days, you will receive an email from me with a link to the survey. The email will come from Qualtrics, a web-based survey tool used by Chapman University for research purposes.

If you have any questions, you can contact me at vento102@mail.chapman.edu, or my dissertation chairperson at dhunter@chapman.edu. You can also visit the Chapman University Institutional Review Board for any other questions relating to research on human subjects at: https://www.chapman.edu/research/integrity/irb/index.aspx.

If you would like to know about the results of this survey, I can be contacted at vento102@mail.chapman.edu.

Thank you very much for your participation in this research and I wish you the best in your very important work with children,

Margaret Vento-Wilson, MA, CCC-SLP

Doctoral Student, Chapman University

CHAPMAN

UN I V E R S T Y

INSTITUTIONAL REVIEW BOARD EXPIRATION DATE: 08/30/2019 


\title{
APPENDIX B
}

\section{Informed Consent}

\author{
Orange, CA 92866 \\ 714-997-6815 \\ kkennedy@chapman.edu \\ Jennifer Ostergren, $\mathrm{PhD}$ \\ Acting Chair, Department of Speech-Language Pathology \\ Associate Dean, College of Health and Human Services \\ 1250 Bellflower Blvd \\ Long Beach, CA 90840 \\ 562-985-4194 \\ Jennifer.Ostergren@csulb.edu \\ STUDY LOCATION(S): \\ A self-administered survey at the participants' location \\ STUDY SPONSOR(S): \\ None
}

Investigator Financial Conflict of Interest:

No one on the study team has a disclosable financial interest related to this research project.

\section{WHY IS THIS RESEARCH STUDY BEING DONE?}

The purpose of this research study is to examine: (1) perceptions of practices, (2) beliefs of and attitudes about language acquisition and development, and (3) perceptions of various language constructs of public elementary-school-based speech-language pathologists (SLPs) in their work with young students who use aided augmentative and alternative communication (AAC) as their primary means of communication. This research is based on the reduced linguistic outcomes of students who use AAC as their primary method of communication.

\section{HOW MANY PEOPLE WILL TAKE PART IN THIS STUDY?}

We expect that 100 people will be in this research study. All study procedures will occur at the participants' place of residence because this study uses a self-administered survey through the use of the web-based survey tool Qualtrics. The survey will be made available on computers, tablets, and phones.

WHAT PROCEDURES ARE INVOLVED WITH THIS STUDY AND HOW LONG WILL THEY TAKE?

1. Potential participants are being identified through publicly available websites of all Special Education Local Planning Areas and school districts in California.

2. The names and email addresses of all identified speech-language pathologists will be entered into a self-managed database.

3. Potential participants will receive an introductory email from Margaret Vento-Wilson with the use of her Chapman email address. This initial email will introduce the study, contain the Informed Consent form, and list the email of Margaret Vento-Wilson for any questions.

4. The following week, potential participants will receive the link to the survey and the informed consent form that will be embedded into the survey form.

5. The survey is expected to take approximately 16 minutes to complete.

6. Reminder emails will be sent every two weeks to participants as a reminder to participate in the research project. 


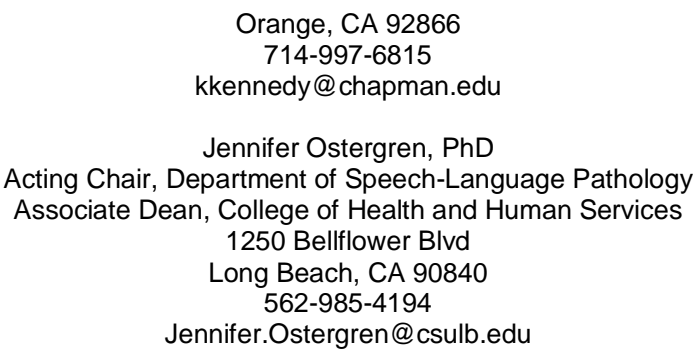

WHY IS THIS RESEARCH STUDY BEING DONE?

The purpose of this research study is to examine: (1) perceptions of practices, (2) beliefs of and attitudes about language acquisition and development, and (3) perceptions of various language constructs of public elementary-school-based speech-language pathologists (SLPS) in their work with young students who use aided augmentative and alternative communication (AAC) as their primary means of communication. This research is based on the reduced linguistic outcomes of students who use AAC as their primary method of communication.

\section{HOW MANY PEOPLE WILL TAKE PART IN THIS STUDY?}

We expect that 100 people will be in this research study. All study procedures will occur at the participants' place of residence because this study uses a self-administered survey through the use of the web-based survey tool Qualtrics. The survey will be made available on computers, tablets, and phones.

WHAT PROCEDURES ARE INVOLVED WITH THIS STUDY AND HOW LONG WILL THEY TAKE?

1. Potential participants are being identified through publicly available websites of all Special Education Local Planning Areas and school districts in California.

2. The names and email addresses of all identified speech-language pathologists will be entered into a self-managed database.

3. Potential participants will receive an introductory email from Margaret Vento-Wilson with the use of her Chapman email address. This initial email will introduce the study, contain the Informed Consent form, and list the email of Margaret Vento-Wilson for any questions.

4. The following week, potential participants will receive the link to the survey and the informed consent form that will be embedded into the survey form.

5. The survey is expected to take approximately 16 minutes to complete.

6. Reminder emails will be sent every two weeks to participants as a reminder to participate in the research project. 
7. Participants will access the survey through a link embedded in the emailed invitation.

8. Participants will take the survey on any device (desk top computer, laptop computer, tablet, mobile phone with internet connection).

9. Upon completion of the survey, the participant will have completed their contribution to the research.

AM I ELIGIBLE TO PARTICIPATE IN THIS STUDY?

Inclusion Requirements

You can participate in this study if you are a currently licensed speech-language pathologist in a California public elementary school who has had at least one emerging aided communicator on your caseload in the past two years.

\section{Exclusion Requirements}

You cannot participate in this study if you do not work in a public elementary school in California, do not currently or have not had an aided AAC user on your caseload in the past two years.

WHAT ARE THE POSSIBLE DISCOMFORTS OR RISKS RELATED TO THE STUDY?

There are no known harms or discomforts associated with this study beyond those encountered in normal daily life. The possible risks and/or discomforts associated with the procedures described in this study include possible anxiety or stress due related to (a) completing the survey during their work day or (b) the stress related to the self-evaluation of intervention.

Breach of Privacy and Confidentiality: As with any study involving collection of data, there is the possibility of breach of confidentiality of data. Every precaution will be taken to secure participants' personal information to ensure confidentiality.

\section{ARE THERE BENEFITS TO TAKING PART IN THE STUDY?}

Participant Benefits

You will not directly benefit from participation in this study.

\section{Benefits to Others or Society}

Benefits to society or science relate to the potential for improved linguistic outcomes for the population of emerging aided AAC communicators. These improved outcomes have the potential to increase communicative competence, improve literacy, and support individual agency.

\section{WHAT OTHER CHOICES ARE THERE IF I DO NOT TAKE PART IN THIS STUDY?}

You may choose not to participate in this research.

\section{WILL I BE PAID FOR TAKING PART IN THIS STUDY?}

You will not be compensated for your participation in this research study. However, Margaret VentoWilson will be donating $\$ 2.00$ (two dollars) for each completed and returned survey, with a maximum of $\$ 1000.00$, to the Orange County Childhood Language Center, a local operating unit of The California Scottish Rite Foundation. The Orange County Childhood Language Center assesses the needs of children with speech and language disorders and provides necessary treatment. It is a 501 (c) 3 corporation.

\section{Reimbursement}

You will not be reimbursed for any out of pocket expenses, such as parking or transportation fees.

Costs

CHAPMAN
IRBH: IRB-19-10 
There are no costs associated with the research.

WHAT HAPPENS IF I AM INJURED BECAUSE I TOOK PART IN THIS STUDY?

It is important that you promptly tell the researchers if you believe that you have been injured because of taking part in this study. You can tell the researcher in person or call him/her at the number listed at the top of this form.

If you become ill or get injured as a result of this study you should seek medical treatment through your doctor or treatment center of choice. The University and/or researchers are not able to offer financial compensation nor to absorb the costs of medical treatment should you be injured as a result of participating in this research.

WHAT HAPPENS IF I WANT TO STOP TAKING PART IN THIS STUDY? You are free to withdraw from this study at any time. If you decide to withdraw from this study you should notify the research team immediately. The research team may also end your participation in this study if you do not follow instructions, miss scheduled visits, or if your safety and welfare are at risk.

If you elect to withdraw or are withdrawn from this research study, the researchers will discuss with you what they intend to do with your study data. Researchers may choose to analyze the study data already collected or they may choose to exclude your data from the analysis of study data and destroy it, as per your request.

HOW WILL MY PERSONAL INFORMATION BE KEPT?

Subject Identifiable Data

There are no subject identifiers linked to the research data.

Data Storage

Research data will be stored electronically on a laptop computer in an encrypted file that is password protected. Data will also be stored on the Qualtrics platform.

\section{Data Retention}

The researchers intend to keep the research data until the research is published and/or presented.

WHO WILL HAVE ACCESS TO MY STUDY DATA?

The research team, authorized Chapman University personnel, and regulatory entities such as the Office of Human Research Protections (OHRP), may have access to your study records to protect your safety and welfare.

Any information derived from this research project that personally identifies you will not be voluntarily released or disclosed by these entities without your separate consent, except as specifically required by law. Study records provided to authorized, non-Chapman University entities will not contain identifiable information about you; nor will any publications and/or presentations without your separate consent.

While the research team will make every effort to keep your personal information confidential, it is possible that an unauthorized person might see it. We cannot guarantee total privacy.

\section{WHO CAN ANSWER MY QUESTIONS ABOUT THE STUDY?}

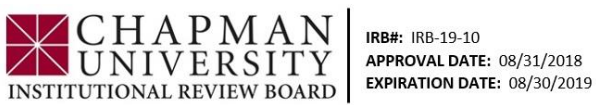


CU IRB: Social/Behav. Consent - August 2017

If you have questions, concerns, or complaints, or think the research has hurt you, talk to the research team at:

$\begin{array}{lll}\text { Dr. Dawn Hunter } & 714-997-6815 & \text { dhunter@chapman.edu } \\ \text { Margaret Vento-Wilson, Doctoral Student } & 562-243-2334 & \text { vento102@mail.chapman.edu } \\ \text { Dr. Judy Montgomery } & 714-997-6815 & \text { montgome@chapman.edu } \\ \text { Dr. Kelly Kennedy } & 714-997-6815 & \text { kkennedy@chapman.edu } \\ \text { Dr. Jennifer Ostergren } & 562-985-4194 & \text { Jennifer.Ostergren@csulb.edu }\end{array}$

This research has been reviewed and approved by an Institutional Review Board ("IRB"). You may talk to them at 714-628-2833 or irb@chapman.edu if:

Your questions, concerns, or complaints are not being answered by the research team.

You cannot reach the research team.

You want to talk to someone besides the research team.

You have questions about your rights as a research participant.

You want to get information or provide input about this research.

\section{HOW DO I AGREE TO PARTICIPATE IN THIS STUDY?}

By checking the box next to the statement "I consent to participate in this study," you are agreeing to participate. You should not check this box until all of your questions about this study have been answered by a member of the research team listed at the top of this form. You may print out or save this document for your records. Participation in this study is voluntary. You may refuse to answer any question or discontinue your involvement at any time without penalty or loss of benefits to which you might otherwise be entitled. Your decision will not affect your future relationship with Chapman University.

CHAPMAN UNIVERSITY

Experimental Subject's Bill of Rights

The rights listed below are the right of every individual asked to participate in a research study. You have the right:

1. To be told about the nature and purpose of the study.

2. To be told about the procedures to be followed in the research study, and whether any of the drugs, devices, or procedures is different from what would be used in standard practice.

3. To receive a description of any side effects, discomforts, or risks that you can reasonably expect to occur during the study.

4. To be told of any benefits that you may reasonably expect from the participation in the study, if applicable.

5. To receive a description of any alternative procedures, drugs, or devices that might be helpful, and their risks and benefits compared to the proposed procedures, drugs or devices.

CHAPMAN 
CU IRB: Social/Behav. Consent - August 2017

6. To be told of what sort of medical treatment, if any, will be available if any complications should arise.

7. To be given a chance to ask any questions concerning the research study both before agreeing to participate and at any time during the course of the study.

8. To refuse to participate in the research study. Participation is voluntary. You may refuse to answer any question or discontinue your involvement at any time without penalty or loss of benefits to which you might otherwise be entitled. Your decision will not affect your right to receive the care you would receive if you were not in the experiment.

9. To receive a copy of the signed and dated written consent form and a copy of this form.

10. To be given the opportunity to freely decide whether or not to consent to the research study without any force, coercion, or undue influence.

If you have any concerns or questions regarding the research study you should contact the research team listed at the top of the consent form.

If you are unable to reach a member of the research team and have general questions, or you have concerns or complaints about the research study, research team, or questions about your rights as a research subject, please contact the Chapman University IRB staff at 714-628-2833 or irb@chapman.edu.

CHAPMAN

IRB\#: IRB-19-10 


\section{APPENDIX C}

Survey 
This survey focuses on the use of aided augmentative and alternative communication (AAC) systems by children with complex communication needs. The descriptor for this population is "Emerging Aided Communicators."

For purposes of this survey, AAC is being defined as a communication system used to compensate for temporary or permanent severe expressive and receptive speech-language impairments (ASHA, 2004; Branson \& Demchak, 2009; Davidoff, 2017).

AAC can be unaided and aided. Unaided AAC can include gestures, signs, body language, and facial expressions. Aided AAC can include both high tech (speech-generating devices) and low tech (low tech communication books, communication boards, pen/paper). People may use a single AAC method or a combination to communicate.

In this survey, instructions have been formatted in italics, questions in bold, and answers in plain text to support greater clarity

\begin{tabular}{|c|c|}
\hline & $\begin{array}{l}\text { Click on the link below to review the Informed Consent document } \\
\text { (link to Informed Consent document pdf) }\end{array}$ \\
\hline QIC1.1 & By checking the box below, I agree that I have read the Informed Consent document and I consent to participate in this survey: \\
\hline & I have read the Informed Consent document and I agree to participate in this survey. \\
\hline & I do not want to proceed in this survey. \\
\hline QIC1.2 & In order to continue in this survey, please check all boxes that apply to you: \\
\hline & I am an SLP in a public elementary school in California \\
\hline & I have had an aided AAC user on my caseload in the past two years \\
\hline
\end{tabular}

SLP Demographics

Introduction:

The first set of questions refers to your certification, the number of years you have been a practicing SLP, and your education. Some of the questions require you to check a box for your response or use a pull down menu, and others require you to manipulate items. 
This is also a new section in the survey, which means you can use the "go back" arrow to review questions and answers.

Q1.1 $\quad$ Indicate your certification or credential level. You may check all that apply:

Currently certified as "Certificate of Clinical Competence" by ASHA.

Currently licensed with a "Speech-Language Pathology Services Credential in Language, Speech and Hearing" by the state of California.

Currently working on a waiver in a public elementary school.

Q1.2 How many years have you been a practicing SLP, including your clinical fellowship year?

$1-5$

6-10

$11+$

As indicated previously, for this survey, AAC is defined as any form of augmentative or alternative methods of communication. AAC can be unaided and aided. Unaided AAC can include gestures, signs, body language, and facial expressions. Aided AAC can include both high tech (speech-generating devices) and low tech (low tech communication books, communication boards, pen/paper). People may use a single AAC method or a combination to communicate.

Q1.3 $\quad$ When did you take an AAC-specific course in your university program?

In my undergraduate program

In my graduate program

I had a course in AAC at both levels

I did not have an AAC-specific course in my undergraduate or graduate program

I am not sure

Q1.4 $\quad$ Do you feel your university program prepared you sufficiently to work with children who use AAC?

Yes

No 


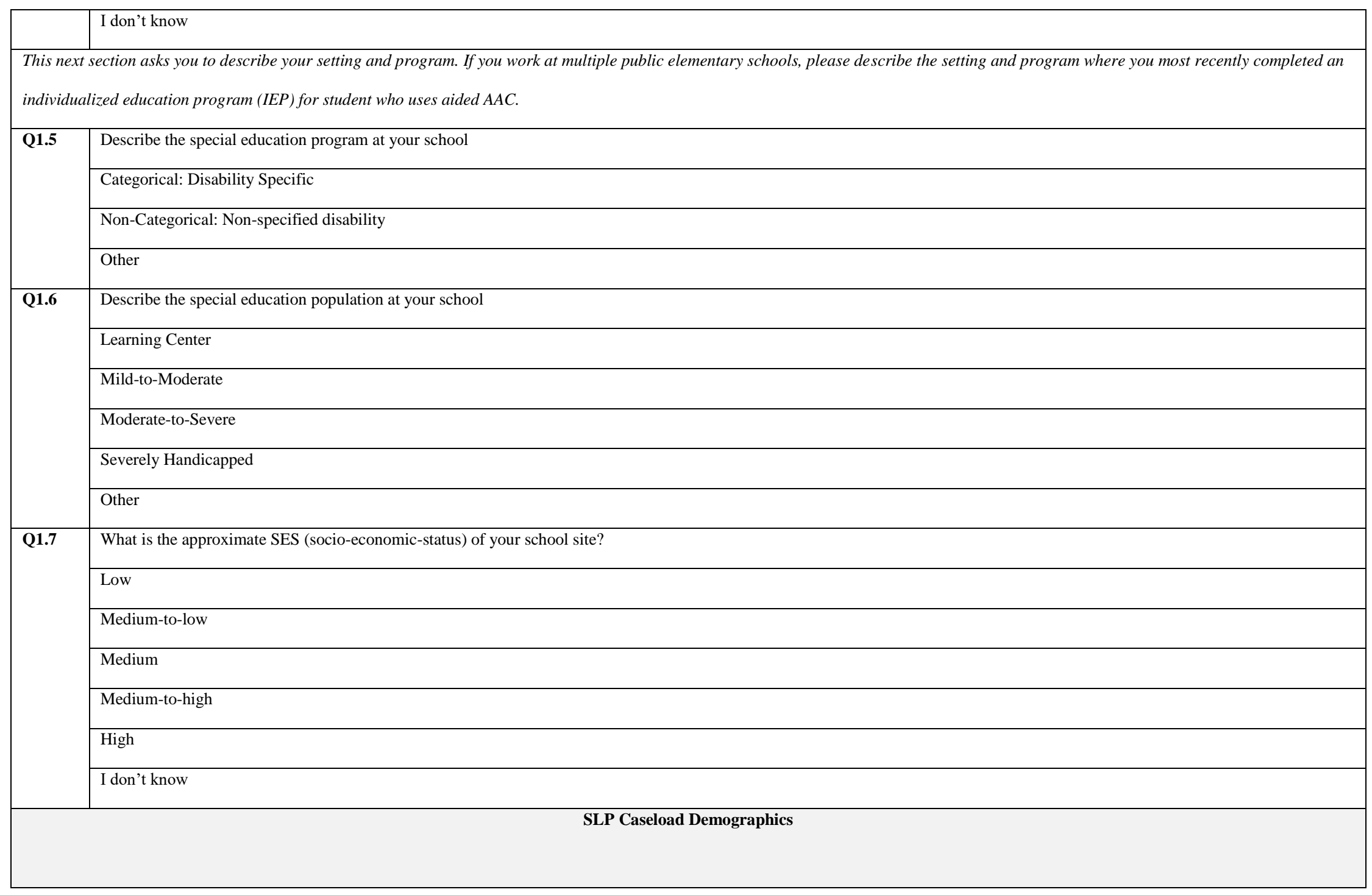




\section{Introduction:}

The next set of questions will ask you about your caseload at your public elementary school. If you currently work at more than one elementary school, please consider the entire population of students on your elementary school caseload, across all settings. The questions focus on the children on your caseload who use aided AAC.

As indicated above, aided AAC can include both high tech (speech-generating devices) and low tech (low tech-communication books, communication boards, pen/paper). People may use a single AAC method or a combination to communicate.

\section{\begin{tabular}{l|l} 
Q2.1 & What is your current caseload size, as measured by the total number of students you see over the course of a month?
\end{tabular}}

\begin{tabular}{|l|}
\hline 19 or fewer \\
\hline $20-29$ \\
\hline $30-39$ \\
\hline $40-49$ \\
\hline $50+$ \\
\hline How many students currently on your caseload use aided AAC (e.g., dedicated device, computer application program on a tablet, keyboard, PECS, communication book)? \\
\hline $1-3$ \\
\hline $4-6$ \\
\hline $7+$ \\
\hline I do not have any AAC aided AAC users on my caseload
\end{tabular}

For purposes of this study, the term "direct select," means that the child uses a finger or other body part to access a specific item on the AAC system. It typically involves physical contact or eye pointing or eye tracking. The term "indirect select," means that the child selects from a set of choices that are presented to him/her. Examples include various types of scanning.

Q2.3 $\quad$ How many of the aided AAC users on your caseload use the following:

\begin{tabular}{|l|l|l|l|l|l|l|l|l|}
\hline & $4+6$ & None & $1-$ & $4-6$ \\
\hline
\end{tabular}




\begin{tabular}{|c|c|c|c|c|c|}
\hline & & & 3 & & \\
\hline & Indirect Select & & & & \\
\hline & Direct Select & & & & \\
\hline & Low-Tech AAC (communication book, PECS Big Mac) & & & & \\
\hline & High-Tech AAC (dedicated device, computer application on a tablet, keyboard) & & & & \\
\hline Q2.4 & How many of the aided AAC users on your caseload use their aided AAC system in the following settings on a daily basis? & & & & \\
\hline & & None & $1-$ & $4-6$ & $7+$ \\
\hline & Pull-out speech-language therapy sessions & & & & \\
\hline & $\begin{array}{l}\text { Push-in speech-language therapy sessions } \\
\end{array}$ & & & & \\
\hline & In the classroom for academic tasks & & & & \\
\hline & $\begin{array}{l}\text { For non-classroom-based activities (e.g., music, lunch tables, recess, library) } \\
\end{array}$ & & & & \\
\hline & In the home & & & & \\
\hline Q2.5 & How many hours a week do you spend on the following tasks: & & & & \\
\hline & & None & $1-$ & $5-8$ & $9+$ \\
\hline & Direct Intervention with an aided AAC user & & & & \\
\hline & Programming high-tech AAC devices & & & & \\
\hline & Making material for low-tech AAC systems & & & & \\
\hline & Collaborating with teachers, allied professionals, or family members on the topic of AAC & & & & \\
\hline & Opinions: General & & & & \\
\hline
\end{tabular}




\section{Introduction:}

The next set of questions asks you to identify factors affecting the language acquisition and development of emerging aided communicators and for oral communicators. Emerging aided communicators are defined as children who are concomitantly in the early stages of language development while learning to use their aided AAC system.

Some of the questions require you to check a box for your response and others require you to manipulate items.

Q3.1 $\quad$ Indicate your level of agreement with the following statements: The acquisition and development of language is driven largely by the comprehension of language. This belief implies that language comprehension is sufficient for the acquisition and development of language.

\begin{tabular}{|l|l|l|l|l}
\hline Do not agree at all & Only slightly agree & Somewhat agree & Agree & Strongly Agree
\end{tabular}

B $\quad$ The acquisition and development of language is driven largely by the production or use of language. This belief implies that language acquisition and development require both comprehension and use of language.

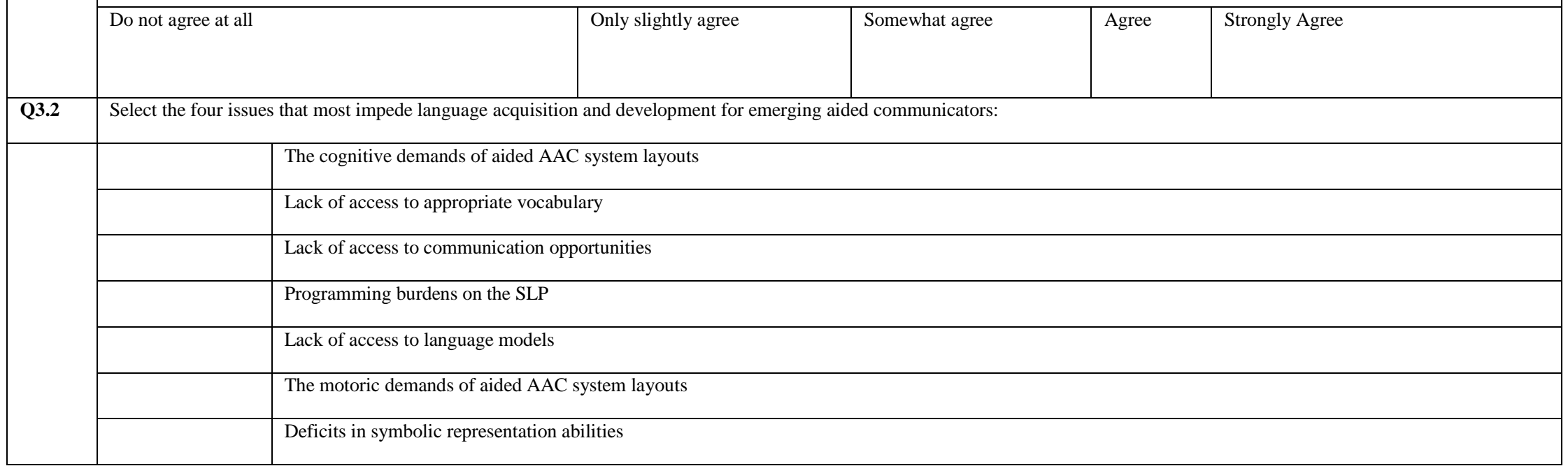




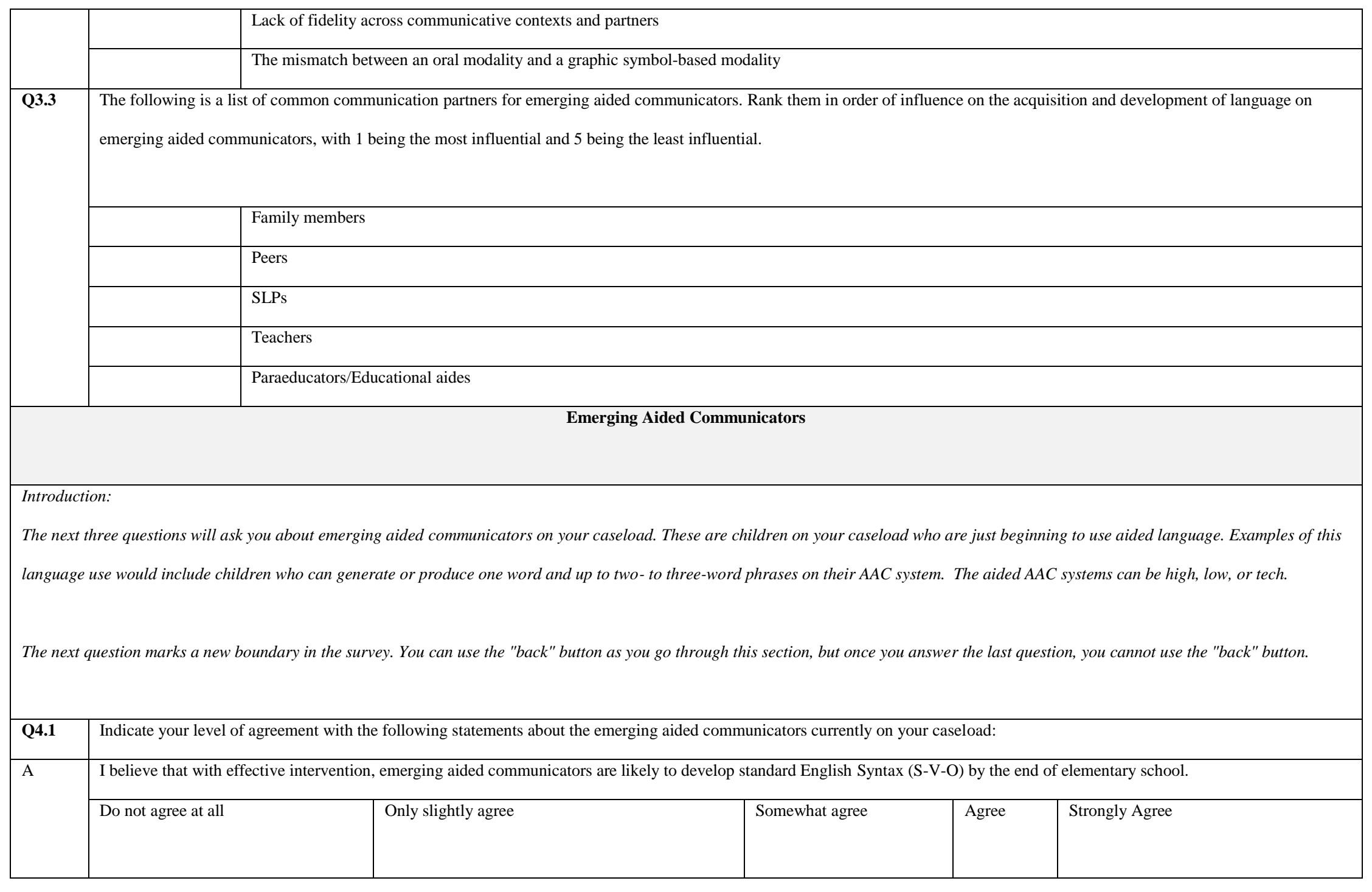




\begin{tabular}{|c|c|c|c|c|c|}
\hline \multirow[t]{2}{*}{ B } & \multicolumn{5}{|c|}{ I believe that language development hierarchies, such as stages of language development, are important components of intervention with emerging aided communicators. } \\
\hline & Do not agree at all & Only slightly agree & Somewhat agree & Agree & Strongly Agree \\
\hline \multirow[t]{2}{*}{$\mathrm{C}$} & \multicolumn{5}{|c|}{ I believe that it is important to consider criterion-referenced norms when analyzing the language acquisition and development of emerging aided communicators } \\
\hline & Do not agree at all & Only slightly agree & Somewhat agree & Agree & Strongly Agree \\
\hline \multirow[t]{2}{*}{$\mathrm{D}$} & \multicolumn{5}{|c|}{ I believe it is important to include a language sample in speech-language assessments for emerging aided communicators. } \\
\hline & Do not agree at all & Only slightly agree & Somewhat agree & Agree & Strongly Agree \\
\hline \multirow[t]{2}{*}{ E } & \multicolumn{5}{|c|}{ I believe that emerging aided communicators can acquire and develop language while learning to use aided AAC. } \\
\hline & Do not agree at all & Only slightly agree & Somewhat agree & Agree & Strongly Agree \\
\hline Q4.2 & Indicate your level & following statements & unicators currently & eload: & \\
\hline \multirow[t]{2}{*}{ A } & \multicolumn{5}{|c|}{$\underline{\text { I am confident in developing an intervention plan for an emerging aided communicator given a thorough assessment report. }}$} \\
\hline & Do not agree at all & Only slightly agree & Somewhat agree & Agree & Strongly Agree \\
\hline \multirow[t]{2}{*}{ B } & \multicolumn{5}{|c|}{ I feel qualified to provide intervention targeting language acquisition for emerging aided communicators. } \\
\hline & Do not agree at all & Only slightly agree & Somewhat agree & Agree & Strongly Agree \\
\hline \multirow[t]{2}{*}{$\mathrm{C}$} & \multicolumn{5}{|c|}{ I am confident that my intervention with emerging aided communicators will result in the acquisition of standard English syntax (S-V-O) by the end of elementary school. } \\
\hline & Do not agree at all & Only slightly agree & Somewhat agree & Agree & Strongly Agree \\
\hline
\end{tabular}




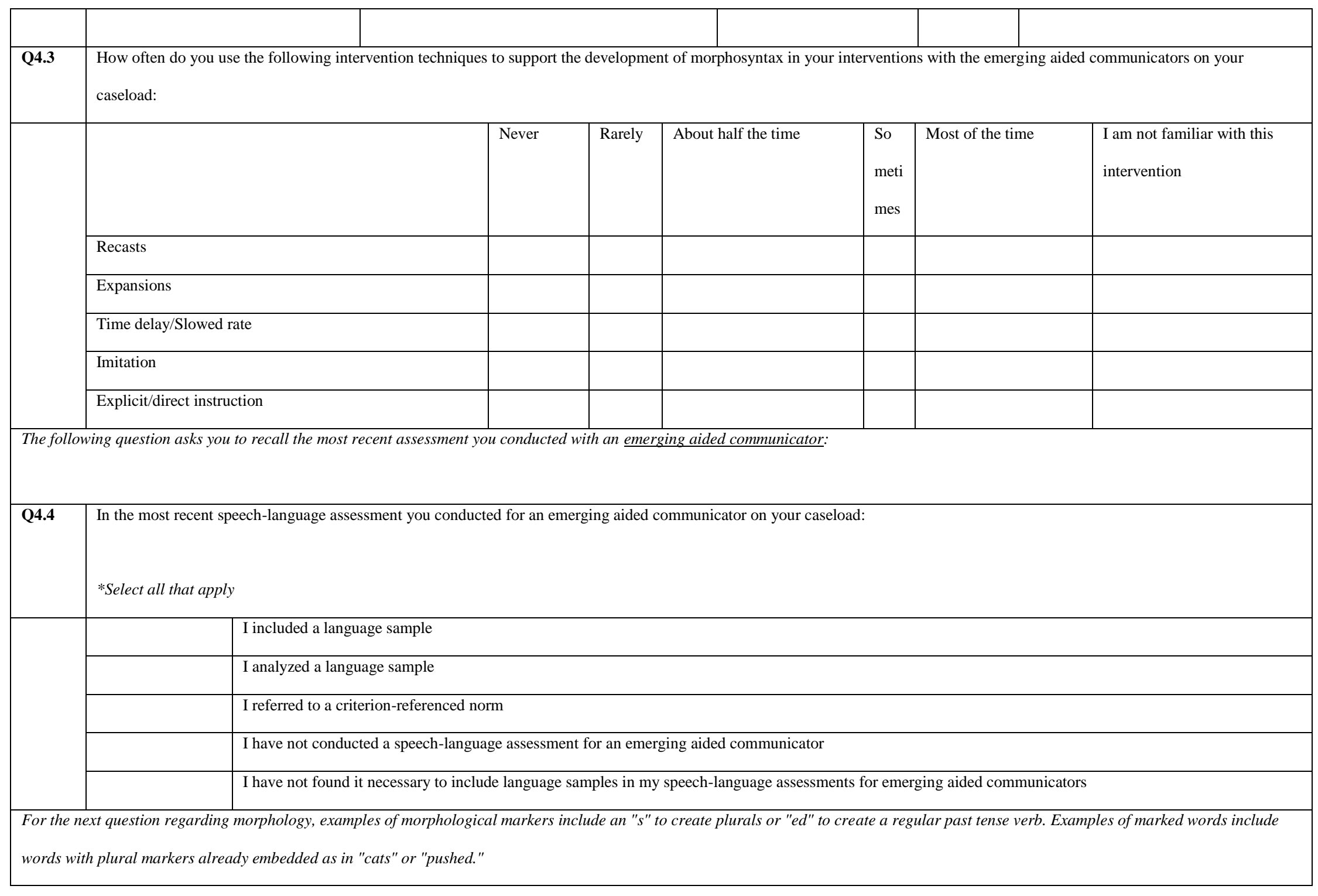




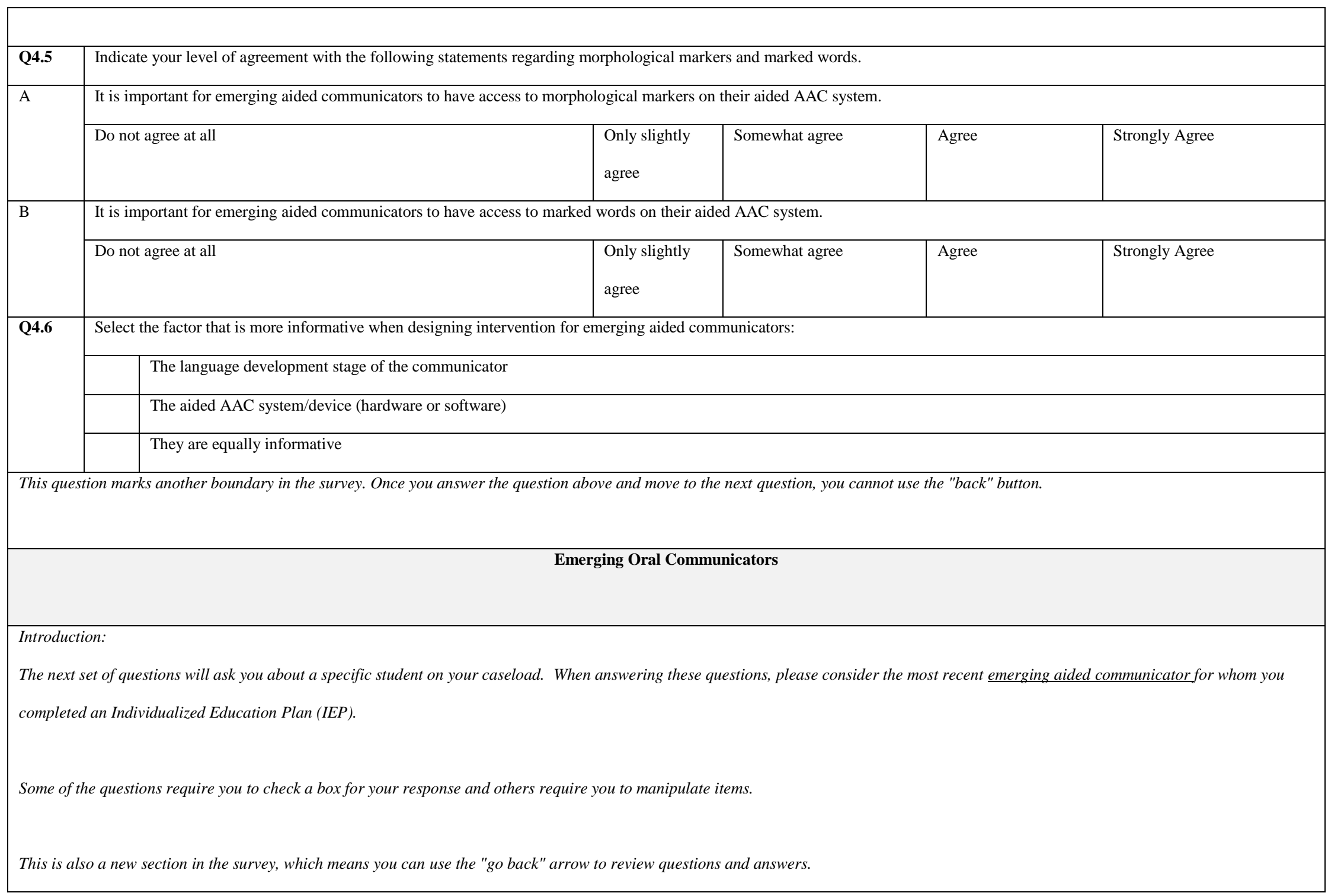




\begin{tabular}{|c|c|c|c|c|c|}
\hline Q5.1 & \multicolumn{5}{|c|}{ Indicate your level of agreement with the following statements about the emerging oral communicators with language impairments currently on your caseload: } \\
\hline \multirow[t]{2}{*}{ A } & \multicolumn{5}{|c|}{ I believe that with effective intervention, emerging oral communicators are likely to develop standard English Syntax (S-V-O) by the end of elementary school. } \\
\hline & Do not agree at all & Only slightly agree & Somewhat agree & Agree & Strongly Agree \\
\hline \multirow[t]{2}{*}{$\mathrm{B}$} & \multicolumn{5}{|c|}{ I believe that language development hierarchies, such as stages of language development, are important components of intervention with emerging oral communicators. } \\
\hline & Do not agree at all & Only slightly agree & Somewhat agree & Agree & Strongly Agree \\
\hline \multirow[t]{2}{*}{$\mathrm{C}$} & \multicolumn{5}{|c|}{ I believe that it is important to consider criterion-referenced norms when analyzing the language acquisition and development of emerging oral communicators. } \\
\hline & Do not agree at all & Only slightly agree & Somewhat agree & Agree & Strongly Agree \\
\hline \multirow[t]{2}{*}{$\mathrm{D}$} & \multicolumn{5}{|c|}{ I believe it is important to include a language sample in speech-language assessments for emerging oral communicators. } \\
\hline & Do not agree at all & Only slightly agree & Somewhat agree & Agree & Strongly Agree \\
\hline Q5.2 & \multicolumn{5}{|c|}{ Indicate your level of agreement with the following statements about the emerging oral communicators with language impairments currently on your caseload: } \\
\hline \multirow[t]{2}{*}{ A } & \multicolumn{5}{|c|}{$\underline{I}$ am confident that my intervention with emerging oral communicators will result in the acquisition of standard English syntax (S-V-O) by the end of elementary school. } \\
\hline & Do not agree at all & Only slightly agree & Somewhat agree & Agree & Strongly Agree \\
\hline \multirow[t]{2}{*}{ B } & \multicolumn{5}{|c|}{$\underline{\text { I feel qualified to provide intervention targeting language acquisition and development for emerging oral communicators. }}$} \\
\hline & Do not agree at all & Only slightly agree & Somewhat agree & Agree & Strongly Agree \\
\hline \multirow[t]{2}{*}{$\mathrm{C}$} & \multicolumn{5}{|c|}{$\underline{\text { I am confident in developing an intervention plan for emerging oral communicators given a thorough assessment report. }}$} \\
\hline & Do not agree at all & Only slightly agree & Somewhat agree & Agree & Strongly Agree \\
\hline
\end{tabular}




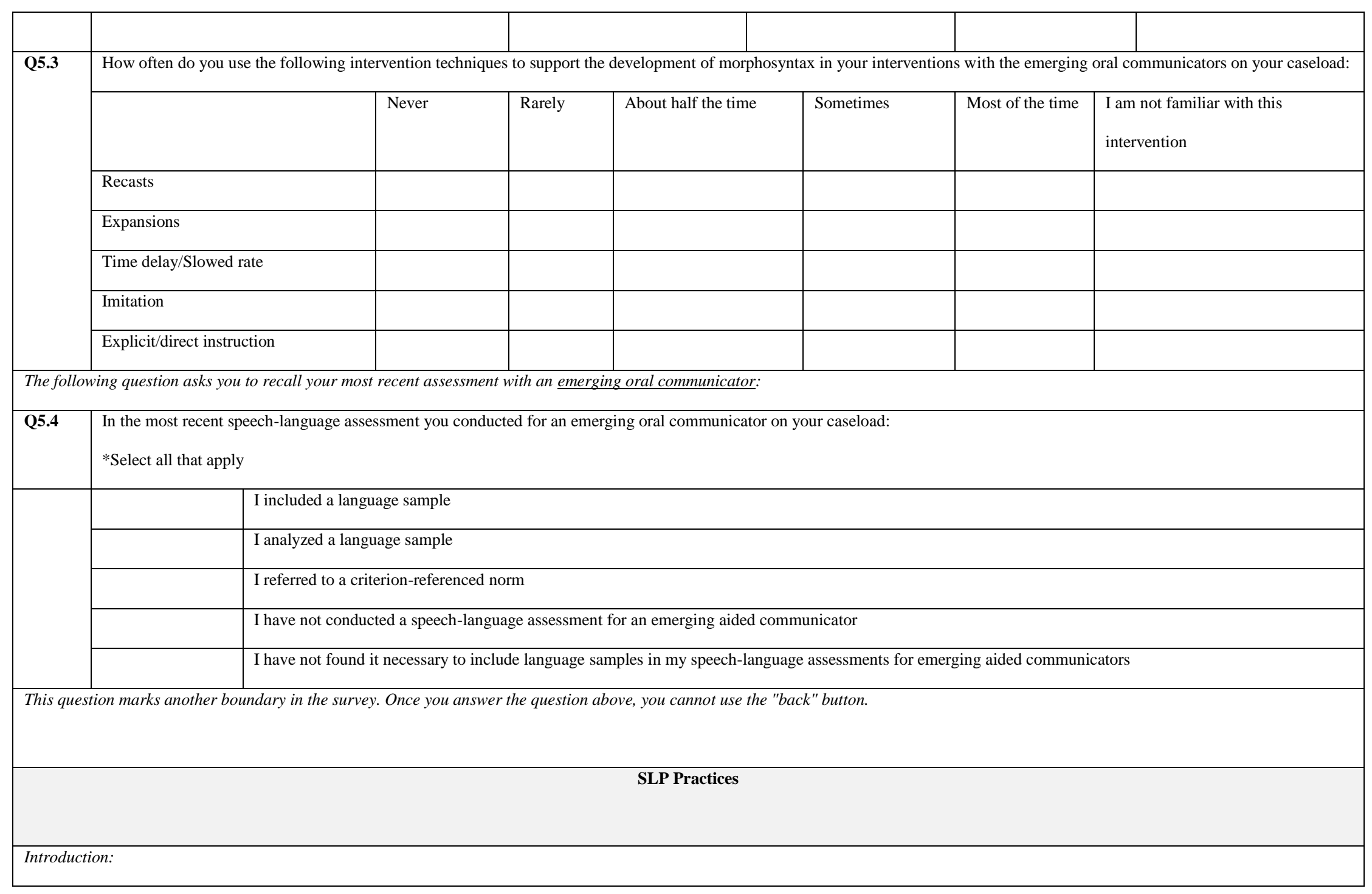


The next set of questions will ask you about a specific student on your caseload. When answering these questions, please consider the most recent emerging aided communicator for whom you

completed an Individualized Education Plan (IEP)

Some of the questions require you to check a box for your response and others require you to manipulate items.

This is also a new section in the survey, which means you can use the "go back" arrow to review questions and answers.

\begin{tabular}{l|l} 
Q6.1 & How long has this emerging aided communicator been on your caseload?
\end{tabular}

\begin{tabular}{|c|c|}
\hline & Less than one-half of an academic year \\
\hline & Approximately one-half of an academic year \\
\hline & Approximately three-quarters of an academic year \\
\hline & A full academic year \\
\hline & More than a full academic year \\
\hline What i & the grade level of this emerging aided communicator \\
\hline & Preschool \\
\hline & Kindergarten \\
\hline & First Grade \\
\hline & Second Grade \\
\hline & Third Grade \\
\hline & Fourth Grade \\
\hline & Fifth Grade \\
\hline & Sixth Grade \\
\hline
\end{tabular}




\begin{tabular}{|c|c|c|c|}
\hline \multirow{3}{*}{\multicolumn{2}{|c|}{ Q6.3 }} & & \\
\hline & & & General Education \\
\hline & & & Special Education \\
\hline \multirow{13}{*}{\multicolumn{2}{|c|}{ Q6.4 }} & & \\
\hline & & & Autism \\
\hline & & & Deaf/Hard of Hearing \\
\hline & & & Deaf/blind \\
\hline & & & Emotional Disturbance \\
\hline & & & Intellectual Disability \\
\hline & & & Multiple Disabilities \\
\hline & & & Other Health Impairment \\
\hline & & & Orthopedic Impairment \\
\hline & & & Specific Language Ability \\
\hline & & & Specific Learning Disability \\
\hline & & & Traumatic Brain Impairment \\
\hline & & & Visual Impairment \\
\hline \multirow{6}{*}{\multicolumn{2}{|c|}{ Q6.5 }} & & \\
\hline & & & Non-Intentional/Non-Symbolic \\
\hline & & & Intentional/Non-Symbolic \\
\hline & & & Intentional/Symbolic \\
\hline & & & Linguistic \\
\hline & & & Other \\
\hline
\end{tabular}




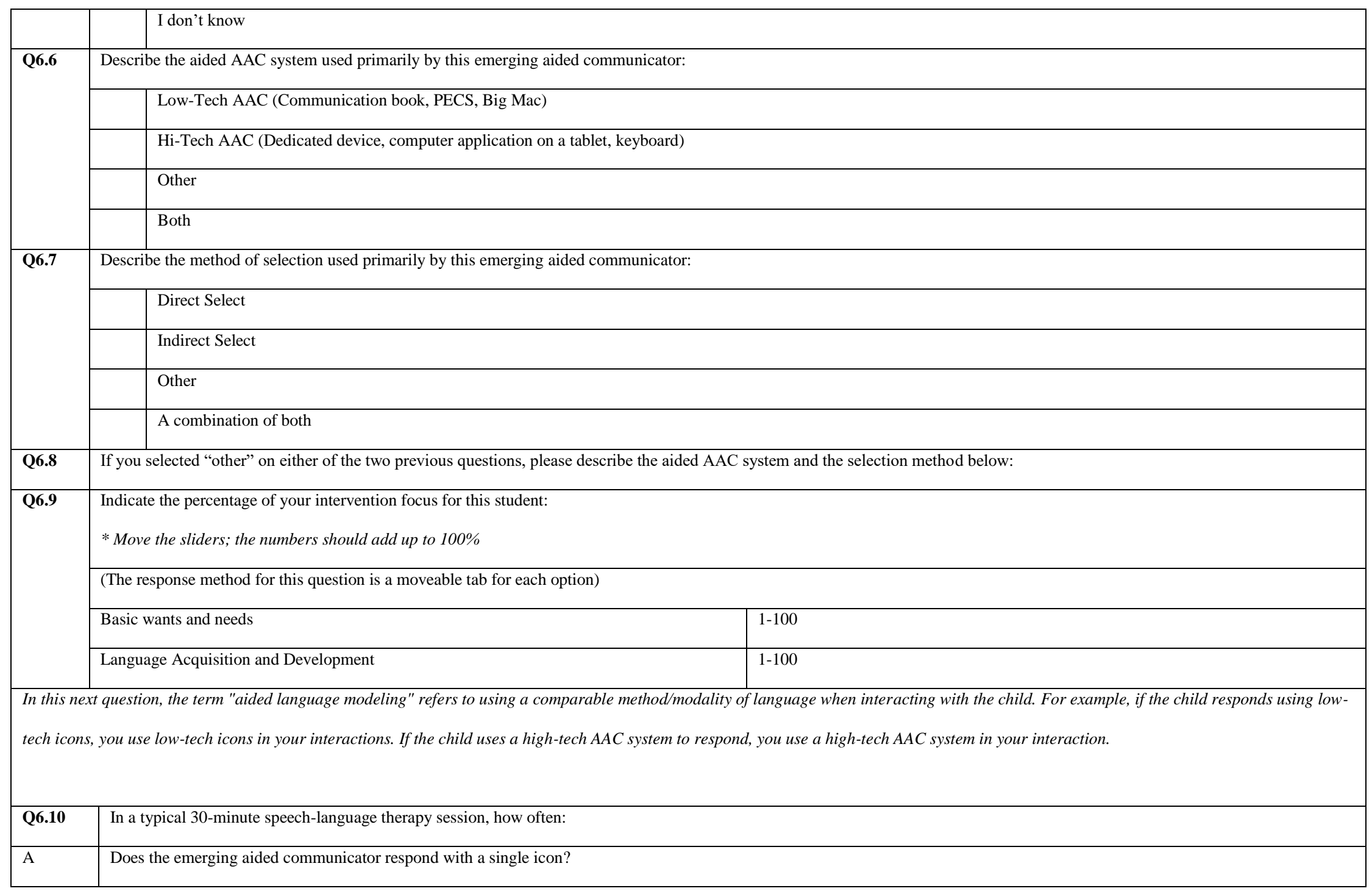




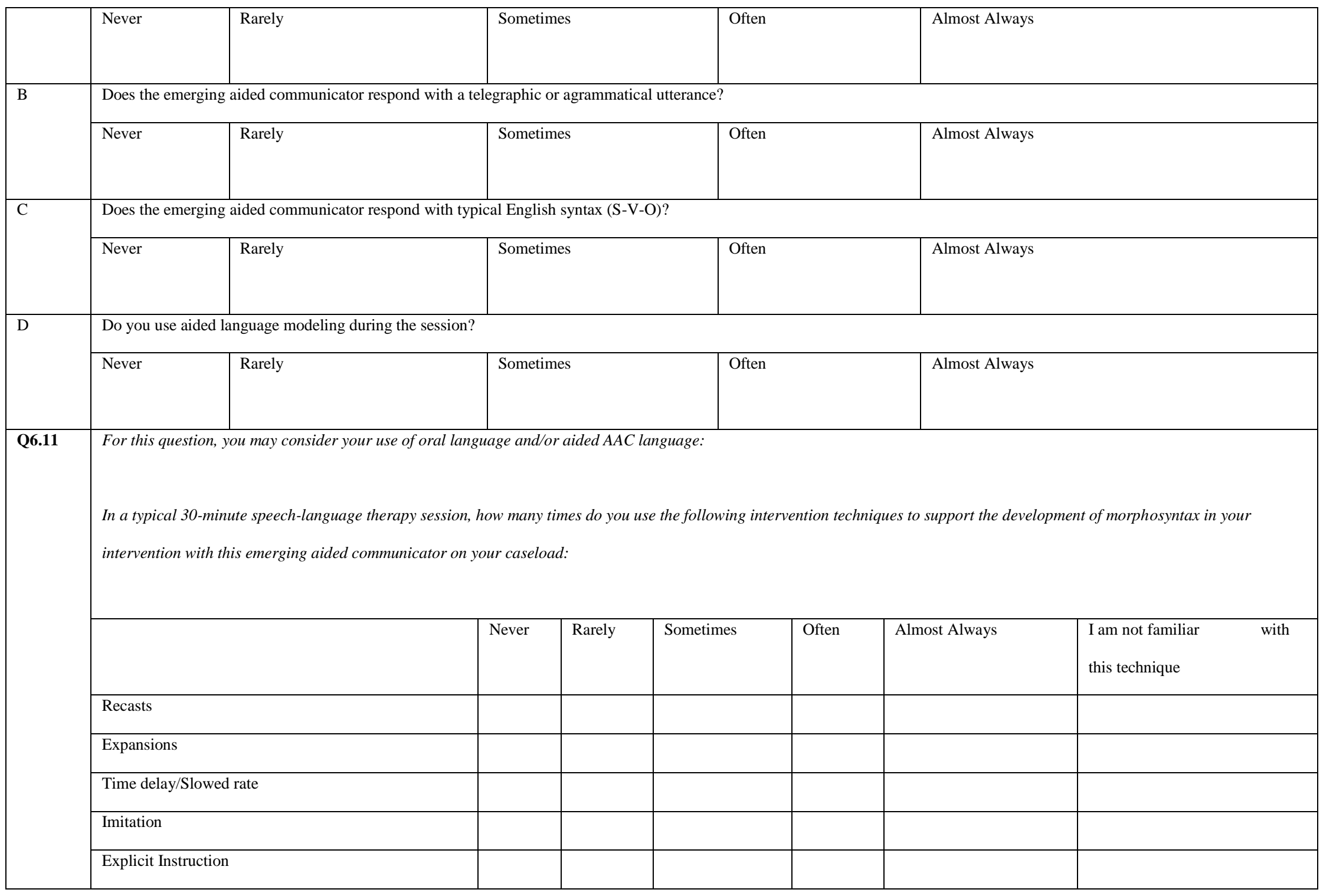


This question marks another boundary in the survey. Once you answer the question above and move to the next question, you cannot use the "back" button.

Narrative Response

Q7.1 $\quad$ As an SLP who works with children who use aided AAC devices/systems, your opinions have a deep and unique value to the world of research. Because of your experience with the language acquisition and development of emerging aided communicators, please describe your perspective on the high frequency of atypical word order and reduced phrase length in the language produced by these children:

As an SLP myself, I understand how valuable your time and expertise are and I want to take this opportunity to thank you for participating in my survey. If you would like to read about the results 
of this work, send an email to vento102@ mail.chapman.edu with the subject line, "Dissertation Results" and I will share my findings.

Thank you again! 


\title{
APPENDIX D
}

\author{
Narrative Responses
}

\begin{tabular}{|c|c|}
\hline Number & Response \\
\hline 1. & $\begin{array}{l}\text { I feel like my responses may be a little skewed. I work with mostly severe } \\
\text { children who are just starting to learn their devices. I'm still working on them } \\
\text { understanding that their devices are a way to communicate and have an effect } \\
\text { on the world around them. I'm mostly working on core vocabulary, which, I } \\
\text { think, has more potential to expand to closer to grammatically correct } \\
\text { sentences than some setups. With the student who I had who was the furthest } \\
\text { along in using their device, I was working on grammar. She mostly talked in } \\
\text { nouns. I worked on SVO with her as well as verb tenses and plurals. I think } \\
\text { that that is an excellent goal if/when it's appropriate for them in their } \\
\text { AAC/communication journey. However, I am working on correct word order } \\
\text { for even my most severe kids (start with I/you/we + verb (go, come, put, help, } \\
\text { get). Also work on questions using the appropriate word order (where go?) }\end{array}$ \\
\hline 2. & $\begin{array}{l}\text { It's very frequent. Causes are multifactorial and include: lack of language } \\
\text { models, cognitive deficits, motor planning deficits, consistency }\end{array}$ \\
\hline 3. & $\begin{array}{l}\text { Personally I am more concerned if the student is able to communicate rather } \\
\text { than being in the correct order. I always recast their utterance to be in the } \\
\text { correct order but I think if they are using all the appropriate words to } \\
\text { communicate effectively, that is a success. }\end{array}$ \\
\hline 4. & $\begin{array}{l}\text { One of the barriers I run up against most often is lack of use of the AAC } \\
\text { device when the child is outside of a speech therapy session. The AAC user is } \\
\text { given a fraction of the communication opportunities that verbal children are } \\
\text { given and I believe that is often reflected in their ability to generate } \\
\text { appropriate word order/appropriate phrase length. I also think that many } \\
\text { educators and parents view devices as a quick miracle fix (if I had a dollar for } \\
\text { every time a parent demanded an iPad..) and don't understand that aided } \\
\text { communicators need to learn language on their device or program the same } \\
\text { way that children learn oral language. It takes time and modeling, and I } \\
\text { believe there's a general lack of understanding of how children learn to } \\
\text { communicate using AAC. Education on the topic is often refuted or ignored } \\
\text { by educators and parents. }\end{array}$ \\
\hline 5. & $\begin{array}{l}\text { Telegraphic speech is often modeled for the student at home and in the } \\
\text { classroom }\end{array}$ \\
\hline 6. & $\begin{array}{l}\text { I have found that the content of the message is more important than incorrect } \\
\text { word order or reduced phrase length. As long as the message is expressed and } \\
\text { conveyed, the intent is known and met. Depending on the device or app if } \\
\text { using high tech AAC, there are certain limitations in editing and selection of } \\
\text { icons and order. For convenience and efficiency, reduced phrase length is } \\
\text { common and acceptable. I feel the message can be more easily accessible and } \\
\text { conveyed using a shorter phrase length. }\end{array}$ \\
\hline
\end{tabular}




\begin{tabular}{|c|c|}
\hline Number & Response \\
\hline 7. & $\begin{array}{l}\text { I work with young children between the ages of } 2 \text { and } 6 \text {. I am usually the first } \\
\text { person to introduce the student and family to an AAC system. As such, most } \\
\text { of my students are at the single word level and are using their device/system } \\
\text { to communicate their needs/ wants. I do understand that and have seen older } \\
\text { children using typing and voice output devices as they grow out of low tech } \\
\text { devices. I always model and expand a student's language with appropriate } \\
\text { word order in hopes that it will stick as they get older. }\end{array}$ \\
\hline 8. & $\begin{array}{l}\text { I think that these children do not always receive good language models since } \\
\text { people feel they need to oversimplify for these children. I also think these } \\
\text { children tend to have a lot of issues with pronoun use since language partners } \\
\text { don't know how to model this for the students: e.g. when modeling in a } \\
\text { conversation the SLP wants to talk about herself so she uses "I" but then also } \\
\text { models "I" for a student request. I also think sometimes SLP's don't do a good } \\
\text { job varying the language/allowing for one word responses. If you ask a } \\
\text { typical child if they want milk or juice, them responding with just "milk" } \\
\text { would be totally typical. But for our students communicating with AAC we } \\
\text { demand "I want milk" as a response, which in reality isn't a super typical } \\
\text { response nor is it efficient for the student. }\end{array}$ \\
\hline 9. & $\begin{array}{l}\text { Ideally, I'd like students to use more morphologically/syntactically complex } \\
\text { utterances. I typically use Core } 40 \text { words which include some descriptors } \\
\text { (place/quantity) to enhance their language and help them communicate more } \\
\text { effectively. However, I am not super critical of student's atypical word order } \\
\text { or phrase length if they're communicating effectively with the intended } \\
\text { listener. }\end{array}$ \\
\hline 10. & $\begin{array}{l}\text { I believe it to be impacted by many things, including The increased time and } \\
\text { effort it takes to generate language through AAC. When motoric demands are } \\
\text { high, linguistic output is low. Therefore, the most important things to } \\
\text { communicate are learned the fastest and the rest can come later (from the } \\
\text { child's perspective). }\end{array}$ \\
\hline 11. & $\begin{array}{l}\text { I believe emerging aided communicators are trying to get their message across } \\
\text { in the most effective way possible and therefore may only produce } 1-2 \text { words } \\
\text { then wait for their communicative partner to ask a follow-up question to } \\
\text { which they will respond 1-2 words again. This is the most effective way for } \\
\text { an emerging aided communicator to get an entire message across. Emerging } \\
\text { aided communicators benefit from language models from adults around them } \\
\text { and direct/explicit instruction of syntax/word order. }\end{array}$ \\
\hline 12. & $\begin{array}{l}\text { I believe that the productions of students using aided AAC devices are largely } \\
\text { a result of the modeling or lack of modeling provided to the student. I most } \\
\text { often see the atypical word order and reduced phrase lengths produced in } \\
\text { settings where the teachers, paraeducators and SLPs are not modeling } \\
\text { sufficiently and providing high-interest language-rich opportunities for the } \\
\text { students. }\end{array}$ \\
\hline 13. & $\begin{array}{l}\text { For my students who use AAC, I find it more important for them to have the } \\
\text { ability to get a message out at all, regardless of grammatical forms. The } \\
\text { biggest problem I see with my student's abilities to use AAC to communicate }\end{array}$ \\
\hline
\end{tabular}




\begin{tabular}{|c|c|}
\hline Number & Response \\
\hline & $\begin{array}{l}\text { is their personal motivation. All of them are able to use their AAC device to } \\
\text { request their most desired items, with appropriate word order. They are } \\
\text { generally not very motivated to develop the same ability to communicate for } \\
\text { academic purposes. Motivation is a huge factor. }\end{array}$ \\
\hline 14. & $\begin{array}{l}\text { I think atypical word order and reduced phrase length are appropriate for } \\
\text { emerging aided communicators. The meaning of their message is more } \\
\text { important than the grammar. They need to learn the power of communicating. } \\
\text { Once they have that down, then we can focus on the specific grammar. }\end{array}$ \\
\hline 15. & $\begin{array}{l}\text { I believe there is a high frequency of atypical word order and reduced phrase } \\
\text { length in children who use aided AAC systems, partially due to the low } \\
\text { language modeling (on the same AAC system) from other communicators and } \\
\text { lack of access to vocabulary/morphological components on the device, and } \\
\text { difficulty with navigation. }\end{array}$ \\
\hline 16. & $\begin{array}{l}\text { These children are essentially learning another language, so there is going to } \\
\text { be atypical word order and reduced phrase length. Their acquisition of } \\
\text { language via their AAC device/system looks similar to a developmental } \\
\text { trajectory. There may be some splintered skills within their learning, but it is } \\
\text { expected to see atypical word order and reduced phrase length in their } \\
\text { language as they are learning to navigate their device. }\end{array}$ \\
\hline 17. & $\begin{array}{l}\text { I think that navigating devices pose a problem with morphological markers. } \\
\text { Also, it can take a while to navigate systems which can be frustrating so } \\
\text { getting the idea across provides quicker exchanges with their communication } \\
\text { partners }\end{array}$ \\
\hline 18. & $\begin{array}{l}\text { I teach functional multi modality communication. I feel functional } \\
\text { communication should be in place before working on word order and phrase } \\
\text { length. }\end{array}$ \\
\hline 19. & $\begin{array}{l}\text { Most students respond using less words than an oral communicator as it takes } \\
\text { more time and effort to communicate their wants/needs. }\end{array}$ \\
\hline 20. & $\begin{array}{l}\text { Thinking of the students on my caseload (mod-severe autism), I think the } \\
\text { trajectory for acquiring language is delayed. In addition, they are having to } \\
\text { navigate learning language through a low or high tech AAC system. Another } \\
\text { important factor is the intervention being utilized by the SLP. It is critical that } \\
\text { SLPs go beyond teaching these children how to request. SLPs need to provide } \\
\text { solid, evidence-based, language intervention. }\end{array}$ \\
\hline 21. & $\begin{array}{l}\text { When modeling use of a dynamic AAC system as a cognitively intact adult, I } \\
\text { can see that using a dynamic AAC system is a challenging task for anyone. I } \\
\text { do not place a heavy burden on word order and syntax errors due to this truth. }\end{array}$ \\
\hline 22. & $\begin{array}{l}\text { The children I've worked with develop telegraphic speech first, and it may or } \\
\text { may not follow English grammar patterns. My focus is more on allowing } \\
\text { them to advocate for themselves and communicate with others versus having } \\
\text { correct grammar but more limited use of language across settings. }\end{array}$ \\
\hline 23. & $\begin{array}{l}\text { I don't have thoughts on the atypical word order for these children. I feel like } \\
\text { I try to use correct word order (ex: I + want }+ \text { item, more +item, descriptor + } \\
\text { noun, etc) as much as possible. I do think that reduced phrase length can be } \\
\text { dependent on the AAC systems we create for these children. Since I am }\end{array}$ \\
\hline
\end{tabular}




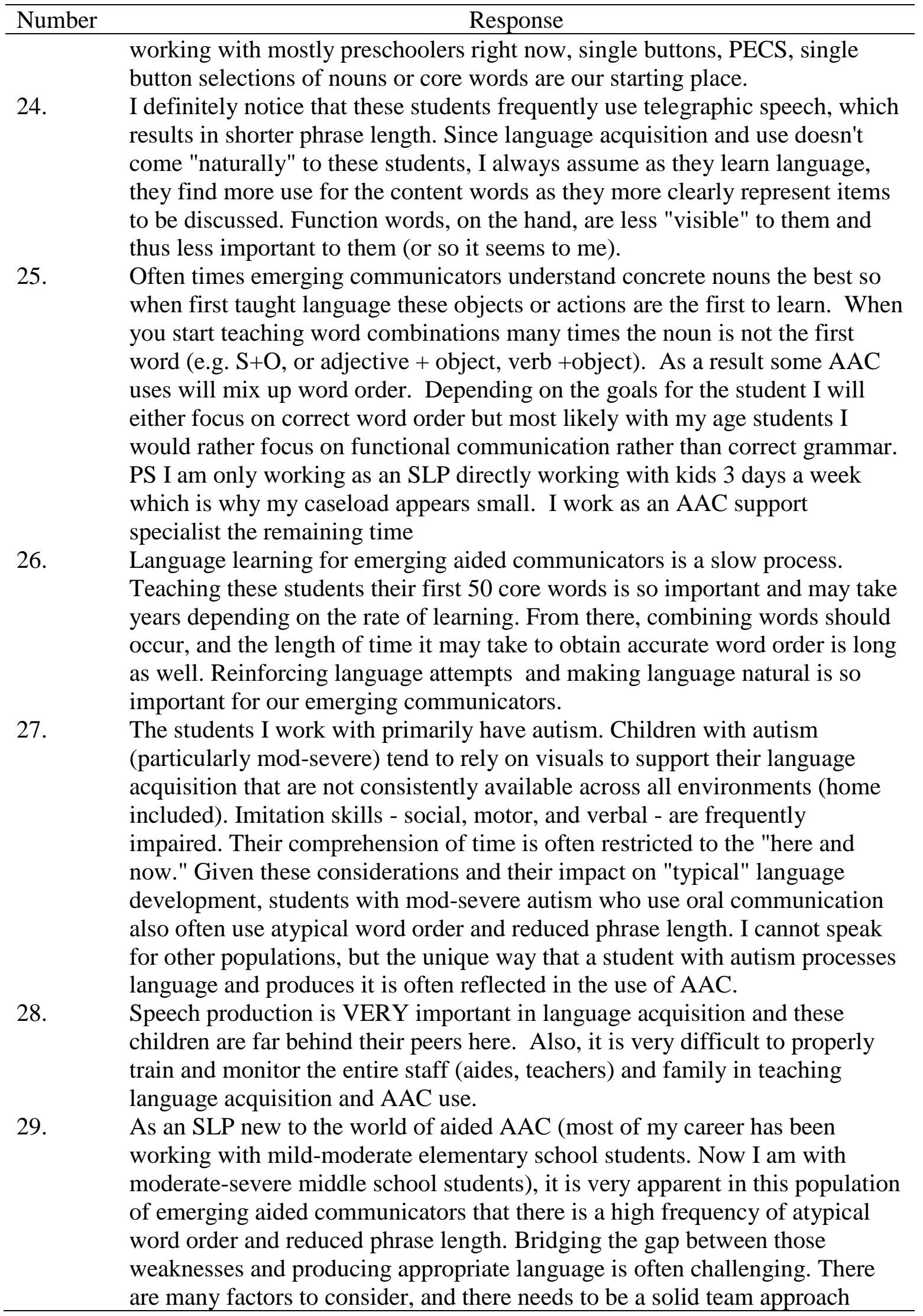




\begin{tabular}{|c|c|}
\hline Number & Response \\
\hline 30. & $\begin{array}{l}\text { (teachers, parents, SLP all on the same page and reinforcing similar concepts). } \\
\text { I believe that often people only expect children who use AAC } \\
\text { devices/systems to use the content words and they don't expect them to use } \\
\text { appropriate word order or an expanded utterance beyond just their basic wants } \\
\text { and needs. }\end{array}$ \\
\hline 31. & $\begin{array}{l}\text { I believe that teaching core words is the most important tool that SLPs can } \\
\text { provide (and train staff on) for emerging AAC users. I am more concerned } \\
\text { about the content of the message than the morphosyntax. Modeling is } \\
\text { essential. I have found, in my experience, that with modeling and the } \\
\text { appropriate amount of supports, emerging aided AAC users will eventually } \\
\text { develop appropriate morphosyntax, but that is not my focus when first starting } \\
\text { out. }\end{array}$ \\
\hline 32. & $\begin{array}{l}\text { I work with children on the Autism spectrum with limited cognitive skills } \\
\text { who are emerging aided communicators. Due to the nature of the disorder, } \\
\text { many children are not interested in communicating beyond requesting. They } \\
\text { want their needs and wants met first. I feel that this impacts word order and } \\
\text { reduced phrase length until they have more motivation to communicate for a } \\
\text { variety of functions (e.g, comment, command). }\end{array}$ \\
\hline 33. & $\begin{array}{l}\text { It seems difficult to make the jump between single words and teo word } \\
\text { phrases, then again the jump to multiple word ohrases and then again to } \\
\text { integrating grammatical morphemes. It's almost as if a kiddo using aac is up } \\
\text { against a much lower expectation. It seems people only ever expect single } \\
\text { words (even in classrooms where aac systems are always out and } \\
\text { encouraged)or they want full lengthy sentences the moment the child receives } \\
\text { aac. They have trouble gradually expecting more. }\end{array}$ \\
\hline 34. & $\begin{array}{l}\text { I have four students, all with different needs, all w/ severely delayed receptive } \\
\text { and expressive language and speech. Two are autistic, and two have down } \\
\text { syndrome w/ severe apraxia. At our site we have an AAC specialist who } \\
\text { works in tandem with the sped teacher during academic instruction. The } \\
\text { paras, who were present during instruction support these students in the gen } \\
\text { ed setting. So, I primarily focus on speech production and verbal language, } \\
\text { supported by use of their devices, including basic syntax. Three have MLU of } \\
\text { 1-3, the fourth is new to me, but has more language. However, he resists } \\
\text { using his talker u/l he is motivated to be understood, and then it is only w/ one } \\
\text { word, even though his MLU is more like 3-4. I believe, with use of all modes } \\
\text { available (combo of device and verbal language) these students will learn } \\
\text { basic morphological markers which are directly taught (e.g. "is", } \\
\text { he/she/they)by the end of elementary school. One of the autistic students may } \\
\text { develop more morphological and syntactic language, but she has become } \\
\text { more verbal recently and less dependent on her talker. She rarely } \\
\text { spontaneously uses her talker. The atypical word order and reduced phrase } \\
\text { length is not surprising since the kids who need them often have cognitive } \\
\text { impairments, and/or severe language delays. The kids resist using their } \\
\text { devices independently unless it is the only way they could be understood } \\
\text { (three of my students are good with nonverbal cues- gestures, etc.), so they }\end{array}$ \\
\hline
\end{tabular}




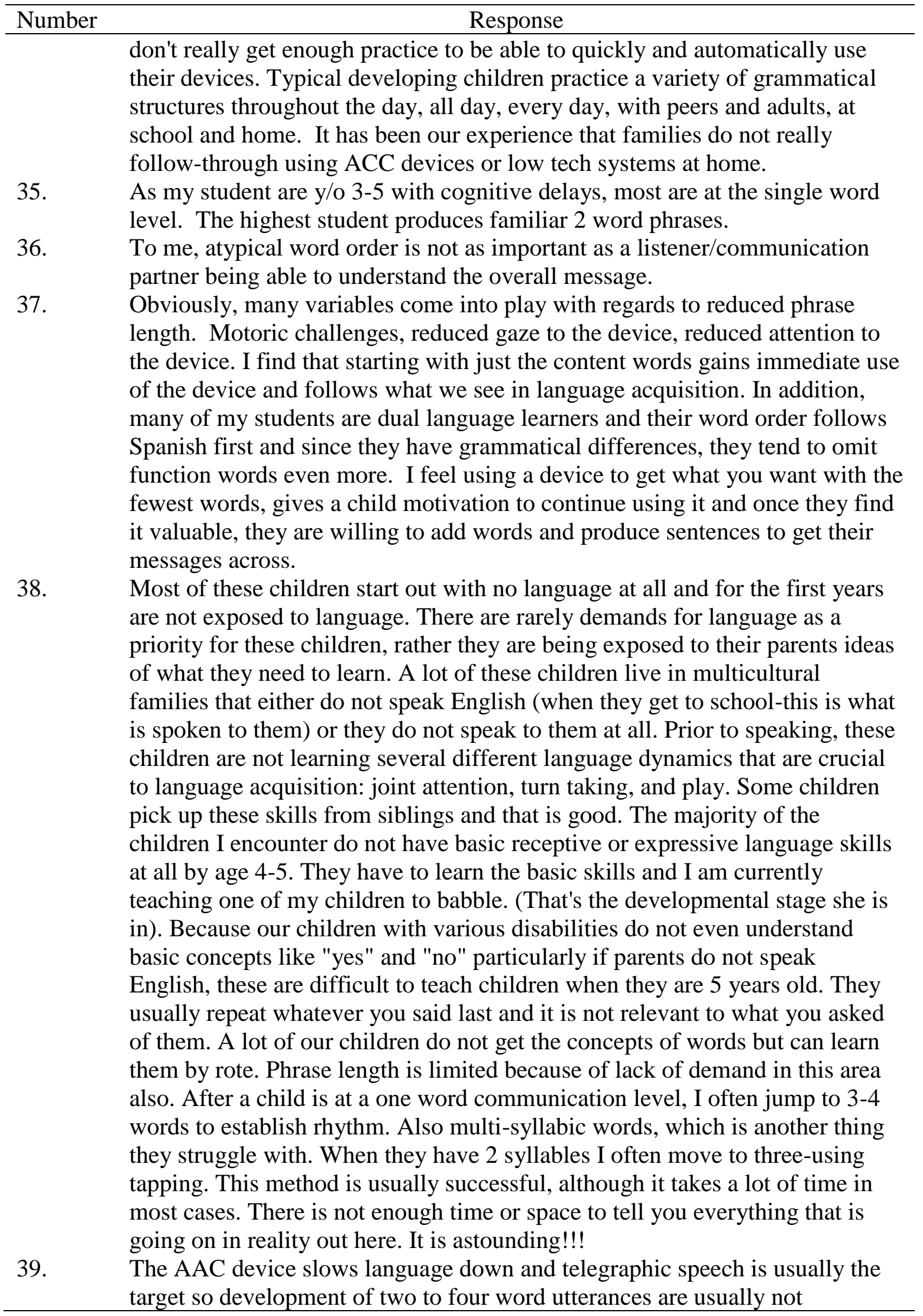




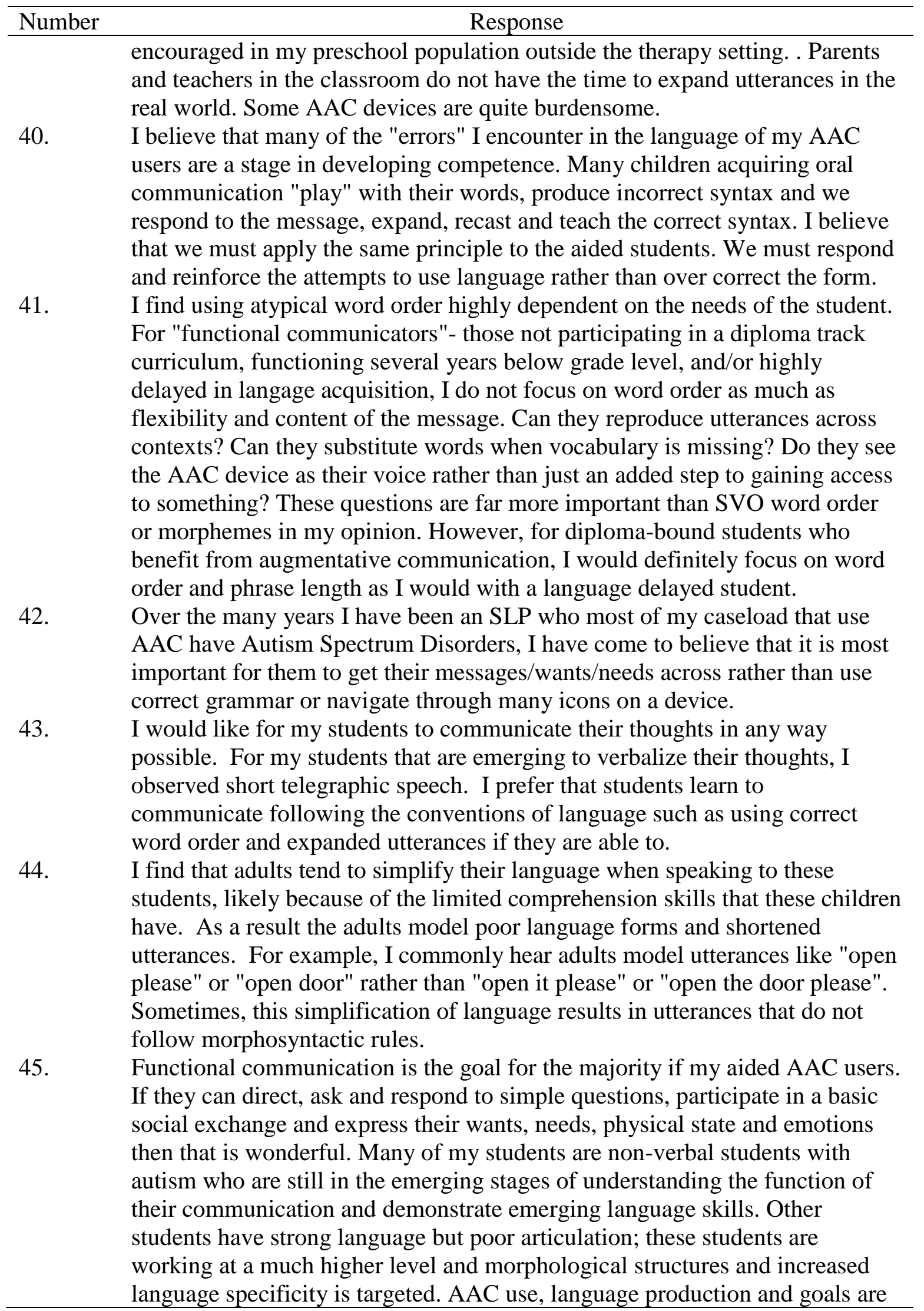




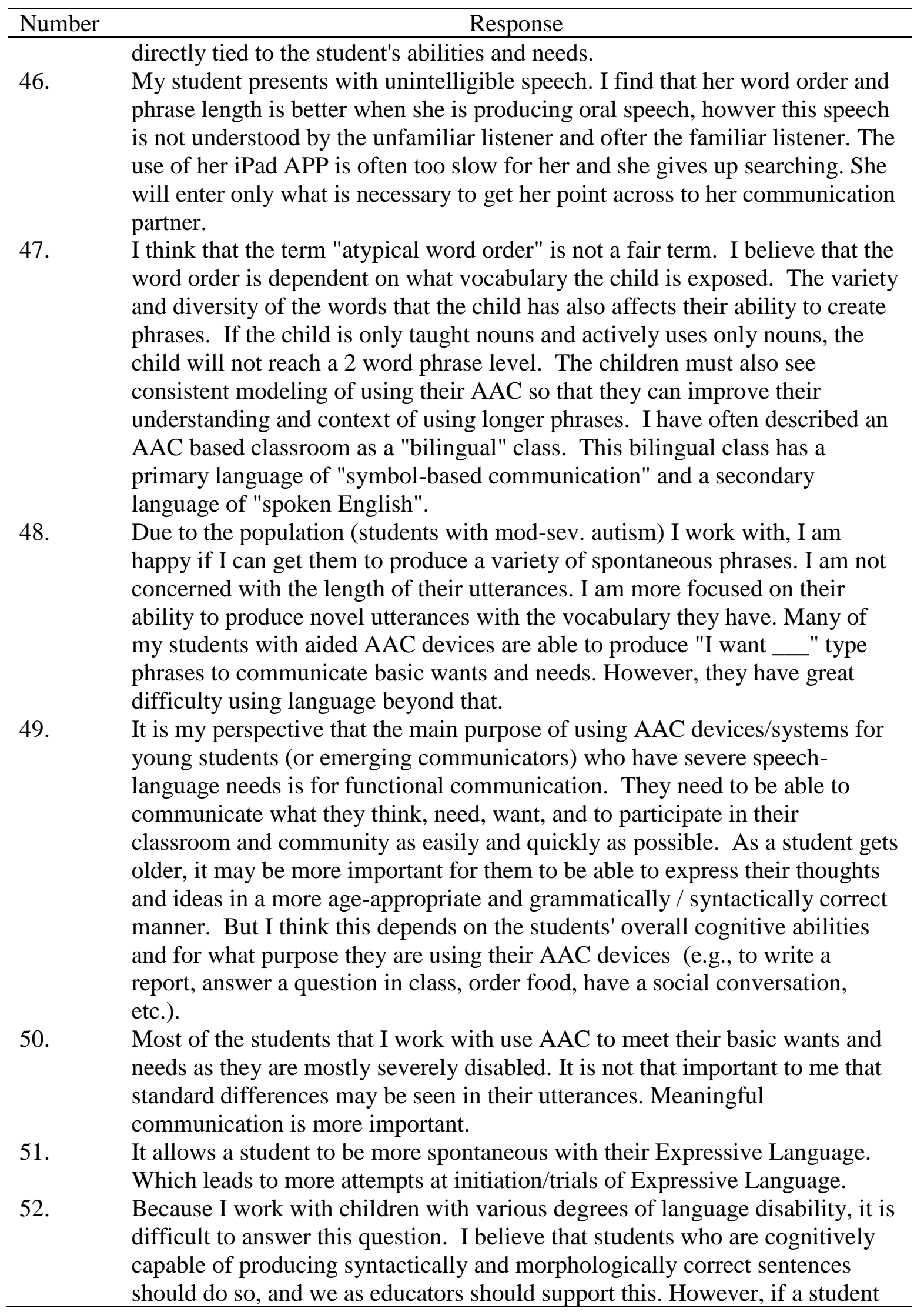




\begin{tabular}{|c|c|}
\hline Number & Response \\
\hline & $\begin{array}{l}\text { is at a functional level in his communication, the meaning of communication } \\
\text { is what should be most supported: the initiation or intent of communication } \\
\text { should be the focus more so than the structure. I believe this (and regarding } \\
\text { most of the questions on this survey) is child specific and there is no right } \\
\text { answer for every kid. }\end{array}$ \\
\hline 53. & $\begin{array}{l}\text { Without supplemental language models using the correct word order and } \\
\text { increased phrase length, I have found that these students have very atypical } \\
\text { speech. If adequate models are provided by the various communication } \\
\text { partners (I have found their aides to be most useful), the speech becomes } \\
\text { more developmental and typical. }\end{array}$ \\
\hline 54. & $\begin{array}{l}\text { I believe that getting functional communicaiton using a SVO (subject, verb, } \\
\text { object) telgrahpic speech to be the primary goal. I think our typical AAC core } \\
\text { vocabulary isn't appropriate to the great majority of our AAC users. Our core } \\
\text { words are based on typical development and would be appropriate for a child } \\
\text { with minimal cognitive/behavioral deficits. But for the majority of the AAC } \\
\text { users I have worked with, I have found that the typical core setup isn't } \\
\text { appropriate. I have actually given distrit and statewide trainings on using } \\
\text { functional core words (functional to the student). I also encourage SLP's and } \\
\text { teachers to remove "want" from the vocab until a student has mastered basic } \\
\text { verbs that this often takes the place of. I think we need to relook at how we } \\
\text { teach language acquistion for our AAC users. Anyone would understand that } \\
\text { "I eat m\&m's" has the same meaning as "I would like to eat m\&m's" and is } \\
\text { quicker and more efficient for early communicators. }\end{array}$ \\
\hline 55. & $\begin{array}{l}\text { In the child that is just starting I am happy if they can communicate or } \\
\text { respond and it had meaning vs. being grammatically correct. As the child } \\
\text { improves I do focus on grammar and expansion and it is amazing what a non- } \\
\text { verbal or unintelligible child can learn. I find during a structured task the } \\
\text { sentence lengths are longer. During a turn taking less structured task the } \\
\text { length is significantly less, but once I model how they could respond the child } \\
\text { does remember. For the first time in this particular child's life he was able to } \\
\text { tell me about his birthday party. That he went to a bowling alley, got a truck, } \\
\text { had cake, grandma went to his party, and that he got a puppy with a black } \\
\text { nose and gold fur. I am not sure how accurate it was, but I was so proud of } \\
\text { him. He was also proud. He did not use appropriate sentence length and } \\
\text { correct grammar, but I understood and the conversation moved forward. In } \\
\text { that moment that's what counted. }\end{array}$ \\
\hline 56. & $\begin{array}{l}\text { Often my student will produce a sentence that is not in perfect syntax, but } \\
\text { when she is *on* I will take it! I feel that if all are understanding her } \\
\text { communicative intent of her words, atypical word order is unimportant. She } \\
\text { communicates with her EYES which is exhausting for her... }\end{array}$ \\
\hline 57. & $\begin{array}{l}\text { I consider word order and phrase length to be comparable with a student's } \\
\text { developmental level. }\end{array}$ \\
\hline 58. & $\begin{array}{l}\text { This is usually due to lack of vocabulary of both nouns and verbs. They often } \\
\text { don't have enough experience/exposure to word structures in their home } \\
\text { enviornment. Sometimes, the parents just don't know HOW to talk to their }\end{array}$ \\
\hline
\end{tabular}




\begin{tabular}{ll}
\hline Number & \multicolumn{1}{c}{ Response } \\
\hline & $\begin{array}{l}\text { children. I think early parent involvement and teaching parents how to } \\
\text { stimulate language at home through play and daily activities, makes a } \\
\text { difference. I love the Hanen program for this reason. }\end{array}$ \\
60. & I am most concerned with the functionality of the communication. \\
61. & $\begin{array}{l}\text { I believe part of the issue is that these emerging aided communicators are not } \\
\text { spoken to with the same frequency or in the same manner as emerging oral } \\
\text { communicators. So much time and energy is consumed focusing on behavior, } \\
\text { compliance, and fulfilling basic needs that they do not receive the same } \\
\text { models (either oral or with AAC) as emerging oral communicators. }\end{array}$ \\
\end{tabular}

